\title{
Fissile Materials Disposition Program Technical Evaluation Panel Summary Report: Ceramic and Glass Immobilization Options
}

\author{
B. R. Myers, W. Brummond, \\ G. Armantrout, H. Shaw, \\ C. M. Jantzen, A. Jostsons, \\ M. McKibben, D. Strachan, \\ and J. D. Vienna
}

December 23, 1997

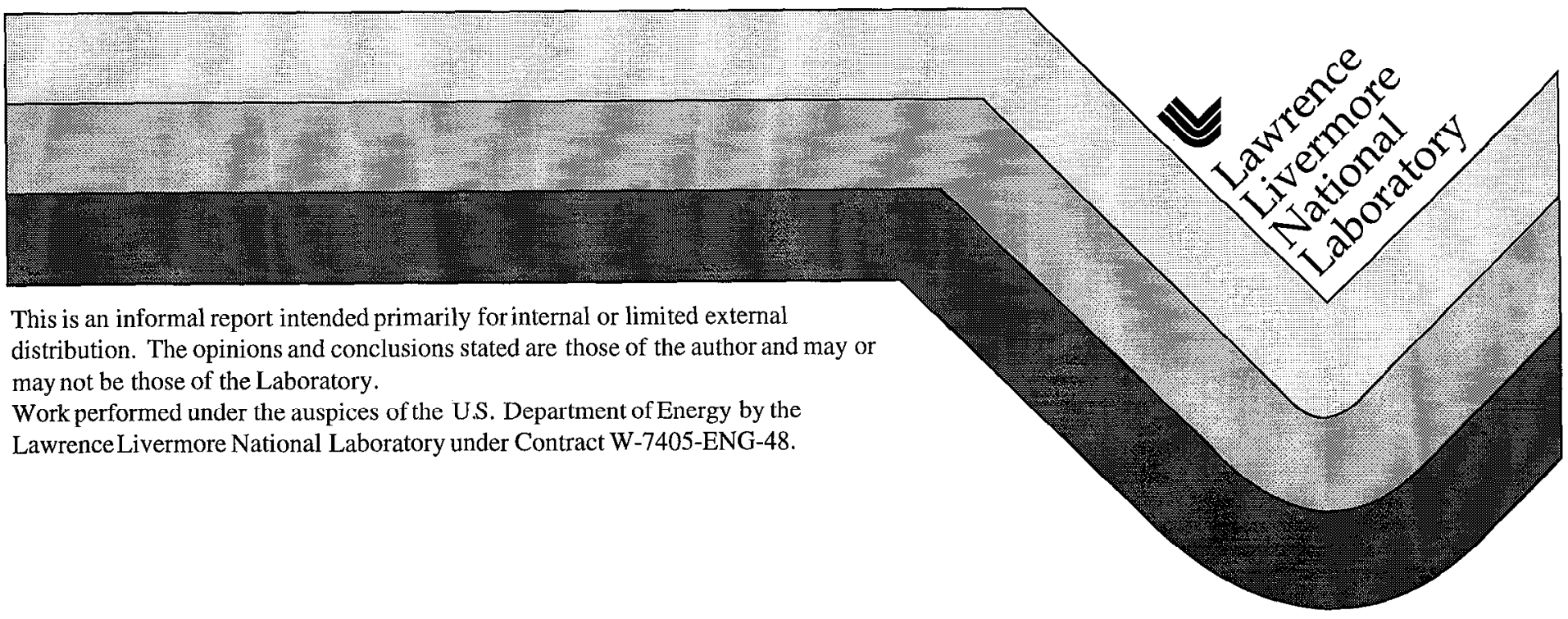




\section{DISCLAIMER}

This document was prepared as an account of work sponsored by an agency of the United States Government. Neither the United States Government nor the University of California nor any of their employees, makes any warranty, express or implied, or assumes any legal liability or responsibility for the accuracy, completeness, or usefulness of any information, apparatus, product, or process disclosed, or represents that its use would not infringe privately owned rights. Reference herein to any specific commercial product, process, or service by trade name, trademark, manufacturer, or otherwise, does not necessarily constitute or imply its endorsement, recommendation, or favoring by the United States Government or the University of California. The views and opinions of authors expressed herein do not necessarily state or reflect those of the United States Government or the University of California, and shall not be used for advertising or product endorsement purposes.

This report has been reproduced directly from the best available copy.

Available to DOE and DOE contractors from the Office of Scientific and Technical Information P.O. Box 62, Oak Ridge, TN 37831

Prices available from (615) 576-8401, FTS 626-8401

Available to the public from the National Technical Information Service

U.S. Department of Commerce

5285 Port Royal Rd.,

Springfield, VA 22161 


\section{Fissile Materials Disposition Program}

Technical Evaluation Panel Summary Report:

Ceramic and Glass Immobilization Options 


\section{Contents}

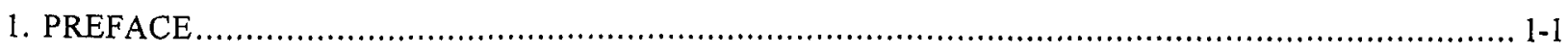

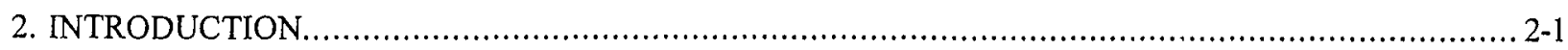

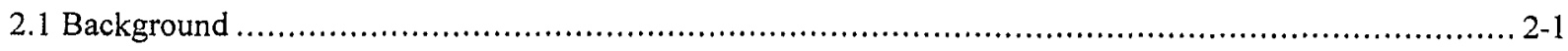

2.1.1 Disposition of Surplus Fissile Material ..................................................................... 2-1

2.1.2 The National Academy Study: the Spent Fuel Standard .................................................. 2-2

2.1.3 The Fissile Materials Disposition Program ........................................................ 2-2

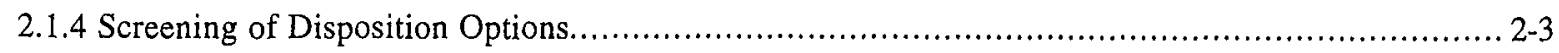

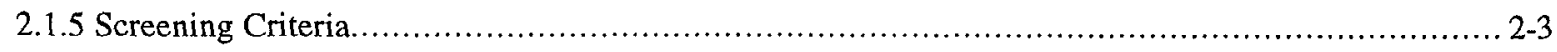

2.1.6 Immobilization in Ceramic or Glass ..................................................................... 2-3

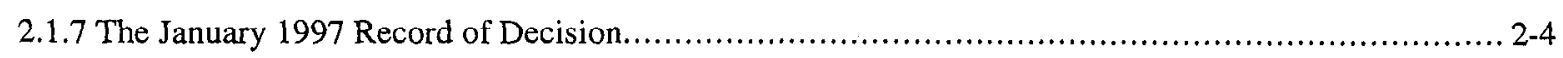

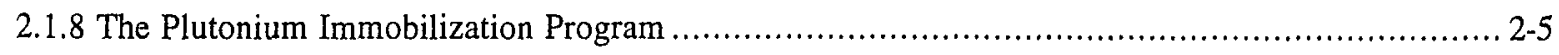

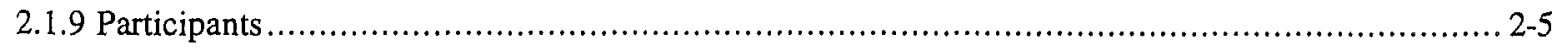

2.1.10 Status of the Plutonium Immobilization Program.................................................. 2-6

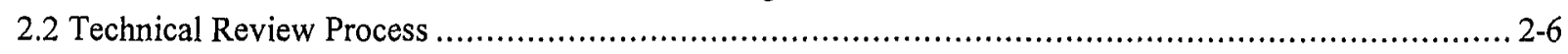

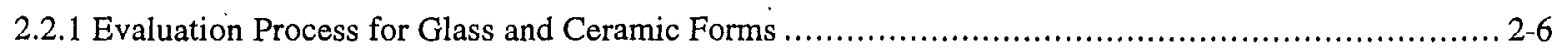

2.2.2 Selection Schedule and Milestones.................................................................. 2-6

2.2.3 The Technical Evaluation Panel Meeting ............................................................ 2-8

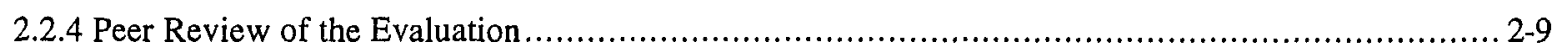

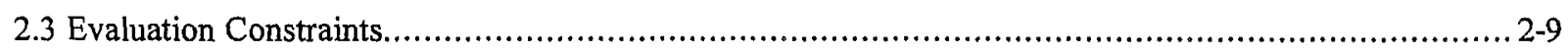

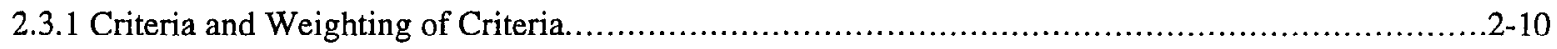

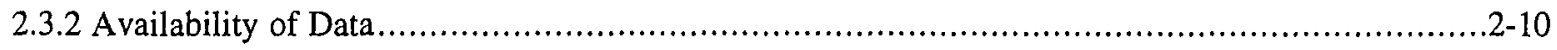

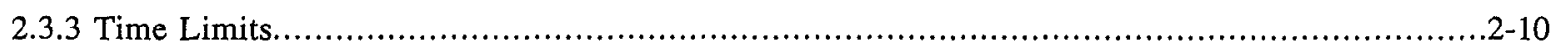

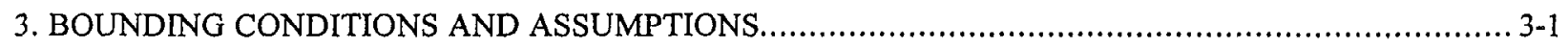

3.1 Assumptions Based on the Record of Decision............................................................. 3-1

3.1.1 Selection of the Can-in-Canister Variant ................................................................... 3-1

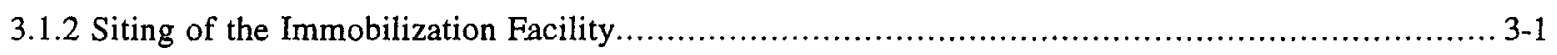

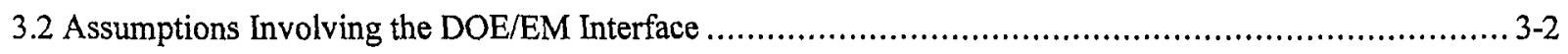

3.2.1 Characteristics and Quantity of the Plutonium to be Immobilized..................................... 3-2

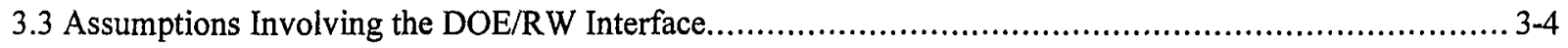

3.3.1 Approval to Dispose of Immobilized Fissile Material in a HLW Repository............................. 3-4

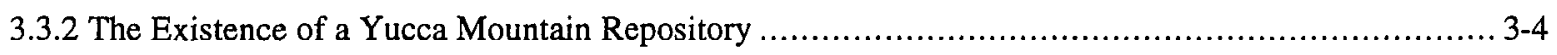

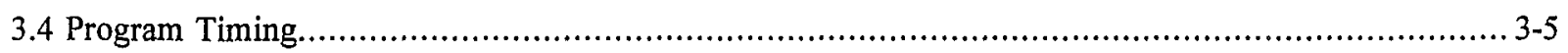

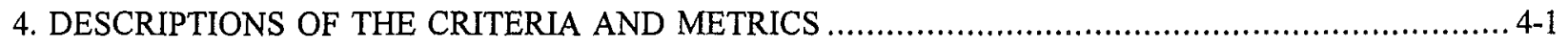

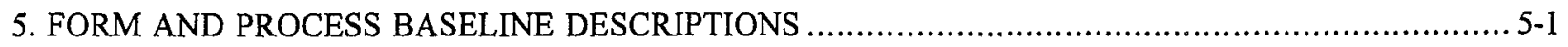

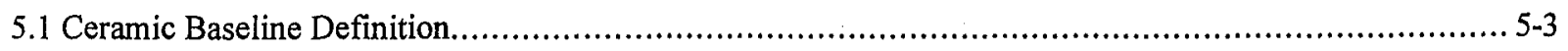

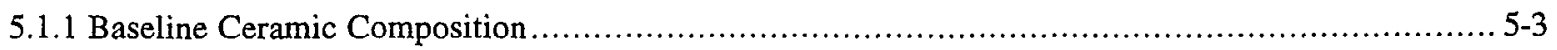

5.1.2 Baseline Ceramic Manufacturing Process ......................................................................

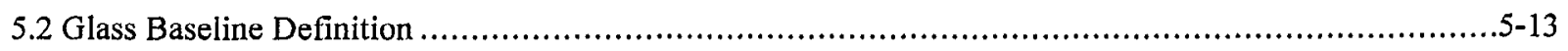

5.2.1 Baseline Glass Composition....................................................................... 5 
5.2.2 Baseline Glass Manufacturing Process ..........................................................................

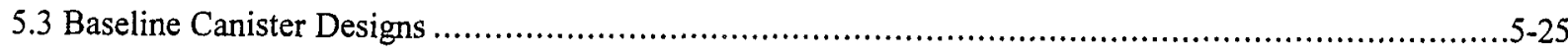

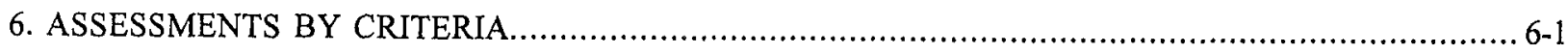

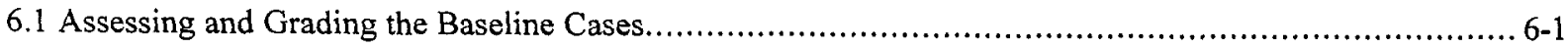

6.2 Resistance to Theft by Diversion by Unauthorized Parties ....................................................... $6-4$

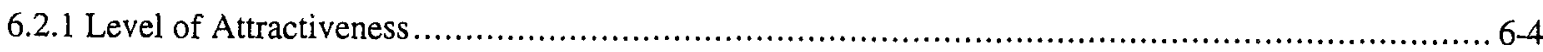

6.2.2 Minimization of Transportation, Facilities, and Processing ................................................. 6-5

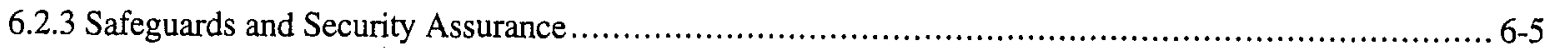

6.2.4 Difficulty of Retrieval and Extraction by a Clandestine Group or Rogue Nation .......................... 6-6

6.3 Resistance to Retrieval, Extraction, and Reuse by Host Nation.................................................... 6-7

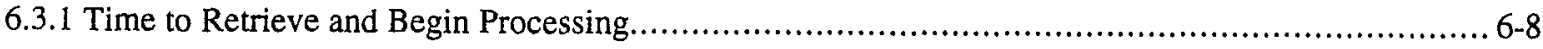

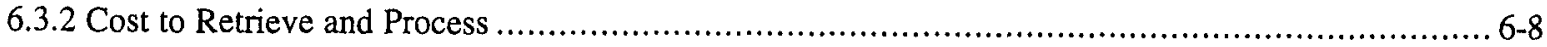

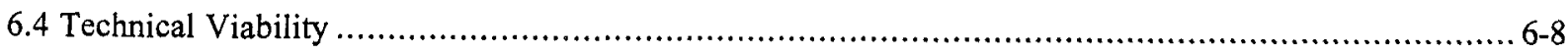

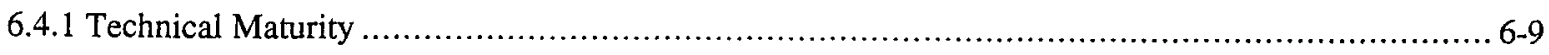

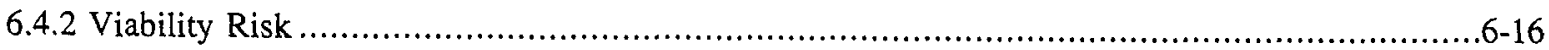

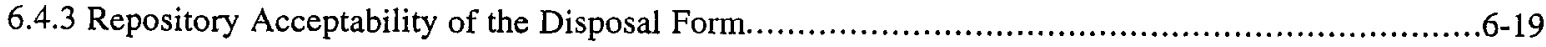

6.5 Environment, Safety, and Health Compliance...................................................................6-29

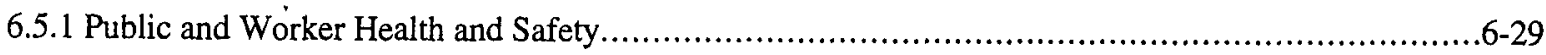

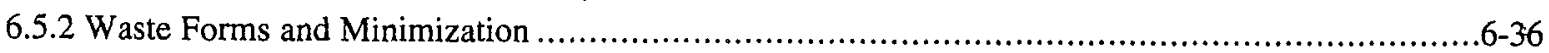

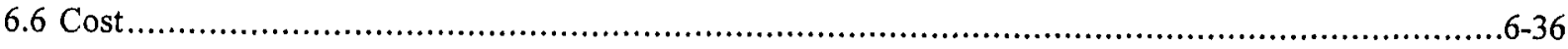

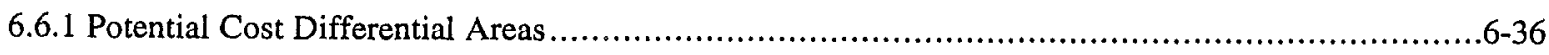

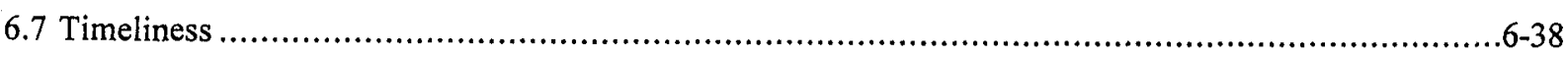

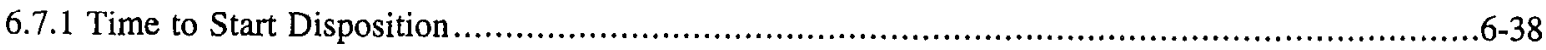

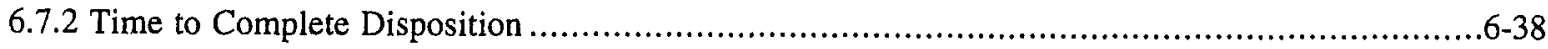

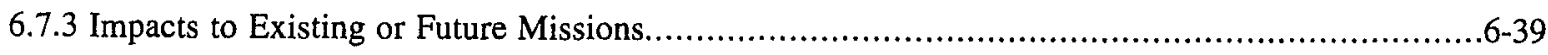

7. ALTERNATIVES TO THE BASELINES ...................................................................... $7-1$

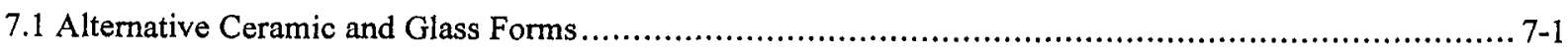

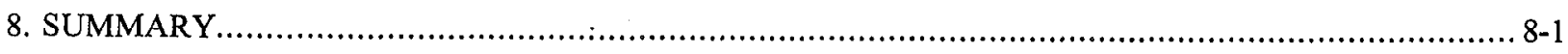

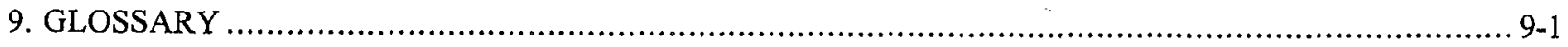

10. SECTION TO COME? OR RENUMBER? .................................................................. 10-1

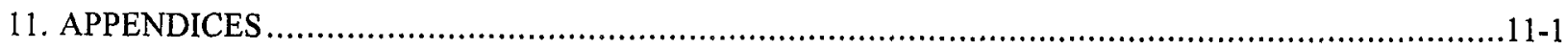

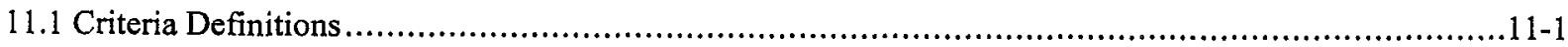

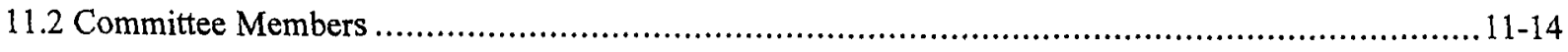

11.3 Review Questions Considered by the Technical Evaluation Panel ...........................................11-24 


\section{List of Acronyms and Abbreviations}

Al aluminum

ALARA as low as reasonably achievable

Am americium

ANL Argonne National Laboratory

ANSTO Australian National Sciences and Technology Organization

Ar argon

ATSR

B

Alternative Technical Summary Report

$\mathrm{Ba}$ boron

BNFL barium

$\mathrm{C}$ British Nuclear Fuels Ltd.

$\mathrm{Ca}$ carbon

CANDU calcium

CIC Canadian deuterium uranium

CISAC

$\mathrm{Cl}$ can-in-canister

$\mathrm{Cr}$ Committee on International Security and Arms Control

$\mathrm{Cs}$ calcium

cesium

CRWMS Civilian Radioactive Waste Management System

D\&D decontamination and decommissioning

DHLW defense high-level wastc

DNFSB Defense Nuclear Facility Safety Board

DOD Department of Defense

DOE Department of Energy

DOE/EM50 Department of Energy/EM-50

DWPF Defense Waste Processing Facility

EA environmental assessment

EIS environmental impact statement

EM Office of Environmental Management (DOE)

ES\&H environment, safety, and health

$\mathrm{Eu} \quad$ europium

$F \quad$ fluorine

$\mathrm{Fe} \quad$ iron

FMDP Fissile Materials Disposition Program

FY fiscal year

$\mathrm{Ga} \quad$ gallium

$\mathrm{Gd} \quad$ gadolinium

GWSB Glass Waste Storage Building at the Savannah River Site

HEU highly enriched uranium

Hf hafnium

HLW high-level waste 


$\begin{array}{ll}\text { IAEA } & \text { International Atomic Energy Agency } \\ \text { K } & \text { potassium } \\ \text { kg } & \text { kilogram } \\ \text { La } & \text { lanthanum } \\ \text { LaBS } & \text { lanthanide borosilicate glass } \\ \text { LBNL } & \text { Lawrence Berkeley National Laboratory } \\ \text { LEU } & \text { low-enrichment uranium } \\ \text { LLNL } & \text { Lawrence Livermore National Laboratory } \\ \text { MC\&A } & \text { material control and accountability } \\ \text { MCC } & \text { Materials Characterization Center } \\ \text { MD } & \text { Office of Materials Disposition (DOE) } \\ \text { MDF } & \text { MOX Fuel Demonstration Facility at Sellafield, U.K. } \\ \text { Mg } & \text { magnesium } \\ \text { MIT } & \text { Massachusetts Institute of Technology } \\ \text { Mo } & \text { molybdenum } \\ \text { MOX } & \text { mixed oxide } \\ \text { MPPF } & \text { Multi-Purpose Processing Facility at the Savannah River Site } \\ \text { MT } & \text { metric ton } \\ \text { MTHM } & \text { metric tons of heavy metal } \\ \text { Na } & \text { sodium } \\ \text { NAS } & \text { National Academy of Sciences } \\ \text { Nd } & \text { neodymium } \\ \text { NDA } & \text { nondestructive analysis } \\ \text { Ni } & \text { nickel } \\ \text { NV } & \text { Nevada } \\ \text { O } & \text { oxygen } \\ \text { OCRWM } & \text { Office of Civilian Radioactive Waste Management } \\ \text { OGS } & \text { oxide grain stabilized } \\ \text { PCT } & \text { product consistency test } \\ \text { P.L. } & \text { public law } \\ \text { PNNL } & \text { Pacific Northwest National Laboratory } \\ \text { PRP } & \text { Peer Review Panel } \\ \text { Pt } & \text { platinum } \\ \text { Pu } & \text { plutonium } \\ \text { PUF } & \text { pressurized unsaturated flow } \\ \text { RD\&D } & \text { research, development, and demonstration } \\ \text { REE } & \text { rare earth element } \\ \text { Rh } & \text { rhodium } \\ \text { ROD } & \text { Record of Decision } \\ \text { S\&S } & \text { safeguards and security } \\ \text { S/V } & \text { ratio of surface area to volume } \\ \text { SFS } & \text { spent fuel standard } \\ \text { Si } & \text { silicon } \\ & \end{array}$




$\begin{array}{ll}\text { Sm } & \text { samarium } \\ \text { SMP } & \text { Sellafield MOX Plant, U.K. } \\ \text { SPFT } & \text { single-pass flow-through test } \\ \text { Sr } & \text { strontium } \\ \text { SRS } & \text { Savannah River Site } \\ \text { SRTC } & \text { Savannah River Technology Center } \\ \text { SYNROC } & \text { synthetic rock } \\ \text { Ta } & \text { tantalum } \\ \text { TEP } & \text { Technical Evaluation Panel } \\ \text { Ti } & \text { titanium } \\ \text { U } & \text { uranium } \\ \text { W } & \text { tungsten } \\ \text { WB } & \text { whole body } \\ \text { WSRC } & \text { Westinghouse Savannah River Company } \\ \text { WVNF } & \text { West Valley Nuclear Fuel } \\ \text { YGS } & \text { yttria grain stabilized } \\ \text { ZGS } & \text { zirconia grain stabilized } \\ \text { Zn } & \text { zinc } \\ \text { ZPPR } & \text { Zero Power Plutonium Reactor } \\ \text { Zr } & \text { zirconium }\end{array}$




\section{PREFACE}

This report documents the results of a technical evaluation of the merits of ceramic and glass immobilization forms for the disposition of surplus weapons-useable plutonium. The evaluation was conducted by a Technical Evaluation Panel (TEP), whose members were selected to cover a relevant range of scientific and technical expertise and represented each of the technical organizations involved in the Plutonium Immobilization Program. The TEP held a formal review at Lawrence Livermore National Laboratory (LLNL) from July 28-August 1, 1997. Following this review, the TEP documented the review and its evaluation of the two immobilization technologies in this report to provide a technical basis for a recommendation by LLNL to the Department of Energy (DOE) for the preferred immobilization form.

The comparison of the glass and ceramic forms and manufacturing processes was a tremendous challenge to the TEP. The two forms and their processes are similar in many ways. The TEP went to great effort to accurately assess what were, in many cases, fine details of the processes, unit operations, and the glass and ceramic forms themselves. The set of criteria used by the Fissile Materials Disposition Program (FMDP) in past screenings and down-selections was used to measure the two options. One exception is that the TEP did not consider criteria that were largely nontechnical (namely international impact, public acceptance, and effects on other : DOE programs).

The TEP's measures and assessments are documented in detail. Care was taken to ensure that the data used were well documented and traceable to their source. Although no final conclusion regarding the preferred form was reached or explicitly stated in this report (this was not within the TEP's charter), no "show stoppers" were identified for either form. Both forms appear capable of satisfying all the criteria, as interpreted by the TEP. The TEP identified a number of distinct and quantifiable differences between the forms for several of the criteria. These differences ranged from insignificant to moderate, depending on the specific criterion and the context in which it was applied.

No summary statement regarding the overall superiority of either form is presented here, as that would imply a weighting of the various criteria, a judgment the TEP was instructed to avoid. This judgment is deferred to the assessment and peer review that will follow this evaluation. The decision to select one form over another will, of course, require the consideration of many additional factors beyond the technical criteria, including the nontechnical criteria, constraints, and policy issues, all of which were outside the scope of this review. 


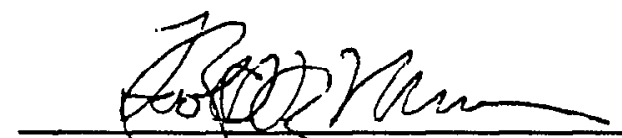

Dr. Boeth R. Myers (Panel Chairman)

Lawrence Livermore National Laboratory

Dr. Carol M. Jantzen

Westinghouse Savannah River Co.

d.m. msticblen

Aalvyn (Mal) McKibben

Westinghouse Savannah River Co.

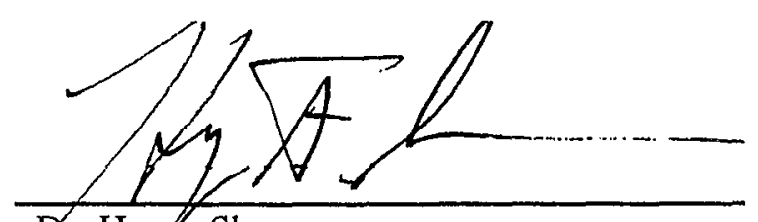

Dr. Henfy Shaw

Lawrence Livermore National. Laboratory

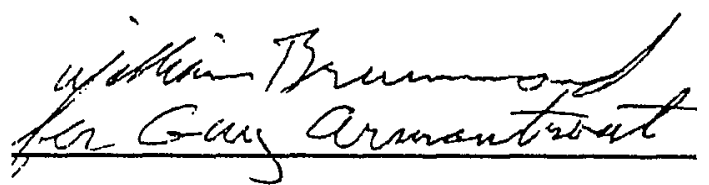

William Brummond for Dr. Guy Armantrout Lawrence Livermore National Laboratory

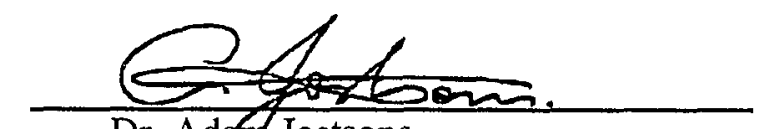

Dr. Adqfor Jostsons

Westinghouse Savannah River Co.

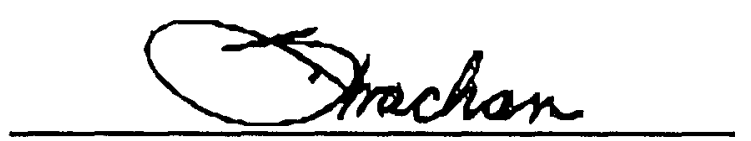

Dr. Denis Strachan

Argonne National Laboratory

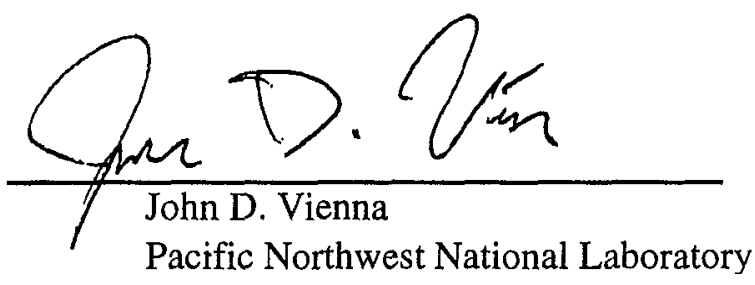




\section{INTRODUCTION}

This report documents the results of a technical evaluation of the merits of ceramic and glass immobilization forms for the disposition of surplus weapons-useable plutonium. The evaluation was conducted from July 28-August 8, 1997, at Lawrence Livermore National Laboratory (LLNL) for the purpose of providing a technical basis for a recommendation by LLNL to the Department of Energy (DOE) as to the preferred immobilization form. The members of the Technical Evaluation Panel (TEP) were selected to cover a relevant range of scientific and technical expertise, and had representation from each of the major technical organizations involved in the Plutonium Immobilization Program.

\subsection{Background}

In the aftermath of the Cold War, the U.S. and Russia have agreed to large reductions in nuclear weapons, a development that has resulted in a large surplus of weapons-useable fissionable materials. The U.S. has determined that these materials pose a danger to national and international security due to their potential for global nuclear proliferation and environmental damage. The broader international community also agrees on the need for action. For example, at the Nuclear Safety and Security Summit held in Moscow in April 1996, the leaders of the Group of Seven industrialized democratic nations and Russia discussed the problems posed by stockpiles of excess fissile materials. The outcome of that meeting was an agreement that these stockpiles should be reduced as quickly as practicable, under effective nonproliferation controls. The principal technical issues relate to the disposition of plutonium, because highly enriched uranium (HEU) can generally be blended with natural or depleted uranium to produce lowenrichment uranium (LEU) that can be used as reactor fuel but is unsuitable for use in weapons.

In keeping with these determinations, the U.S. is taking actions that will (1) enhance the security of nuclear materials in the former Soviet Union and (2) ensure the safe, secure, long-term storage and disposition of surplus weapons-useable fissile materials in both countries. To demonstrate the United States' commitment to these objectives, President Clinton announced* in March 1995 that approximately 50 metric tons (MT) of plutonium, including about 38 MT of weapons-grade material, was considered surplus to U.S. defense needs. In parallel actions, Russia has declared a similar quantity of plutonium as surplus. Both countries have committed to seeking a course of action that will render these materials permanently unattractive for use in nuclear weapons, a process commonly referred to as "disposition" of the fissile materials.

\subsubsection{Disposition of Surplus Fissile Material}

Plutonium (or another fissile material such as highly enriched uranium) is an essential ingredient of nuclear weapons. A number of nations and subnational groups are believed to be technically capable of producing a nuclear weapon if they were in possession of sufficient quantities of fissile material. Therefore, control over the access to these materials is the primary barrier to nuclear proliferation in the world today. Given this situation, the U.S. National

\footnotetext{
"President Clinton's addresses to the Nixon for Peace and Freedom Policy Conference (March 1, 1995) and the Department of Energy Openness Initiative (February 6, 1996).
} 
Academy of Sciences (NAS) Committee on International Security and Arms Control [NAS, 1994] suggested the following objectives for storage and disposition of excess fissile materials:

"The primary goal in choosing options for management and disposition of excess nuclear weapons and fissile materials should be to minimize the risks to national and international security posed by the existence of this material. This security goal can be divided into three main objectives:

(1) to minimize the risk that weapons or fissile materials could be obtained by unauthorized parties;

(2) to minimize the risk that weapons or fissile materials could be reintroduced into the arsenals from which they came, halting or reversing the arms reduction process; and

(3) to strengthen the national and international control mechanisms and incentives designed to ensure continued arms reductions and prevent the spread of nuclear weapons."

The NAS Committee's report identified the continued existence of large quantities of excess weapons-usable fissile materials as a "clear and present danger to national and international security" and recommended that these stockpiles be reduced as quickly as practicable.

\subsubsection{The National Academy Study: the Spent Fuel Standard}

To establish a metric for assessing the various alternatives for plutonium disposition, the NAS recommended that the national objective should be to make the surplus plutonium "roughly as inaccessible for weapons use as the much larger and growing quantity of plutonium that exists in spent fuel from commercial reactors." The NAS defined this state of inaccessibility as the Spent Fuel standard (SFS) [NAS, 1994].

The DOE has modified this definition to read [DOE, 1996]:

"A concept to make the plutonium as unattractive and inaccessible for retrieval and

weapons use as the residual plutonium in the spent fuel from commercial reactors."

The DOE modification makes explicit the idea of material attractiveness, which was implicit in the NAS recommendation. The SFS is not a specification-type standard. Rather, it is meant to encompass a range of barriers that would deter accessibility to and use of plutonium, including such barriers as a radiation field, dilution, inaccessible location, and size and weight. In the aggregate, these barriers achieve a degree of inaccessibility and a difficulty of extraction of the plutonium comparable to that of plutonium in "typical" commercial spent fuel. Having achieved this standard, the formerly surplus weapons-usable plutonium would be no more attractive for use in nuclear weapons than the much larger and growing inventory of plutonium in commercial spent fuel.

\subsubsection{The Fissile Materials Disposition Program}

On January 24, 1994, Secretary of Energy Hazel O'Leary created a department-wide project within the DOE to improve coordination of the department's activities on fissile materials. In affirmation of this action, the Congress acted, through the passage of The National Defense Authorization Act for Fiscal Year 1995 (P.L. 103-335), to create an Office of Fissile Materials 
Disposition within the DOE. This office is responsible for the Fissile Materials Disposition Program (FMDP), which covers all activities of the DOE relating to the management, storage, and disposition of fissile materials from weapons and weapons systems that are excess to the national security needs of the United States.

\subsubsection{Screening of Disposition Options}

Building on the NAS work, the FMDP completed a screening process in March 1995 [DOE, 1995] in which numerous concepts for the disposition of plutonium were evaluated. The options that remained after the screening process were identified as reasonable alternatives and have been analyzed for environmental impacts in the draft Programmatic Environmental Impact Statement (PEIS) [DOE, 1996].

The reasonable alternatives fall into three categories (or combinations of them): reactor burning of plutonium; immobilization of plutonium; and deep borehole disposal of plutonium. In the reactor-burning alternatives, plutonium would be used as a fuel source for commercial reactors, with the result that the residual plutonium would be incorporated in highly radioactive spent fuel assemblies. In the immobilization alternatives, the plutonium would be fixed in various matrices in large canisters that also contain highly radioactive material. The ultimate resting place for both classes of alternatives would be a national high-level-waste (HLW) repository. In the deep-borehole alternative, the plutonium would be emplaced at depths of several kilometers. In : all three categories of alternatives, barriers would be created to make recovery and reuse of the plutonium difficult; however, the nature of the barriers to recovery and reuse vary from category to category.

\subsubsection{Screening Criteria}

To assist in the screening process, the DOE used a fixed set of criteria against which all the proposed alternatives were evaluated. These criteria were:

- Resistance to theft and diversion by unauthorized parties.

- Resistance to retrieval, extraction, and reuse by the host nation.

- Technical viability.

- Environment, safety, and health compliance.

- Cost effectiveness.

- Timeliness.

- Fostering of progress and cooperation with Russia and other countries.

- Public and institutional acceptance.

- Additional benefits.

These same criteria were used for the present technical evaluation, and are discussed in more detail in Section 4 of this report.

\subsubsection{Immobilization in Ceramic or Glass}

For the purposes of the FMDP, immobilization is defined as the fixation of surplus fissile materials in an environmentally benign form such that the fissile material from the immobilized form is inherently as difficult to recover (unattractive and inaccessible) as it is from spent fuel. 
In 1995-1996, the FMDP carried out an extensive screening study [LLNL, 1996] of more than 70 technologies and forms for the immobilization of surplus weapons plutonium. The individual forms were grouped into families that shared common chemical and/or physical characteristics and their properties reviewed. The screening process resulted in a ranking of 16 immobilization forms, in which borosilicate glass and titanate-based (SYNROC-like) ceramics ranked first and second, respectively. On the basis of these rankings, borosilicate glass and titanate-based ceramics were selected for more detailed examination. A third option, immobilization of plutonium in a glass-bonded zeolite (based on technology proposed for use in the Integral Fast Reactor fuel cycle) was also examined but was subsequently dropped from consideration.

Both the glass- and ceramic-based immobilization alternatives can be implemented in several ways to achieve the spent fuel standard. Five different immobilization variants were identified, three for glass and two for ceramic:

- Glass can-in-canister variant, in which small cans containing a plutonium- and neutronabsorber-bearing glass are surrounded by highly radioactive HLW glass, which, in turn, is contained in an outer storage canister.

- Glass variant consisting of an adjunct melter to the Defense Waste Processing Facility (DWPF) that produces a glass containing plutonium, neutron absorber(s), and ${ }^{137} \mathrm{Cs}$ separated $\mathrm{HLW}$, which is then encapsulated in a storage canister.

- New Greenfield facility that produces a glass containing plutonium, neutron absorber(s), and

${ }^{137} \mathrm{Cs}$ (as a radiological barrier), which is then encapsulated in a storage canister.

- Ceramic can-in-canister variant in which small cans containing a ceramic that incorporates the plutonium and neutron absorber(s) are surrounded by HLW glass, which, in turn, is contained in an outer storage canister.

- New Greenfield facility that produces a ceramic containing plutonium, neutron absorber(s), and ${ }^{137} \mathrm{Cs}$, which is then encapsulated in a storage canister.

LLNL evaluated these variants using the same criteria as in the overall screening process for disposition options [Gray and Gould, 1997], which concluded that the glass and ceramic can-incanister variants were clearly superior to the others based on timeliness, technical viability, cost, and to a lesser extent environment, safety, and health risks.

\subsubsection{The January 1997 Record of Decision}

In January 1997, the DOE released a Record of Decision for the Storage and Disposition of Weapons-Useable Fissile Material (ROD) which committed the U.S. to a dual-track approach to plutonium disposition involving both the immobilization and reactor-burning options [DOE, 1997]. In doing so, the ROD eliminated disposition in deep boreholes as an alternative. The ROD identified that at least $30 \%$ of the plutonium that has been or may be declared surplus to national defense needs would require extensive purification for use in reactor fuel and therefore will likely be immobilized. The ROD further states that DOE has already determined that at least $8 \mathrm{MT}$ of plutonium has already been determined to be unsuitable for use in reactor fuel and will be immobilized. The DOE has reserved the option of using the immobilization approach for all surplus plutonium. 
The ROD stated that DOE will use, to the extent practical, new as well as modified existing buildings and facilities for portions of the plutonium disposition mission. DOE will analyze and compare existing and new buildings, facilities, and technology variations, in a site-specific Environmental Impact Statement (EIS), which is scheduled to be issued in the summer of 1998. For the EIS, DOE anticipates that the preferred alternative for glass or ceramic immobilization will be the can-in-canister variant (see Section 3), utilizing the existing HLW and DWPF at Savannah River Site (SRS). Alternatively, new immobilization facilities could be built at Hanford or SRS. As noted above, the immobilized material would be disposed of in a geologic repository.

\subsubsection{The Plutonium Immobilization Program}

To achieve the goals of the Plutonium Immobilization Program, the program participants have jointly prepared a nine-year integrated plan [Integrated Immobilization Plan, 1997] that lays out the logic for the technology development and major project activities that will be necessary to support the deployment of the immobilization approach for disposition of surplus weaponsusable plutonium. The plan contains the detailed research, development, and testing (RD\&T) tasks needed to provide technical data for the design and operation of a plutonium immobilization plant. The plan also presents tasks for the characterization and evaluation of the immobilization form to develop the basis for repository acceptance of the plutonium form and a repository license application. The data and information presented to the TEP (which constitute the basis of this report) were gathered under the auspices of this overall plan.

\subsubsection{Participants}

LLNL is the technical lead laboratory for the Plutonium Immobilization Program and has overall responsibility for the conduct of the RD\&T activities. LLNL leads a team of other laboratories and organizations:

- Lawrence Livermore National Laboratory (LLNL): Program technical lead, form characterization and qualification, ceramic form development lead, process/equipment development with plutonium, process systems testing and validation for both conversion and immobilization.

- Savannah River Technology Center (SRTC): Glass form development lead, partner with LLNL in process/equipment development activities, process/product validation testing with plutonium, technology transfer to the plant.

- Argonne National Laboratory (ANL): Properties/characterization of immobilization forms, glass form development.

- Pacific Northwest National Laboratory (PNNL): Glass form development, properties/characterization of forms.

A number of subcontractors are supporting specific task areas:

- Bechtel Corporation: preconceptual engineering studies.

- British Nuclear Fuels Ltd. (BNFL): plutonium feed preparation technology.

- Lawrence Berkeley National Laboratory (LBNL): chemical valence state measurements.

- Massachusetts Institute of Technology (MIT): thermodynamic properties of neutron absorbers. 
- University of California at Davis: thermodynamic properties of constituents in titanate ceramic.

- Clemson University: melter development, ceramic fabrication, feed preparation support).

- The Australian National Science and Technology Organisation (ANSTO): ceramic development support.

The Civilian Radioactive Waste Management System (CRWMS) and its subcontractors are responsible for HLW repository performance assessments as well as for oversight of the waste form acceptance process.

\subsubsection{Status of the Plutonium Immobilization Program}

The Plutonium Immobilization Program is conducting a focused RD\&T program to establish the relative technical merits of the glass and ceramic approaches. This work has been in progress for approximately 24 months.

\subsection{Technical Review Process}

\subsubsection{Evaluation Process for Glass and Ceramic Forms}

The Plutonium Immobilization Program has carried two technical alternatives forward in its current program plan [Integrated Immobilization Plan, 1997]. Although the technical characteristics are not rigorously defined at this point, the alternatives use either a specially formulated glass (vitrification alternative) or a mineral-based ceramic (ceramic alternative) as a medium into which the excess plutonium is mixed for disposition. Current FMDP plans require a selection of the preferred process for future development and deployment. This selection by the DOE is scheduled to occur by September 30,1997. To support this decision, LLNL as the lead laboratory for immobilization will deliver a recommendation for the preferred form to the DOE by the end of August 1997. To meet this schedule, the following activities were set into motion:

- Collection of experimental data and analysis from the ongoing R\&D program.

- Selection of a Technical Evaluation Panel (TEP) from within the program.

- Definition of baseline forms and processes for each alternative.

- Technical evaluation of data and analysis against the criteria by the TEP.

- Documentation of the evaluation (TEP report).

- Management assessment of the TEP report.

- Review by a Peer Review Panel (PRP) of outside experts.

- Recommendation to DOE/MD.

\subsubsection{Selection Schedule and Milestones}

The schedule for the selection activities is shown in Figure 2.2.1. The key milestones are:

- Data presentation by ceramic and glass teams, TEP review complete: July 31.

- TEP evaluation and draft report completed: August 8.

- Draft of recommendation and logic complete: August 15. 
- TEP report issued: August 22.

- PRP assessment and letter report completed: August 22.

- Recommendation and documentation issued to DOE/MD: August 29.

Figure 2.2.1. Sequence and schedule for the ceramic/glass selection process.

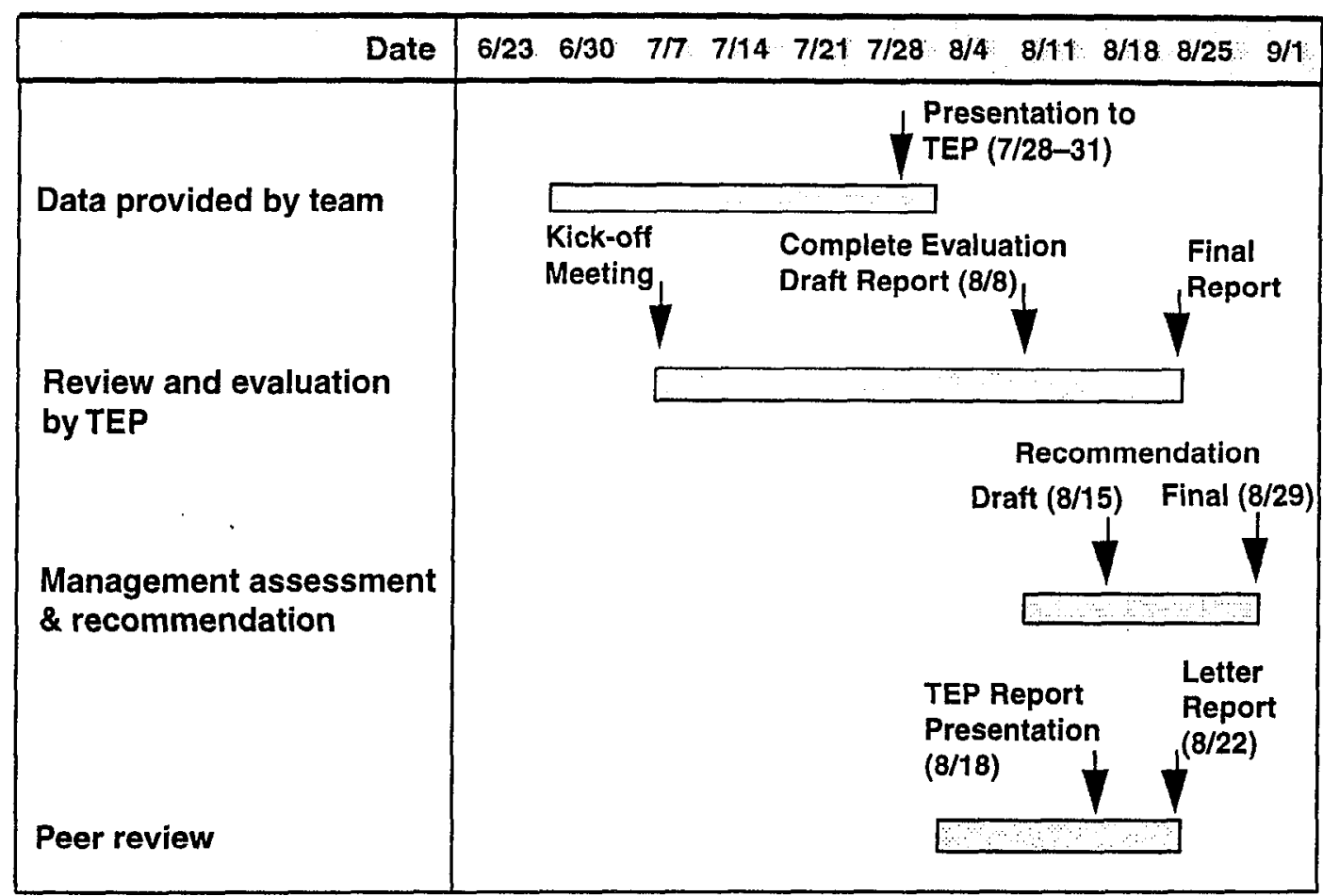

The first step was the formal collection of the experimental and analytical data for the evaluation, which began in June 1997. This activity drew on work carried out over the past several decades and on data developed specifically by and for the Plutonium Immobilization Program during the past two years.

The next step was the selection, in June 1997, of the Technical Evaluation Panel (TEP) by the program management. Following its formation, the TEP met twice in July to prepare for the formal review. TEP members were:

- Dr. Booth Myers, Lawrence Livermore National Laboratory (chairman).

- Dr. Guy Armantrout, Lawrence Livermore National Laboratory.

- Dr. Carol Jantzen, Westinghouse Savannah River Technology Center.

- Dr. Adam Jostsons, Australian Nuclear Science and Technology Organisation.

- Mr. Malvyn McKibben, Westinghouse Savannah River Corporation.

- Dr. Henry Shaw, Lawrence Livermore National Laboratory.

- Dr. Denis Strachan, Argonne National Laboratory. 
- Mr. John Vienna, Pacific Northwest National Laboratory.

The TEP met on July 9, 1997, in Dallas, Texas, and on July 16, 1997, at the Savannah River Technology Center in Aiken, South Carolina, to prepare for the formal review scheduled for late July. At these two preparatory meetings, the TEP reviewed the criteria to be used for the evaluation and defined protocols for conducting the review. Following the first of the two meetings, the TEP requested that the Plutonium Immobilization Program generate baseline cases for the forms and processes. The group also requested program guidance on the relative weighting or relative importance that each criterion should be assigned to help in setting priorities for the review. The panel also generated an agenda and scheduled the formal review meeting for the week of July $28,1997$.

The TEP used criteria for this technical evaluation that were drawn from a set of criteria previously developed and used by the FMDP for screening and down-selecting immobilization options. Each of the criteria has a set of metrics developed to help assess how well a particular form or process meets the criteria. The criteria, listed below, are defined in Section 4 and documented in depth in Section 11.1. The TEP's main departure from the previous screening was the elimination of the criteria that are inherently nontechnical and outside the expertise of the TEP members.

Criteria addressed by the TEP:

- Resistance to theft and diversion by unauthorized parties.

- Resistance to retrieval, extraction, and reuse by the host nation.

- Technical viability.

- Environment, safety, and health compliance.

- Cost effectiveness.

- Timeliness.

Criteria not addressed in the review:

- Fostering of progress and cooperation with Russia and other countries.

- Public and institutional acceptance.

- Additional benefits.

The management at each of the program sites provided a list of review presenters (proponents) from the respective glass and ceramic development teams. The TEP generated a number of questions to be answered or addressed by the technical presenters in the formal review (see Section 11.3). The questions were distributed to the presenters early in the week preceding the review.

\subsubsection{The Technical Evaluation Panel Meeting}

The formal review took place at LLNL on July 28 through July 31, 1997, with a peak attendance of approximately 45 scientists and engineers from LLNL, ANL, PNNL, WSRC, SRTC, and ANSTO. The proponents gave approximately 30 presentations, from both development teams and independent research teams, with active participation and questioning by all present. Many of the presentations extended beyond their scheduled times, and the meeting agenda was adjusted to accommodate all the planned presentations. Several ad hoc sessions were 
added to the agenda to address issues raised during the scheduled presentations. In addition to data, information, and analysis from outside the Plutonium Immobilization Program, the data and analysis were presented on:

- Ceramic and glass formulation development (LLNL, SRS).

- Form characterization for repository disposal (ANL, PNNL, LLNL).

- Process development, including preliminary fabrication of large-scale forms (LLNL, SRS).

- Preconceptual designs and EIS studies (LLNL, SRS, Bechtel, Hanford).

- Nonproliferation evaluations of can-in-canister concepts (LLNL, SRS).

The TEP met daily during the week after the formal review to assess the material presented. Following initial discussions in which the TEP weighed the two options against the criteria and metrics, the documentation process began. Initial drafts for each section of this report were drafted by TEP members and then circulated for review and comments. For topics requiring indepth review, ad hoc groups of two or more TEP members met and worked to arrive at a consensus. The initial draft of this report was forwarded to the LLNL FMDP office on August 9, 1997.

\subsubsection{Peer Review of the Evaluation}

For the next step in the selection process, the FMDP management reviewed and assessed the TEP analysis report and other available information and prepared the overall rationale for the recommendation as well as a letter report to DOE/MD with the recommendation and supporting information. A Peer Review Panel (PRP) conducted a review of the TEP report and drafted a letter report with immobilization form recommendation. The PRP was composed of experts external to the immobilization project in the areas of glass and ceramic materials technology, plutonium processing, and repository performance. The PRP reviewed the TEP analysis as well as the LLNL Nonproliferation, Arms Control, and International Security (NAI) Directorate's proposed recommendation and addressed the following:

- Appropriateness of the criteria and metrics.

- Validity of TEP analysis and LLNL's recommendation.

- Future R\&D program plans to address identified needs of the selected form.

- Confidence level of the selection.

The PRP members had access to the same data provided to the TEP. A letter report on the immobilization form recommendation, with TEP and PRP documentation, was due late August 1997 with a recommendation with documentation to be forwarded to DOE/MD by the end of that month.

\subsection{Evaluation Constraints}

Although the evaluation reported in this document was carried out to the best of the TEP's ability, it was conducted under a number of constraints. 


\subsubsection{Criteria and Weighting of Criteria}

All comparisons in this technical evaluation are based on the given criteria, the factors, and metrics. In many cases, the criteria are accurately defined (e.g., cost, time duration), where a single numerical value defines how the a charactcristic measures up against the metric. In these cases, a comparison of two options is straightforward, provided the numbers are known or can be generated with sufficient accuracy.

However in other cases, the TEP found the application of the criteria themselves anything but straightforward. For example, in defining the resistance to theft of plutonium in a processing line or of an immobilized form at some point in its manufacturing or transport, it became difficult to weigh the options even against the coarsest of scales.

In still other cases, direct comparisons could be made between the same characteristic for the two forms and even slight differences could be resolved with confidence. For example, the neutron radiation dose to workers from the two forms is very difficult to calculate but a clear difference exists between the two forms.

Thus, the TEP's assessments vary from the very accurate and defensible to engineering or scientific judgments based on experience and limited data or designs. The reader should consider this constraint when weighing the comparative evaluations in Section 6.

\subsubsection{Availability of Data}

The development program for immobilization was accelerated during the past year, resulting in considerably less time to produce data than was originally planned. In addition, as the development effort proceeded, improvements were identified and changes made. Although these changes may be beneficial in the long term, the TEP reviewed a great deal of data on form variants that had been dropped from consideration and thus were not directly applicable to the review of the baseline form and process. In addition, data was often taken using plutonium surrogates (for cost savings), and questions of applicability remain. In many cases, data needed to make an assessment were simply not available at the time of the review. Some of the key data on forms containing plutonium (as opposed to a plutonium surrogate) arrived shortly before or during the briefings.

\subsubsection{Time Limits}

The review was carried out in a very short and intense period. The subject areas covered were diverse and complex, and many of the topics are in evolving technical areas (e.g., long-term repository behavior). Many technical discussions in the review were not carried to completion or resolution. In such cases where it was judged critical to the review to try to reach resolution, offline or ad hoc meetings were held. In the four days of formal reviews, each day's session stretched well into the evening and discussions were ended more by exhaustion than by technical closure. When the TEP undertook the writing of its report, it had nine days in which to resolve the comparisons of the forms and processes as well as to write, review, and iterate the report to concurrence. 


\section{BOUNDING CONDITIONS AND ASSUMPTIONS}

For the purposes of this evaluation, the Plutonium Immobilization Program and the TEP made several assumptions regarding the future development of the immobilization program and related activities. Some of these assumptions were based on the likely preferred paths for plutonium disposition as expressed in the ROD [DOE, 1997]. Other assumptions involve information and decisions that straddle the interfaces between the FMDP and other portions of the chain of custody for the fissile materials, specifically the Fissile Material Stabilization Program (DOE/EM) and the Civilian Radioactive Waste Management System (CRWMS, $\mathrm{DOE} / \mathrm{RW}$ ). The final set of assumptions relates to the timing and anticipated duration of the disposition program.

\subsection{Assumptions Based on the Record of Decision}

\subsubsection{Selection of the Can-in-Canister Variant}

The ROD [DOE, 1997] identified the can-in-canister variants as the preferred immobilization alternatives. Consequently, the Plutonium Immobilization Program has concentrated its research, development and demonstration (RD\&D) efforts on issues related to the development of the technology relevant to can-in-canister disposition, and this evaluation considers only that option.

In the can-in canister variant, small cans, each containing on the order of 1 kilogram of plutonium immobilized in a glass or ceramic matrix, would be arranged on a rack within an empty HLW glass pour canister. HLW glass containing large quantities of ${ }^{137} \mathrm{Cs}$ and other fission products would then be poured into the canister, enclosing the plutonium-bearing cans.

\subsubsection{Siting of the Immobilization Facility}

The implementation of the can-in-canister variant requires the existence of a large-scale $\mathrm{HLW}$ vitrification facility.

Currently, such a facility is operating at SRS in the form of the

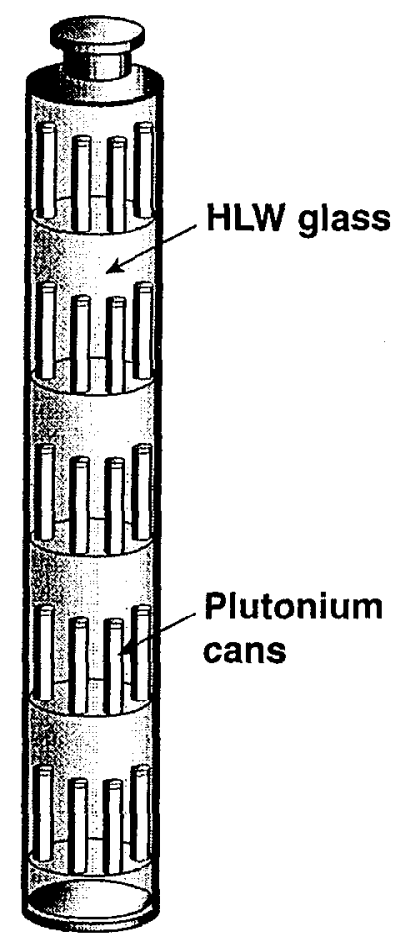

Figure 3.1.1. Schematic diagram of the can-incansiter configuration. DWPF and the ROD identifies the DWPF as the likely preferred site of the eventual immobilization facility [DOE, 1997]. For the purposes of this evaluation, the Plutonium Immobilization Program and the TEP have assumed that the immobilization facility will be located at SRS and that standard DWPF canisters will be used as the outer canister. Some relevant aspects of the DWPF canisters are given in Table 3.1.1. 
Table 3.1. Physical characteristics of a DWPF canister.

\begin{tabular}{ll}
\hline Canister outer diameter, $\mathrm{m}$ (in.) & $0.6(24)$ \\
Canister inner diameter, $\mathrm{m}$ (in.) & $0.591(23.25)$ \\
Overall canister height, $\mathrm{m}(\mathrm{ft})$ & $3.0(10)$ \\
Nominal pour height of $\mathrm{HLW}$ glass, $\mathrm{m}$ (in.) & $2.3-2.4(90-96)$ \\
Mass of HLW glass in full canister, $\mathrm{kg}$ & $\sim 1680$ \\
Density of HLW glass, $\mathrm{g} / \mathrm{cm}^{3}$ & $\sim 2.7$ \\
\hline
\end{tabular}

Because the DWPF is an operating facility with its own schedule and mission, the Plutonium Immobilization Program has taken the stance that implementation of the can-in-canister variant must be accomplished with no impact to the DWPF mission. This includes all aspects of the DWPF program, from plant operations to repository qualification of the vitrified HLW waste produced by the facility.

\subsection{Assumptions Involving the DOE/EM Interface}

\subsubsection{Characteristics and Quantity of the Plutonium to be Immobilized}

The $50 \mathrm{MT}$ of plutonium that have been declared surplus fall into several general categories (Table 3.2.1). These materials are located at several DOE weapons-complex sites across the country, and would be transferred from those sites to the immobilization facility for disposition. The largest quantity of material $(\sim 31.8 \mathrm{MT})$ is weapons-grade material. This material is quite pure, containing very little in the way of impurity elements and no uranium. Other categories of material contain significant quantities of both uranium and other elements that must be accommodated successfully by the immobilization form. The working assumption is that the FMDP will only be responsible for the disposition of materials that contain $>50 \mathrm{wt} \%$ plutonium, except in the case of fuels. Other DOE programs will handle the disposition of materials containing $<50 \mathrm{wt} \%$ plutonium. This dividing line is the topic of ongoing discussions within DOE.

Table 3.2.2. Quantities and categories of surplus plutonium [Diaz, 1997].

\begin{tabular}{lccc}
\hline Category & Plutonium, MT & Uranium, MT & Other, MT \\
\hline Weapon-pit oxides & 31.8 & 0 & 0 \\
Metals & 3.4 & 0 & 0.1 \\
Nonpit oxides & 9.0 & 2.0 & 1.2 \\
Alloys & 1.0 & 0.3 & 0.1 \\
Fuels (unirradiated) & 4.8 & 14.5 & 0.1 \\
Total & 50.0 & 17.0 & 1.5 \\
\hline
\end{tabular}

The actual quantity of plutonium that will be immobilized (as opposed to fabricated into mixed-oxide (MOX) fuel for burning in reactors) has not yet been determined. For this 
evaluation, the FMDP issued guidance to consider a case in which all $50 \mathrm{MT}$ of plutonium would be immobilized as well as a case in which only the $18.2 \mathrm{MT}$ of nonweapons-pit plutonium would be immobilized. In both cases, the quantity of uranium and other impurities to be immobilized would remain the same because the weapons material does not contain these components. The case in which 18.2 MT of plutonium would be immobilized is commonly referred to as the "17-MT case" and that convention is followed here. Table 3.2.2. summarizes the general nature and concentrations of the non-uranium impurity elements contained in the non-pit materials. At present, there remains considerable uncertainty over the identity and concentrations these impurities in the nonpit oxide classification. Better definition of the composition of this feed will be forthcoming as the program matures.

Table 3.2.2. Impurity element concentrations in surplus plutonium [Meaker and Peeler, 1997a; Ebbinghaus et al., 1997]. NA indicates that data were not available to the TEP. Average concentrations reflect the average concentration in the nonpit plutonium; maximum concentrations reflect the maximum concentrations reported in Diaz [1997].

\begin{tabular}{lll}
\hline $\begin{array}{l}\text { Impurity } \\
\text { element }\end{array}$ & $\begin{array}{l}\text { Average } \\
\text { concentration, wt\% }\end{array}$ & $\begin{array}{l}\text { Maximum } \\
\text { concentration, wt\% }\end{array}$ \\
\hline $\mathrm{B}$ & 0.00 & 0.13 \\
$\mathrm{Ba}$ & $\mathrm{NA}$ & $\mathrm{NA}$ \\
$\mathrm{Ca}$ & $\mathrm{NA}$ & $\mathrm{NA}$ \\
$\mathrm{Cl}$ & 0.12 & 1.7 \\
$\mathrm{Cr}$ & 0.01 & 0.11 \\
$\mathrm{~F}$ & 0.06 & 0.45 \\
$\mathrm{Fe}$ & 0.06 & 0.45 \\
$\mathrm{Ga}$ & 0.12 & 1.1 \\
$\mathrm{~K}$ & $\mathrm{NA}$ & $\mathrm{NA}$ \\
$\mathrm{Mg}$ & $\mathrm{NA}$ & $\mathrm{NA}$ \\
$\mathrm{Mo}$ & 0.09 & 0.45 \\
$\mathrm{Na}$ & 0.05 & 0.45 \\
$\mathrm{Ni}$ & 0.03 & 0.32 \\
$\mathrm{REE}$ & $\mathrm{NA}$ & $\mathrm{NA}$ \\
$\mathrm{Si}$ & 0.10 & 0.85 \\
$\mathrm{Ta}$ & 0.05 & 0.65 \\
$\mathrm{~W}$ & 0.00 & 1.7 \\
$\mathrm{Zn}$ & 0.01 & 0.10 \\
$\mathrm{Zr}$ & $\mathrm{NA}$ & $\mathrm{NA}$ \\
\hline
\end{tabular}




\subsection{Assumptions Involving the DOE/RW Interface}

\subsubsection{Approval to Dispose of Immobilized Fissile Material in a HLW Repository}

It is not clear that current legislation* governing the licensing and operation of a HLW repository in the U.S. would allow for the inclusion of immobilized fissile material. Surplus fissile material does not clearly fall into any existing category (currently spent fuel and HLW) that are statutorily allowed to be included. Some form of administrative or legislative action will likely be required to clarify this point and clear the way for final disposition of immobilized plutonium in a repository. The Plutonium Immobilization Program assumes that such action will occur.

\subsubsection{The Existence of a Yucca Mountain Repository}

The U.S. does not have a licensed repository for HLW and spent fuel. Development of a repository is the responsibility of the Civilian Radioactive Waste Management System (CRWMS). CRWMS is studying the suitability of a candidate repository site at Yucca Mountain, Nevada. For the purposes of planning and evaluation, the Plutonium Immobilization Program has assumed that this site will be found suitable, a repository constructed there, and the immobilized plutonium transferred there for permanent burial.

A HLW repository at Yucca Mountain would be located in a series of tuffaceous rocks some $200 \mathrm{~m}$ above the present water table. The water flux through a repository at the site is expected to be quite low and dominated by seepage through fractures.

A final design for the HLW waste packages has not yet been established. The currently preferred concept involves horizontally emplaced packages consisting of a thick steel shell surrounding a corrosion-resistant inner shell. Each waste package would contain four or five HLW canisters. It has not yet been decided how many canisters in each waste package would contain immobilized plutonium.

The most likely condition for degradation of the immobilized form, should the waste package fail, would be contact with water vapor, dripping water, or small amounts of standing water. In all cases, water will move slowly through the pores of the host rock, remaining engineered barrier materials with corrosion products, and waste forms. For the can-in-canister configuration, any water contacting the plutonium-bearing form will most likely have passed through the surrounding canister and interacted chemically with the DWPF glass.

Based on previous experience, the immobilized form will likely have to conform to a set of yet-to-be-determined repository acceptance criteria. In the case of vitrified HLW, these criteria include requirements to report on the chemistry, phases, physical properties, and product consistency of the immobilized form. As such, it is important to be able to ensure stringent control over the fabrication process to ensure good and consistent product quality. It is assumed that, at a minimum, the immobilized form will be required to comply with the existing HLW acceptance criteria. These criteria will likely be further enhanced to provide assurance that the

\footnotetext{
"The Nuclear Waste Policy Act of 1982 (P.L. 97-425, as amended).
} 
actinides present in the immobilized form do not generate the potential for criticality in (or out of) the repository (see Section 6.4.3).

\subsection{Program Timing}

The goal is to begin processing surplus plutonium (i.e., begin meeting the spent fuel standard) by 2005. FMDP guidance directed the Plutonium Immobilization Program to plan a program and facility design assuming that all $50 \mathrm{MT}$ of plutonium would be immobilized. This campaign is to be completed within ten years. (The actual quantity of plutonium to be immobilized has not been determined; see Section 2.1.7.) This aggressive schedule is driven largely by the desire to begin as soon as possible to convert surplus fissile material into a form resistant to diversion or reuse in weapons. Figure 3.4.1 provides a timeline for the major program activities, from form development to the initiation of hot operations of the facility. The ability to achicve this schedule is contingent primarily on the availability of the funding levels in the RD\&D plan.

Figure 3.4.1. Immobilization top-level schedule defined as the baseline schedule for the TEP evaluation [Integrated Immobilization Plan, 1997].

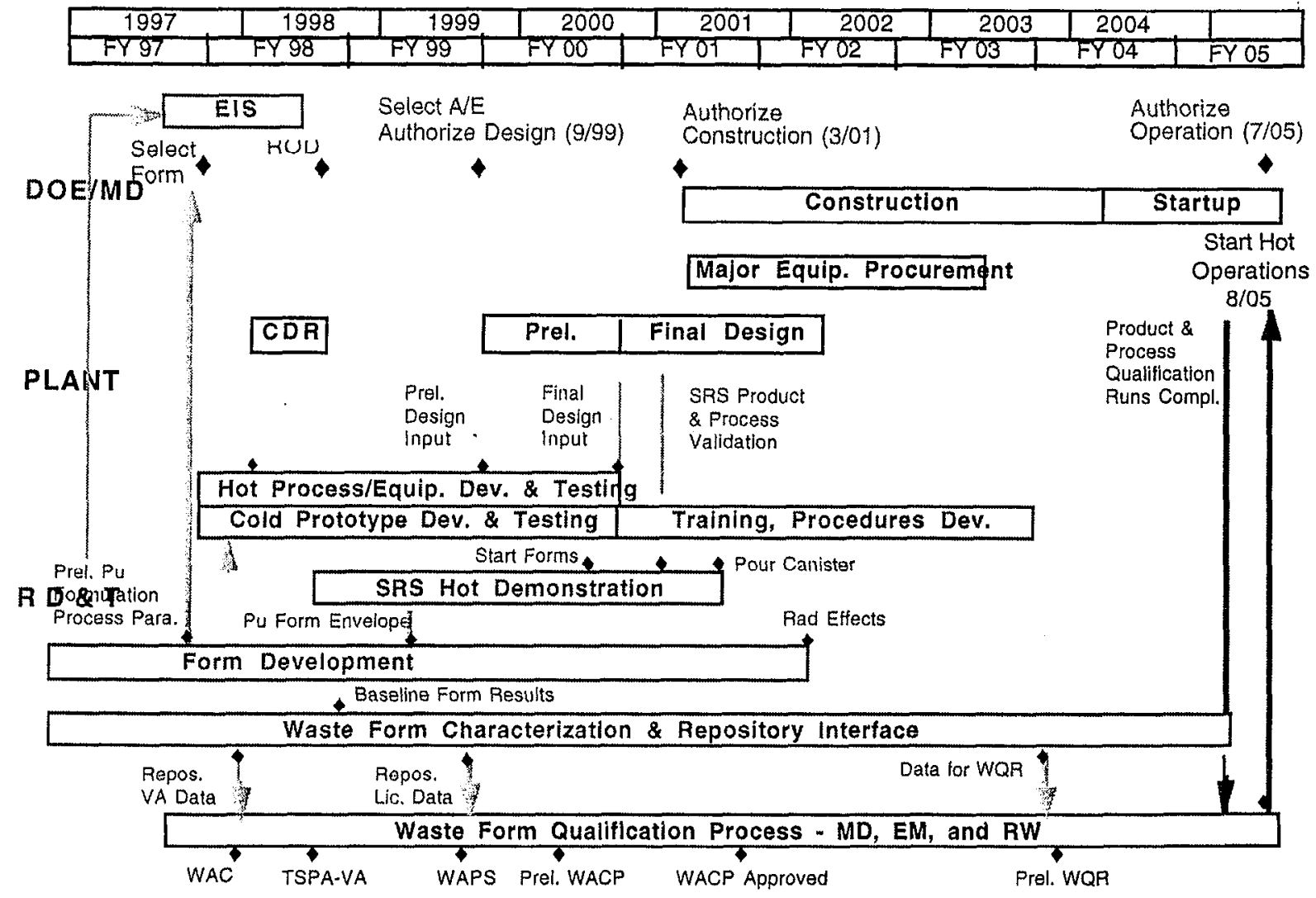




\section{DESCRIPTIONS OF THE CRITERIA AND METRICS}

Criteria were developed by DOE's Office of Material Disposition (MD) to best achicve the goals of the U.S. government in the selection of technical options for fissile nuclear material disposition. These criteria incorporate the policy objectives articulated in the President's Nonproliferation and Export Control Policy of September 1993 and the January 1994 "Agreement between the United States and Russia on Nonproliferation of Weapons of Mass Destruction and their Means of Delivery" as well as the analytical framework established by the NAS in their study on the disposition of surplus plutonium [NAS, 1994].

For the purposes of the TEP review, only the first six of the nine criteria were used. The last three criteria, concerning international impacts, public acceptance, and other benefits, involve judgments and expertise that are outside the scientific and engineering disciplines represented by the TEP members and were not addressed in this review (Section 2.2). They are included here and in the Appendix (Section 11.1) for completeness.

The criteria were developed [DOE, Summary Report of Screening Process] to reflect the following goals related to the disposition of surplus plutonium:

- Consistent with national policy and nonproliferation strategy, develop a national program for management, control, and disposition of all U.S. surplus, weapons-usable fissile nuclear materials which will:

1. Minimize or eliminate the risk that these materials will be reused in weapons.

2. Ensure that environmental, safety, and health risks do not exceed acceptable norms.

3. Provide a practical demonstration for other nations' nuclear material disposition programs and provide the technical basis to support negotiations for bilateral or multilateral reductions in surplus fissile material inventories.

4. Be cost effective consistent with meeting strategic objectives and these programmatic goals.

5. Achieve government and public consensus through stakeholder and public involvement in the program planning and decision process.

- Foster cooperation with Russia and other countries through joint studies to help reach consensus in their implementation of comparable programs to reach similar goals on a comparable schedule.

- Ensure that, at the earliest practical date, all U.S. surplus fissile nuclear materials are placed in safe, controlled, inspectable storage.

- For weapon-usable plutonium, provide credible options, which can be utilized, for safe and controlled disposition of approximately $50 \mathrm{MT}$ of these materials.

DOE presented a preliminary set of these criteria to the public and stakeholders through a set of questionnaires and public hearings. Input from questionnaire responses, comments received during meetings, and written input to the department were incorporated into revised criteria [Gray and Gould, 1997]. The criteria used for both the screening and selection of disposition and immobilization options are listed in Table 4.0.1. 
Table 4.0.1. Criteria for plutonium disposition.

Criterion 1. Resistance to theft or diversion by unauthorized parties. Each step in the disposition process must be capable of providing for comprehensive protection and control of weapons-usable fissile material.

Criterion 2. Resistance to retrieval, extraction, and reuse by the host nation. The surplus material must be made highly resistant to potential reuse in weapons to reduce reliance on institutional controls and demonstrate that the arms reductions will not be easily reversed.

Criterion 3. Technical viability. There should be a high degree of confidence that the alternative will be technically successful.

Criterion 4. Environment, safety, and health compliance. High standards of public and worker health and safety, and environmental protection must be met, and significant additional ES\&H burdens should not be created.

Criterion 5. Cost effectiveness. Disposition should be accomplished in a cost effective manner:

Criterion 6. Timeliness. There is an urgent need to minimize the time period that surplus fissile materials remain in weapons-usable form.

Criterion 7. Fostering of progress and cooperation with Russia and other countries. The alternative must establish appropriate standards for the disposition of surplus weaponsusable fissile material inventories; support negotiations for bilateral or multilateral reductions in these materials, and at each step in the disposition process allow for international inspections.

Criterion 8. Public and institutional acceptance. An alternative should be able to muster a broad and sustainable consensus on the manner in which disposition is accomplished.

Criterion 9. Additional benefits. The ability to leverage government investments for the disposition of surplus materials to contribute to other national or international initiatives should be considered.

Each criterion has factors and metrics that can be used to assess how well a particular disposition option meets the desired goal of the criterion. These factors and metrics were created to ensure that an assessment considered the most important and relevant aspects of the criterion and as an aid to achieving greater accuracy and objectivity in the assessment. Thus each criterion has one or more factors to be considered, and under each factor is one or more metrics that provide a quantitative or graded qualitative rating. These factors are listed in Table 4.0.2. As with the criteria, a more detailed description of these criteria is provided in the Appendix (Section 11.1). 
Table 4.0.2. Plutonium disposition criteria with factors.

Criterion 1. Resistance to theft or diversion by unauthorized parties:

- Low inherent attractiveness.

- Minimization of transportation, facilities, and sites.

- Minimization of processing.

- Safeguards and security assurance.

- Difficulty of retrieval, extraction, and use by a clandestine group or rogue nation.

Criterion 2. Resistance to retrieval, extraction, and reuse by the host nation:

- Difficulty of retrieval, extraction, and reuse.

- Assurance of detection of diversion and extraction.

Criterion 3. Technical viability:

- Technical maturity.

- Viability risks.

- Repository acceptability of disposal form.

Criterion 4. Environment, safety, and health compliance:

- Public and worker health and safety.

- Waste minimization.

- Known and manageable waste forms.

Criterion 5. Cost effectiveness:

- Life-cycle cost.

- Investment and start-up cost.

- Establish product acceptability requirements.

- Potential for cost sharing.

- Utilization of existing infrastructure.

- Cost estimate certainty.

Criterion 6. Timeliness:

- Time to start disposition or time to open facility.

- Time to complete.

- Impacts to existing or future missions.

Criterion 7 Fostering of progress and cooperation with Russia and other countries:

- Appropriateness as international standard.

- Leverage provided for international negotiations.

- Transparency.

Criterion 8. Public and institutional acceptance:

- Ability to create a sustainable consensus.

- Socioeconomic impacts.

- Policy and statute compatibility.

Criterion 9. Additional benefits:

- Contributions to national initiatives. 
A substantial amount of discussion centered on achieving the SFS as an adequate degree of proliferation resistance. To meet the SFS, options for the disposition of weapons plutonium should seek to make this plutonium roughly as inaccessible or unattractive for weapons use as the much larger and growing quantity of plutonium that exists in spent fuel from commercial reactors. By meeting the SFS, the proliferation and rearmament threat associated with the surplus plutonium would be no greater than the threat resulting from plutonium in spent fuel, and the surplus plutonium would no longer require a unique level of domestic and international safeguards. Achieving the SFS relates to the first two disposition criteria.

The SFS described here consists of three parts: the radiological, physical, and chemical properties of the material form that make any residual surplus plutonium as inaccessible for recovery as the plutonium in commercial spent fuel. These characteristics directly influence the particular requirements, regulations, and practices for the application of safeguards and security for both domestic and international purposes. Therefore, the material needs to meet all three characteristics in order to satisfy the SFS:

- High radiation dose rate: lethal to unprotected humans facilitates monitoring of material.

- Large and heavy integral assembly: impossible for an individual to move without machinery.

Dilute, substantially homogeneous solid matrix: concentrations of less than a few weight percent and dispersed along with other elements to complicate chemical separations.

The nuclear properties of the plutonium (isotopic composition) have only a secondary effect on proliferation resistance. There is a concern for potential theft or diversion of nonweaponsgrade plutonium by unauthorized parties because these materials can be used in a nuclear explosive device. However, isotopic qualities can make the material less attractive for U.S. and Russia to reuse, because both countries have based their entire technology and infrastructure on the use of weapons-grade plutonium. Inability to test new designs, as results from a Comprehensive Test Ban Treaty, would make the use of reactor-grade plutonium by these countries even less likely.

The NAS recognized that the radiation barrier associated with spent fuel will eventually decay and that long-term steps to reduce the proliferation risks associated with the entire global stock of plutonium will be needed. The Nuclear Waste Policy Act, as amended, establishes the path forward for ultimate disposal of spent fuel in a mined geologic repository, where geologic barriers reduce the proliferation risks beyond the time period of decay for the radiation barrier. 


\section{FORM AND PROCESS BASELINE DESCRIPTIONS}

In this section, the baseline immobilization forms and the baseline production processes are described. Oxide-based ceramics, such as the crystalline ceramic waste form commonly known as synthetic rock (SYNROC), and the amorphous ceramic waste form commonly known as glass, are described for the immobilization of excess weapons-usable plutonium.

The SYNROC strategy is to immobilize radioactive wastes in durable multiphase titanate ceramics with phases chosen to be similar to titanate minerals that have existed in nature for billions of years. Such key SYNROC phases as pyrochlore, zirconolite, and perovskite have successfully immobilized naturally occurring radioactive elements (e.g., uranium, thorium) in a wide range of geochemical settings. SYNROC formulations have been developed and tested for a wide variety of wastes, including PW-4b wastes (SYNROC C) and defense wastes at the Savannah River Site (SYNROC D) [Ringwood et al., 1988]. Zirconolite-rich and zirconolite/ pyrochlore titanate ceramics have been developed for surplus plutonium disposition [Jostsons et al., 1996]. A pyrochlore-rich SYNROC $F$ was developed for spent fuel disposal [Kesson and Ringwood, 1983] and for CANDU fuel [Solomah et al., 1987]. SYNROC processing on a 10-kg/h scale has been demonstrated in a nonradioactive plant by ANSTO [Jostsons, 1994] using uniaxial hot-pressing. Hot isostatic pressing of cans of plutonium-containing zirconolite rich ceramics has been demonstrated by Moricca et al. [1997] and Solomah et al. [1987] used cold-pressing and sintering for SYNROC processing.

Borosilicate glasses are currently being used successfully on the production scale to vitrify high-level liquid wastes (HLLW) at the Savannah River Site (SRS) and at the West Valley Nuclear Fuel (WVNF) site in the United States [Brumley, 1985; Knabenschuh, 1985]. Similar production facilities for the stabilization of commercial nuclear wastes are in operation in Sellafield in the United Kingdom, the Pamela plant in Belgium, the La Hague and Marcoule facilities [Jouan et al., 1985 ] in France, and the Mayak facility in Russia (Figure 5.0.1). In addition, production-scale vitrification plants for the stabilization of mixed (hazardous and radioactive) wastes are currently in operation at SRS and the Oak Ridge Reservation [Bowan and Brandys, 1995; Jantzen et al., 1993, 1994; Schumacher et al., 1994; Whitehouse et al., 1995]. Vitrification has been chosen for stabilization of Rocky Flats plutonium residues [Vienna et al., 1997], the Hanford high-level [Weber et al., 1995] and low-level wastes [Wilson et al., 1995], the Idaho Chemical Processing Plant defense wastes [Staples, 1985], and is under investigation for stabilization of lead-based paint wastes [Marra, 1996], asbestos wastes [Bowan, personal communication; Jantzen, personal communication], and mining industry wastes [Jantzen, personal communication].

The crystalline ceramic form and the amorphous borosilicate glass form for immobilization of excess plutonium have different baseline formulations, some processing similarities, and some processing differences. In addition, the two forms have different densities and different physical attributes which lead to different can-in-canister arrays. The baseline ceramic and glass forms for each plutonium feed are presented in Table 5.0.1. A comparison of additives to the baseline ceramic and LaBS glass is given in Table 5.0.2. The form composition, manufacturing processes, and can-in-canister arrays of each baseline are described in Sections 5.1, 5.2, and 5.3. 
Figure 5.0.1. Radioactive waste glass facilities, present and future.

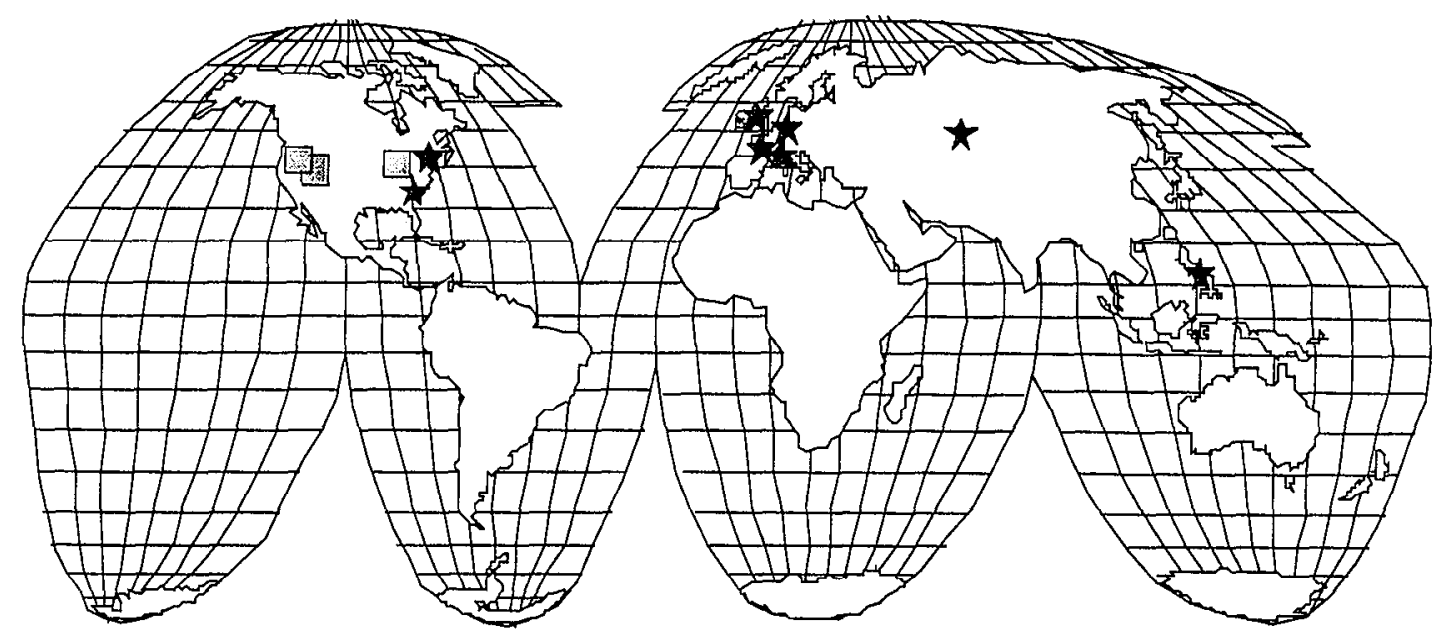

Existing radioactive waste glass vitrification production facilities

Other planned facilities

Table 5.0.1. Identified individual feed streams for the Plutonium Immobilization Program [Meaker and Peeler, 1997a].

\begin{tabular}{lccrl}
\hline Plutonium source & Plutonium, \% & Uranium, \% & Total minor components, \% \\
Clean metal (A)* & 98.0 & 0.0 & 2.0 & $\mathrm{Ca}, \mathrm{Mg}, \mathrm{Ga}, \mathrm{Zn}$ \\
Impure metal (A) & 78.6 & 0.0 & $21.4 \mathrm{Ca}, \mathrm{Mg}, \mathrm{Fe}, \mathrm{Cr}, \mathrm{Ni}, \mathrm{K}, \mathrm{Ta}, \mathrm{W}, \mathrm{Al}$ \\
Plutonium alloy & 65.3 & 32.6 & $2.1 \mathrm{Ca}, \mathrm{Mg}, \mathrm{Fe}, \mathrm{Mo}, \mathrm{Al}, \mathrm{Zr}$ \\
Clean oxide & 98.5 & 1.1 & 0.4 & $\mathrm{Al}$ \\
U/Pu Oxide & 33.4 & 60.4 & $6.3 \mathrm{Ca}, \mathrm{Mg}, \mathrm{Fe}, \mathrm{Ni}, \mathrm{K}, \mathrm{Na}, \mathrm{Mo}, \mathrm{Ta}, \mathrm{Ba}, \mathrm{W}$ \\
Plutonium/uranium & 47.1 & 0.0 & $52.9 \mathrm{Ca}, \mathrm{Mg}, \mathrm{Cl}, \mathrm{Fe}, \mathrm{Cr}, \mathrm{Ni}, \mathrm{F}, \mathrm{K}, \mathrm{Na}, \mathrm{Mo}, \mathrm{Ba}, \mathrm{W}, \mathrm{Si}$ \\
$\quad$ compounds and & & & & \\
$\quad$ impure oxide (A)* & & & & \\
Impure oxide (T)* & 86.4 & 0.0 & $13.6 \mathrm{Ca}, \mathrm{Mg}, \mathrm{Cl}, \mathrm{Fe}, \mathrm{Cr}, \mathrm{Ni}, \mathrm{F}, \mathrm{K}, \mathrm{Na}, \mathrm{Mo}, \mathrm{Ba}, \mathrm{W}, \mathrm{Si}$ \\
ZPPR fuel & 28.0 & 69.0 & $3.0 \mathrm{Mo}$ \\
\hline
\end{tabular}

* $\mathrm{A}=$ atypical $\mathrm{T}=$ typical. 
Table 5.0.2. Comparison of baseline ceramic and LaBS glass additives for 50-MT and 17-MT plutonium immobilization.

\begin{tabular}{lcc}
$\begin{array}{c}\text { Oxide } \\
\text { Additive 1 }\end{array}$ & $\begin{array}{c}\text { Ceramic, } \\
\mathbf{w t} \%\end{array}$ & $\begin{array}{c}\text { LaBS glass } \\
\mathbf{B}, \mathbf{w t} \%\end{array}$ \\
\hline $\mathrm{Al}_{2} \mathrm{O}_{3}$ & - & 21.3 \\
$\mathrm{~B}_{2} \mathrm{O}_{3}$ & - & 11.6 \\
$\mathrm{CaO}$ & 15.4 & - \\
$\mathrm{Gd}_{2} \mathrm{O}_{3}$ & 12.4 & 12.8 \\
$\mathrm{HrO}_{2}$ & 16.5 & 6.6 \\
$\mathrm{La}_{2} \mathrm{O}_{3}$ & - & 8.1 \\
$\mathrm{Nd}_{2} \mathrm{O}_{3}$ & - & 8.2 \\
$\mathrm{SiO}_{2}$ & - & 28.9 \\
$\mathrm{SrO}$ & - & 2.5 \\
$\mathrm{TiO}_{2}$ & 55.7 & - \\
$\mathrm{Total}$ & $\mathbf{1 0 0}$ & $\mathbf{1 0 0}$
\end{tabular}

Additive 2

$\mathrm{UO}_{2}$

$12-20^{\dagger}$

* Depends on how much $\mathrm{UO}_{2}$ is incoming with feed baselines 1 and 2; see Table 5.2 .1 for details.

${ }^{\dagger}$ LaBS glass " $\mathrm{B}$ " is defined as the baseline frit and glass whereas LaBS glass " $\mathrm{A}$ " was an earlier frit formulation that contained $\mathrm{ZrO}_{2}$ instead of $\mathrm{HFO}_{2}$.

\subsection{Ceramic Baseline Definition}

\subsubsection{Baseline Ceramic Composition}

The baseline formulation is targeted for a phase assemblage that is dominated by pyrochlore. Other compatible titanate phases are expected to form and provide the ability to cope with variations in feed, including impurities (Table 5.0.1), with a single four-component precursor: $55.7 \mathrm{wt} \% \mathrm{TiO}_{2}, 16.5 \mathrm{wt} \% \mathrm{HfO}_{2}, 15.4 \mathrm{wt} \% \mathrm{CaO}$, and $12.4 \mathrm{wt} \% \mathrm{Gd}_{2} \mathrm{O}_{3}$ (Table 5.0.2). This precursor is common to both baseline cases (baseline 1: $50 \mathrm{MT}$ plutonium; baseline 2: $17 \mathrm{MT}$ plutonium) and to the variants discussed in Section 7. In each baseline case, $11.9 \mathrm{wt} \% \mathrm{PuO}_{2}(10.5$ $\mathrm{wt} \%$ plutonium) and $23.7 \mathrm{wt} \% \mathrm{UO}_{2}(20.9 \mathrm{wt} \%$ uranium) are added to the precursor to make the overall mix. This amounts to three input streams to the process (precursor, $\mathrm{UO}_{2}$, and $\mathrm{PuO}_{2}$, which are preblended; Figures 5.1.3 and 5.1.4). The fundamental baseline parameters are summarized in Table 5.2.1.

The pyrochlore-rich titanate ceramic has been chosen for plutonium immobilization to ensure high loading of plutonium, uranium, and the neutron absorbers (gadolinium and hafnium). The neutron absorbers are present to ensure criticality control in the repository. High loadings of ${ }^{238} \mathrm{U}$ are intended to ensure additional criticality control in the ceramic form through limitation of ${ }^{235} \mathrm{U} /{ }^{238} \mathrm{U}$ ratio as ${ }^{239} \mathrm{Pu}$ decays to ${ }^{235} \mathrm{U}$ in the long term. The baseline 1 and 2 ceramics contain 
$31.4 \mathrm{wt} \%$ plutonium plus uranium $\left(35.6 \mathrm{wt} \% \mathrm{PuO}_{2}\right.$ plus $\left.\mathrm{UO}_{2}\right)$. The required plutonium-plusuranium loading will be achieved by blending $\mathrm{UO}_{2}\left(\right.$ or $\left.\mathrm{U}_{3} \mathrm{O}_{8} / \mathrm{UO}_{3}\right)$ with the incoming $\mathrm{PuO}_{2}$ feed. The neutron absorber loadings are also identical in both baseline ceramics at $8.0 \mathrm{wt} \% \mathrm{Gd}_{2} \mathrm{O}_{3}$ ( $7 \mathrm{wt} \%$ gadolinium) and $10.6 \mathrm{wt} \% \mathrm{HfO}_{2}(\sim 10 \mathrm{wt} \%$ hafnium $)$.

The phases present in the baseline pyrochlore-rich ceramic, determined from extensive studies along the pyrochlore/zirconolite composition regime [Ebbinghaus et al., 1997a-d; Vance et al., 1997], are shown as a $\left(\mathrm{TiO}_{2}\right)=1$ (i.e., rutile excess) slice of the phase diagram in Figure 5.1.1. This phase diagram shows the phase compatibility near the pyrochlore end-member that is the region of interest. The baseline design region $\mathrm{Hf} / \mathrm{Pu}=1$ is indicated by the boundary between the two shaded regions that intersect and extend beyond the zirconolite/pyrochlore join.

Figure 5.1.1 Ternary phase diagram of the baseline ceramic.

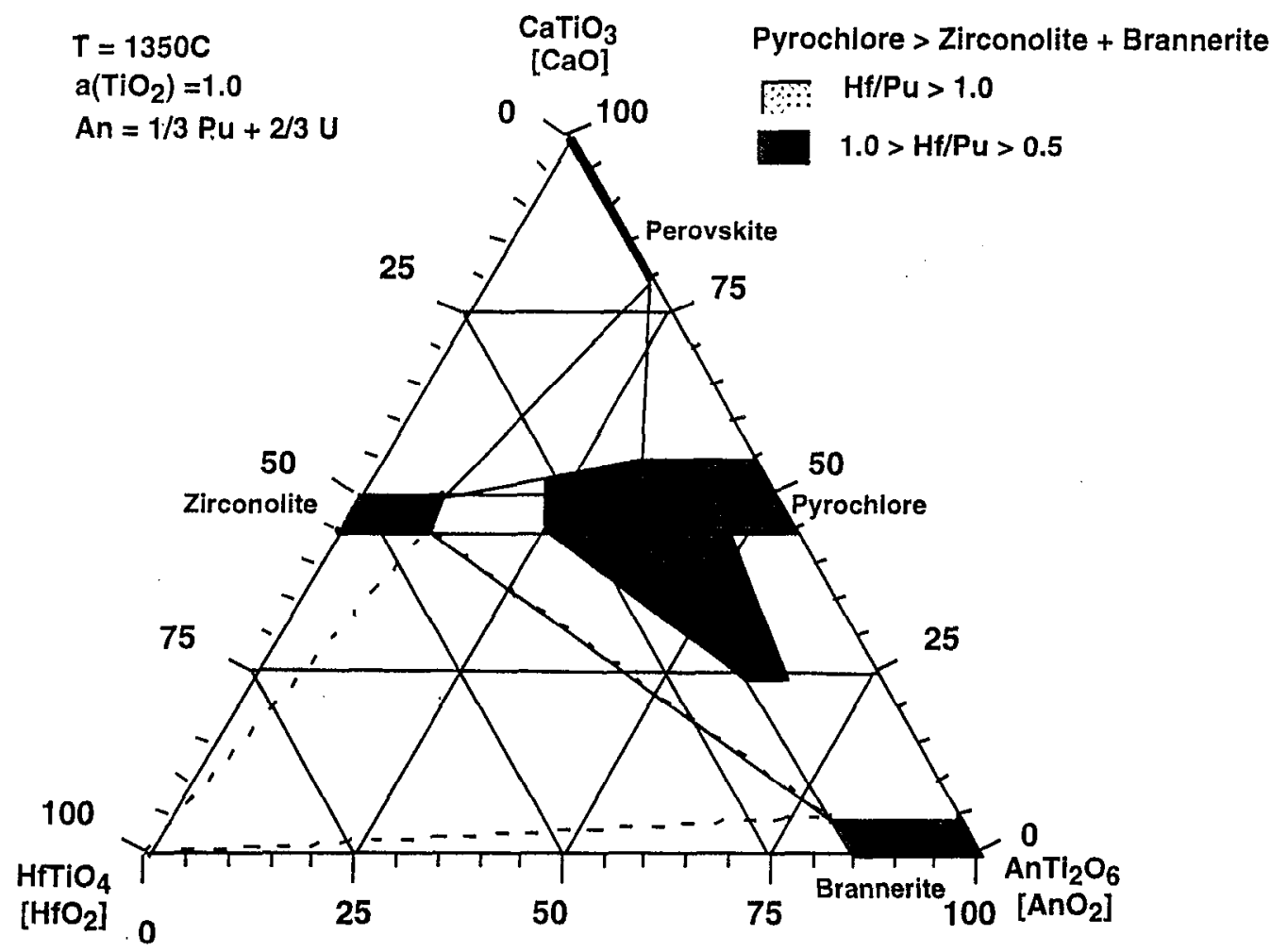

The cubic pyrochlore phase can be regarded as an ordered anion-deficient fluorite structure with a general formula of $\mathrm{ABTi}_{2} \mathrm{O}_{7}$. The $\mathrm{B}$ site is occupied by plutonium, uranium, hafnium, zirconium, and some of the gadolinium. Plutonium and uranium in end members (e.g., $\mathrm{CaPuTi}_{2} \mathrm{O}_{7}$ ) fully occupy the B site, giving a maximum loading of approximately $50 \mathrm{wt} \%$ of plutonium or uranium. Plutonium and uranium are fully interchangeable on the $\mathrm{B}$ site of pyrochlore. [The gadolinium end-member of pyrochlore $\left(\mathrm{Gd}_{2} \mathrm{Ti}_{2} \mathrm{O}_{7}\right)$ results from the complete occupation of both $\mathrm{A}$ and $\mathrm{B}$ sites by gadolinium.] In zirconolite, $\mathrm{CaZrTi}_{2} \mathrm{O}_{7}$, the $\mathrm{B}$ site is occupied by the same atoms but is dominated by zirconium and/or hafnium. The pyrochlore/zirconolite phase 
boundary in the baseline ceramic lies at an actinide (plus lanthanide) value of about 0.72 formula units, i.e., about $36 \mathrm{wt} \%$ actinide metal [Ebbinghaus et al., 1997s]. Phase boundaries of the pyrochlore field in these systems appear to be independent of temperature in the regime of interest for the baseline ceramic waste form. Actinide solubility in zirconolite that is in equilibrium with pyrochlore appears to increase with temperature above $1200^{\circ} \mathrm{C}$ [Ebbinghaus, 1997a], but this may be due to stabilization of additional zirconolite polytypes. Jostsons et al. [1996] demonstrated that two zirconolite polytypes coexisted in equilibrium with pyrochlore in

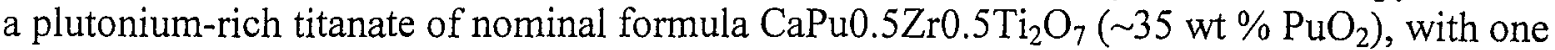
zirconolite polytype containing approximately $18 \mathrm{wt} \% \mathrm{PuO}_{2}$ and the other $36 \mathrm{wt} \%$. Hafnium can be substituted in the B site in pyrochlore and completely for zirconium in zirconolite while gadolinium enters both phases. Americium that is present in the plutonium feed will behave similarly to gadolinium. Americium that is present in the plutonium feed is expected to partition between phases similarly to gadolinium, and the release of americium from the titanate ceramic is usually less than for plutonium [Jostsons et al., 1996, 1997].

The phase development in the baseline ceramic formulation was influenced by the kinetics of the dissolution of high-fired $(\mathrm{U}, \mathrm{Pu}) \mathrm{O}_{2}$ feed particles significantly exceeding $20 \mu \mathrm{m}$. Trace amounts $(<1 \mathrm{wt} \%$ ) of a residual fluorite structured ( $\mathrm{U}, \mathrm{Pu}, \mathrm{Hf}, \mathrm{Zr}, \mathrm{Gd}) \mathrm{O}_{2}$ phase were observed after sintering at $1350^{\circ} \mathrm{C}$ for $4 \mathrm{~h}$ [Ebbinghaus et al., 1997b]. The fluorite phase contained as much as $2.9 \mathrm{wt} \%$ gadolinium and $7.8 \mathrm{wt} \%$ hafnium and/or zirconium. The baseline processing temperature was determined to be $1350^{\circ} \mathrm{C}+50 /-25^{\circ} \mathrm{C}$ from data obtained after sintering tests at 1300,1325 , 1350,1375 and $1400^{\circ} \mathrm{C}$ for $4 \mathrm{~h}$. Brannerite, $(\mathrm{U}, \mathrm{Pu}) \mathrm{Ti}_{2} \mathrm{O}_{6}$, was found to encapsulate the (U,Pu)containing fluorite phase.

The baseline process assumes that uranium is added as prepurchased $\mathrm{UO}_{2}$ and not as $\mathrm{U}_{3} \mathrm{O}_{8}$ or $\mathrm{UO}_{3}$ and that the pellets are sintered in argon. It was also demonstrated that the pellets can be sintered in air if uranium is added as $\mathrm{UO}_{2}$, and that uranium can be added as $\mathrm{U}_{3} \mathrm{O}_{8}$ if the pellets are sintered in argon. It has not been demonstrated that uranium can be added as $\mathrm{U}_{3} \mathrm{O}_{8}$ (or $\mathrm{UO}_{3}$ ) and sintered in air.

The flexibility of the baseline ceramic formulation to utilize a single precursor for the various anticipated feeds was demonstrated-by successfully testing representative categories of all plutonium feed streams (Table 5.0.1). It is assumed that any blending strategy is bounded by the successful incorporation of the representative unblended feed categories. Impurity test compositions containing plutonium and uranium were prepared and characterized by ANSTO and LLNL. Compositions of the nine forms produced, including impurities, are shown in Table 5.1.1. A complementary test program was carried out on specimens containing uranium and cesium (which was substituted for plutonium on a molar basis) at ANSTO, LLNL and SRS. The results of these studies have been summarized by Ebbinghaus et al. [1997c]. Specimens were generally prepared from high-fired $(\mathrm{Pu}, \mathrm{U}) \mathrm{O}_{2}$ and oxide precursors. A few duplicate samples were prepared with alkoxides and nitrates in an attempt to determine closer approximations to the equilibrium phase assemblages. Samples were formed by sintering at $1350^{\circ} \mathrm{C}$ in argon for $4 \mathrm{~h}$. In every test, pyrochlore was the dominant phase, ranging from a low of about $65 \mathrm{wt} \%$ abundance to $90 \mathrm{wt} \%$, depending on the impurity loading. The elimination of the residual plutonium/ uranium-rich fluorite phase and reduction in the brannerite content was strongly aided by impurities, particularly $\mathrm{SiO}_{2}$. The $(\mathrm{U}, \mathrm{Pu}, \mathrm{Hf}, \mathrm{Zr}, \mathrm{Gd}) \mathrm{O}_{2}$ fluorite phase was not present in specimens (Suites 7, 8, 9; Table 5.1.1) prepared by the alkoxide route rather than by high-fired oxide feeds [Ebbinghaus et al., 1997b; Vance et al., 1997]. Consequently, the fluorite phase is 
clearly not an equilibrium phase and is not expected to be present in the ceramic form prepared from high-fired $(\mathrm{Pu}, \mathrm{U}) \mathrm{O}_{2}$ with commercial grinding and blending equipment (described in Section 5.1.2).

The silica-bearing phase, micro-encapsulated by the titanate phases rather than existing as a continuous network on grain boundaries, was observed in all tests on samples containing more than about 0.2 wt \% $\mathrm{SiO}_{2}$ [Ebbinghaus et al., 1997c; Vance et al., 1997]. The silica-bearing phase contained mainly 38 wt $\% \mathrm{SiO}_{2}, 20 \mathrm{wt} \% \mathrm{Al}_{2} \mathrm{O}_{3}, 13 \mathrm{wt} \% \mathrm{CaO}, 10 \mathrm{wt} \% \mathrm{TiO}_{2}, 4.3 \mathrm{wt} \% \mathrm{UO}_{2}$, and $3.1 \mathrm{wt} \% \mathrm{PuO}_{2}$ accompanied by the neutron absorbers $1 \mathrm{wt} \% \mathrm{Gd}_{2} \mathrm{O}_{3}$ and $2 \mathrm{wt} \% \mathrm{HfO}_{2}$. Even in the worst case with about $13 \mathrm{wt} \%$ impurity loading, only a few weight percent of the silicabearing phase was formed. From the maximum abundance of the silica phase and the elemental composition, it is determined that less than $0.7 \%$ of the plutonium inventory was in the silica phase [Ebbinghaus et al., 1997]. There have been no definite tests that firmly identify the character of the siliceous phase, which may be either amorphous or present in too small a quantity to produce evidence of crystallinity in $x$-ray diffraction tests.

The approximate compositions of the coexisting titanate phases observed in the baseline form are shown in Table 5.1.2. Zirconolite is stabilized by magnesium, aluminum, gallium, iron, and nickel. Pyrochlore is stabilized by molybdenum and tungsten [Ebbinghaus et al., 1997c]. Brannerite abundance decreases with increasing sintering temperature [Ebbinghaus et al., 1997a]. Perovskite was only observed in cerium-based preparations under reducing conditions. A few percent of perovskite was observed in all cerium-based samples that were sintered in $\mathrm{CO} / \mathrm{CO}_{2}$ $\left(\mathrm{p}\left(\mathrm{O}_{2}\right) \leq \sim 10^{-7} \mathrm{~atm}\right)$ and a few of the cerium-based samples that were sintered in argon. For tests with the baseline pyrochlore-rich formulation, perovskite was not observed in any of the plutonium-based forms when sintered in argon or air, i.e. $\left(p\left(\mathrm{O}_{2}\right) \leq \sim 10^{-7} \mathrm{~atm}\right)=0.2 \mathrm{~atm}$.

The chemical durability of the plutonium-containing baseline pyrochlore ceramic, prepared by sintering in argon for $4 \mathrm{~h}$ at $1300-1350^{\circ} \mathrm{C}$, was insensitive to the impurity contents investigated (i.e., up to $13 \mathrm{wt} \%$; Table 5.1.1). In 7-day $\mathrm{MCC}-1$ type tests at $70^{\circ} \mathrm{C}$ in water, the total normalized plutonium release varied by less than a factor of two from $1 \times 10^{-4} \mathrm{~g} / \mathrm{m}^{2}-\mathrm{d}$ (see Figure 5.1.2) [Vance 1997]. This implies that the durability of the pyrochlore form prepared with a single precursor is predictable, within the range of impurities investigated (Table 5.1.2) and that the presence or absence of the fluorite phase ( $\mathrm{U}, \mathrm{Pu}, \mathrm{Hf}, \mathrm{Zr}, \mathrm{Gd}) \mathrm{O}_{2}$, the presence or absence of the silica-bearing phase, variations in the contents of zirconolite, brannerite, and rutile minor phases, or wet and dry milling processes have no significant impact. The release of nuclides from titanate ceramics decreases with time, and a total normalized release of plutonium at $\mathrm{pH} \approx 6$ at $70^{\circ} \mathrm{C}$, in modified MCC-1 tests with frequent replacement of water, is less than $1 \times 10^{-5} \mathrm{~g} / \mathrm{m}^{2}-\mathrm{d}$, corresponding to a long term alteration rate of $\sim 0.01 \mathrm{~mm}$ in 104 years [Jostsons et al., 1997]. This is consistent with the results of Bourcier [1997] as shown in Figure 6.4.2 in Section 6.4.3.

The plutonium-containing phases may become metamict following alpha-decay damage. The response of synthetic pyrochlores and zirconolite to accelerated alpha-decay damage from ${ }^{244} \mathrm{Cm}$ and ${ }^{238} \mathrm{Pu}$ and the durability of their natural mineral analogues containing high loadings of uranium and thorium in well-characterized geochemical settings has been reviewed by Ewing et al. [1995] and Lumpkin et al. [1994, 1995, 1996, 1997]. Lumpkin et al. [1996] concluded that uranium, thorium, and rare earths are effectively retained by pyrochlore for geological time periods up to 1.4 billion years. Brannerite is known [Pabst, 1954] to contain significant quantities of thorium as well as uranium and is found as a metamict mineral in nature. There are no known tests of alpha- 
decay damage on synthetic brannerites. Nevertheless, Vance et al. [1995] found that uraniumbearing zirconolite ceramics containing brannerite were durable.

The influence of impurities on densification is now discussed. The density of the asfabricated baseline ceramic is $5.5 \mathrm{~g} / \mathrm{cm}^{3}$. The theoretical density of the target pyrochlore-rich ceramic is about $6.0 \mathrm{~g} / \mathrm{cm}^{3}$. The experimental density of the actual baseline $(\mathrm{Pu}+U)$ ceramic was as high as $5.6 \mathrm{~g} / \mathrm{cm}^{3}$. No significant variations in density were found with impurity loadings up to $5.1 \mathrm{wt} \%$ in the ceramic. The density of the ceramic with $13 \mathrm{wt} \%$ of impurities was reduced to about $5.2 \mathrm{~g} / \mathrm{cm}^{3}$ [Vance et al., 1997], due partly to the presence of lighter elements in the impurities. The sintering atmosphere (argon or air), the method of mixing in the $\mathrm{PuO}_{2}$ and $\mathrm{UO}_{2}$ (wet or dry), or the sintering temperature $\left(1275-1400^{\circ} \mathrm{C}\right.$ ) had little if any effect on the product density [Ebbinghaus et al., 1997b]. Note that the processing conditions have not yet been optimized for density, but the work so far has prevented open porosity.

The thermal and mechanical stability of the ceramic form in the heating and cooling cycle in the DWPF canister pour has been tested by ANSTO [Vance et al., 1997b] and LLNL [Ebbinghaus et al., 1997e]. The tests were made on specimens with plutonium, plutonium and uranium, and cesium and uranium and included specimens containing up to $13 \mathrm{wt} \%$ of impurities. Quantitative elemental analyses of the individual phases, including the silica-bearing phase, and scanning electron microscopy analyses have shown that there is no detectable change in microstructure or the chemistry of the individual phases as the result of the imposed DWPF thermal regime. Similar conclusions were reached by ANSTO [Moricca et. al., 1997] on the stability of zirconolite-rich SYNROC ceramics containing $~ 14 \mathrm{wt} \%$ plutonium, consolidated by hot isostatic pressing in cans measuring $62 \mathrm{~mm}$ in diameter and $41 \mathrm{~mm}$ high, i.e., of a size relevant to the baseline ceramic pellets. 
Table 5.1.1. Overall compositions of ceramic forms and measured phase contents in the impurity tests $(w t \%)$, prepared with the reference precursor. ${ }^{t-4}$

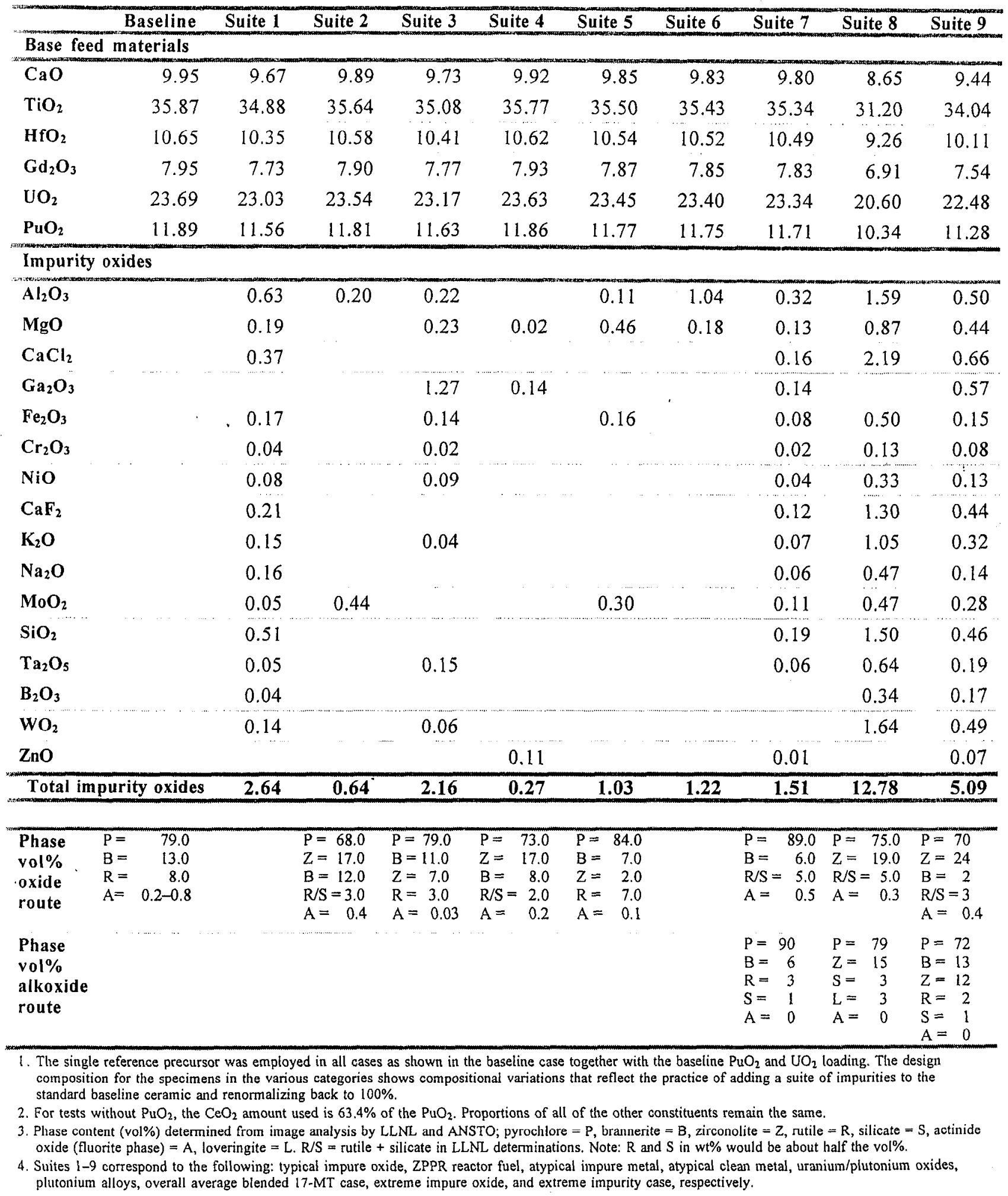


Figure 5.1.2. Normalized plutonium leach rates from 7-day $\mathrm{MCC}-1$ tests at $70^{\circ} \mathrm{C}$ in deionized water from pyrochlore-rich ceramics containing various impurity oxides.

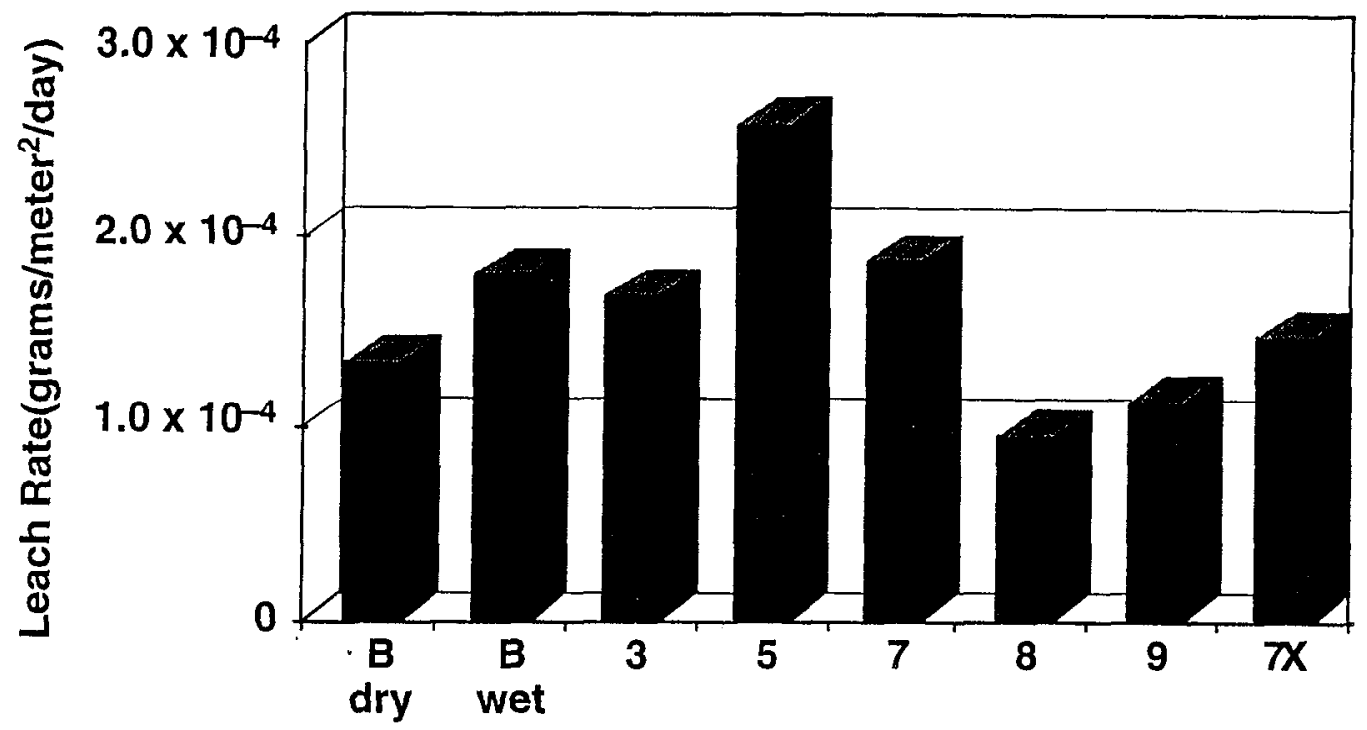

- B: baseline composition (dry or wet milled) without impurities, sintered for $4 \mathrm{~h}$ at $1325^{\circ} \mathrm{C}$ in argon, oxide route.

- 3, 5: oxide route, wet milled, sintered in argon for $4 \mathrm{~h}$ at $1350^{\circ} \mathrm{C}$.

- 7, 8, 9: (alkoxide route) sintered in argon for $4 \mathrm{~h}$ at $1350^{\circ} \mathrm{C}(7)$ and at $1300^{\circ} \mathrm{C}(8,9)$.

- 7x: oxide route, wet milled, sintered in argon for $4 \mathrm{~h}$ at $1325^{\circ} \mathrm{C}$.

- Numbers above refer to specimen suites given in Table 5.1.1. Normalized plutonium leach-rate is typically $\pm 20 \%$.

Table 5.1.2. Approximate elemental compositions of the coexisting phases in the baseline ceramic form (compositions are based on microprobe data [Ebbinghaus, 1997d] and quantitative EDS data [Vance et àl., 1997]).

\begin{tabular}{lccccccccc} 
Phase & Al & Ca & Gd & Hf & U & Pu & Ti & $\begin{array}{c}\text { Sum of } \\
\text { metals }\end{array}$ & $\begin{array}{c}\text { O equi- } \\
\text { valent }\end{array}$ \\
\hline Pyrochlore & 0.10 & 0.85 & 0.22 & 0.27 & 0.44 & 0.22 & 1.90 & 4.00 & 6.99 \\
Zirconolite & 0.28 & 0.72 & 0.15 & 0.80 & 0.16 & 0.12 & 1.77 & 4.00 & 7.07 \\
Brannerite & 0.05 & 0.06 & 0.10 & 0.12 & 0.53 & 0.24 & 1.90 & 3.00 & 5.87 \\
Rutile & 0.01 & & & 0.09 & 0.01 & & 0.89 & 1.00 & 2.00 \\
\hline
\end{tabular}




\subsubsection{Baseline Ceramic Manufacturing Process}

The ceramic baseline processing flowchart is shown in Figure 5.1.3 [Brummond, 1997]. The plant feeds include $\mathrm{PuO}_{2}, \mathrm{UO}_{2}$, and the reference ceramic precursor, which are all stored outside the ceramic processing facility. The processing facility will use gloveboxes similar to those in MOX fuel fabrication facilities. The ceramic precursor, calcined at $750^{\circ} \mathrm{C}$ for $1 \mathrm{~h}$, will be supplied by a vendor to specifications on powder size, chemistry, and homogeneity. In common with MOX fuel fabrication practice, the ceramic plant will operate in batch mode to facilitate materials accountancy and nuclear criticality avoidance.

\section{Figure 5.1.3. Ceramic process flowsheet.}

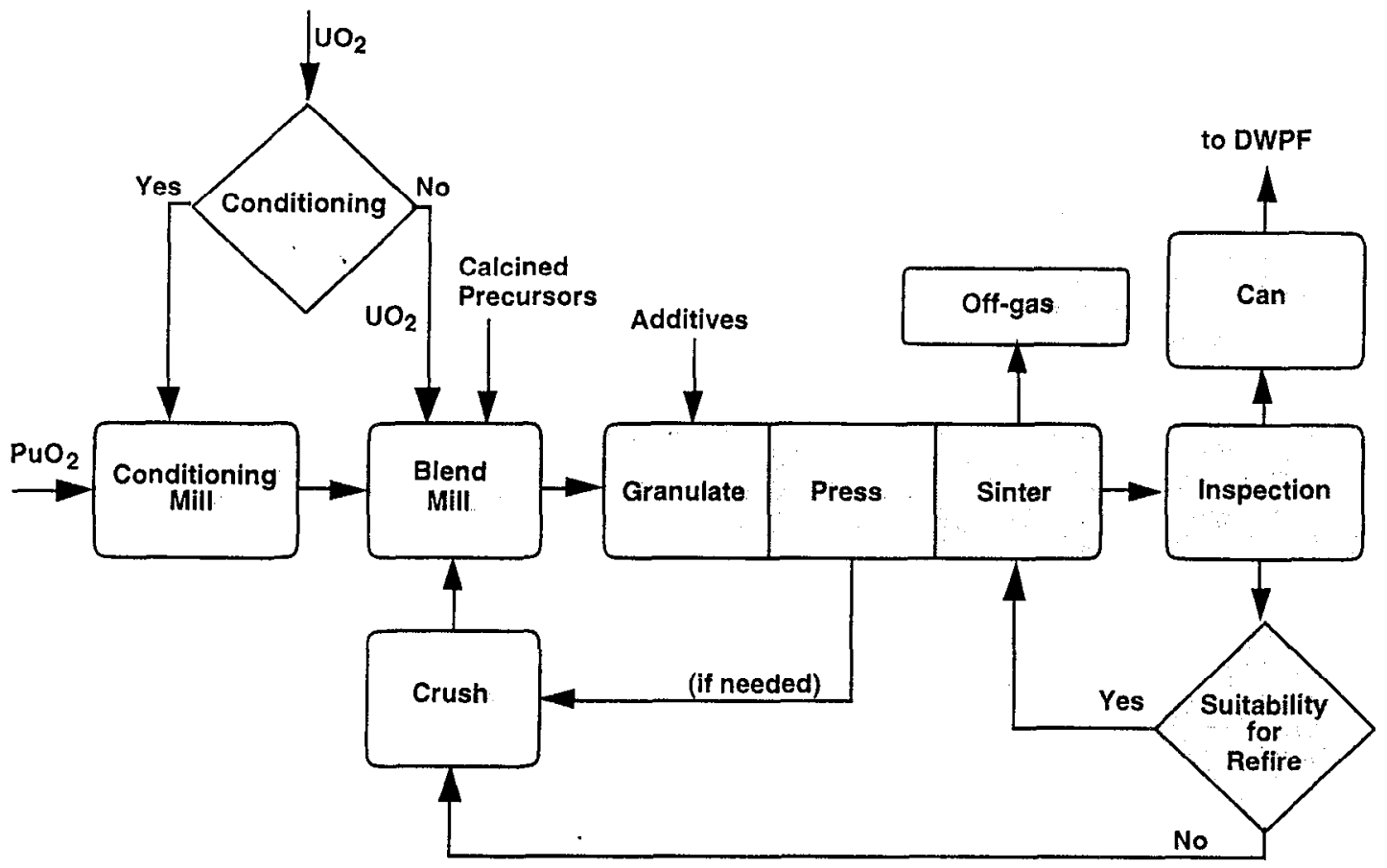

A schematic of the baseline plant arrangement, Figure 5.1.4 [Brummond, 1997], clearly shows that the $\mathrm{PuO}_{2}$ feed will be first blended by co-milling with $\mathrm{UO}_{2}$ (or $\mathrm{U}_{3} \mathrm{O}_{8} / \mathrm{UO}_{3}$ ) before attrition blending with the reference ceramic precursor. The front end of the baseline plant closely resembles the BNFL plc short binderless route MOX fuel fabrication plants at Sellafield, U.K. [Brown et al., 1997; Edwards et al., 1996]. The MDF with a capacity of $8 \mathrm{MTHM} / \mathrm{y}$ has been operating since 1993 on a $25-\mathrm{kg}$ batch scale and the Sellafield MOX Plant (SMP), with a capacity of $120 \mathrm{MTHM} / \mathrm{y}$, is in startup. The SMP uses fixed-shell high-energy attritor mills for grinding and blending on a $50-\mathrm{kg}$ batch scale. Hard piping connections and gravity feed will be used in the baseline ceramic plant to transfer powder between process items without the need to break containment. The blended powders will be granulated to produce free-flowing, spherical, dustfree granules $(\sim 100 \mu \mathrm{m})$ suitable for pressing. The $40-\mathrm{kg}$ batch scale chosen for the ceramic process is of intermediate size to those used in the two BNFL MOX plants. 
Figure 5.1.4. Baseline ceramic process.

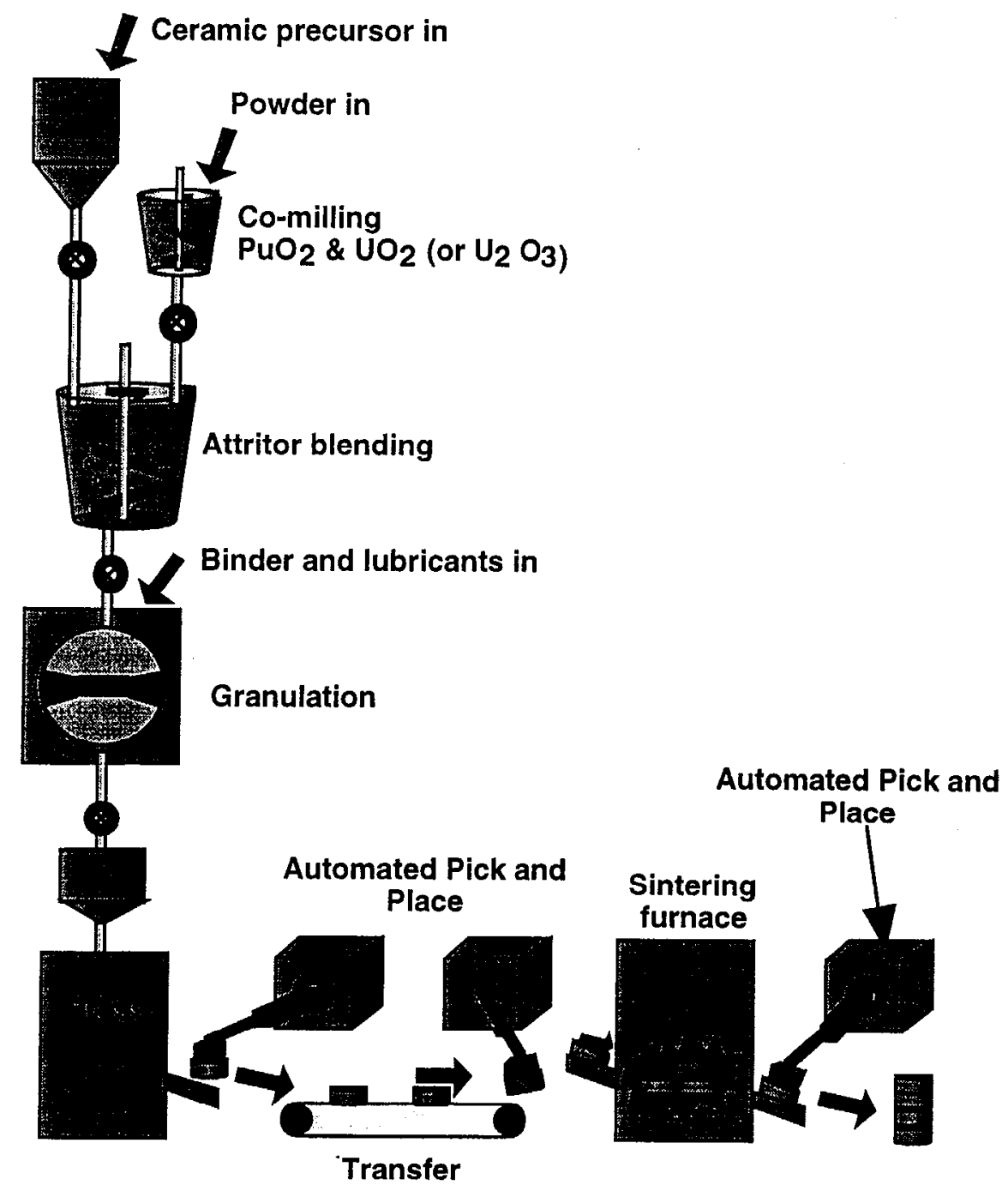

The similarities between powder processing needs for ceramic immobilization and commercial MOX fuel fabrication industry have been identified by Kaiser et al. [1997], who provided an extensive list of relevant potential commercial process equipment and vendors. Equipment selection and experimental development of ceramic powder processing regimes is required before a glovebox ceramic baseline process plant can be constructed. Nevertheless, the milling and blending of the $\mathrm{PuO}_{2}$ and $\mathrm{UO}_{2}$ feeds have been demonstrated by the commercial MOX industry at the scale relevant to the baseline ceramic process. The subsequent attritor blending of the ceramic precursor and the $(\mathrm{Pu}, \mathrm{U}) \mathrm{O}_{2}$ powder involves powder streams with a greater density difference than usually handled in MOX plants. There is, however, relevant commercial experience with the blending of $\mathrm{UO}_{2}$ and $\mathrm{Gd}_{2} \mathrm{O}_{3}$ in the thermal reactor fuel fabrication industry. In these fuels, $\mathrm{Gd}_{2} \mathrm{O}_{3}$ is used as a burnable neutron absorber to limit excessive burnup variations across a reactor core. There is also a large body of experience in the ceramics industry for handling and blending of powders with large differences in physical properties. The uniform 
blending of the ceramic precursor and $\mathrm{UO}_{2}$ can be readily demonstrated with full-size attritors. A cold demonstration has been performed of the blending of the ceramic precursor with $\mathrm{CeO}_{2}$ powder as a surrogate for $\mathrm{PuO}_{2}$ in attritor mills, and sintered pellets made from this material were homogeneous on the 100- $\mu \mathrm{m}$ scale, [Brummond, 1997].

Blended and free-flowing powders are then loaded into dies in a double piston hydraulic press. The process has been demonstrated in prototype equipment and produced about 840 ( $\sim 30$-kg plutonium equivalent) green pellets which have been successfully sintered to $>93 \%$ density at $1350^{\circ} \mathrm{C}$ in off-the-shelf furnaces that require little or no adaptation. The burnout of binder has also been demonstrated at LLNL [Brummond, 1997]. In the area of pellet pressing, transport to the furnace, and sintering, the ceramic production process is much less demanding than in MOX fuel fabrication. Fewer pellets need to be produced per unit time and dimensional control of the final pellet is not as critical as in MOX fuel fabrication. Similarly, the control required on the sintering atmosphere in the fuel fabrication is far more demanding than in ceramic pellet sintering at $1350^{\circ} \mathrm{C}$ compared with $1700^{\circ} \mathrm{C}$ for $\mathrm{MOX}$ fuel sintering.

The baseline process flowchart has provision for recycle of unacceptable material after inspections of the green pellets and after sintering, before can loading. This provision for inspection and recycle is normal in MOX fabrication plants, where tight controls of homogeneity, dimension, isotopic content, grain size, porosity, and weight are essential. The materials accountancy requirements are also more onerous for a MOX fabricator because the fuel is made for export to external clients.

The on-line inspection of green pellets for dimensional and weight consistency as well as for fissile material content provides early feedback to the powder grinding, blending, conditioning, and granulation equipment so that timely process adjustments can be made. These inspections also provide timely warning of die wear and pellet ejection equipment. The recycle of rejected green pellets is relatively straightforward. Provision for recycling of green pellets also provides the means to recover from process upsets.

The on-line inspection of sintered pellets is mainly a materials accountancy requirement before the pellets are loaded into cans, prior to leaving the plant via bagless transfer. The inspection step after sintering provides an opportunity to take samples from a pellet to provide more accurate methods of materials accountancy verification. This sampling could also be used to check the microstructure of the ceramic for phase content, porosity, etc., and even for leach testing to confirm acceptable chemical durability, if required. Such sampling could be performed on a batch basis or on the basis of change in the incoming plutonium stream. The recycle of sintered pellets is considered to be a rare occurrence since the key inspections on product homogeneity and reproducibility are performed during the green pellet inspection as well as by chemical tests on the granulated powder. Careful control of the conditions used in milling, blending, and granulating results in press feed of consistent and excellent quality that ensures similar consistency in the sintered pellets [Brown et al., 1997]. The on-line inspections in the ceramic processing plant are less onerous than in the MOX plant in which 17 million fuel pellets are produced annually in a plant of $120 \mathrm{MTHM} / \mathrm{y}$ capacity versus about 100,000 pellets annually in the ceramic processing plant. The main design parameters for the ceramic baseline process are summarized in Table 5.1.3. 
Table 5.1.3. Main processing parameters of the 50-MT and the 17-MT baseline processes (For the 17-MT process, the process equipment remains the same as in the 50-MT process. Note that the 17-MT process will require blending of less $\mathrm{UO}_{2}$ into the incoming plutonium feed to maintain the design plutonium/uranium ratio [Table 5.0.2]).

\begin{tabular}{ll} 
Batch size & $39.7 \mathrm{~kg}$ \\
Batch contents & $25.5 \mathrm{~kg}$ of ceramic precursor \\
& $4.167 \mathrm{~kg}$ plutonium $\left(4.727 \mathrm{~kg} \mathrm{PuO}_{2}\right)$ \\
& $8.333 \mathrm{~kg}$ uranium $(9.453 \mathrm{~kg} \mathrm{UO})_{2}$ \\
& $2.65 \mathrm{in.}$ \\
Pellet diameter & $1.00 \mathrm{in}$. \\
Pellet height & 80 \\
Pellets/batch & $52.1 \mathrm{~g}$ plutonium $\left(59.1 \mathrm{~g} \mathrm{PuO}_{2}\right)$ \\
Pu/pellet & 20 \\
Pellets/can & $1.04 \mathrm{~kg}$ plutonium $\left(1.18 \mathrm{~kg} \mathrm{PuO}_{2}\right)$ \\
Pu/can & 4 \\
Cans/batch & $3 \mathrm{in}$. OD and $2.75 \mathrm{in.} \mathrm{ID}$ \\
Can diameter & $21 \mathrm{in}$. \\
Can height & $6\left(25 \mathrm{~kg}\right.$ plutonium or $\left.28.4 \mathrm{~kg} \mathrm{PuO}_{2}\right)$ \\
Number of batch/d & 6 \\
Number of sinter furnaces & $5.0 \mathrm{MT}$ plutonium in 3 shifts at 200 days/year \\
Annual production & $47.6 \mathrm{MT}$ of ceramic/year \\
\hline
\end{tabular}

\subsection{Glass Baseline Definition}

\subsubsection{Baseline Glass Composition}

A homogeneous single phase lanthanide borosilicate (LaBS) glass has been developed for the vitrification of surplus fissile materials. The LaBS glass frit components bond the plutonium and uranium feed components to the rare earth elements and boron in the form of oxide components in the glass structure. Complete dissolution of at least $11.8 \mathrm{wt} \%$ plutonium $\left(13.4 \mathrm{wt} \% \mathrm{PuO}_{2}\right)$ has been demonstrated in the LaBS glass $\mathrm{A}$ at $1500^{\circ} \mathrm{C}$ [Vienna, 1996]. The concentration of $\mathrm{UO}_{3}$ that the LaBS glass can accommodate in the absence of $\mathrm{PuO}_{2}$ is in the range of $25-30 \mathrm{wt} \%$ [Meaker, 1995]. Complete dissolution of $15-20 \mathrm{wt} \% \mathrm{PuO}_{2}$ plus $\mathrm{UO}_{3}$ (combined loadings) have also been demonstrated [Meaker and Peeler, 1997a]. The LaBS glass formulation was developed from high $\mathrm{La}_{2} \mathrm{O}_{3}$-containing glasses for the technical glass industry [Loffler, 1932; U.S. Patent $\# 2150694$ by Morey, 1939]. Rare-earth glasses, such as the Loffler glass, and $\mathrm{CeO}_{2}$-doped glasses have been used in nuclear physics for protective purposes and as neutron poisons since lanthanide elements have large thermal neutron cross sections [Fanderlik, 1958].

Higher loading of $\mathrm{PuO}_{2}$ plus $\mathrm{UO}_{3}$ (combined loadings) may be achievable in forced convection melting such as in the stirred glass melter described in Section 5.2.2. This is based on comparisons of stirred and static melts [Vienna, 1996] and on the results of melting a $\mathrm{ZrO}_{2}$ containing frit " $\mathrm{A}$ " LaBS glass containing $9.4 \mathrm{wt} \% \mathrm{HfO}_{2}$ as a surrogate for $\mathrm{PuO}_{2}$ and another frit A glass containing $10 \mathrm{wt} \%$ plutonium $\left(11.3 \mathrm{wt} \% \mathrm{PuO}_{2}\right)$ in a tilt pour melter at LLNL [Riley, 1997]. The latter study concluded that jet-milled high-fired (at $1000^{\circ} \mathrm{C}$ ) $\mathrm{PuO}_{2}$ of $<3-\mu \mathrm{m}$ particle size dissolved into the glass in less than one hour without stirring, although final evaluation of the 
glass has been delayed. Riley's study [1997] concluded that glass-immobilized fine-particle-size $\mathrm{PuO}_{2}$ without careful mixing because the plutonium dissolves quickly into the glass.

In addition, the LaBS glass can incorporate neutron absorbing elements such as hafnium, samarium, europium, and gadolinium as $\mathrm{HfO}_{2}, \mathrm{Sm}_{2} \mathrm{O}_{3}, \mathrm{Eu}_{2} \mathrm{O}_{3}, \mathrm{Gd}_{2} \mathrm{O}_{3}$ alone or in combination up to $55 \mathrm{wt} \%$ [Peeler et al., 1997a]. The flexibility of the LaBS glass to the wide range of $\mathrm{RE}_{2} \mathrm{O}_{3}$ (where $\mathrm{RE}_{2} \mathrm{O}_{3}=\mathrm{Sm}_{2} \mathrm{O}_{3}, \mathrm{Eu}_{2} \mathrm{O}_{3}, \mathrm{Gd}_{2} \mathrm{O}_{3}$ ) and $\mathrm{HfO}_{2}$ concentrations provide a greater than 1:1 ratio of neutron absorber to plutonium and uranium in the glass on an elemental weight basis [Ramsey et al., 1995; Meaker, 1995; McIntyre et al., 1997a,b; Meaker and Peeler, 1997]. Although not accounted for via glass formulation efforts as a criticality control measure, boron is also an effective neutron absorber [Etherington, 1958].

The same glass-making additives are used for both the 50-MT and the 17-MT plutonium feeds (baselines 1 and 2). The feed additives are a prefabricated, prefused baseline frit containing the neutron absorbers hafnium and gadolinium as shown in the composition given in Table 5.0.2. The composition of the LaBS frit will be controlled to stringent specifications during manufacture since it consists of 75-85 wt\% of the final vitrified product (Table 5.2.1). Control of the frit composition during its manufacture allows greater tolerance of the final glass form to compositional variation in the input streams while still allowing for the stringent statistical process/product control strategy [Jantzen and Brown, 1993] that allows for zero reject rate.

Through extensive laboratory testing, the LaBS frit has been found to be flexible enough to accommodate the $\mathrm{PuO}_{2}$ and $\mathrm{UO}_{3}$ feed variations in the presence of neutron absorbers as discussed above [Vienna, 1996; Peeler et al., 1997b; Meaker, 1996,1997; Ramsey et al., 1995; Bibler et al., 1996; Meaker and Bibler, 1997a,b; and Li et al., 1997]. In addition, this frit has been shown to be extremely tolerant to feed impurities [Meaker and Peeler, 1997; Peeler et al., 1997b], thereby minimizing plutonium-feed blending concerns based on impurity tolerances. The frit is flexible to the $\mathrm{UO}_{3}$ concentration variation of the incoming 50-MT and 17-MT baseline feeds as given in Table 5.2.1 for the targeted feed loadings. Note that no additional $\mathrm{UO}_{3}$ is added as ${ }^{238} \mathrm{U}$ oxide for criticality control, although the glass form is tolerant of higher concentrations of $\mathrm{UO}_{3}$.

When the LaBS baseline frit is mixed with the two different baseline feed compositions at different plutonium and uranium loadings, it will give glasses of slightly different composition (Table 5.2.2). This is in keeping with the statistical process/product control strategy used for HLLW vitrification and planned for plutonium vitrification [Marra, 1997], whereby one frit composition is used to accommodate one or more variable feeds at variable waste loadings [Jantzen and Brown, 1993]. Thus a region of acceptable glass composition is defined that simultaneously meets all the product performance and processing requirements.

For the 50-MT plutonium feed, the baseline LaBS glass feed loadings consist of $10 \mathrm{wt} \%$ $\mathrm{PuO}_{2}$ (8.8 wt\% plutonium), $3 \mathrm{wt} \% \mathrm{UO}_{3}(2.5 \mathrm{wt} \%$ uranium), and up to $3 \mathrm{wt} \%$ impurities on an oxide basis. The 50-MT LaBS composition is, therefore, designated as 10/3/3 and has the following neutron absorber:plutonium molar ratios: hafnium:plutonium $=0.71: 1.0$, gadolinium:plutonium $=1.61: 1.0$, and boron:plutonium $=8.2: 1$. 
Table 5.2.1. Baseline feed streams and bascline processes for the immobilization of plutonium in ceramic or glass.

\begin{tabular}{|c|c|c|c|c|c|c|}
\hline \multirow[b]{2}{*}{ Parameters } & \multicolumn{2}{|c|}{$\begin{array}{c}\text { Plutonium feed baseline } 1 \\
\text { (50 MT plutonium + } 16 \text { MT uranium) }\end{array}$} & \multicolumn{2}{|c|}{$\begin{array}{c}\text { Plutonium feed baseline } 2 \\
\text { (17 MT plutonium + 16 MT uranium) }\end{array}$} & \multicolumn{2}{|c|}{$\begin{array}{l}\text { Plutonium feed baselines } 1 \text { and } 2 \\
\text { (50- and 17-MT) } \\
\text { immobilization form variants }\end{array}$} \\
\hline & Ceramic & LaBS glass & Ceramic & LaBS glass & $\begin{array}{c}\text { Ceramic } \\
(50 \text { and } 17 \mathrm{MT})\end{array}$ & $\begin{array}{l}\text { LaBS Glass } \\
\text { (50 and } 17 \mathrm{MT})\end{array}$ \\
\hline Technology* & $\begin{array}{l}\text { Press/reactive phase } \\
\text { sinter }\end{array}$ & Vitrification & $\begin{array}{l}\text { Press/reactive } \\
\text { phase sinter }\end{array}$ & Vitrification & $\begin{array}{l}\text { Press/reactive } \\
\text { phase sinter }\end{array}$ & Vitrification \\
\hline $\begin{array}{l}\text { Feed baseline plutonium/uranium } \\
\text { ratio, elemental wt } \%\end{array}$ & $76 / 24$ & $76 / 24$ & $52 / 48$ & $52 / 48$ & $76 / 24+52 / 48$ & $76 / 24$ or $52 / 48$ \\
\hline $\begin{array}{l}\text { Plutonium loading, elemental wt\%/ } \\
\text { oxide wt\% }\end{array}$ & $10.5 / 11.9$ & $8.8 / 10.0^{\dagger}$ & $10.5 / 11.9$ & $7.1 / 8$ & $\begin{array}{l}15.7 / 17.8+ \\
16.2 / 18.3\end{array}$ & $>10.6 / 12.0$ \\
\hline $\begin{array}{l}\text { Uranium tolerance, elemental } w \mathrm{t} \% / \\
\text { oxide } \mathrm{UO}_{3} \mathrm{wt} \%\end{array}$ & $20.9 / 25.11$ & $3 / 4.2^{b}$ & $20.9 / 25.11$ & $6.7 / 8$ & $\begin{array}{l}15.7 / 17.8+ \\
15.2 / 17.3\end{array}$ & $10 / 12.0$ \\
\hline $\begin{array}{l}\text { Feed uranium concentration at } \\
\text { given plutonium loadings, } \\
\text { elemental } w t \% \text { oxide } \mathrm{UO}_{3} \mathrm{wt} \%\end{array}$ & $3.4 / 4.1$ & $2.8 / 3.4$ & $9.9 / 11.9$ & $6.7 / 8.1$ & $\begin{array}{l}5.0 / 6.0(50 \mathrm{MT}) \\
15.2 / 17.3(17 \mathrm{MT})\end{array}$ & $\begin{array}{l}3.4 / 4.1(50 \mathrm{MT}) \\
10.0 / 12.0(17 \mathrm{MT})\end{array}$ \\
\hline $\begin{array}{l}\text { Impurity tolerance tested, } \\
\text { oxide wt } \%\end{array}$ & 13 & 6 & 13 & 6 & 13 & 6 \\
\hline Feed form additives, oxide wt $\%$ & $\begin{array}{l}\sim 20 \% \mathrm{UO}_{2}^{\S} \text { and } \\
\sim 65 \% \text { preblended } \\
\text { oxides of } \mathrm{CaO}, \mathrm{HrO}_{2} \text {, } \\
\mathrm{TiO}_{2}, \mathrm{Gd}_{2} \mathrm{O}_{3}\end{array}$ & $\begin{array}{l}\sim 84 \% \text { prefused frit } \\
\text { oxides of } \mathrm{SiO}_{2} \\
\mathrm{~B}_{2} \mathrm{O}_{3}, \mathrm{Al}_{2} \mathrm{O}_{3}, \mathrm{SrO} \\
\mathrm{HfO}_{2}, \mathrm{RE}_{2} \mathrm{O}_{3} \\
\mathrm{Gd}_{2} \mathrm{O}_{3}\end{array}$ & $\begin{array}{l}\sim 12.5 \% \mathrm{UO}_{2} \text { and } \\
\sim 65 \% \text { preblended } \\
\text { oxides of } \mathrm{CaO} \\
\mathrm{HfO}_{2}, \mathrm{TiO}_{2}, \mathrm{Gd}_{2} \mathrm{O}_{3}\end{array}$ & $\begin{array}{l}\sim 81 \% \text { prefused frit } \\
\text { oxides of } \mathrm{SiO}_{2} \\
\mathrm{~B}_{2} \mathrm{O}_{3}, \mathrm{Al}_{2} \mathrm{O}_{3}, \mathrm{SrO}, \\
\mathrm{HfO}_{2}, \mathrm{RE}_{2} \mathrm{O}_{3} \\
\mathrm{Gd}_{2} \mathrm{O}_{3}\end{array}$ & $\begin{array}{l}\sim 12 \% \text { or } 0 \% \mathrm{UO}_{2} \\
\text { and } \sim 65 \% \\
\text { preblended oxides } \\
\text { of } \mathrm{CaO}, \mathrm{HfO}_{2}, \mathrm{TiO}_{2} \text {, } \\
\mathrm{Gd}_{2} \mathrm{O}_{3}\end{array}$ & $\begin{array}{l}\sim 85 \% \text { or } 82 \% \\
\text { prefused frit } \\
\text { oxides of } \mathrm{SiO}_{2} \\
\mathrm{~B}_{2} \mathrm{O}_{3}, \mathrm{Al}_{2} \mathrm{O}_{3}, \mathrm{SrO} \\
\mathrm{HfO}_{2}, \mathrm{RE}_{2} \mathrm{O}_{3} \\
\mathrm{Gd}_{2} \mathrm{O}_{3}\end{array}$ \\
\hline Number of additives & Two & One & Two & One & Two/one & One/one \\
\hline Additive formulation & Single composition & $\begin{array}{l}\text { Single } \\
\text { composition }\end{array}$ & Single composition & Single composition & Single composition & $\begin{array}{l}\text { Single } \\
\text { composition }\end{array}$ \\
\hline
\end{tabular}

- For definitions of sintering, liquid phase sintering, reactive phase sintering, vitrification, frit, see Section 9.

${ }^{t}$ Complete dissolution of $15-20 \mathrm{wt} \% \mathrm{PuO}_{2}+\mathrm{UO}_{3}$ (combined loading) have also been demonstrated [Meaker and Peeler, 1997$]$.

$\$ 6$ oxide $w t \%$ is two times the impurity oxide concentration expected; 13 oxide wt\% is four times the concentration expected.

$\S\left(24 \mathrm{wt} \% \mathrm{UO}_{3} \times 0.944 \mathrm{l}=22.66 \mathrm{UO}_{2}\right)-\left(3 \mathrm{wt} \% \mathrm{UO}_{3} \times 0.9441=2.83 \mathrm{UO}_{2}\right)=19.83 \mathrm{UO}_{2}$. 
Table 5.2.1. (Cont.)

\begin{tabular}{|c|c|c|c|c|c|c|}
\hline \multirow[b]{2}{*}{$\begin{array}{l}\text { Nominal size of } \mathrm{PuO}_{2} \text { being } \\
\text { processed, } \mu \mathrm{m}\end{array}$} & \multicolumn{2}{|c|}{$\begin{array}{c}\text { Plutonium feed baseline } 1 \\
\text { (50 MT plutonium + 16 MT uranium) }\end{array}$} & \multicolumn{2}{|c|}{$\begin{array}{c}\text { Plutonium feed baseline } 2 \\
\text { (17 MT plutonium + 16 MT uranium) }\end{array}$} & \multicolumn{2}{|c|}{$\begin{array}{l}\text { Plutonium feed baselines } 1 \text { and } 2 \\
\text { (50- and 17-MT) } \\
\text { immobilization form variants }\end{array}$} \\
\hline & $<20$ & $-20^{*}$ & $<20$ & $\sim 20^{\mathrm{e}}$ & $<20$ & $-20^{\mathrm{e}}$ \\
\hline Process temperature, ${ }^{\circ} \mathrm{C}$ & $1350+50 /-25$ & $1500 \pm 50$ & $1350+50 /-25$ & $1500 \pm 50$ & $1350+50 /-25$ & $1500 \pm 50$ \\
\hline $\begin{array}{l}\text { Theoretical/measured form density, } \\
\mathrm{g} / \mathrm{cm}^{3}\end{array}$ & $6.0 / 5.5$ & NA/3.8 & $6.0 / 5.5$ & $\mathrm{NA} / 3.8$ & $6.0 / 5.5$ & $\mathrm{NA} / 3.8$ \\
\hline Porosity, vol \% & -8 & 0 & -8 & 0 & $\sim 8$ & 0 \\
\hline Processing atmosphere & Argon & Air & Argon & Air & Argon & Air \\
\hline Phases in form ${ }^{\dagger}$ & $\begin{array}{l}\text { Pyrochlore, } \\
\text { zirconolite, } \\
\text { brannerite, rutile as } \\
\text { (Ti,Hf) } \mathrm{O}_{2} \text {, silicate, } \\
\text { fluorite phasc as } \\
(\mathrm{U}, \mathrm{Pu}, \mathrm{Hf}, \mathrm{Ti}) \mathrm{O}_{2}\end{array}$ & $\begin{array}{l}\text { Glass } \\
\text { (homogeneous and } \\
\text { thermally stable) }\end{array}$ & $\begin{array}{l}\text { Pyrochlore, } \\
\text { zirconolite, } \\
\text { brannerite, rutile } \\
\text { as (Ti,Hf)O } \\
\text { silicate, fluorite } \\
\text { phase as } \\
\text { (U,Pu,Hf,Ti)O }{ }_{2}\end{array}$ & $\begin{array}{l}\text { Glass } \\
\text { (homogeneous and } \\
\text { thermally stable) }\end{array}$ & $\begin{array}{l}\text { Pyrochlore, } \\
\text { zirconolite, } \\
\text { brannerite, rutile as } \\
(\mathrm{Ti}, \mathrm{Hf}) \mathrm{O}_{2} \text {, silicate, } \\
\text { fluorite phase as } \\
(\mathrm{U}, \mathrm{Pu}, \mathrm{Hf}, \mathrm{Ti}) \mathrm{O}_{2}\end{array}$ & Glass $+\mathrm{PuO}_{2}$ \\
\hline Can dimensions (diam./height), in. & $3 / 21$ & $4.5 / 21$ & $3 / 21$ & $4.5 / 21$ & $3 / 21$ & $4.5 / 21$ \\
\hline Number of cans in canister $f$ & 28 & 16 & 28 & 16 & 28 & 16 \\
\hline $\begin{array}{l}\text { Amount of plutonium per canister, } \\
\mathrm{kg}\end{array}$ & $29[\mathrm{Kan}, 1997]$ & $21[\mathrm{Kan}, 1997]$ & $29[$ Kan, 1997$]$ & $17[\mathrm{Kan}, 1997]$ & $43 / 45$ [Kan, 1997] & $26[\mathrm{Kan}, 1997]$ \\
\hline
\end{tabular}

\footnotetext{
* Data by Chamberlin et al. of ANL [TEP presentation, 1997] indicate that $99.9 \%$ of $\mathrm{PuO}_{2}$ particles sized in the range of $20-45 \mu \mathrm{m}$ dissolved into LaBS glass when stirred.

${ }^{\dagger}$ Refer to text for details.

${ }^{\ddagger}$ Based on successful pour modeling using ProCast code, configuration for ceramics is 7 cans per row and 4 rows per canister, configuration for glass is 4 cans per row and 4 rows per canister. Other configurations may be possible but not all have been modeled.
} 
Table 5.2.2. Comparison of the final glass compositions for LaBS glass baseline for 50-MT and 17-MT plutonium immobilization.

\begin{tabular}{|c|c|c|}
\hline Oxide & $\begin{array}{c}\text { LaBS 50-MT baseline, } \\
\text { wt } \%\end{array}$ & $\begin{array}{c}\text { LaBS 17-MT haseline, } \\
\text { wt } \%\end{array}$ \\
\hline $\mathrm{Al}_{2} \mathrm{O}_{3}$ & 17.9 & 17.3 \\
\hline $\mathrm{B}_{2} \mathrm{O}_{3}$ & 9.7 & 9.4 \\
\hline $\mathrm{Gd}_{2} \mathrm{O}_{3}$ & 10.8 & 10.4 \\
\hline $\mathrm{HfO}_{2}$ & 5.5 & 5.3 \\
\hline $\mathrm{PuO}_{2}$ & 10.0 & 8.0 \\
\hline $\mathrm{La}_{2} \mathrm{O}_{3}$ & 6.8 & 6.6 \\
\hline $\mathrm{Nd}_{2} \mathrm{O}_{3}$ & 6.9 & 6.6 \\
\hline $\mathrm{SiO}_{2}$ & 24.3 & 23.4 \\
\hline $\mathrm{SrO}$ & 2.1 & 2.0 \\
\hline $\mathrm{UO}_{3}$ & 3.0 & 8.0 \\
\hline Impurities & 3.0 & 3.0 \\
\hline Total & 100.00 & 100.00 \\
\hline
\end{tabular}

The solubility of the following feeds were tested in the baseline LaBS frit (Table 5.2.2):

- $50 \mathrm{MT}$ plutonium plus $16 \mathrm{MT}$ uranium (baseline 1).

- $17 \mathrm{MT}$ plutonium plus $16 \mathrm{MT}$ uranium (baseline 2).

- Blending schemes intermediate between the baseline 1 and baseline 2 feeds considered to be worst-case scenarios.

- Two individual (unblended) feed streams considered to be worst-case scenarios including the ZPPR and impure oxide " $\mathrm{A}$ " (for atypical) streams (see Table 5.0.1)

- Two partially blended streams: a 60/40 plutonium/uranium stream and a 40/60 plutonium alloy stream (see Table 5.0.1).

For the 17-MT plutonium feed, the baseline LaBS glass feed loading consists of $8 \mathrm{wt} \% \mathrm{PuO}_{2}$ (7.1 wt \% plutonium), $8 \mathrm{wt} \% \mathrm{UO}_{3}(6.7 \mathrm{wt} \%$ uranium), and up to $3 \mathrm{wt} \%$ impurities on an oxide basis. The 17-MT LaBS composition is, therefore, designated as $8 / 8 / 3$ and has the following neutron absorber:plutonium molar ratios: hafnium:plutonium $=0.85: 1.0$, gadolinium:plutonium $=$ 1.94:1.0, and boron:plutonium $=8.0: 1$

The ZPPR stream bounds the worst case (highest) $\mathrm{UO}_{3}$ concentration tested in these studies [Meaker and Peeler, 1997] and represents a totally unblended ZPPR plutonium feed stream. The impure atypical oxide frit A stream bounds the worst case (highest) impurity concentrations $(\sim 50 \mathrm{wt} \%)$ tested in these studies [Meaker and Peeler, 1997] and represents a totally unblended atypical impure oxide feed stream. A study with pure $\mathrm{PuO}_{2}$ feed [Vienna et al., 1996] bounds the worst case (highest) $\mathrm{PuO}_{2}$ oxide concentration tested. The other two partially blended feed stream cases studied are intermediate in terms of their compositions relative to the three bounding cases already discussed.

The 10/3/3 LaBS 50-MT baseline glass (see Table 5.2.4) was fabricated and tested by PNNL and found to be homogeneous upon fabrication. The 10/3/3 LaBS baseline glass remained 
homogencous after heat treatment with the temperature profile calculated by Stein ${ }^{*}$ to simulate the temperatures that a can of plutonium glass would see during pouring of the DWPF canister [Peeler et al., 1997b]. This test was performed at PNNL where it was exposed to a slightly more extreme thermal cycle than that calculated by Stein.

The LaBS 8/8/3 17-MT baseline glass was homogeneous upon fabrication and remained homogeneous after heat treatment (Table 5.2.3). This glass was tested at SRTC with the thermal profile shown in Table 5.2.4. The 8/8/3 glass remained homogeneous during the thermal profile test. Testing of all of the extreme feed blends in the LaBS frit as well as testing of all of the individual plutonium feed streams yielded homogeneous glass upon fabrication.

Table 5.2.3. Homogeneity of glasses formed with baseline-case and worst-case plutonium feed streams and LaBS glass.

\begin{tabular}{|c|c|c|c|c|c|}
\hline Melt & $\begin{array}{c}\text { Feed loading, } \\
\text { wt\% } \\
\text { [Meaker and } \\
\text { Peeler, 1997] }\end{array}$ & $\begin{array}{c}\mathrm{PuO}_{2} \text { in glass, } \\
\text { wt\% } \% \\
\text { [Meaker and } \\
\text { Peeler, 1997] }\end{array}$ & $\begin{array}{c}\mathrm{UO}_{2} \text { in glass, } \\
\text { wt \% } \\
\text { [Meaker and } \\
\text { Peeler, 1997] }\end{array}$ & $\begin{array}{l}\text { Homogeneous on } \\
\text { fabrication }\end{array}$ & $\begin{array}{l}\text { Homogeneous } \\
\text { after heat } \\
\text { treatment }\end{array}$ \\
\hline \multicolumn{6}{|l|}{ SRTC } \\
\hline $60 / 40(9 / 6 / 0)$ & $>15$ & 9.0 & 6.0 & Yes & No \\
\hline $\begin{array}{l}\text { Impure oxide A } \\
(6.6 / 0 / 7.4)\end{array}$ & $>14$ & 6.6 & 0 & Yes & Yes \\
\hline ZPPR $(4.3 / 11.1 / 0.6)$ & $>16$ & 4.3 & 11.1 & Yes & Not tested \\
\hline $\begin{array}{l}\text { Plutonium alloy } \\
(9.1 / 4.6 / 0.3)\end{array}$ & $>14$ & 9.14 & 4.56 & Yes & Not tested \\
\hline $8 / 8 / 3$ & 19 & 8 & 8 & Yes & Yes \\
\hline $12 / 12 / 0$ & 24 & 12 & 12 & $\mathrm{No}^{t t}$ & Yes \\
\hline $9 / 6 / 6$ & 21 & 9 & 6 & Yes & Not tested \\
\hline \multicolumn{6}{|l|}{ PNNL } \\
\hline $7 / 3 / 3$ & 13 & 7 & 3 & Yes & Yes \\
\hline $8 / 3 / 3$ & 14 & 8 & 3 & Yes & Yes \\
\hline $10 / 3 / 3$ & 16 & 10 & 3 & Yes & Yes \\
\hline $9 / 3 / 3$ & 14 & 9 & 3 & Indeterminate $^{\dagger}$ & Yes \\
\hline \multicolumn{6}{|l|}{ ANL } \\
\hline $9 / 3^{*}$ & 12 & 9 & 3 & Yes & Not tested \\
\hline
\end{tabular}

\footnotetext{
"Werner Stein, LLNL, Thermal Fluids Group, "Modeling of Glass Temperature Distributions in a DWPF Canister," calculations using the ProCast Code to model flow of hot glass as it fills an initially empty canister and the temperature history during filling and subsequent cooling (1997).
} 
Table 5.2.4. Thermal profiles used at SRTC and PNNL to test the thermal stability of glasses in Table 5.2.3.

\begin{tabular}{lll} 
Thermal cycle & SRTC/ANL & PNNL \\
Heat-up ramp & 650 to $915^{\circ} \mathrm{C}$ in $1.25 \mathrm{~h}$ & 650 to $955^{\circ} \mathrm{C}$ in $1.25 \mathrm{~h}$ \\
Hold at temperature & $915^{\circ} \mathrm{C}$ for $1.25 \mathrm{~h}$ & 955 to $915^{\circ} \mathrm{C}$ for $0.33 \mathrm{~h}$ \\
& & $915^{\circ} \mathrm{C}$ for $0.92 \mathrm{~h}$ \\
Cool-down ramp & 915 to $650^{\circ} \mathrm{C}$ in $5.5 \mathrm{~h}$ & 915 to $650^{\circ} \mathrm{C}$ in $5.5 \mathrm{~h}$ \\
\hline
\end{tabular}

Only one glass containing $9 \mathrm{wt} \% \mathrm{PuO}_{2}$ (the $60 / 40$ plutonium/uranium blend) crystallized $\mathrm{PuO}_{2}$ upon thermal treatment. Only one glass (the 12/12/0 blend, containing $12 \mathrm{wt} \% \mathrm{PuO}_{2}$ ) contained undissolved $\mathrm{PuO}_{2}$ in a sample from the bottom of the crucible. This glass was prepared under static conditions; complete dissolution of the sample may have been possible if the melt had been stirred or if it had been tested in a stirred melter (see Section 5.2.2). Further testing of these high-plutonium-loaded compositions is necessary in stirred melter systems. However, it should be noted that precipitation of additional $\mathrm{PuO}_{2}$ in the glass has been shown to decrease the release of plutonium from the glass during MCC-1 (ASTM C1220-92) ${ }^{*}$ [Chamberlain et al., 1996] and PCT (ASTM C1285-94)* durability testing [Meaker and Bibler, 1997a,b; Bibler et al:, 1996]. Precipitation of $\mathrm{PuO}_{2}$ significantly lowers the plutonium recovery rates from the glass [Chamberlin, 1997]. The high- $\mathrm{PuO}_{2}$-containing glass $(12 / 12 / 0)$ is considered a glass form alternate baseline and will be discussed in Section 7.0.

The conclusions drawn above for the plutonium/uranium tolerance of the hafnium baseline (frit B) LaBS glass composition tested at SRTC, PNNL, and ANL with $\mathrm{PuO}_{2}$ (Table 5.2.5) were extensively supported by previous work with frit A which contained $\mathrm{ZrO}_{2}$ instead of $\mathrm{HfO}_{2}$ [Peeler et al., 1997b; Meaker and Peeler, 1997; Meaker et al., DRAFT; Vienna, 1996], $\mathrm{CeO}_{2}$ as a surrogate for $\mathrm{PuO}_{2}$ [Li et al., 1997], and $\mathrm{ThO}_{2}$ as a surrogate for $\mathrm{PuO}_{2}$ [McIntrye et al., 1997b; Meaker, 1996]. LaBS glasses fabricated in a 90 glass statistically designed [Edwards, 1997] variability study with frit A were also tested by various laboratories in an interlaboratory program among SRTC, PNNL, and ANL [Peeler et al., 1997b].

The impurity tolerances tested in the LaBS frit with the baseline 1 and baseline 2 plutonium/uranium feeds were defined to be the maximum concentrations for any one element in any one of the individual waste streams being considered for immobilization. In this manner, an impurity mixture designated as "other" provided a worst-case impurity mixture: the LaBS glass should never see extremes such as tested in the "other" mixture due to the blending planned for immobilization [Diaz, 1997]. The impurity mixture in the blended "other" feed component represents only $3 \mathrm{wt} \%$ in the feed. The tolerance of the baseline frit was tested at $6 \mathrm{wt} \%$ oxide impurities, which represents twice the maximum concentration of impurities anticipated. The LaBS glass performed well in all of the impurity testing, as shown in Table 5.2.3 [Peeler et al., 1997b; Meaker and Peeler, 1997a].

In addition, two blends and two composition feed extremes were tested [Meaker and Peeler, 1997a] as defined above: e.g., ZPPR with $70 \%$ uranium, the $60 / 40$ plutonium/uranium mix, the

\footnotetext{
*Annual Book of ASTM Standards (ASTM, Philadelphia, 1995), Vol. 12.01.
} 
plutonium alloy, and the impure oxide streams containing $>50 \mathrm{wt} \%$ minor components. In these cases, the impurity mixture was different for each of the four feed streams tested. For example, the impure oxide feed contained $~ 50 \%$ impurities at $14 \mathrm{wt} \%$ feed loading, which gave a maximum concentration of $7 \mathrm{wt} \%$ impurities (see Table 5.2.3) [Meaker and Peeler, 1997]. The impurity tolerance of the LaBS glass to the variable impurity streams was excellent and caused no second phase formation or devitrification [Meaker and Peeler, 1997]. In addition, the presence of the impurities in the LaBS glass did not affect the relative durability of the glasses produced [Meaker and Bibler, 1997b].

The conclusions drawn above for the minor components tolerance of the hafnium baseline (frit B) LaBS glass composition tested at SRTC, PNNL, and ANL with $\mathrm{PuO}_{2}$ (Table 5.2.3) were extensively supported by previous work with frit A containing $\mathrm{ZrO}_{2}$ instead of $\mathrm{HfO}_{2}[\mathrm{Peeler}$ et al., 1997b; Meaker and Peeler, 1997; Meaker et al., DRAFT, Vienna, 1996], $\mathrm{CeO}_{2}$ as a surrogate for $\mathrm{PuO}_{2}$ [Li et al., 1997], and $\mathrm{ThO}_{2}$ as a surrogate for $\mathrm{PuO}_{2}$ [McIntrye et al., 1997b; Meaker, 1996]. Indeed, Li's [1997] study examined each of the feed-stream minor components individually to determine their maximum solubility in the LaBS glass. The maximum limits determined in Li's study provide high confidence in the ability of the LaBS glass to tolerate minor components. LaBS glasses fabricated in a 90 glass statistically designed [Edwards, 1997] variability study with frit A were also tested by various laboratories in an interlaboratory program among SRTC, PNNL, and ANL [Peeler et al., 1997b].

The tolerance of the glass to impurities and to the combined $\mathrm{PuO}_{2}+\mathrm{UO}_{3}$ feed loading therefore defines a conservative processing range which expresses the flexibility of the LaBS frit and defines a conservative processing range for the LaBS glass in terms of feed loading (expressed as $\mathrm{PuO}_{2}+\mathrm{UO}_{3}$ ), LaBS frit, and minor components (see Figure 5.2.1). In addition, based on preliminary viscosity [Vienna, 1996] and preliminary liquidus [Meaker, 1997] measurements with a $\mathrm{ZrO}_{2}$-based LaBS frit, a preliminary processing range can be outlined in terms of actinide solubility expressed as $\mathrm{PuO}_{2}$, lanthanum oxides expressed as $\mathrm{Ln}_{2} \mathrm{O}_{3}$, and the remaining frit components. Exceeding the actinide solubility of the glass causes the glass to be inhomogeneous, i.e., all of the $\mathrm{PuO}_{2}$ does not dissolve [Vienna, 1996; Peeler et al., 1997b] and appears as $\mathrm{PuO}_{2}$ crystals in the glass and/or the glass devitrifies [Meaker and Peeler, 1997b; Peeler et al., 1997b]. As discussed previously, the precipitation of additional $\mathrm{PuO}_{2}$ in the glass has been shown to decrease the release of plutonium from the glass during durability testing and to significantly lower plutonium recovery rates. The high- $\mathrm{PuO}_{2}$-containing glass is considered a glass form alternate baseline and will be discussed in Section 7.0.

The LaBS glass has a measured density of 3.85 (Table 5.2.1). The glass contains no open porosity but may exhibit some thermal stresses on cooling unless it is annealed. Unannealed glass can exhibit some cracking, as does the HLLW glass, with minimal effect on the glass durability [Bickford and Pellerin, 1986].

Additional data on the LaBS glass radiation stability and durability appear in Section 6.4. 
Figure 5.2.1. Glass tcrnary phase diagram and processing region.

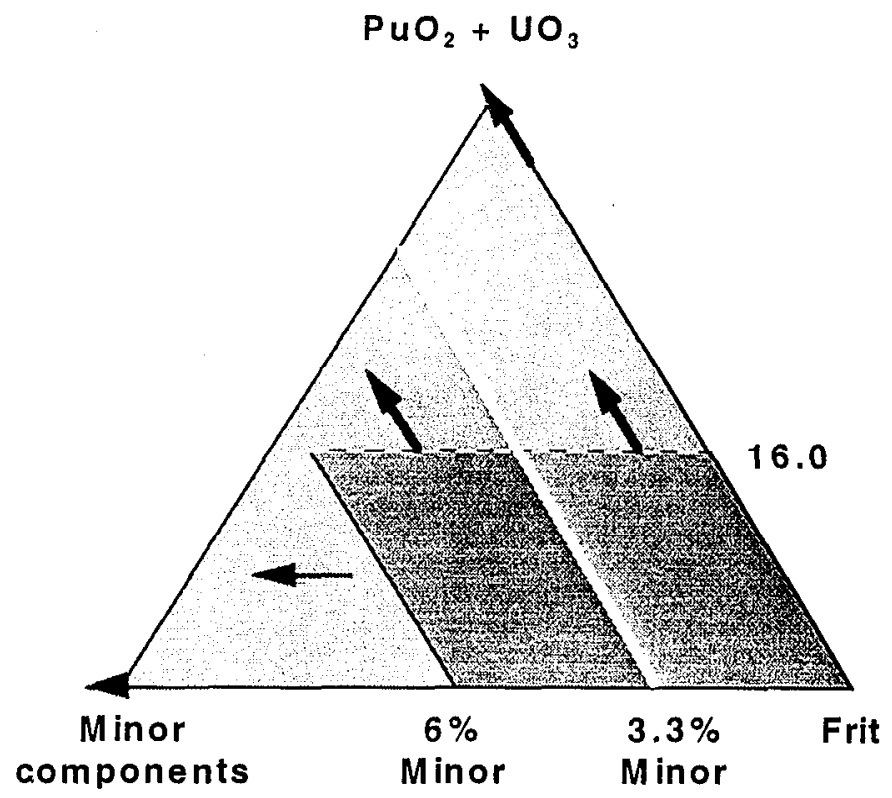

\subsubsection{Baseline Glass Manufacturing Process}

The baseline LaBS glass process will operate in batch mode, which facilitates material accountability and avoids criticality (Figure 5.2.3). The powder handling steps prior to vitrification in the melter are identical to those of the ceramic immobilization baseline process. Upon receipt, the feed will be milled in a dry state and at a high speed in an attrition mill. This mill is similar to that used in the front end of the BNFL short binderless route MOX fuel fabrication plants at Sellafield, U.K., as described for the ceramic immobilization baseline process in Section 5.1.2. All operations will be performed in gloveboxes similar to those in MOX fuel fabrication facilities.

Glass immobilization forms will have higher neutron radiation dose rates than ceramic immobilization forms because of the presence of boron in the glass matrix. Alpha emissions from plutonium isotopes and ${ }^{241} \mathrm{Am}$ will produce (alpha,n) reactions with the boron (see Section 6.5). To be certain that operators will receive radiation exposures below site limits, and therefore below DOE limits, several steps will be taken.

Almost all material handling will be performed with automated, hands-off equipment. Preliminary assessments by the SRS Robotics group have indicated that this will be possible. The current designs of shielded gloveboxes at SRS have 7-in. composite side-walls that are very effective neutron shields (see Section 6.5). With automated handling and the 7-in. sides, operators will receive acceptably low hand and whole body exposures during normal operation, especially since most of the operator's time will not be spent close to the glovebox. For nonroutine maintenance, SRS has experience to show that exposures can be kept acceptably low by a combination of designs, temporary shielding, and administrative controls. 
Figure 5.2.2. Actinide processing region (similar to processing region defined for HLW programs based on process control models).

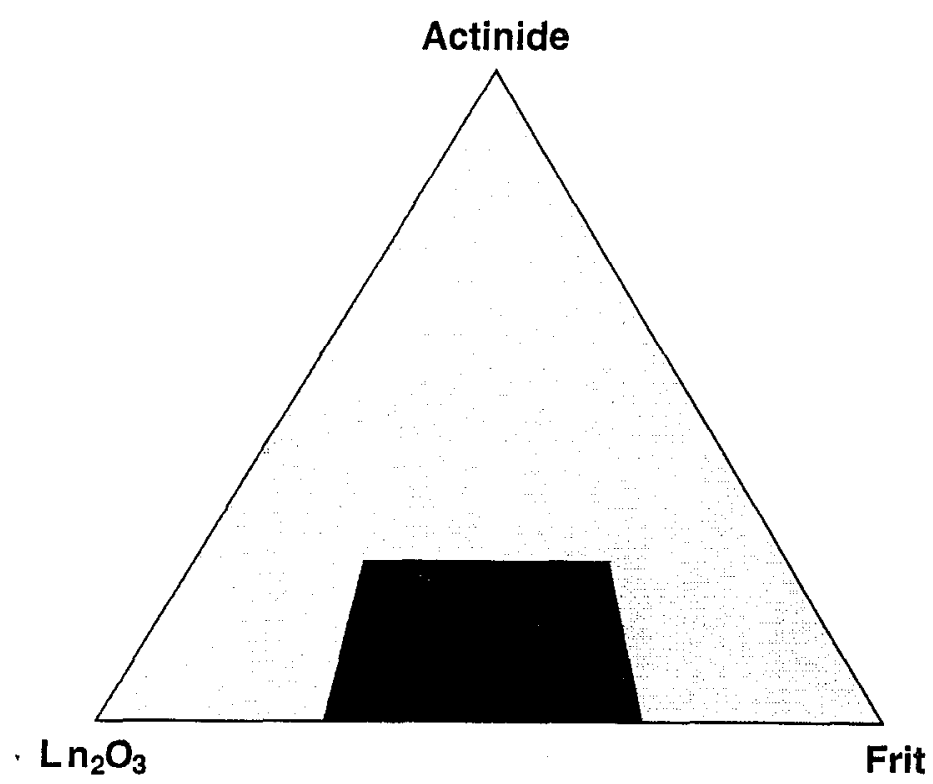

Figure 5.2.3. Baseline glass process.

Vitrification Process Flowsheet

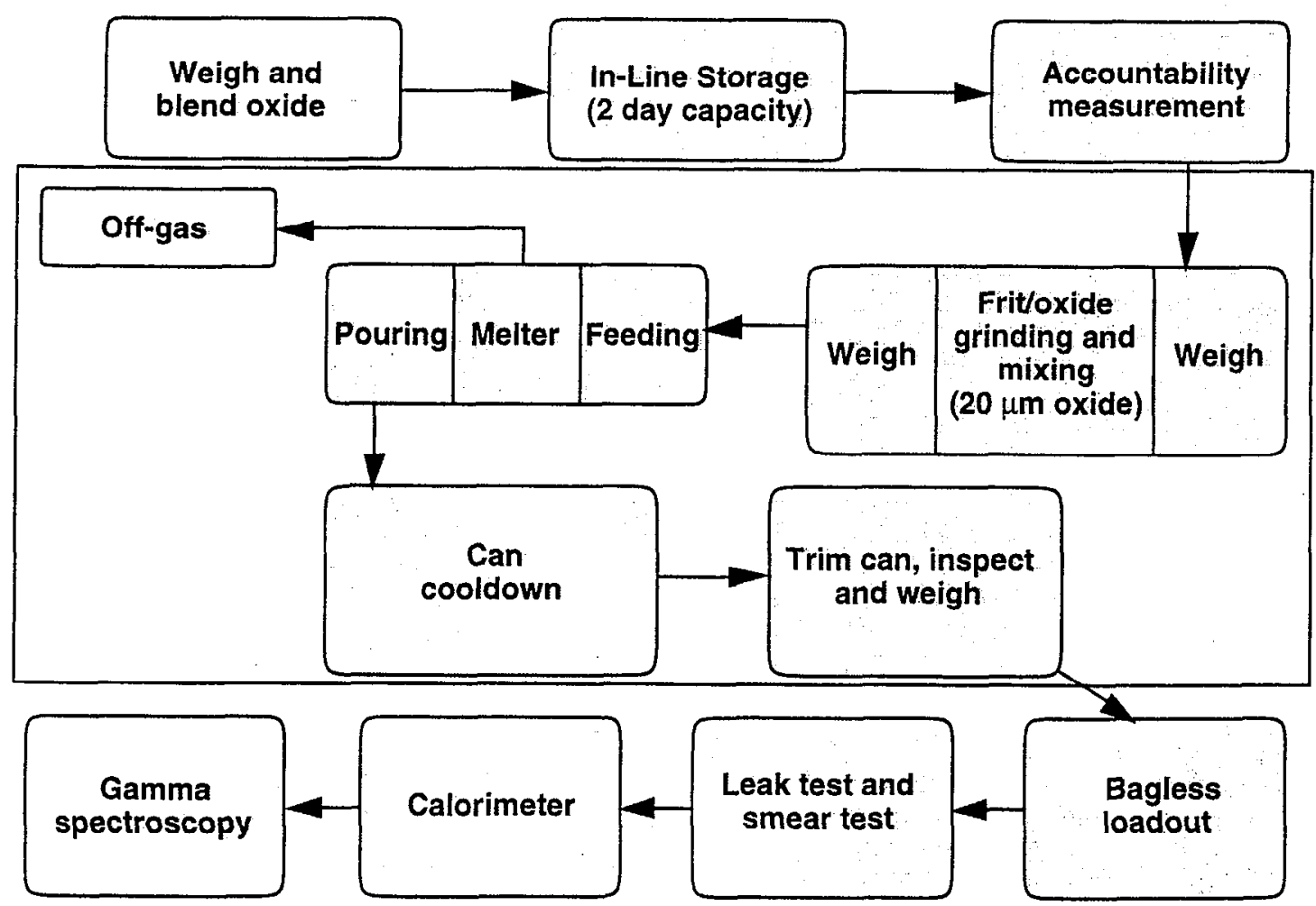


The incoming baseline feed $\left(\mathrm{PuO}_{2}\right.$ powdered feed admixed with incoming oxidized uranium feeds, "which will be in the form of mixed $\mathrm{UO}_{3}, \mathrm{U}_{3} \mathrm{O}_{8}$, and $\mathrm{UO}_{2}$ (see Table 3.2.1), will be comilled with the prefabricated, prefused LaBS frit (see Table 5.2.2). The LaBS glass is capable of molecularly bonding any combination of mixed uranium oxide valence states in the glass structure. At the current time no additional $\mathrm{UO}_{2}$ or $\mathrm{UO}_{3}$ above that coming in with the feed is being added to the LaBS glass formulations. Excess ${ }^{238} \mathrm{U}$, if deemed necessary for long-term criticality control, can be accommodated.

The LaBS frit, which is abrasive and has a density of 3.2 [Vienna, Monthly Report],will assist in the size reduction of the $\mathrm{PuO}_{2} / \mathrm{UO}_{x}$ feed during the co-grinding [Marra, 1997 TEP presentation]. This co-grinding step simultaneously grinds and blends dry powder streams with a large density difference (c.g., a larger density difference than is usually handled in MOX plants). However, there is vast experience in the commercial nuclear fuel industry and in the ceramic industry for handling and blending of powders with large differences in density (as discussed in Section 5.1.2). In addition, there a large body of experience in the commercial glass industry with blending of $>30 \mathrm{wt} \% \mathrm{PbO}$ and $\sim 60 \mathrm{wt} \% \mathrm{SiO}_{2}$ to make leaded glass crystal.

At the current time, it is intended that the $\mathrm{PuO}_{2}$ feed stream and frit mixture will be milled to the baseline $\sim 20 \mu \mathrm{m}$. (Table 5.2.1) to enhance the dissolution of the $\mathrm{PuO}_{2}$ in the melt. However, it should be noted that initial testing of $\mathrm{PuO}_{2}$ powders in range of $>20 \mu \mathrm{m}$ but $<45 \mu \mathrm{m}$ has shown that $99.9 \%$ of the mass dissolves completely into the LaBS glass when manually stirred twice during 8 hours at $1500^{\circ} \mathrm{C}$ in a static crucible test [Chamberlin, 1997]. A continuously stirred melter may allow for milling to $>20 \mu \mathrm{m}$ rather than $<20 \mu \mathrm{m}$.

As for HLLW vitrification, the composition of the LaBS frit will be controlled to tight chemical tolerances during manufacture since it consists of $75-85 \mathrm{wt} \%$ of the final vitrified product (Table 5.2.1). Tight control of the frit composition during its manufacture allows greater tolerance of the final glass form to compositional variation in the input streams while still allowing for the stringent statistical process/product control strategy [Jantzen and Brown, 1993] that allows for zero reject rate. In addition, the size of the frit is controlled to ensure reactivity with the feed and flowability [Schumacher, 1997a,b] into the attritor. The homogeneity of the frit is controlled by the nature in which it is fabricated (e.g., fused at elevated temperature).

According to Coughlin et al. [1997], the co-ground frit and $\mathrm{PuO}_{2} / \mathrm{UO}_{x}$ feed will be fed directly to the melter via a hard-piped closed-system screw conveyer such as the closed systems used in the commercial glass industry to eliminate the dusting of silica. The direct closed system feeding of the co-ground frit and feed through a sealed penetration [Coughlin et al., 1997] in the melter plenum (top) will minimize dusting.

Data taken to date have not indicated the need for a granulation step in the LaBS glass process. As an example, the studies performed by Riley [1997] indicated that jet-milled $(<3-\mu \mathrm{m})$ high-fired $\left(1000^{\circ} \mathrm{C}\right) \mathrm{PuO}_{2}$ dissolved into the glass readily in the tilt-pour melter tests performed at LLNL.

"No additional $\mathrm{UO}_{2}$ or $\mathrm{UO}_{3}$ is added other than that of the incoming feed. 
The screw feeder delivers the admixed frit/feed directly to the melter. The melter is an induction-heated ${ }^{*}$ cylindrically agitated platinum vessel [Coughlin et al., 1997; Marshall et al., 1997; Smith and Hardy, 1997; Diebler et al., 1997; Schumacher, 1997a,b]. The design of the melter system includes the following major components: melter and drain tube, melter and drain tube induction heating system, feed system, and control system [Coughlin et al., 1997]. The design of the melter (Figure 5.2.4) is patterned after a commercially operating melter currently in service at Corning, Inc., Corning, New York [Coughlin et al., 1997; Marshall, 1997]. The melter and drain tube consist of a zirconia-grain-stabilized platinum-rhodium alloy which will be heated to approximately $1500^{\circ} \mathrm{C}$ [Coughlin et al., 1997]. The batch size is $15 \mathrm{~kg}$ of glass and the cycle time is $8 \mathrm{~h}$ followed by a cool down of the can in a separate station of the glovebox [Marra, 1997].

The top of the melter is fabricated from Inconel ${ }^{690}$ [Coughlin et al., 1997]. A platinumrhodium agitator is used to stir the glass to reduce the plutonium dissolution times and the prevent buildup of $\mathrm{PuO}_{2}$ on the vessel bottom [Coughlin et al., 1997]. An additional feature of the agitator is that it also doubles as a glass-pour emergency shutoff valve by lowering the shaft into the drain-tube. The agitator design is based on tested commercial designs and is proprietary to the glass industry [Marshall, 1997].

The induction heating power supply and controls can easily be installed remotely away from the melter, providing a proven and easily maintainable heating system for glovebox operations [Coughlin et al., 1997]. Self calibrating (poly-color) optical pyrometers provide accurate and reliable measurement of melter temperature and have the potential to be remotely installed outside the glovebox environment [Coughlin et al., 1997]. Thermocouples will be used as backup temperature measurement sensors [Coughlin et al., 1997]. The integrity of the melter is ensured through the use of redundant temperature monitoring and shut-down controls (safety interlocks).

The conceptual off-gas system is designed to be a dry off-gas system that will not use any water streams for particulate scrubbing. This system is capable of working with feed water contents of 0-20 wt $\%$ if necessary and is described in Coughlin et al. [1997]. This offgas system minimizes air inleakage to about $0.1 \mathrm{scfm}$ and a secondary eductor induces a slight vacuum (0.5-5 in. of water). The vacuum also dilutes water in the off-gas line to prevent condensation, which could be a criticality concern.

The melter and drain tube are heated with separate induction systems. The average time to start a pour is $1 \mathrm{~min}, 18 \mathrm{~s}$. The average time to stop a pour varies with the amount of glass in the melter but

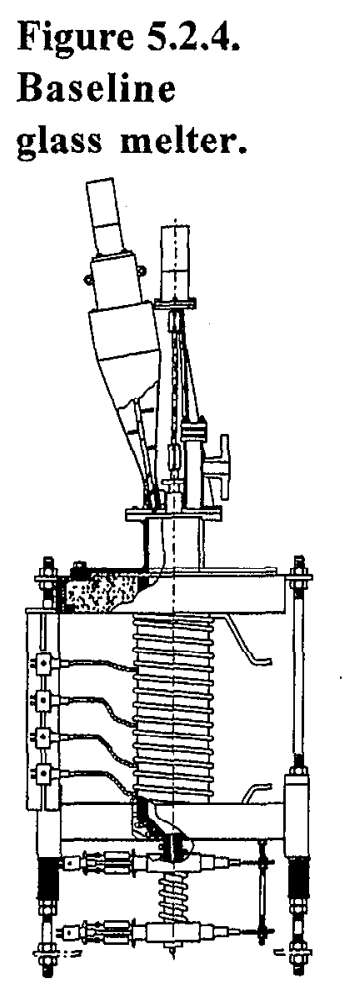

\footnotetext{
"Induction heating was first invented in 1831 by Michael Faraday. Shortly after 1850, a large number of patents were issued, both in the U.S. and abroad, covering the high-frequency apparatus for heating metals [Smith and Hardy, 1997]. The first successful induction melting on a production basis took place in 1917. The first patent for application in the glass fiber industry was in 1948 [Schlehr, 1948]. This patent is essentially the basis for the glass fiber industry today, which uses induction heating and resistance heating to form glass fibers.
} 
is on the order of 10-60 s [Marra, 1997]. When the melter is drained, no glass remains on the bottom. The glass exits through the drain tube and is stopped and started with air jets [Coughlin et al., 1997]. As noted above, the stirrer can be used as a glass-pour emergency-shutoff valve by lowering the shaft into the drain tube.

Surrogate testing has been performed at Corning, New York, in a prototypical melter with a stirrer and a flat bottom. The $\mathrm{ZrO}_{2}$ containing LaBS frit $\mathrm{A}$ was used and $\mathrm{HfO}_{2}$ was used as a surrogate for $\mathrm{PuO}_{2}$ [Marshall, 1997]. The solubility of $\mathrm{HfO}_{2}$ has been shown to be equivalent to the solubility of $\mathrm{PuO}_{2}$ on a 1:1 molar basis [McIntrye et al., 1997a]. Based on the Corning tests, $8 \mathrm{wt} \% \mathrm{HfO}_{2}$ was soluble in the LaBS frit $\mathrm{A}$, which corresponds to $10.4 \mathrm{wt} \% \mathrm{PuO}_{2}$ feed loading. This is in agreement with the findings of the 50-MT baseline $10 / 3 / 3 \mathrm{PuO}_{2} / \mathrm{UO}_{3} /$ impurity loadings in the LaBS baseline frit $\mathrm{B}$. After pouring and cooling, the cans are cut off with a commercially available pipe cutter above the meniscus and removed from the glovebox via a bagless transfer system.

From this point, the process is the same for glass or ccramic. After the plutonium-glass cans are removed from the glovebox, they are sent to the DWPF "canyon" for storage, loading into frames, and placing into empty DWPF canisters. All of this will be done remotely behind 3-5-ftthick walls. The canister containing the cans of plutonium glass will be remotely placed into a shielded box on a flatbed and a lid put on the box. Upon arrival in S-Area (DWPF), a monorail crane will be used to remove the lid and place the canister in a shielded container for storage in a. shielded, secure vault. These operations will not produce operator radiation levels of consequence.

\subsection{Baseline Canister Designs}

Numerous engineering tradeoffs are required to optimize canister utilization efficiency, proliferation resistance, and assurance of successful glass pour in the DWPF. At this stage in the engineering understanding, the following have been established as the baseline canister configurations for form selection. Both configurations have a high probability of a successful DWPF pour and will meet the overall program requirements based on the defined baselines for the glass and ceramic forms. 
Table 5.3.1 Baseline dimensions for cans and canisters for the 50-MT case.

\begin{tabular}{lll}
\hline Form characteristics & Ceramic & Glass \\
Diameter, in. & 2.5 & 1.937 \\
Height, in. & 1 & 20.6 \\
Density, g/cm ${ }^{3}$ & 5.5 & 3.8 \\
Plutonium loading, wt\% & 10.5 & 8.8 \\
$\quad$ Mold thickness & $\mathrm{NA}$ & 0.125 \\
Can dimensions & & \\
Thickness, in. & 0.125 & 0.125 \\
Outer diameter, in. & 3 & 4.5 \\
Height, in & 21 & 21.6 \\
Head space over form & 0.5 & 0.5 \\
Can-form spacing, in. & 0.125 & 0.063 \\
Canister characteristics & & \\
Canister fill height, in. & 95.5 & 95.5 \\
Canister inside diameter, in. & 23.25 & 23.25 \\
Number of cans in a circle & 7 & 4 \\
Number of can levels & 4 & 4 \\
Can rack displacement, $\mathrm{ft}^{3}$ & 0.23 & 0.23 \\
Can/rack DWPF glass displacement, \% & 11.20 & 14.50 \\
Plutonium loading & & \\
Plutonium per can, kg & 0.93 & 1.33 \\
Plutonium per canister, kg & 26 & 21 \\
Canisters impacted & & \\
Additional canisters & 216 & 341 \\
Total canisters & 1923 & 2347 \\
\hline
\end{tabular}


Figure 5.3.1(a). Baseline canister design for glass (a) and ccramic (b).
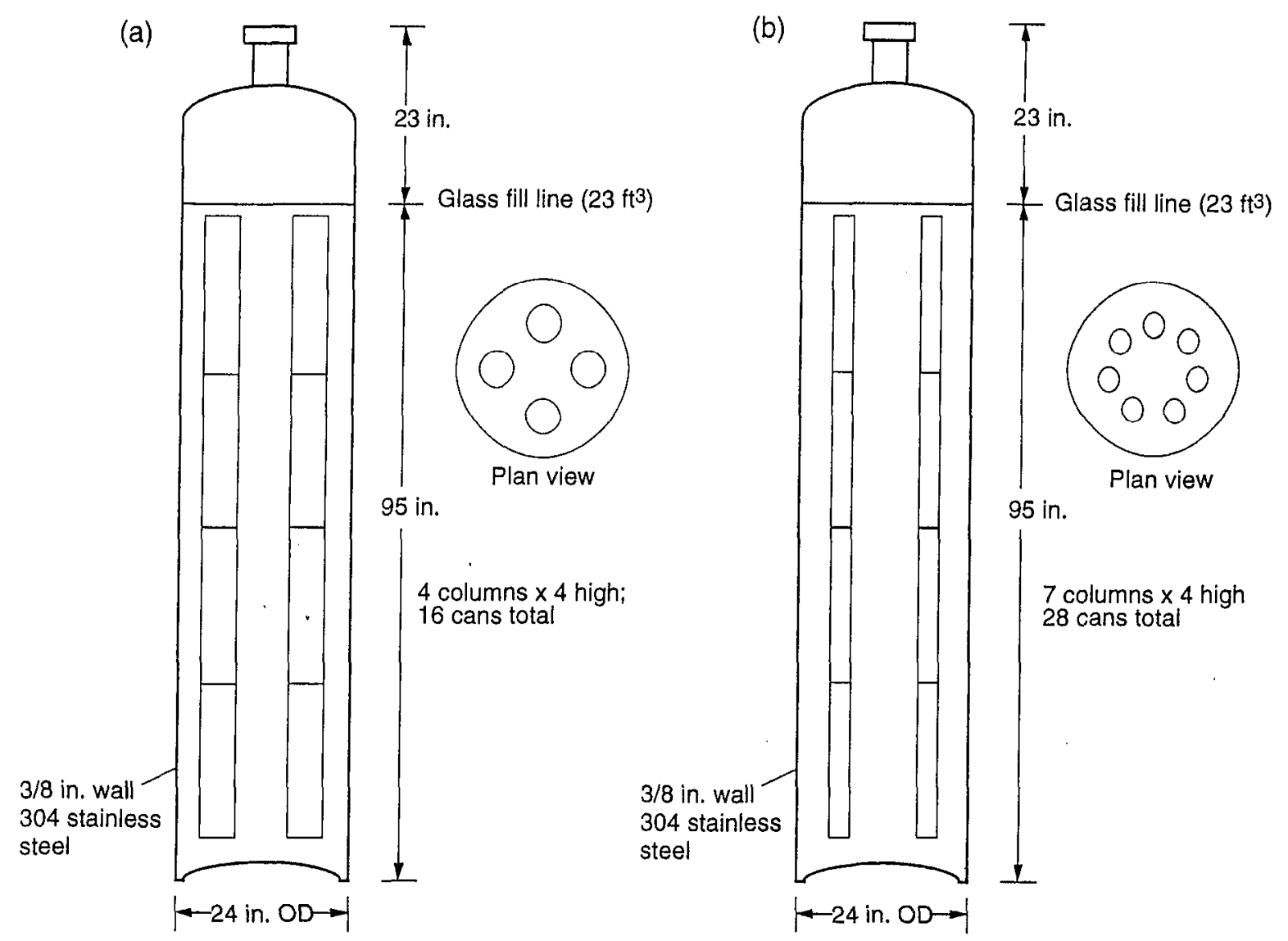


\section{Can Dimensions - Ceramic}

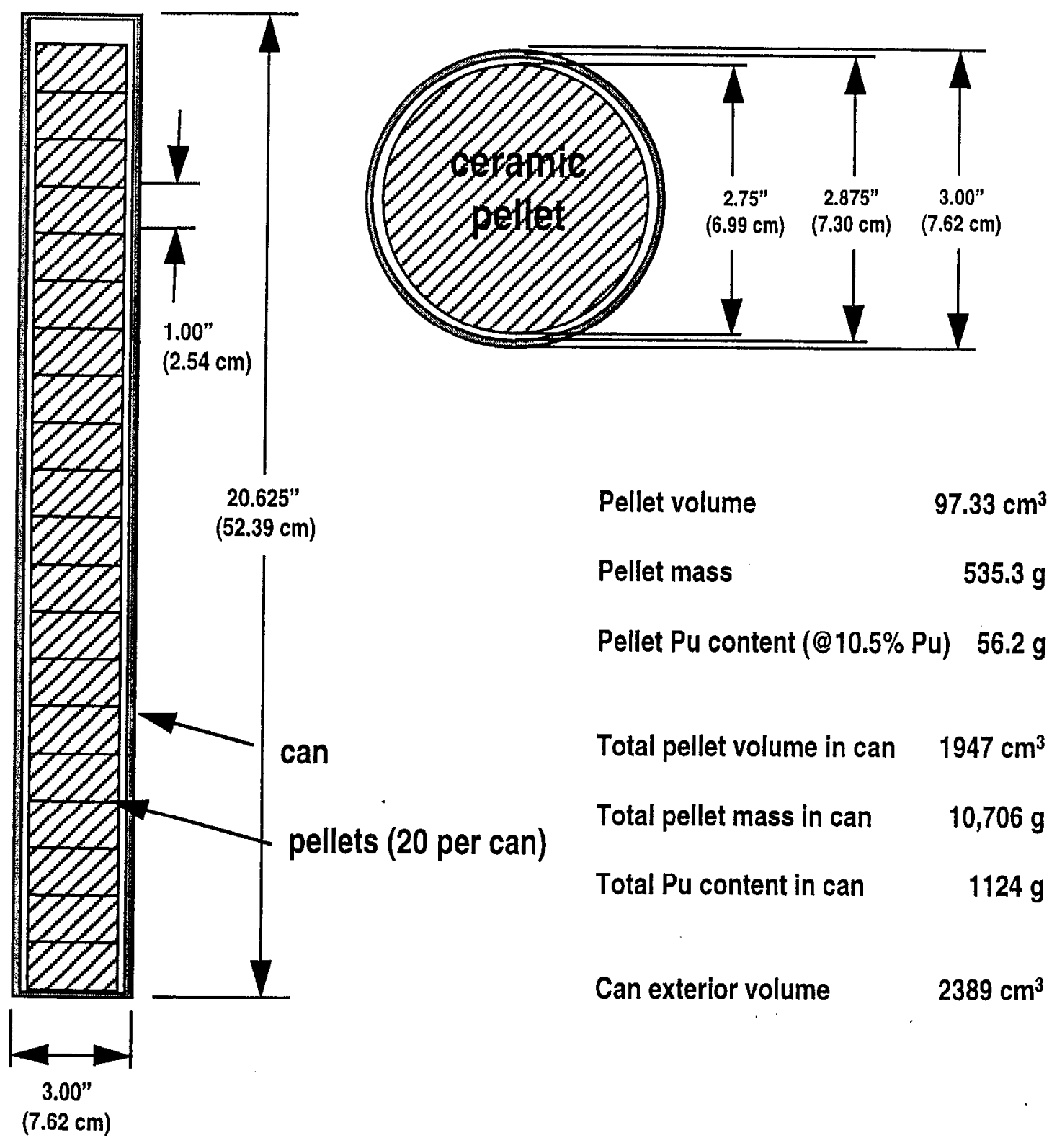




\section{Can Dimensions - Glass}

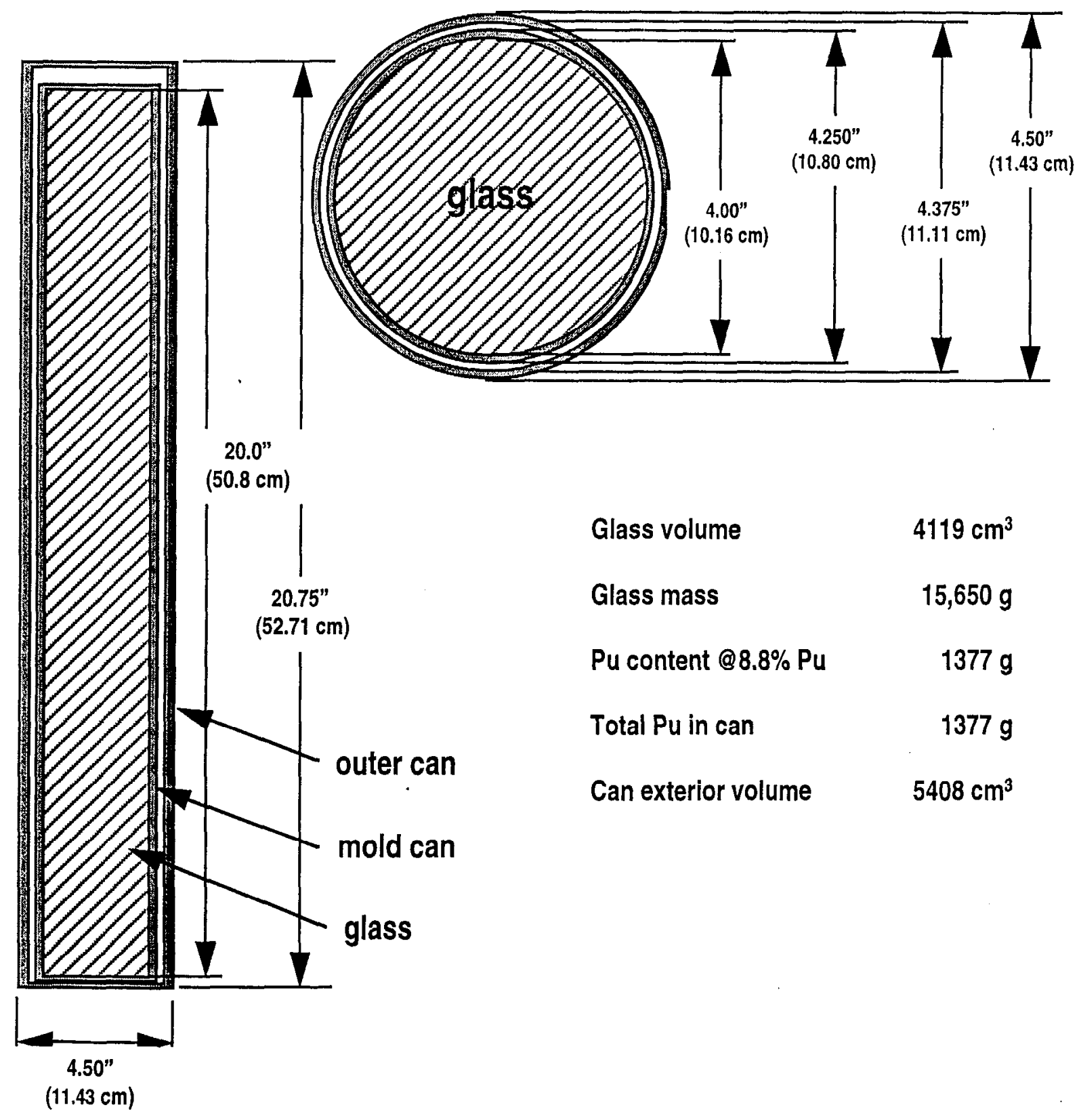




\section{ASSESSMENTS BY CRITERIA}

\subsection{Assessing and Grading the Baseline Cases}

Following the formal reviews, the TEP spent the following week evaluating material presented during the review as well as other collected information. The goal was to compare the two immobilization options against each of the established criteria in detail. The TEP began its assessments with discussions of the technical maturity of the baseline process steps. A grading system was established and tried, which we document below for completeness. The TEP found that in order to grade the technical maturity of a process step, several issues needed to be addressed simultaneously. To reflect the quality of the grading, both the quality of the data supporting the assessment and the clarity of the criterion used had to be evaluated as well. The grading of an option could then be assigned a confidence level, albeit qualitative. The TEP also attempted to estimate the overall importance or impact of the grading, although this was found to be difficult to estimate in many cases. This approach used the grading guidelines documented below for both technical viability criterion.

Using this evaluation approach, it took considerable time for the TEP to complete the processing steps for glass and ceramic alone. It quickly became obvious that the review schedule would not allow the TEP to continue through all the criteria using this process, however desirable it might be (or not). Therefore, the TEP was forced by the time limit to use an ad hoc approach, with small subgroups from the TEP debating, assessing, and documenting the assessments for each of the criteria. Initial drafts for each section of this report were drafted by TEP members and then circulated for review and comments. For topics requiring in-depth review, additional ad hoc groups of two or more TEP members met and then worked to achieve consensus. The draft report was forwarded to the LLNL FMDP office on August 9, 1997.

Sections 6.2 through 6.7 present the TEP's consensus assessment of the glass and ceramic options against each of the criteria. In many cases, a true consensus was not reached and a compromise position is documented.

Shown below is a sample table of the type used to rank assess the baseline options. Actual assessments using this format are presented in Section 6.4. Following the table are the definitions used by the TEP for the gradings assigned.

Table 6.1.1. Ranking used in assessing technical viability $(H=$ high, $M=$ medium, $L=$ low).

\begin{tabular}{c|cc|cc|cc|cc|}
\hline $\begin{array}{c}\text { Technical } \\
\text { maturity }\end{array}$ & \multicolumn{2}{|c|}{$\begin{array}{c}\text { Panel } \\
\text { assessment }\end{array}$} & \multicolumn{2}{|c|}{$\begin{array}{c}\text { Confidence in } \\
\text { data/information }\end{array}$} & \multicolumn{2}{c|}{$\begin{array}{c}\text { Clarity of } \\
\text { the metric }\end{array}$} & \multicolumn{2}{c|}{$\begin{array}{c}\text { Assessment of } \\
\text { overall impact }\end{array}$} \\
\hline Process & Ceramic & Glass & Ceramic & Glass & Ceramic & Glass & Ceramic & Glass \\
\hline Step 1 & H & H & H & H & M & M & L & L \\
Step 2 & H & H & H & H & M & M & L & L \\
Step 3 & H & H & H & H & M & M & L & L \\
Step 4 & H & H & H & H & H & H & H & H \\
\hline
\end{tabular}




\section{Definition of Ranking Areas}

- Panel Assessment. The TEP's consensus assessment of how well the baseline form, form characteristic, process step, or process characteristic satisfies or achieves the listed metric:

- High $(\mathrm{H})$ : Ranks highly against the metric; achieves the metric's implied goal or goals as interpreted by the TEP.

- Medium (M): Ranks moderately against the metric; partially achieves the metric's implied goal or goals as interpreted by the TEP.

- Low (L): Ranks poorly; only achieves a minor part of the metric's implied goal or goals as interpreted by the TEP.

- Confidence in Data or Information. The extent to which the data, information presented to or available to the TEP, or the TEP's collective experience will support an accurate assessment of how well the baseline form, form characteristic, process step, or process characteristic satisfies or achieves the listed metric:

- High $(\mathrm{H})$ : The data or information presented or available to the TEP or the TEP's collective experience are judged adequate to support an accurate assessment.

- Medium (M): The data or information presented or available to the TEP or the TEP's collective experience is judged adequate to support a tentative assessment, which could change in the event that more or better information was available, more time was available for the TEP's assessment, or the TEP's experience base was more aligned with the specific topic.

- Low (L): The data or information presented or available to the TEP or the TEP's collective experience is judged inadequate to support a reasonable assessment, or the assessment might very possibly change in the event that more or better information was available, more time was available for the TEP's assessment, or the TEP's experience base was more aligned with the specific topic.

- Clarity of the Metric. A measure of how well the metric is defined and how readily it can be applied to measure or assess this specific form, form characteristic, process, or process characteristic. Reflects the clarity with which the metric or its implied goals, if any, can be understood and agreed upon by the TEP. Also reflects the appropriateness of the metric for assessing the specific form, form characteristic, process, or process characteristic:

- High $(\mathrm{H})$ : The metric is clearly defined and would allow the TEP (with adequate data or information available or with adequate and relevant experience) to make a defensible and documentable assessment with high confidence. Also can mean that the metric has a clearly defined or implied goal(s) that are readily understood and concurred with by the TEP.

- Medium (M): The metric is somewhat unclear, subject to significantly differing interpretations among the TEP members, or is context-dependent and thus would allow the TEP to have only moderate collective confidence in applying the metric (even with adequate data or information available or with adequate and relevant experience). Also can mean that the metric has a loosely defined or implied goal(s) that are not easily understood or concurred with by the TEP. 
- Low (L): The metric is very unclear, subject to widely differing interpretations within the TEP, or is highly context-dependent and thus would allow the TEP to have only low confidence in applying the metric (even with adequate data or information available or with adequate and relevant experience). Also can mean that the metric has a poorly defined or implied goal(s) that are not understood or concurred with by the TEP.

- Assessment of Overall Impact. An assessment by the TEP of the relative importance of metric assessment of this specific form, form characteristic, process, or process characteristic in determining the overall performance of the immobilization effort. Impact may be linked to the performance of other form or process parameters or characteristics:

- High $(\mathrm{H})$ : High project impact; a poor ranking of this specific form, form characteristic, process, or process characteristic against this particular metric alone would seriously impact the immobilization effort.

- Medium (M): Medium project impact; a poor ranking of this specific form, form characteristic, process, or process characteristic against this particular metric alone or in combination with other performance shortfalls could have a significant impact on the success of the immobilization effort.

- Low (L): Low project impact; a poor ranking of this specific form, form characteristic, process, or process characteristic against this particular metric alone, unless in combination with other performance shortfalls, would probably not have significant impact on the success of the immobilization effort.

\subsection{Resistance to Theft by Diversion by Unauthorized Parties}

This criterion addresses the risk of theft of weapons-usable plutonium by terrorists, subnational groups, aspiring weapons nations, or disgruntled employees. The scope of this assessment for plutonium in glass and ceramic disposal forms includes processing operations, interim storage, and transportation to the repository It includes evaluation of theft (getting away with it), transport of the plutonium to a secure (for the thieves) location, and conversion of the plutonium to purified metal suitable for manufacture of explosive devices.

Risk is reduced by applying effective safeguards and security measures and by rapidly processing the material to a form that has low inherent attractiveness. The Stored Weapons Standard [NAS, 1974] is applied to the plutonium from its receipt through processing until it is in its final form, encapsulated in a DWPF canister filled with highly radioactive high-level-waste (HLW) glass, at which time it satisfies the Spent Fuel Standard [NAS, 1974].

\subsubsection{Level of Attractiveness}

The applicable metric for inherent attractiveness is DOE's Attractiveness Levels as defined in DOE Order $5633.3 \mathrm{~b}$. Specifically, it is the processing time and cost required to reach Attractiveness Level II-D or lower.

The plutonium is in its most attractive state during initial sizing and feed blending operations because during these operations it is in its purest and most concentrated state. However, during these initial processing operations, the material forms for glass and ceramic options are identical and therefore the level of attractiveness is identical. The final blending and milling with glass frit 
or ceramic precursors significantly reduces attractiveness because impurities have been added and the plutonium concentration has been substantially reduced.

The next steps in the ceramic process are to press the "green" (unsintered) pellets and then sinter them to produce the final pellets. For glass, the next step is to pour the glass into a

stainless steel can. Both of these forms meet Attractiveness Level II-D.

After processing through the DWPF, the final can-in-canister form for both options will be stored in the Glass Waste Storage Building (GWSB) vaults until sent to the federal repository. In this form, both glass and ceramic exceed the minimum requirements for DOE Attractiveness Level II-D and both meet or exceed the spent fuel standard.

Only minor differences exist in the levels of attractiveness of the glass and ceramic options during processing, interim storage in the GWSB at the DWPF, and transportation to the federal repository. The ceramic option is slightly more attractive during the processing operations once the feed has been blended with the immobilization form because of slightly higher plutonium concentration (10.5 vs $8.8 \mathrm{wt} \%$ ) and the higher neutron dose rate from the glass. Similarly, since ceramic has a higher canister plutonium loading ( $29 \mathrm{vs} 21 \mathrm{~kg}$ ) (see Table 5.1), it may be somewhat more attractive as a source of plutonium for potential theft.

\subsubsection{Minimization of Transportation, Facilities, and Processing}

Generally, the more complex the handling, processing, and moving of plutonium, the more opportunities that exist for theft. The metrics for the transportation step are the number of trips and the total number of miles transported. For processing, the number of distinct process steps and the complexity of those steps are used. Overall, the number of process steps, the complexity of the process steps, and the transportation miles are essentially the same for the glass and ceramic options.

During initial processing operations, prior to pressing the green ceramic pellet or melting the glass, the complexity of glass and ceramic options is essentially identical. The next two steps for ceramic (pressing and sintering) are equivalent to the single glass melting step. However, the additional step adds very little to the vulnerability of the ceramic process.

Processing through the DWPF, storing the filled canisters in the GWSB waste vault, and transporting the canisters to the federal repository have identical levels of complexity for the glass and ceramic options and identical transportation miles.

\subsubsection{Safeguards and Security Assurance}

The effectiveness of the safeguards and security (S\&S) program depends on the level of security applied, the form of the plutonium, and the process and facility characteristics. As used here, security refers to the avoidance of unauthorized access to the plutonium, and the metric for security is the number and effectiveness of the barriers to theft. Safeguards refers to the ability to adequately account for the plutonium in a timely manner, and the metrics for safeguards are the frequency of accounting and the accuracy and reliability of the accounting measurement.

Assessments of security for glass and ceramic options show them to be identical because security procedures and practices during processing and interim storage are the same, following normal DOE practices. Security during transport to the repository is also identical for glass and ceramic options. Security during transport is designed to ensure negligible risk of theft. 
To safeguard ceramics, standard calorimetry and gamma spectrometry methods are used for all processing. After the sintering step, pellets are weighed; they can also be core-sampled and assayed. Thereafter, "piece count" is the primary accounting technique.

For the glass option, standard nondestructive analysis techniques are used up to the point where the feed is mixed with the glass frit. Thereafter, a combination of process control modeling based on feed analyses (similar to the DWPF) and sampling and analysis is used. The techniques are developed and validated for plutonium accountability.

Accountability practices for the baseline glass and ceramic flowsheets have yet to be determined. Both processes must demonstrate acceptable plutonium accountability for the final form.

\subsubsection{Difficulty of Retrieval and Extraction by a Clandestine Group or Rogue Nation}

This section assesses the risk of theft of immobilized plutonium followed by its purification for weapons use by unauthorized parties such as terrorists or rogue nations. To a degree, this section overlaps the previous section on safeguards and security. Clearly, if S\&S programs create scenarios in which the probability of theft is very low, then the overall probability of theft, purification, and weapons manufacture by terrorists or rogue states is also very low. This subject of this section and the next is discussed in detail in Gray et al. [1997].

In the baseline cases, the effectiveness of security programs is high during processing and interim storage. The $221-\mathrm{F}$ building, located in the middle of a 300 -square-mile secure site, already has all necessary security for a plutonium handling facility. Interim storage of the highly radioactive canisters containing the cans of immobilized plutonium is in an underground waste storage vault in the DWPF Area (S Area), which is appropriately secured for this mission. No differences exist between the level of security for glass and ceramic options.

The plutonium is assumed to be most vulnerable to theft during transport to the federal repository. However, this assumption may not be true if an enhanced level of security is used or if modifications are made to the baseline designs of the transfer cask, the canister retention system, and the rack holding the cans of immobilized plutonium. Such modifications could significantly lengthen the time required for thieves to remove cans of plutonium.

This section presents the results of an assessment of differences that may exist between glass and ceramic options involving the difficulty of (1) separating a sufficient number of cans of immobilized plutonium from the HLW-glass radiation barrier, (2) transporting the cans to a secure location, and (c) purifying at a significant quantity of plutonium for weapons use.

The assumptions of this scenario are:

- The plutonium thieves intercept the shipment, subdue the guard force, open the transfer cask, select and remove the single plutonium-containing canister out of the four or five identical canisters in the transfer cask, blast open the canister without shattering the cans of immobilized plutonium that are embedded in the HLW glass inside the canister, remove several cans of immobilized plutonium, separate the cans from HLW-glass, and escape via helicopter within 20 minutes.

- The thieves are willing to take high doses of radiation, but the doses must be below the doses that would render them incapable of completing the mission. 
- Once the thieves have the immobilized plutonium is in a secure location, the plutonium is removed from the cans and purified. This could be done with simple equipment and procedures and without normal safety guidelines. Common commercial (nonnuclear) equipment is available and sufficient for this purpose.

There appear to be no discriminators between glass and ceramic for gaining access to the cans of immobilized plutonium, because both forms could take advantage of any improved designs to the cans or to the frame that holds the cans.

Once the cans of immobilized plutonium have been successfully moved to a secure location, it is somewhat more difficult to chemically recover the plutonium from the ceramic than from the glass. The plutonium in the glass can be recovered by leaching the plutonium from the glass with commonly available acids. Recovering the plutonium from ceramic is slightly more complicated chemically, gives somewhat lower yield, costs slightly more, and perhaps takes longer. Although these differences are scenario-dependent, they are not viewed as significant barriers to a dedicated and organized terrorist group or a roguc nation intent on acquiring nuclear weapons. Details of these assessments are given in Gray et al. [1997].

\subsection{Resistance to Retrieval, Extraction, and Reuse by Host Nation}

The objective of this criterion is to ensure confidence that the immobilized plutonium will never be used in nuclear weapons. This can be done by making recovery and reuse of the immobilized plutonium substantially less attractive than other methods of making weaponsusable plutonium. This is accomplished by creating a combination of barriers such as a disposal form that does not lend itself to easy recovery, a disposal location that makes retrieval difficult, and the application of such international institutional controls as bilateral inspections and IAEA oversight.

The report of the Committee on International Security and Arms Control of the National Academy of Sciences [NAS, 1994] coined the term Spent Fuel Standard (SFS). Although they did not define the term in detail, it is generally taken to mean that the immobilized plutonium is less attractive to a potential weapons producer than the plutonium in the spent nuclear fuel from commercial power reactors that use low-enrichment uranium (LEU) fuel. This SFS standard is more applicable to terrorists or nations trying to develop nuclear weapon capability than to host nations because it is not likely that a nation with a sophisticated nuclear weapons program (e.g., the U.S. or Russia) would be interested in making weapons from the poorer quality reactor-grade plutonium in spent fuel.

Specific assessments in this report assume that the host nation is the U.S. However, the plutonium disposition efforts may be driven by concerns in Russia and elsewhere.

The metric for this assessment is the time and cost required to retrieve and process immobilized plutonium, producing purified plutonium at a rate of at least $1 \mathrm{MT}$ per year.

The assumption is made that a national mission to recover immobilized plutonium for weapons production has a very high national priority. It is also assumed that for several decades into the future, either of the two SRS reprocessing plants $(221-\mathrm{F}$ or $221-\mathrm{H})$ could be upgraded and retrofitted for this mission. The F-Area facility is preferred because it would require less preparatory work. Several other facilities in the U.S. could be used, but they are less suitable or 
would require substantially more time and money for upgrading and retrofitting. Assessment details can be found in Gray et al. [1997].

In the baseline cases that were assessed, canisters are retrieved from interim storage or the repository and delivered to $221-\mathrm{F}$. The cans of either plutonium-loaded glass or ceramic are intact and surrounded by highly radioactive HLW glass. The canisters are cut open and the HLW glass removed. This step would probably be performed in the Multi-Purpose Processing Facility (MPPF), which has a series of hot cells located in the 221-F "hot canyon." The removed HLW glass is recycled to DWPF. The pieces of canister are decontaminated and sent to the SRS lowlevel waste vault. The cans of immobilized plutonium are cut open and the immobilized form is removed, pulverized, and processed.

\subsubsection{Time to Retrieve and Begin Processing}

For this assessment of time requirements for glass and ceramic, it is assumed that the limiting time is the time required to prepare the $221-\mathrm{F}$ to receive and process immobilized plutonium. That is, the plutonium-bearing canisters are retrieved from interim storage or the repository before the processing building is ready to receive and process them.

It would take about eighteen months to three years to prepare $221-\mathrm{F}$ under high priority (i.e., full funding availability and minimum regulatory oversight). Under these conditions, preparing for the ceramic form would take about six months to a year longer than for glass because the ceramic process would involve several additional steps, additional and new waste treatment steps, and some new tanks, pipe, and equipment with different materials of construction. Once operational, the facility production rate would be the same for glass or ceramic, at about five or more kilograms of plutonium per day. Also, some process development work would be needed to fully develop and demonstrate the "head end" treatment for the ceramic form. Conceptual processes for this step already exist [Gray et al., 1997]. Presumably, this chemical development could be done during the time the building was being prepared.

\subsubsection{Cost to Retrieve and Process}

In the absence of preliminary designs and other relevant data on the amount of retrofitting required, the cost estimates given here are the best judgments of experienced process and project personnel. The cost of recycling the HLW glass to DWPF is not included.

The TEP assumed that priority would be given to rapid startup and therefore existing equipment would be used to the extent possible. Design, procurement, and construction costs would be at least $\$ 100$ million for the glass case, and the ceramic option would cost about $\$ 75$ million more than the glass option. This cost difference would not be a significant deterrent to a host nation that felt a strong need for additional fissile material for either weapons or power.

\subsection{Technical Viability}

Because of the need for high degree of confidence that a form will be technically successful, it is prudent to rely on technologies that have proved successful for similar applications. New technologies or new applications of existing technologies may also require an extended period for licensing or regulatory approval due to the immaturity of the process or regulatory framework. Technical viability can be used as a discriminator between the immobilization forms by 
considering three key factors: technical maturity, viability risk, and repository acceptability of the disposal forms.

\subsubsection{Technical Maturity}

Ceramic and glass are both considered by the TEP to be mature technologies, with some distinctions between the maturity of individual process steps and form chemistry. Both technologies require further development before implementation. An assessment of the risks involved with this development is discussed in the following section; here we compare the current technological maturity of each form and its processes.

The metric for technical maturity is broadly defined as deployment readiness [Booth et al., 1996]. A common measure of deployment readiness is the gate process used by DOE/EM50. An adaptation of this process for the purposes of plutonium immobilization is given in Section 5.1.

Each baseline technology, evaluated in its entirety, is in the exploratory development stage wherein:

- Benchtop experiments with radioactive materials have been successful.

- All process steps have been successfully demonstrated at some scale.

- The performance and costs of processes and products are reasonably established.

- Product requirements have not yet been clearly defined.

- Integrated demonstrations on a laboratory scale have not yet been performed with the full range of radioactive feedstocks.

Individual process steps for both forms are at higher (and in some cases lower) stages of development. A closer examination of immobilization forms and baseline process steps clearly shows the maturity of each technology. For the purposes of disposal form selection, only the form-specific process steps are considered. These steps begin with the precalcined oxide feed receipt from blending operations and continue through the bagless transfer of can out of the process line. Differences in canister rack design and HLW glass pouring are also considered since technological issues exist for this process step which, according to baseline technology definition (Section 5.0), are different for the different forms.

\subsubsection{Ceramic Maturity}

The baseline ceramic contains roughly $95 \%$ pyrochlore with lesser amounts of rutile, brannerite, and ( $\mathrm{Pu}, \mathrm{U}, \mathrm{Ti}, \mathrm{Hf}) \mathrm{O}_{2}$, (Section 5.1). This composition has been fabricated over a range of processing conditions of atmosphere (argon and air), temperature $\left(1275-1400^{\circ} \mathrm{C}\right.$ ), and impurity concentrations [Ebbinghaus et al., 1997; Vance et al., 1997]. Impurities likely to be found in the plutonium feed material were tested in different mixtures and concentrations ranging from 0-13 wt\% (of the product) [Ebbinghaus et al., 1997; Congdon, 1997; Vance et al., 1997]. The addition of impurities caused the formation of additional phases, primarily zirconolite (up to $25 \mathrm{wt} \%$ ) and a silicate phase (up to several weight percent containing on the order of $3 \mathrm{wt} \%$ $\mathrm{PuO}_{2}$ in some cases). Perovskite was also found in those samples with excess $\mathrm{CaO}$ [Ebbinghaus et al., 1997; Vance et al., 1997]. Composition development is in an advanced stage. Further development work is required to quantify the concentrations of the phases formed in the ceramic with varying impurities and to determine the partitioning of actinides and neutron absorbers in these phases. 
The baseline process includes dry, high-speed attrition milling of $\mathrm{UO}_{2}$ and $\mathrm{PuO}_{2}$ powder feed, followed by attrition milling of that feed with a preblended oxide precursor. The purpose of this step is to reduce the $\mathrm{UO}_{2}$ and $\mathrm{PuO}_{2}$ particle size to below roughly $20 \mu \mathrm{m}$ diameter and to blend the precursor. Adequate milling and blending is required to ensure powder homogeneity and reaction kinetics. This process step is similar to that used in the BNFL MDF line. The expected material throughputs for the ceramic attritors are $4.2 \mathrm{~kg}$ plutonium $\left(4.8 \mathrm{~kg} \mathrm{PuO}_{2}\right)$ and $40 \mathrm{~kg}$ total ceramic per batch, six batches per day [Brummond, 1997]. These throughputs are well below those demonstrated in the ceramic and MOX fuel industries. Although particle sizes and density differences vary from those used in most of the ceramic and MOX industries, process optimization will enable adequate mixing. A cold (cesium surrogate) demonstration of the proposed attrition mill showed promising results [Brummond, 1997]. A sintered sample of the blended powders appeared homogeneous on a roughly $100-\mu \mathrm{m}$ scale. This process step has been demonstrated with prototypic equipment but not optimized for the specific process.

Granulation is performed on the premixed feed material to aid in material flow, minimize powder segregation, and ensure proper die filling. The baseline process includes granulation with a spherodiser similar to that used in the MOX industry [Brummond, 1997]. This process step has not been demonstrated with typical ceramic feed material. However, use of the spherodiser in the MOX industry provides adequate demonstration to ensure that this process step will be successful with optimization.

The granulated ceramic precursor material is volumetrically loaded into a 3.5 -in.-diameter die with a standard hopper design and the powder is then compacted with a double piston hydraulic press. Ceramic pellet size, density, and sinterability are influenced by this process step. The pressing step has been demonstrated with prototypic equipment to fabricate roughly 900 simulated ceramic pellets and roughly 70 scaled radioactive pellets [Brummond, 1997]. The effect of pressing pressure on sintered ceramic density was demonstrated to be negligible over the processing range of 1800-2500 psi [Brummond, 1997]. Volumetric feeding was not demonstrated for this material using prototypic equipment. However, the wealth of industrial experience with volumetric feeding gives a very high confidence that this process step will be successful. Process optimization will be required for this step.

Reactive sintering is the process thought to be responsible for pellet densification and formation of the desired microstructure and mineral phases. This process is sensitive to several parameters, including temperature, atmosphere, time, composition, particle size, mix, and concentration and composition of the liquid phase. The baseline process assumes that pellets are sintered in a resistance-heated furnace with an argon atmosphere. The pellets are heated to a binder burnout stage $\left(300^{\circ} \mathrm{C}\right)$, and held for $2 \mathrm{~h}$, heated to the sintering stage $\left(1350^{\circ} \mathrm{C}\right)$ for $4 \mathrm{~h}$, and then cooled to room temperature. The equipment for this processing step is a sintering furnace. Several furnace designs are available off the shelf. These furnaces are capable of performing this process step with little or no adaptation.

Preliminary studies were performed to identify the appropriate parameters for pellet sintering [Ebbinghaus et al., 1997; Vance et al., 1997; Brummond, 1997]. A study of temperature effects on reaction extent showed that, at $1300^{\circ} \mathrm{C}$, reaction of precursors was not complete after up to $8 \mathrm{~h}$. At 1350 and $1400^{\circ} \mathrm{C}$, reaction of precursors was complete after $4 \mathrm{~h}$ [Ebbinghaus, 1997]. This study was performed under argon with approximately $20 \mu \mathrm{m} \mathrm{PuO}{ }_{2}$ feed. A study of sample density and phase formation as a function of impurity composition was also performed. 
The sample densities varied from roughly $4.4-5.6 \mathrm{~g} / \mathrm{cm}^{3}$. Predominantly pyrochlore samples were fabricated over a range of atmospheres (air and argon); more reducing conditions favor perovskite formation whereas more oxidizing conditions favor brannerite formation. Nonradioactive ceramic pellets were formed in large quantities ( $\sim 900$ pellets) with good consistency with $93-94 \%$ theoretical density in a prototypic scale sintering furnace in air [Brummond, 1997]. Although preliminary results are promising, further development is needed to quantify the effects of blending, composition, particle size, time, and temperature on the final phase mixtures and the microstructures of the ceramics.

The ceramic process line will be automated using a variety of "pick and place" machines. These machines will be used to count, weigh, measure, and move ceramic pellets from the press to the sintering furnace and from the furnace to the bagless transfer can. Automated equipment will also be used for canister rack loading prior to DWPF glass filling. In-line analyses will be facilitated by pick-and-place equipment. Design, procurement, and testing of the automated systems will occur during detailed design of the process. Off-the-shelf or customized equipment will be capable of handling these tasks.

The ceramic process will be controlled remotely with commercially available control and sensing systems, including thermocouples, actuators, valves, and PID (spell out) furnace power control. This equipment is routinely used in commercial and nuclear industries and is considered very mature.

Repository acceptance requires product control, which in turn requires knowledge of phases, chemistry, and properties of the final immobilization form (see Section 3.3). Qualification of the ceramic process requires that this information be consistently predicted. An approach to product control is being developed but has not yet been completed for the ceramic form; there is a high confidence that an adequate product control strategy can be developed. The maturity of the product control step of this process is low compared to that for glass, due to the potential for glass to apply the HLW glass model for product control.

Canister rack (can array) design must be completed to optimize the competing needs of proliferation resistance [Gray et al., 1997], canister filling [Stein, 1997], and form loading [Kan, 1997]. Preliminary designs described in Section 3 have not been tested to ensure canister filling. The results from the mass/heat flow model suggest that these pours will be successful [Stein, 1997]. However, the model has not yet been adequately validated. In addition, the nonproliferation requirements on can placement have not yet been defined. Because significant development efforts are required for canister rack design and testing, the maturity of this process step is low.

The capability of recycling will be available at selected steps in the ceramic process line. By definition, it is not reasonably possible to recycle the final product. Every attempt will be made to control the processing parameters tightly enough to ensure that once the feed materials are characterized and blended, the final product will meet all appropriate specifications. The preferred recycle point will be before the pellets are sintered. However, the plant will be capable of recycling sintered pellets if necessary (outside of the normal process line). Close tolerance to maintain adequate products and the logistics of recycle have both been demonstrated in the MOX industry. This technology will be designed and tested for the ceramic plant. The technical maturity of this process is high. 


\subsubsection{Glass Maturity}

The baseline glass is a LaBS frit composed of $28.9 \mathrm{wt} \% \mathrm{SiO}_{2}, 11.6 \mathrm{wt} \% \mathrm{~B}_{2} \mathrm{O}_{3}, 21.3 \mathrm{wt} \%$ $\mathrm{Al}_{2} \mathrm{O}_{3}, 2.5 \mathrm{wt} \% \mathrm{SrO}, 6.6 \mathrm{wt} \% \mathrm{HfO}_{2}$, and $29.1 \mathrm{wt} \%(\mathrm{Nd}, \mathrm{La}, \mathrm{Gd})_{2} \mathrm{O}_{3}$ with up to $16 \mathrm{wt} \%(\mathrm{Pu}, \mathrm{U}) \mathrm{O}_{2}$ (see Section 5.2). This frit composition and a similar one with $\mathrm{ZrO}_{2}$ rather than $\mathrm{HfO}_{2}$ containing $29.1 \mathrm{wt} \% \mathrm{SiO}_{2}, 11.7 \mathrm{wt} \% \mathrm{~B}_{2} \mathrm{O}_{3}, 21.5 \mathrm{wt} \% \mathrm{Al}_{2} \mathrm{O}_{3}, 2.5 \mathrm{wt} \% \mathrm{SrO}, 1.3 \mathrm{wt} \% \mathrm{ZrO}_{2}$, and $33.8 \mathrm{wt} \%$ $(\mathrm{Nd}, \mathrm{La}, \mathrm{Gd})_{2} \mathrm{O}_{3}$ have been studied in depth. For clarity in this assessment, the baseline frit will be called " $\mathrm{B}$ " and the previous frit "A." A series of 4-h laboratory-scale melts at $1500^{\circ} \mathrm{C}$ produced homogeneous, thermally stable glasses with up to $10 \mathrm{wt} \%$ plutonium oxide, $12 \mathrm{wt} \%$ uranium oxide, and $21.5 \mathrm{wt} \%$ combined $\left(9.5 \mathrm{wt} \% \mathrm{PuO}_{2}+12 \mathrm{wt} \% \mathrm{UO}_{3}\right)$ using frit $\mathrm{B}$. The time for dissolution of both high- and low-fired $\mathrm{PuO}_{2}$ was determined on a laboratory scale to be $2 \mathrm{~h}$ or less with frit A [Vienna et al., 1996]. Maximum concentrations of expected impurities were soluble in both frit A and B [Meaker et al., 1997; Li et al., 1997; Peeler et al., 1997]. A statistical study of 90 glasses was used to develop an initial glass composition region defined by acceptable $\mathrm{PuO}_{2}$ solubility, thermal stability, and impurity tolerance [Peeler et al., 1997]. This study defined a relatively large composition region of processable glasses, showing process flexibility to frit and feed composition. Composition development is in an advanced stage but is not yet complete; composition optimization for viscosity, liquidus temperature, actinide solubility, and thermal stability is required. This is a highly mature process step.

The baseline process includes attrition milling of $\mathrm{PuO}_{2}$ powder feed with glass frit. The purpose of this step is to reduce the $\mathrm{PuO}_{2}$ particle size to below roughly $20 \mu \mathrm{m}$ in diameter and to blend the feed and frit to aid in melting. This step is the same as that described above for ceramic and is not optimized for the specific process. This is a high maturity process step.

The frit and $\mathrm{PuO}_{2}$ mixture will be loaded into an induction-heated platinum/rhenium melter with a commercially available screw feeder. The screw feeder will transfer volumetric portions of the blended $\mathrm{PuO}_{2} /$ frit feed into the melter plenum system, where it will enter the melter crucible through a water-cooled feed tube. Screw feeders have been used extensively in industry to transport powders with characteristics similar to the $\mathrm{PuO}_{2} /$ frit feed. However, the baseline frit contains the $\mathrm{PuO}_{2}$ as a milled oxide within a milled frit matrix. The frit is expected to be somewhat larger in particle size, based on experience thus far, and is expected to control the transfer characteristics satisfactorily. However, the finer $\mathrm{PuO}_{2}$ may cause some dusting if fed in this form. If dusting control is not adequate with the screw feeder and plenum system design as planned in the baseline, a feed granulation approach (such as the one discussed in the ceramic maturity section) will be used. Satisfactory granulation will likely be achievable but will be limited to identified additives that are compatible with the crucible system.

The feed will be fused into a homogeneous melt using the stirred induction-heated platinum/rhenium melter defined for the base design. Melters similar to this design have been used routinely in the glass industry for the melting of custom high-temperature glasses [Rathmann, 1997; Schumacher, 1997]. One such melter at Corning Glass has demonstrated hightemperature operation for several years with regular thermal cycling [Hardy, 1997]. This melter was used to demonstrate the processing of frit $\mathrm{A}$ with a $\mathrm{HfO}_{2}$ surrogate equivalent to $8 \mathrm{wt} \%$ and $10 \mathrm{wt} \% \mathrm{PuO}_{2}$, and good melt homogeneity and composition control were achieved in this melter test [Marshal et al., 1997]. The proposed modifications to this melter for $\mathrm{PuO}_{2}$ include a plenum designed to accommodate the screw feeder, a water-cooled transfer tube, and off-gas systems as necessary. Additional modifications are required to the stirrer drive system for incorporation into 
the plenum system. Design modifications of the overall melter system may also be needed to ensure operability and maintainability in a glovebox environment and to incorporate safety systems to guard against the possibility of plutonium release or criticality for possible failure scenarios.

A preliminary design has been completed for many of these modifications [Couglin et al., 1997]. Construction and testing of this melter system with the baseline glass and hafnium (as a surrogate for plutonium) are planned in the near future. An integrated melter system must be then installed and demonstrated in a glovebox environment with representative plutonium feed streams to assess the operability of all systems (feeding, melting, stirring, pouring) and the adequacy of insulation, airflow, operability, and maintainability. There is a good confidence that the necessary modifications and testing can be accomplished and that this melter will perform adequately in the glovebox environment for the plutonium immobilization mission, assuming the appropriate engineering and testing is completed.

Current experience with plutonium dissolution in the baseline frit has been limited to a large number of small-scale platinum crucible tests and two initial runs in the LLNL tilt-pour induction melter. The tilt-pour induction melter was used to melt $225-\mathrm{g}$ quantities of $\mathrm{PuO}_{2}$ in $2.5 \mathrm{~kg}$ of LaBS frit A glass [Riley, 1997]. These tests demonstrated a step in the scaleup from the crucible experiments. The crucible experiments demonstrated $11.4 \mathrm{wt} \% \mathrm{PuO}_{2}(10 \mathrm{wt} \%$ plutonium) dissolved in frit $\mathrm{A}$ in less than $2 \mathrm{~h}$ [Vienna et al., 1996]. The tilt-pour furnace melts, which used: finely milled $\mathrm{PuO}_{2}(<5 \mu \mathrm{m})$ and no stirring, achieved dissolution at 9.1 and $11.4 \mathrm{wt} \% \mathrm{PuO}_{2}$ (8 and $10 \mathrm{wt} \%$ plutonium respectively), although additional evaluation is still required. Scaleup and demonstration of the baseline design case of $15 \mathrm{~kg}$ glass with $10 \mathrm{wt} \% \mathrm{PuO}_{2}$ (with $8.8 \mathrm{wt} \%$ plutonium) remain to be done.

The lifetime of the platinum/rhenium crucible is important in determining furnace maintenance cycles and potential melter failures during production operations. A preliminary corrosion effects study has been completed [Sundaram et al., 1997]. In this test, static and electrochemical corrosion rates of ZGS platinum melter construction material were evaluated under isothermal conditions but with temperature cycling to match expected crucible temperature cycles. In these tests, a "worse case" LaBS glass simulant was used. This study indicated that, given a crucible thickness of $2.29 \mathrm{~mm}$ and uniform corrosion, the static dissolution rate of $1.6 \mathrm{~mm} / \mathrm{y}$ for the melter construction material would allow for a potential lifetime of roughly $1.3 \mathrm{y}$ with impure feed materials, so long as other corrosion mechanisms do not cause earlier failure. Additional testing and evaluation is strongly advised for other melter environments and operating conditions, including the impact of temperature gradients and hot spots.

The projections of successful melter operation are good based on the Corning tests and the glass industry experience. However, substantial engineering and testing remains for adaptation of this melter technology to plutonium glovebox production operations.

The glass process line will be automated using a screw, an automated pipe cutter, and pickand-place machines. These machines will be used to feed the melter, transfer the product cans out. of the melter cooling station and into the examination station, trim the poured glass can, and load the bagless transfer can. All subsequent operations involving the handling, storage, and transfer of the canned glass product will require automated or remote handling due to the relatively high neutron dose rate from the glass form (see Section 6.5). Automated equipment will also be used for canister rack loading prior to DWPF glass filling. Design, procurement, and testing of the 
automated systems will occur during detailed design of the process. Off-the-shelf or customized equipment should be capable of handling the tasks.

The glass process will be controlled remotely with standard commercially available control and sensing systems, including thermocouples, actuators, valves, optical pyrometers, and induction power control. This equipment is routinely used in commercial and nuclear industries and is considered very mature.

A product control scheme for HLW glass has been developed and implemented at the DWPF and West Valley HLW glass plants [Marra et al., 1995; Jantzen and Brown, 1993; Palmer, 1994]. These control systems rely on composition measurements and controls of melter operating conditions and melter feed to ensure a final product with known properties. Product properties are determined from models based on the continuity of glass properties with changing composition [Volf, 1988]. The models currently available to ensure process control and product acceptability have been developed and demonstrated on operating HLW glass plants; these models will have to be further developed and validated for the LaBS glass. The maturity of the HLW glass pouring process is rated medium (see Section 6.4.1.1).

A recycling capability will be available at selected steps in the glass process line. By definition, it is not reasonably possible to recycle the final canister after the HLW glass pour. It also would not be desirable to recycle the LaBS glass containing plutonium from the mold after the melter pour and, barring catastrophic failure, such recycle is unlikely to be required. Every attempt will be made to control the processing parameters tightly enough to ensure that once the feed materials are characterized and blended, the final product will meet all appropriate specifications. The preferred recycle point will be at the stage of $\mathrm{PuO}_{2}$ feed and frit blending in the attrition mill. This assumption of little or no recycle of the poured LaBS glass is based on the experience in HLW glass plants in the U.S. and Europe, where glass recycle is assumed to be zero after the melting stage. Off-specification melter feed is identified before melting. Melter feed is treated to ensure that the final glass is in compliance with product specifications, effectively eliminating post-melt recycle. However, the plant will be capable of recycling glass cans if necessary (outside of the normal process line). The technology will be designed and tested for the glass plant. Due to the small number of cans likely involved, this process operation is felt to have a reasonable degree of viability and is not a significant concern.

\subsubsection{Technical Maturity Comparison}

Ceramic and glass technologies are of similar overall technical maturity for plutonium immobilization (assuming the can-in-canister radiation barrier system). Both forms are sufficiently mature that eventual plant implementation can be expected to be successful. However, several of the individual process steps for both technologies differ significantly in maturity. A comparison of process steps for each form reveals finer detail to enable direct comparison of the two forms (see Table 6.4.1). A majority of process steps were rated high maturity by the TEP; exceptions are discussed below. It is difficult to fully understand the factors behind these differences without reference to the technology discussions. Conclusions should not be drawn by simply using the summary categorizations in Table 6.4.1.

Both the glass and ceramic forms require data that relate the resulting product from the immobilization operation for the variations in feed streams and processing conditions to the parameters of concern for projecting repository performance. In the case of glass, the product 
control strategy depends on the adaptation of the HLW process control model defining the operating regions for feed and process conditions that will result in an acceptable glass product as formed. In the case of ceramic, the product control strategy requires the development of a similar set of data and operating conditions defining the impacts of various feed compositions and processing parameters on the formation of the mix of mineral phases in the ceramic product which, in turn, can be related to the repository acceptance parameters (which have yet to be defined for both immobilization forms).

The generation of this data has begun for both glass and ceramic and must be completed so that appropriate specifications can be placed on the feed materials and process operations. To the extent that the baseline assumptions of a homogeneous glass form are achieved and remain that way during the DWPF heating cycle, it should be possible to use the process model and approach currently used for HLW glass for the plutonium immobilization glass form, provided the necessary data are obtained. No similar model exists currently for the ceramic form. For the glass form where precipitation of $\mathrm{PuO}_{2}$ occurs (an identified variant to the baseline process), additional data necessary to develop such a model are needed.

It is worth noting that the current HLW glass waste acceptance program allows for a limited degree of devitrification of the product. These low levels of devitrification have been proven not to degrade product properties for the DWPF glass, and similar data for the LaBS glass indicate that this might also apply to the glass system under consideration (see Section 7.0). There is a high degree of confidence that an acceptable model and product control strategy will result with little risk for both ccramic and precipitated $\mathrm{PuO}_{2}$ glass, based on the leach rate data reported in Section 6.4.3 and the identified glass phases (glass form) and mineral phases (ceramic form) that have been formed with widely varying plutonium feed streams.

The melting step in the glass process operation requires the adaptation of the Corning melter design into a properly engineered melter for operation in a plutonium glovebox environment that meets the requirements for processing, maintainability, accountability, and nuclear safety. Successful glass melting with surrogate materials has been demonstrated on the melter system at Corning, and this melter design forms the basis for the current plutonium melter approach. Modifications must be made to this melter as discussed above. Based on the experience of the glass industry with melters of similar designs and on preliminary tests with surrogates, there is good confidence that a successful melter system for plutonium immobilization can be developed and operated.

The HLW glass pouring step is of medium maturity for both ceramic and glass processes. To evaluate the HLW-glass-filling capacity of the canister designs, a mass and heat transport model has been developed. This model has not yet been validated with obstructed-canister-filling data. Additional modeling and model validation are required to optimize canister design. In addition, there are a number of implementation approaches and engineering design tradeoffs that must be evaluated. The higher plutonium loading per unit volume of the ceramic waste form may be of advantage in these engineering tradeoffs due to the smaller volume of DWPF glass that will be displaced. Requirements for the nonproliferation implications associated with canister pouring are poorly defined at this time.

Technical maturity of automation is rated medium for both ceramic and glass processes. The automation technology that can be applied to either glass or ceramic handling is relatively mature 
and there is little risk of failure, although system designs have not yet been initiated to permit a more detailed comparison and evaluation.

\subsubsection{Viability Risk}

Risks are associated with advancing the program from where it is today through plant operation to RD\&T and closeout. Most of the programmatic risks are independent of the immobilization form, and their assessment is beyond the scope of this document. Therefore, this evaluation focuses only on those program risks associated with the individual process steps discussed above (Section 6.4.1).

- Form Compositions. Ceramic and glass formulations are in advanced stages of development. The baseline ceramic composition has successfully demonstrated tolerance to impurities, atmosphere, temperature, and heat treatment while maintaining adequate properties. The baseline glass composition has successfully demonstrated tolerance to impurities, heat treatment, and $\mathrm{PuO}_{2}$ and $\mathrm{UO}_{2}$ loading while maintaining adequate properties. Further development work is required for both formulations, but there is low risk of failure.

- Mixing and Grinding. Mixing and grinding will be performed with a commercially available high-speed attrition mill. This equipment has been implemented in currently operating MOX plants at the scale required for the Plutonium Immobilization Program. A successful demonstration of this equipment on surrogate ceramic feed showed promising results [Brummond, 1997]. Risks are low for both ceramic and glass in this process step.

- Granulation and Material Feed. Ceramic feed material will be granulated with a commercially available spherodiser. This equipment has also been implemented in currently operating MOX and ceramic plants at the appropriate scale [Brummond, 1997]. There is a high degree of confidence that the spherodiser will be adequate with minor optimization for implementation. In addition, several backup technologies exist for the spherodiser (e.g., Vblenders). Glass feed will be fed directly to the melter without granulation. If dust control becomes a problem, a granulator can be added to the process line. This process step is low risk.

- Pressing. Ceramic material will be fed into a commercially available double-piston hydraulic press. A full-scale press has been successfully demonstrated with surrogate ceramic feed. Hydraulic presses are extensively used in the ceramic industry and are likely to be adequate for this program. This step is a low program risk.

- Sintering. Sintering of ceramics will be performed in a commercially available resistanceheated furnace with an argon atmosphere. Atmosphere-controlled furnaces capable of meeting the temperature and rate requirements for this process are readily available and used regularly in the ceramics industry. Furnace selection and modification for glovebox operation and remote handling are details dependent on the overall plant design. There is low risk in this process step.

- Melting. Glass will be fused in an induction-heated platinum/rhenium melter. Similar melters are used in the glass industry for applications with high-temperature glasses that are stirred. Engineering adaptation, development, and testing are required to adapt the glass furnace to plutonium glovebox operation and to verify operability and maintainability. Further work is also required to fully understand potential furnace failure modes and to complete the corrosion evaluation under the full range of conditions expected for furnace operation. 
Although preliminary corrosion test results are positive, melter failure modes are not fully understood nor are the effects of all combinations of impurities and redox on melter corrosion. This is a medium-risk process because, although there is a good deal of confidence an adequate system can be developed, this application of a melter system has never been demonstrated.

- Process Automation. Process automation is required for achieving ALARA (as low as reasonably achievable) radiation doses, product quality control, and cost effectiveness. A high degree of sophistication exists in commercially available automation equipment. The ceramic process will use automated equipment to lift, weigh, measure, assay, and move ceramic pucks. The glass process will require a screw feeder, an automated pipe cutter, and a pickand-place transfer system. Both forms will require automated analysis, assay, and canister loading and welding equipment. Design, installation, and testing of these systems will be required before implementation. The risk associated with implementation of automation for either form is considered low.

- Process Control. Process control systems for both technologies are similar to those widely used in a variety of industries including nuclear applications. This equipment is commercially available, can be used with little adaptation for this program, and poses little risk given an adequate testing and shakedown program.

- Product Control. Product control for both ceramic and glass involves careful control of feed chemistry and process parameters. Statistical sampling of intermediate products will be required to ensure that control is maintained during all process steps. The HLW glass industry has developed and is using a product control strategy that is applicable to but will require additional model development and validation for plutonium immobilization in the LaBS glass baseline case. The HLW glass control system is based on continuous properties of the glass form as a function of glass composition and the homogeneity of glass. If the glass variant involving higher plutonium loading is considered, the resulting glass product is no longer uniform and the value of the application of the HLW glass model is likely not straightforward.

Product control for the ceramic waste form will need to relate the effects of changing composition and processing parameters on the phase assemblages and component partitioning in the ceramic product. It will also be necessary to develop and test systems to identify material properties that signal off-specification products. It is not likely that the HLW glass model is directly applicable for this process, and an alternate product control strategy will have to be developed. However, many of the elements and concepts from the glass model may be useful in developing the ceramic strategy. The need to develop the required data for product control of the ceramic form is a medium risk compared to glass, since the homogeneous glass baseline can likely utilize the HLW glass model (provided the necessary data are obtained). It should be noted that there is substantial work required in the development and characterization of both waste forms outside of the application of the HLW glass control model. Preliminary data for both forms in terms of preliminary dissolution and leach rate measurements (Section 6.4.3) indicate that successful control is likely to be achieved within the time scale necessary to build and bring the immobilization plant into operation.

- Canister Filling. HLW glass will be poured into the canister loaded with racks of cans containing the immobilization form. It is assumed that the DWPF melter will pour this glass 
(Section 3.1.2). The HLW melter design, canister design, and glass properties will be fixed by the choice of immobilization site. Therefore, only the canister rack design and can size will be adjusted to ensure proper glass filling (unless other proliferation-resistance measures are employed). Canister rack designs will be developed to optimize canister filling, form volume, proliferation resistance, and repository acceptance. Data and models to assess canister filling are not yet adequate to provide high confidence in the ability to predict canister filling [Stein, 1997]. Nonproliferation requirements have not yet been defined (Sections 6.2, 6.3), and repository acceptance criteria are likewise incompletely defined and subject to change (Section 6.4.3). If the canister filling fails, there are no obvious means to recycle the material to an acceptable product.

It is worth noting that the achievement of higher plutonium loading per unit volume is of benefit in performing the engineering tradeoffs in this area since less DWPF glass will be displaced for a given canister loading. Both glass and ceramic can increase their respective loading as indicated in the variant definitions (Section 7.0). However for higher glass loading, a new product control model would have to be developed. This process stage is considered by the TEP to be a medium program risk for both glass and ceramic since it heavily depends on the drivers of environmental management programs.

The DOE/EM mission will determine the canister filling schedule and will control the DWPF to optimize for tank waste remediation priorities and funding. The FMDP will require and to a large extent receive full cooperation from DOE/EM. Some possible interaction difficulties include melter operation life, canister pouring schedule, and radiation availability. As the engineering tradeoffs are undertaken, one of the variables will be canisters affected. This issue will have to be worked with DOE/EM.

- Recycling. Intermediate products that fail to meet specifications will be recycled through the process line. The final (can in canister) product does not easily lend itself to recycle (by design). Every attempt will be made to control the processing parameters tightly enough to ensure that, once the feed materials are characterized and blended, the final product will meet all appropriate specifications. The preferred recycle stage is before the material is heat-treated (sintered or melted). In the case of failed equipment or unforeseen process upsets, off-line equipment will be needed to recycle post-heat-treated parts. Only preliminary consideration has been given to this issue and it is felt to have a low impact on the overall viability of either process. Recycle is considered to be a low risk issue for both glass and ceramic.

Table 6.4.2 summarizes the risks involved with individual process steps for the ceramic and glass technologies. Slight differences are evident in the risk associated with the two forms. The ceramic technology's defined data requirement for the development of a product control model has a rating of medium, differentiating it from the glass product control maturity afforded by the HLW glass model. The glass technology has an engineering development cost and schedule risk of medium in the area of glass melter development and testing, discriminating it from the corresponding ceramic process steps of pressing and sintering which are low risk. 
Table 6.4.1. Summary of technical maturity by process step for glass (G) and ceramic (C) forms.

\begin{tabular}{|c|c|c|c|c|c|c|c|c|}
\hline \multirow[t]{2}{*}{ Process step } & \multicolumn{2}{|c|}{ TEP assessment } & \multicolumn{2}{|c|}{$\begin{array}{c}\text { Confidence in } \\
\text { data/information }\end{array}$} & \multicolumn{2}{|c|}{$\begin{array}{l}\text { Clarity of the } \\
\text { metric }\end{array}$} & \multicolumn{2}{|c|}{$\begin{array}{l}\text { Assessment of } \\
\text { overall impact }\end{array}$} \\
\hline & Ceramic & Glass & Ceramic & Glass & Ceramic & Glass & Ceramic & Glass \\
\hline Formulation $(\mathrm{G}, \mathrm{C})$ & $\mathrm{H}$ & $\mathrm{H}$ & $\mathrm{H}$ & $\mathrm{H}$ & M & $\mathrm{M}$ & $\mathrm{H}$ & $\mathrm{H}$ \\
\hline Grinding $(G, C)$ & $\mathrm{H}$ & $\mathrm{H}$ & $\mathrm{H}$ & $\mathrm{H}$ & M & $M$ & $\mathrm{~L}$ & L \\
\hline Blending $(\mathrm{G}, \mathrm{C})$ & $\mathrm{H}$ & $\mathrm{H}$ & $\mathrm{H}$ & $\mathrm{H}$ & M & M & $\mathrm{H}$ & L \\
\hline Granulation (C) & $\mathrm{H}$ & N/A & $\mathrm{H}$ & N/A & $\mathrm{M}$ & N/A & L & $\mathrm{N} / \mathrm{A}$ \\
\hline Pressing (C) & $\mathrm{H}$ & $\mathrm{N} / \mathrm{A}$ & $\mathrm{H}$ & $\mathrm{N} / \mathrm{A}$ & M & N/A & $\mathrm{H}$ & N/A \\
\hline Sintering (C) & $\mathrm{H}$ & N/A & $\mathrm{H}$ & N/A & M & N/A & $\mathrm{H}$ & N/A \\
\hline Melting (G) & N/A & M & N/A & $\mathrm{H}$ & $\mathrm{N} / \mathrm{A}$ & $\mathrm{M}$ & $\mathrm{N} / \mathrm{A}$ & $\mathrm{H}$ \\
\hline Automation $(\mathrm{G}, \mathrm{C})$ & $\mathrm{M}$ & M & L & L & $\mathrm{M}$ & M & M & M \\
\hline Process control $(\mathrm{G}, \mathrm{C})$ & $\mathrm{H}$ & $\mathrm{H}$ & $\mathrm{H}$ & $\mathrm{H}$ & M & M & $\mathrm{H}$ & $\mathrm{H}$ \\
\hline Product control $(\mathrm{G}, \mathrm{C})$ & $\mathrm{L}$ & M & M & $\mathrm{H}$ & $\mathrm{L}$ & $\mathrm{L}$ & $\mathrm{H}$ & $\mathrm{H}$ \\
\hline HLW glass pour $(G, C)$ & M & M & $\mathrm{L}$ & $\mathrm{L}$ & $\mathrm{M}$ & $\mathrm{M}$ & $\mathrm{H}$ & $\mathrm{H}$ \\
\hline Product recycle $(\mathrm{G}, \mathrm{C})$ & $\mathrm{H}$ & $\mathrm{H}$ & $\mathrm{L}$ & $\mathrm{L}$ & $\mathrm{L}$ & $\mathrm{L}$ & $\mathrm{L}$ & $\mathrm{L}$ \\
\hline
\end{tabular}

$\mathrm{H}=$ high; $\mathrm{M}=$ medium $\mathrm{L}=$ low $\mathrm{N} / \mathrm{A}=$ not applicable

\subsubsection{Repository Acceptability of the Disposal Form}

It is assumed for the purposes of this evaluation that the geologic repository for the U.S. is located at Yucca Mountain (Section 3.3). Therefore, the immobilization form must be compatible with that area's groundwater chemistry and geologic strata to be acceptable to the Civilian Radioactive Waste Management System (CRWMS). At present, there is no directly applicable guidance for the plutonium immobilization form. Therefore, TEP assumed that the requirements for HLW glass provide the basis for the minimum requirements. Because plutonium immobilization presents new issues related to criticality safety that are not of concern for the disposal of HLW, it is possible that additional requirements or specifications will be imposed.

There are several requirements that apply to waste forms and that both immobilization forms meet, even in their current state of development (e.g., no free water, no combustible material). In fact, earlier studies [TRW, 1997; CRWMS, 1996] have shown that the intact as-fabricated waste forms have properties well within the Nuclear Regulatory Commission's requirements for criticality control and other controls, as indicated in 10 CFR 60, Disposal of High-Level Radioactive Wastes in Geologic Repositories. Therefore, for either plutonium immobilization form, only the degraded form need be considered with respect to criticality. In addition, because the total radionuclide inventory of the immobilized material is small with respect to the total projected inventory of the repository, the release of the other components in the immobilization form is not expected to affect the results of the total system performance assessment in which release to the accessible environment was determined [CRWMS, 1995]. 
Table 6.4.2. Summary of technical risk by process step for glass $(G)$ and ceramic $(C)$ forms.

\begin{tabular}{|c|c|c|c|c|c|c|c|c|}
\hline \multirow[t]{2}{*}{ Process } & \multicolumn{2}{|c|}{ TEP assessment } & \multicolumn{2}{|c|}{ Process summary (key points) } & \multicolumn{2}{|c|}{ Required development } & \multicolumn{2}{|c|}{ Backup technology } \\
\hline & Ceramic & Glass & Ceramic & Glass & Ceramic & Glass & Ceramic & Glass \\
\hline $\begin{array}{l}\text { Formulation } \\
(\mathrm{G}, \mathrm{C})\end{array}$ & $\mathbf{L}$ & $\mathbf{L}$ & Pyrochlore/rutile & LaBS frit B & Optimize & Optimize & $\begin{array}{l}\text { Other SYNROC } \\
\text { blends }\end{array}$ & $\begin{array}{l}\text { Other glass } \\
\text { compositions }\end{array}$ \\
\hline Grinding $(G, C)$ & $\mathbf{L}$ & $\mathrm{L}$ & Attritor & Attritor & Optimize & Optimize & Jet mill & Jet mill \\
\hline Blending $(G, C)$ & $\mathrm{L}$ & $\mathbf{L}$ & Attritor & Altritor & Optimize & Optimize & V-blender & V-blender \\
\hline Granulation (C) & $\mathbf{L}$ & $\mathbf{L}$ & Spherodiser & none & Optimize & Demonstrate & V-blender & Spherodiser \\
\hline Pressing (C) & $\mathrm{L}$ & N/A & Hydraulic & N/A & Hot demo & N/A & None & N/A \\
\hline Sintering (C) & $\mathrm{L}$ & N/A & Argon furnace & N/A & $\begin{array}{l}\text { Select, optimize, } \\
\text { demonstrate }\end{array}$ & N/A & Tunnel kiln & N/A \\
\hline Melting (G) & N/A & $\mathbf{M}$ & N/A & Platinum induction & N/A & Modify, test & N/A & Altemative design \\
\hline $\begin{array}{l}\text { Automation } \\
(\mathrm{G}, \mathrm{C})\end{array}$ & $\mathrm{L}$ & L & Pick/place & $\begin{array}{l}\text { Screw, pick/place, } \\
\text { cutter }\end{array}$ & Design, test & Design, test & $\begin{array}{c}\text { Alternative } \\
\text { design, worker }\end{array}$ & Alternative design \\
\hline $\begin{array}{l}\text { Process control } \\
(G, C)\end{array}$ & $\mathrm{L}$ & $\mathrm{L}$ & $\begin{array}{c}\mathrm{T} / \mathrm{C} \text {, actuators, } \\
\text { valves, etc. }\end{array}$ & $\begin{array}{l}\mathrm{T} / \mathrm{C} \text {, actuators, } \\
\text { valves, etc. }\end{array}$ & Design, test & Design, test & Alternative design & Alternative design \\
\hline $\begin{array}{l}\text { Product control } \\
(\mathrm{G}, \mathrm{C})\end{array}$ & $\mathbf{M}$ & $\mathrm{L}$ & $\begin{array}{l}\text { Composition and } \\
\text { parameter control }\end{array}$ & $\begin{array}{l}\text { Composition } \\
\text { control, continuous } \\
\text { properties models }\end{array}$ & Develop, test & Modify, test & $\begin{array}{c}\text { Further } \\
\text { development }\end{array}$ & Development \\
\hline $\begin{array}{l}\text { HI.W glass pour } \\
(G, C)\end{array}$ & $\mathbf{M}$ & $\mathbf{M}$ & $\begin{array}{c}\text { Baseline canister } \\
\text { design }\end{array}$ & $\begin{array}{c}\text { Baseline canister } \\
\text { design }\end{array}$ & $\begin{array}{c}\text { Generate data, } \\
\text { optimize model, } \\
\text { determine criteria }\end{array}$ & $\begin{array}{l}\text { Generate data, } \\
\text { optimize model, } \\
\text { determine criteria }\end{array}$ & Alternative design & Alternative design \\
\hline $\begin{array}{l}\text { Product recycle } \\
(\mathrm{G}, \mathrm{C})\end{array}$ & $\mathbf{L}$ & $\mathrm{L}$ & $\begin{array}{l}\text { Adjust at attritor, } \\
\text { off-line crusher }\end{array}$ & $\begin{array}{c}\text { Adjust at attritor, } \\
\text { off-line crusher }\end{array}$ & Demo & Demo & In-line equipment & In-line equipment \\
\hline
\end{tabular}

$\mathrm{H}=$ high, $\mathrm{M}=$ medium, $\mathrm{L}=$ low; $\mathrm{N} / \mathrm{A}=$ not applicable. 


\subsubsection{Degraded Form Criticality Considerations}

Regarding criticality, there are two important considerations. First, so long as the immobilized material remains undegraded, there are no issues related to criticality due to the overabundance of neutron absorber in the waste forms. The magnitude of the dissolution or reaction rate of the forms with groundwater in the repository is the key factor controlling how long the forms will remain in an undegraded state.

Second, as the forms degrade, the fissile elements (uranium, plutonium) and the neutron absorbers (hafnium, gadolinium) will be released from the waste package, potentially at different rates. The relative release rates of the elements will be governed by the kinetics by which the immobilization form degrades in response to the chemical conditions within the waste package and the chemical characteristics of the elements in question. Elemental release rates from the waste package may be controlled by the solubility of alteration phases or by the reaction rate of the form, depending on the solubility of the element in question and the propensity of the element to form or adsorb to colloidal particles.

In a preliminary assessment by TRW [1997] of the degraded mode criticality of the contents of a waste package, three configurations were considered:

- Insoluble waste form alteration products precipitated at the bottom of the waste package in a clayey mass in a cylindrical geometry.

- Plutonium and uranium precipitated on metal surfaces.

- Plutonium and uranium trapped in the material directly below the waste package.

The study focused primarily on the first configuration. The findings were that either form would not result in a criticality if the ceramic contained less than $100 \mathrm{~kg}$ plutonium or the glass less than $50 \mathrm{~kg}$ plutonium per waste package (four DWPF canisters per waste package). The analysis leading to this conclusion was performed for a ceramic with hafnium equal to about $2 \%$ of the zirconium ( $\mathrm{Zr}=13.7 \%$ of the solid; $\mathrm{Hf}=0.3 \%$ of the solid $)$ and no hafnium in the glass. However, in the current baseline flowsheets, both forms incorporate substantial amounts of hafnium. It is also possible to place only one DWPF canister containing the plutonium immobilization form in randomly located waste packages in order to further distribute the immobilized plutonium. Thus, within the context provided by the preliminary repository assessment of degraded-mode waste-package criticality, it appears that both immobilization materials would be acceptable to the repository from the standpoint of criticality within the waste package and the invert immediately below the degraded waste package. There is also concern about the far-field criticality for both immobilization forms. (Far-field criticality can be mitigated through the use of depleted uranium, a topic to be covered in a future TRW report.) The results from the CRWMS Total System Performance Assessment [1995] suggest that for the HLW glass, the radionuclide release is not a major issue for the far-field dose to man. Because the important radionuclide releases from the repository are ${ }^{99} \mathrm{Tc},{ }^{237} \mathrm{~Np},{ }^{129} \mathrm{I}$, and ${ }^{14} \mathrm{C}$ and the inventory of plutonium in the spent nuclear fuel in the repository is far in excess of the plutonium inventory that is in the immobilization form, release of plutonium to the accessible environment from the immobilization form is insignificant. Note that this conclusion is based on performance assessments that did not consider the possibility of colloidal transport of radioactive species. If further study shows that colloidal transport to the accessible environment is possible, this conclusion may change. Therefore, the remaining discussion of the 
immobilization forms with respect to repository issues is focused on the differences in form behavior that enhance criticality safety.

Dissolution Rate. In the degraded-mode assessment of the plutonium immobilization forms, dissolution of the forms, followed by sorption and/or precipitation of fissile elements and neutron absorbers in the invert or waste package was the primary means for achieving criticality [TRW, 1997]; TRW used bounding values for their analysis (see Table 6.4.3.1).

Table 6.4.3.2. Maximum and minimum dissolution rates used by TRW.*

\begin{tabular}{|c|c|c|}
\hline Material & $\begin{array}{c}\operatorname{Maximum} \\
\mathrm{g} /\left(\mathrm{m}^{2}-\mathrm{d}\right)\end{array}$ & $\begin{array}{c}\text { Minimum, } \\
\mathrm{g} /\left(\mathrm{m}^{2}-\mathrm{d}\right)\end{array}$ \\
\hline DHLW glass & $3.7 \times 10^{-3}$ (at $\left.66^{\circ} \mathrm{C}\right)$ & $1.5 \times 10^{-4}\left(\right.$ at $\left.26^{\circ} \mathrm{C}\right)$ \\
\hline ATS glass $^{\dagger}$ & $1.3 \times 10^{-3}$ & $8 \times 10^{-6}$ \\
\hline Ceramic (SYNROC-C) & $10^{-4}$ & $10^{-7}$ \\
\hline
\end{tabular}

Dissolution rates of the candidate immobilization forms have been measured on preliminary materials. Static and open-system (flow) tests have been performed on these materials and were presented to the TEP. These tests, performed at ANL, ANSTO, LLNL, PNNL, and SRTC, consisted of static tests [MCC-1 and product consistency test (PCT)] and open-system tests [single-pass flowthrough (SPFT) and pressurized unsaturated flow (PUF)].

The MCC-1 test [ASTM, 1992] is a static test in which a monolithic specimen with a surface area on the order of $10^{-4} \mathrm{~m}^{2}$ is placed in a solution with a volume consistent with a surface-tovolume ratio (S/V) of $10 \mathrm{~m}^{-1}$ (e.g., $4 \times 10^{-4} \mathrm{~m}^{2}$ for the solid test specimen and $40 \mathrm{ml}$ of the test leachant). The test is performed at $90^{\circ} \mathrm{C}$. The MCC-1 test was developed to measure the earlytime dissolution rate of materials and to compare the rates from various waste forms, including glasses and ceramics.

The PCT is also a static test [ASTM, 1994] in which a crushed specimen is placed in an aqueous solution without any stirring. In version $\mathrm{A}$ of the $\mathrm{PCT}$, the $\mathrm{S} / \mathrm{V}$ is $2000 \mathrm{~m}^{-1}$, the solution is demineralized water, and the temperature is $90^{\circ} \mathrm{C}$. In version $\mathrm{B}$, the test may be performed at any $\mathrm{S} / \mathrm{V}$ achievable with any specified aqueous solution and at any specified temperature. These two tests have been certified by the ASTM and have the ASTM designations C-1220-92 and C1285-94, respectively [ASTM, 1992, 1994].

There are two variations of the SPFT [McGrail, 1995; Bourcier, 1997] that are similar and yield essentially equivalent results. In these tests, a crushed specimen is in contact with a flowing aqueous stream. The flow rate is adjusted so that the measured dissolution rate is independent of the flow rate. Usually the dissolution rate of the material increases with increasing flow up to some limiting value. At this flow rate, the forward dissolution rate of the material is obtained at the temperature and $\mathrm{pH}$ of the solution. By measuring the dissolution rate at a number of $\mathrm{pH}$ 
values and temperatures, the intrinsic dissolution rate is determined. The intrinsic dissolution ratc depends only on the composition of the material.

A new test that has been used on these plutonium immobilization forms is the PUF test, which is under development at PNNL. In this test, the aqueous solution is passed through a crushed specimen such that the pore space is not completely filled with solution (i.e., the specimen is hydraulically unsaturated). It is anticipated that the information from this test will be more directly applicable to the unsaturated conditions at Yucca Mountain. Changes in effluent solution chemistry and hydraulic conductivity occur during the test. These changes are thought to be related to precipitation events during which secondary alteration products begin to form in the test column. The PUF test also offers the ability to conduct integrated tests in which DWPF glass (or other waste package component) is tested in combination with the immobilized form.

The TEP was very interested in the results from this test. However, because the test is approximately one year under development and there are only results from a few tests with single materials and from only two tests with combinations of DWPF glass and plutonium immobilized forms, the TEP decided to place emphasis on the results from the older and more traditional tests. However, the TEP felt that the use of the PUF test may reveal important interactive effects between different components of the waste package, as is noted later in this section.

Comparison of Ceramic and Glass Dissolution Rates. Results from the dissolution tests are typically reported in units of $\mathrm{g} / \mathrm{m}^{2}$ and $\mathrm{g} /\left(\mathrm{m}^{2}-\mathrm{d}\right)$ for elemental mass loss and dissolution rate, respectively. These terms are normalized to the amount of element in the material and to the surface area of the material in the test. These values are calculated from the following equations:

$$
\begin{aligned}
& N L_{i}=\frac{C_{i}-C_{i}^{\circ}}{\frac{S}{V} \cdot f_{i}}, \\
& N R_{i}=\frac{\left(C_{i}-C_{i}^{\circ}\right) F}{S \cdot f_{i}},
\end{aligned}
$$

where $N L_{i}=$ normalized elemental mass loss for element $\mathrm{i}$ (in $\mathrm{g} / \mathrm{m}^{2}$ ), $N R_{i}=$ normalized elemental rate for element $\mathrm{i}$ (in $\left.\mathrm{g} /\left(\mathrm{m}^{2}-\mathrm{d}\right)\right), C_{i}=$ concentration of element $\mathrm{i}$ in the leachate $\left(\mathrm{g} / \mathrm{m}^{3}\right)$, $C_{i}^{0}=$ concentration of element $\mathrm{i}$ in the leachant and or blank $\left(\mathrm{g} / \mathrm{m}^{3}\right), S=$ solid surface area $\left(\mathrm{m}^{3}\right)$, $V=$ solution volume $\left(\mathrm{m}^{3}\right), F=$ flow rate $\left(\mathrm{m}^{3} / \mathrm{d}\right)$, and $f_{i}=$ fraction of element $i$ in the solid.

The dissolution behavior of the neutron absorbers (gadolinium and hafnium) and the plutonium is important. Both the absolute magnitude and the relative release rates of the neutron absorbers and fissile element are relevant to whether the contents of a degraded waste package will ever reach a critical configuration. The experimentally determined releases of all these elements are very low for both the ceramic and glass; the releases from ceramic are consistently lower than those from glass, regardless of the type of test. The magnitude of the difference in release rate does vary from element to element and from one test type to another.

Insofar as the other constituents of the materials indicate the behavior of the matrix of the immobilization form, information on the release of other elements serves a useful purpose. For instance, information on the behavior of boron from the LaBS glass is useful valuable because the 
solubility of even the least-soluble solid phases containing boron is so high that none precipitates during dissolution experiments. A similar element for the ceramic does not appear to be available. All of the elemental constituents of the ceramic appear to be at or near their solubility limits in the static leaching tests. For example, anatase $\left(\mathrm{TiO}_{2}\right)$ has been found for the titanium in the ceramic, as has calcite $\left(\mathrm{CaCO}_{3}\right)$ for calcium [Bakel and Buck, 1997].

The dissolution mechanism for ceramic has not been established. It is expected that the dissolution reaction will either be surface-controlled, as in the case of glass dissolution, or diffusion-controlled. Diffusion-controlled reaction rates will always be less than or equal to a surface-controlled rate. Maximum dissolution rates of the ceramic phases can be measured with the SPFT tests described above.

By contrast, the mechanism by which silicate glasses dissolve is very well studied. There is general agreement by those studying nuclear waste glasses that the mechanism of glass dissolution is one of congruent dissolution, followed by precipitation of mineral phases as the leachant becomes saturated with respect to those phases. It is also generally agreed that the ratelimiting step in the dissolution mechanism involves only silicic acid $\left(\mathrm{H}_{4} \mathrm{SiO}_{4}\right)$. The rate equation is given by McGrail [1997] as:

$$
R_{i}=v_{i} \times a_{H^{+}}^{-\eta(T)} \times k_{0} \times \exp \left(\frac{E_{a}}{R T}\right) \times\left[1-\left(\frac{Q}{K}\right)\right],
$$

where $R=$ dissolution rate, $v=$ stoichiometric coefficient, $\alpha=$ activity of the hydronium ion, $\eta_{H^{+}}=$order of the kinetic reaction with respect to hydronium ion, $k_{0}=$ intrinsic rate constant, $E_{a}=$ activation energy for the rate limiting step, $R=$ gas constant, $T=$ temperature, $Q=$ ion activity product, and $K=$ solubility of the $\mathrm{SiO}_{2}$ surrogate. In SPFT experiments, $Q$ goes to zero and the remaining terms describe the maximum rate at any given temperature and $\mathrm{pH}$. This is the forward dissolution rate. This equation appears to hold for many different glasses, including HLW and low-activity waste glasses.

The estimated forward dissolution rates for the ceramic (Figure 6.4.3.1) are two or more orders of magnitude lower than the maximum rate considered by TRW [1997] (Table 6.4.3.1).

Forward dissolution rates for the glass are measurable and vary as a function of $\mathrm{pH}$ and temperature in the same manner as other silicate-based glasses. In fact, the behavior of all silicatebased glasses is remarkably consistent. At $70^{\circ} \mathrm{C}$ and $\mathrm{pH} 8$, the dissolution rate for LaBS glass is about $3 \times 10^{-3} \mathrm{~g} /\left(\mathrm{m}^{2}-\mathrm{d}\right)$. This dissolution rate is $\sim 2.5$ times higher than that used by TRW in their assessment (Table 6.4.3.1) [TRW, 1997]. However under repository conditions and in groundwater that contains appreciable quantities of dissolved silica, the dissolution rate is expected to be several orders of magnitude lower than this forward rate. The expected dissolution rate is thus within the range of dissolution rates considered by TRW.

The solubilities of gadolinium considered in the TRW study are eight times higher than the solubility of plutonium phases; hafnium solubility is not considered. There are no direct comparisons to experimental data, but the data from the static experiments at the high solid surface-to-solution volume ratio suggest that the solubility of both gadolinium and plutonium are the same. As shown in Figure 6.4.3.3, the releases are calculated on the total amount of gadolinium and plutonium released from the solid and includes the gadolinium and plutonium in solution, in any colloids, and on the walls of the stainless-steel test vessel. Of the amount released, roughly $30 \%$ is in solution after a 182 -day test; less than $10 \%$ is in solution in shorter- 
term tests. The observed differences in concentrations between gadolinium and plutonium are within the range of the differences in release rates considered in the degraded-mode analysis by TRW [1997].

Figure 6.4.3.1. Maximum dissolution rates vs $\mathrm{pH}$ for (a) LaBS glass, zirconolite, and HLW SRL-202 glass $\left(70^{\circ} \mathrm{C}\right)$ and (b) LaBS glass and uranium/cerium- and uranium/plutoniumcontaining pyrochlore ceramic $\left(25^{\circ} \mathrm{C}\right)$ [Bourcier, 1997].

(a)

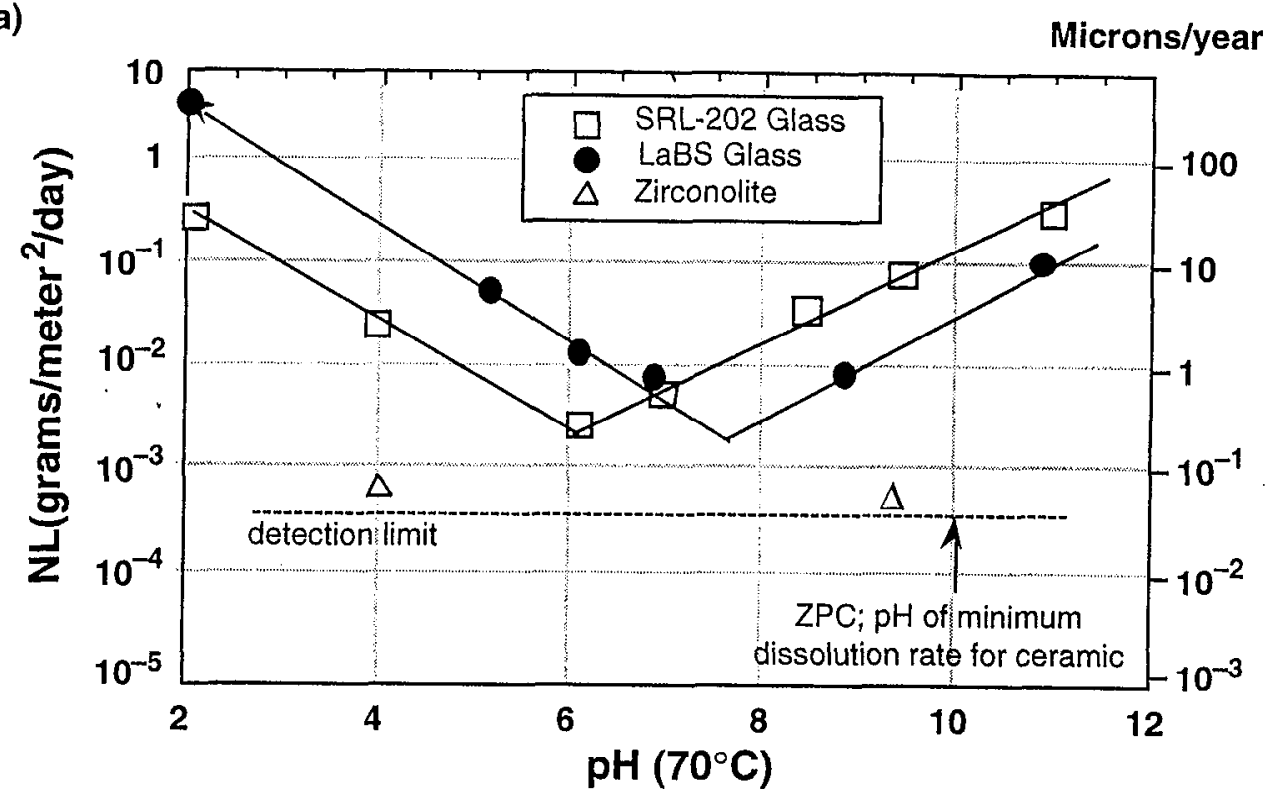

(b)

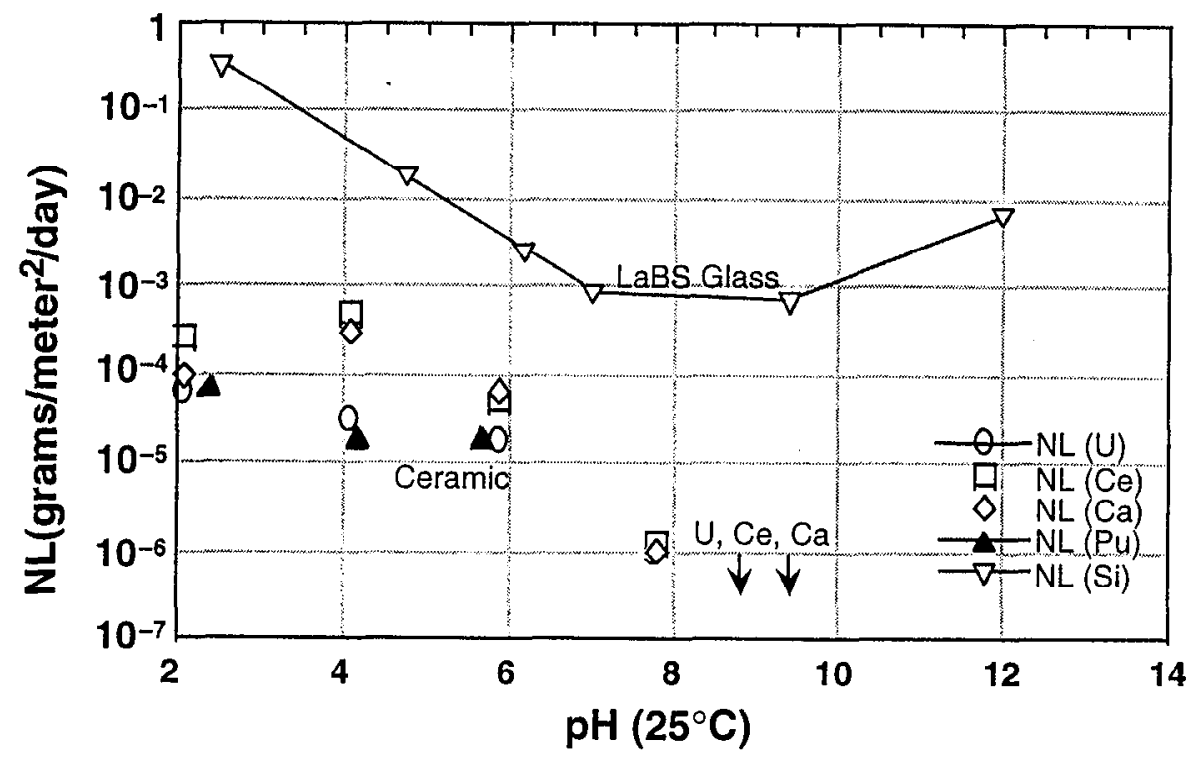


Figure 6.4.3.2. Results from PCT tests of plutonium-containing glasses (a) and ceramics (b) at $90^{\circ} \mathrm{C}$ and $2000 \mathrm{~m}^{-1}$ [Chamberlain et al., 1997].

(a)

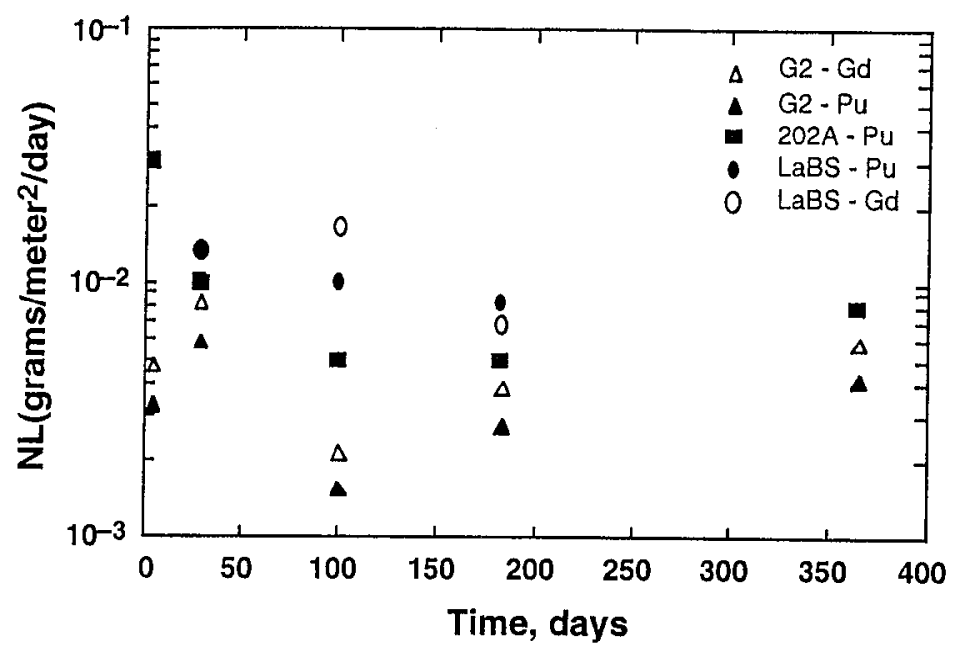

(b)

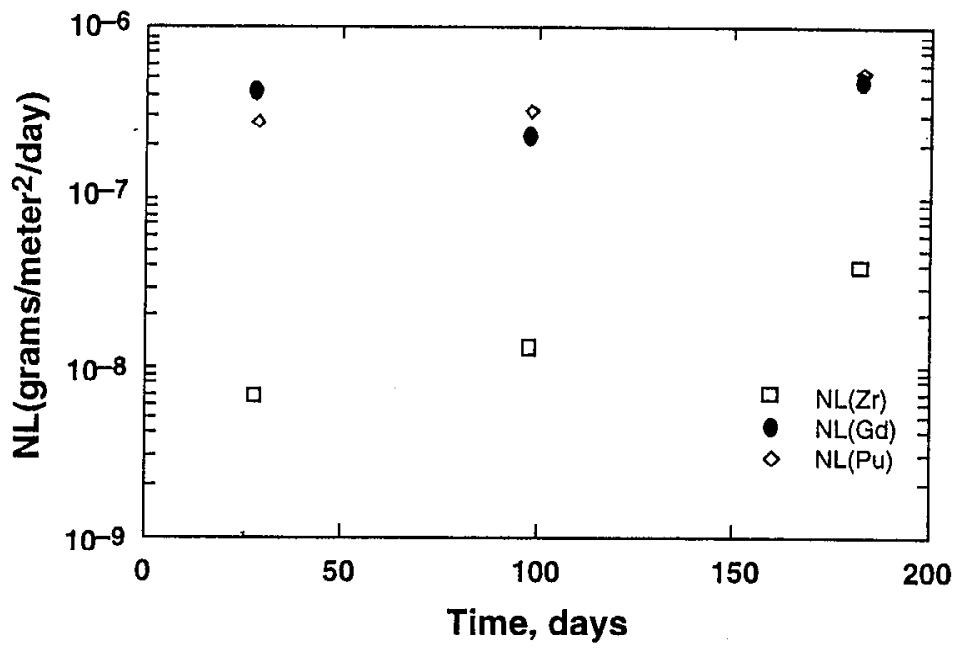

Effect of Product Quality on the Dissolution Results. Data are insufficient to make a definite statement about the effect of the product quality on the dissolution of the ceramic or glass waste form. However, both of studied materials are not the optimum materials that would be produced in an operating plant. In fact, most of the early data on the ceramic material was collected on a mixture of several zirconolite-based ceramic compositions which, in many cases, had not been fully reacted. Tests on more prototypic material gave similar results. Variations in product quality are expected to be greatly reduced during the product qualification efforts.

Effect of Surface Area and Radiation Damage on Release. The TRW study [1997] used very conservative estimates of surface areas. In the case of the ceramic, an increase of $10^{4}$ was assumed to take place as a result of radiation-induced microcracking. However, pyrochlore is the 
major phase in the current ceramic baseline formulation, whereas zirconolite was assumed in the TRW study. One of the reasons for changing to pyrochlore was to address the fracturing that might occur as the solid swells from the radiation damage. Pyrochlore is a cubic solid. In cubic solids, the swelling from radiation damage is expected to be the same in all directions (isotropic). In zirconolite, the swelling was assumed by TRW to yield fracturing of the solid phase because the solid crystal structure is monoclinic and thus swelling is expected to be different along the unequal axis of the crystal. Nevertheless, Weber et al. [1986] did not observe microcracking or fracturing in zirconolite doped with ${ }^{244} \mathrm{Cm}$ and rendered metamict. The effects of radiation damage on the glass can cause either swelling or shrinking, but neither is expected to be more than 2 vol\%. No fracturing of the glass solid is expected as the material swells or contracts. No significant increase in the surface area of either the ceramic or glass is expected from radiation damage.

Radiation damage to the ceramic will eventually leave it metamict (see Section 9). This is expected to increase the dissolution of the ceramic by perhaps a factor of ten. There are no hard data on this topic and the effect remains to be measured, but the consensus of expert opinion suggests an increase by a factor of ten. A threefold increase in plutonium release from glass was observed by Weber et al. [1985] from specimens containing ${ }^{238} \mathrm{Pu}(5 \mathrm{GBq} / \mathrm{g})$ compared with a glass containing an equivalent concentration of ${ }^{239} \mathrm{Pu}$. Some of this increase in release from either material may be due to alpha-radiolysis of air-saturated water. These effects need to be experimentally documented in future planned work on alpha-damaged ceramics and glasses [Integrated Immobilization Plan, 1997]. During the process of alteration of the metamict ceramic by the action of water, the radiation damage energy that is stored in the ceramic material will be released, but no faster than the material is altered by the interaction with water. Thus, the effects of radiation damage on the release from the ceramic are likely to be of small consequence, given the already low dissolution rate of this material. Natural-analog data on metamict zirconolite and pyrochlore minerals were presented to the TEP in partial support of this conclusion [Van Konynenburg, 1997; Vance 1997].

Although the glass will also be affected by radiation damage, the effect may be either swelling or shrinking of the glass solid. Little or no change to the dissolution rate of the glass is likely to occur. This also needs to be experimentally verified by the planned studies of alpha-damaged LaBS glass [Integrated Immobilization Plan, 1997]. More important, however, is the fact that the release of gadolinium, hafnium, and plutonium are likely to be controlled by the solubility of the alteration products that form and contain these elements. Therefore, no significant change in the release rates of gadolinium, hafnium, or plutonium is expected due to radiation damage. If the release of any of these elements is controlled not by their solubility but by transport as colloidal particles, then this conclusion is not valid. Some preliminary data from the PUF tests were presented that indicated that when the glass and ceramic forms were tested together with DWPF glass, up to $90 \%$ of the released plutonium was in the form of particulate material [McGrail, 1997].

Not covered in the current FMDP studies is the effect of peroxides on the dissolution of the ceramic and glass. The dominant chemical species that forms in aqueous solution as a result of alpha-radiolysis is hydrogen peroxide $\left(\mathrm{H}_{2} \mathrm{O}_{2}\right)$. This species can build to high concentrations in the thin film of water that forms on the surface of the solids in an unsaturated environment or in humid environments. Finn et al. [1997] have shown that alpha-radiolysis of the thin film of water that occurs on spent fuel can lead to highly oxidizing conditions. Neither the ceramic nor the glass 
should be particularly affected by highly oxidizing conditions. Locally, however, the solubility of plutonium and uranium are likely to be affected. Because alpha radiolysis effects are short range and the $\mathrm{H}_{2} \mathrm{O}_{2}$ decomposes readily, the oxidation state of the sensitive elements is likely to be quickly dominated by the repository environment, which is at ambient atmosphere.

Solubility Effects. For the main elements of concern, the releases are likely to be controlled by the solubility of the alteration phases in which the particular element or elements are located. There is evidence from the examination of the alteration products for the glass that gadolinium and plutonium are sometimes found in a silicate phase that is similar in composition to a rare earth silicate. There are insufficient data to suggest that this phase controls the concentrations of gadolinium and plutonium in solution and there are no thermodynamic data for plutonium silicates or mixed gadolinium/plutonium silicates. Results from static experiments at high $\mathrm{S} / \mathrm{V}$ suggest that both gadolinium and plutonium approach a constant normalized release (Figure 6.4.3.2a). The solubilities of plutonium phases generally decrease with increasing $\mathrm{pH}$ as do the solubilities of the rare earth phases. The presence of carbonate and phosphate can change that behavior. Phosphate and carbonate complexes of gadolinium and plutonium are not completely understood, with some thermodynamic data coming from single determinations of stability constants, often under conditions not applicable to the Yucca Mountain groundwater. Gadolinium carbonate solution species are being studied at PNNL, and hafnium carbonate solution species are being studied at the Massachusetts Institute of Technology as part of the Plutonium Immobilization Program [Integrated Immobilization Plan, 1997]. The Yucca Mountain groundwater is about $\mathrm{pH} 8$ and is saturated with respect to $\mathrm{CO}_{2}$ gas at a partial pressure of about $3 \times 10^{-4} \mathrm{~atm}$.

As mentioned above, there is evidence from the PUF test that the interaction of the solution from HLW glass and either ceramic or glass yields plutonium that is transported in or on colloids [McGrail, 1997]. However, even taking this evidence into account, the release of the plutonium from either material under these conditions still falls within the range of release rates covered in the preliminary degraded-mode assessment [TRW, 1997]. Although up to $90 \%$ of the plutonium was reported as being filterable and there was no mention if the gadolinium was also filterable, both the gadolinium and hafnium concentrations in the unfiltered effluent were at or below detection limits. However, these results were from tests that were of ten days duration [McGrail, 1997]. Results from earlier tests of longer duration with single materials indicate that considerable changes in effluent chemistry occur during the course of the longer experiments. If the plutonium release continues in the same manner as the first ten days, this could provide a mechanism for the separation of the neutron absorbers and the plutonium. Maintaining a criticality safe configuration may be impacted by this effect.

Overall Evaluation with Respect to Repository Issues. Within the uncertainties caused in large part by the paucity of data, both immobilization forms appear to be adequate with respect to behavior in a geologic repository. The results from the tests performed to date are generally within the range of dissolution rates, solubilities, and differential releases of gadolinium and plutonium in the TRW study [1997]. Less than $100 \mathrm{~kg}$ of plutonium per waste package (four DWPF canisters) for the ceramic and $50 \mathrm{~kg}$ of plutonium for the glass was needed to prevent criticality for the case analyzed by TRW. The presence of hafnium in the zirconolite-based ceramic that TRW considered allowed for two times more plutonium than in the glass. However, ample amounts of hafnium are present in the current baseline for both forms that it is likely that more than $100 \mathrm{~kg}$ of plutonium could be safely placed in each waste package. The current 
baseline processes call for $27 \mathrm{~kg}$ of plutonium per DWPF canister for ceramic in both the 50-MT and 17-MT options and $23 \mathrm{~kg}$ and $16 \mathrm{~kg}$ of plutonium per DWPF canister for glass in the 50-MT and 17-MT options, respectively (lable 5.1).

Although both immobilization forms appear adequate, there are resolvable differences between them. The degree to which these differences may have value was not assessed by the TEP. The resolvable differences are in the rates at which the materials degrade in water, as measured with the four types of dissolution tests. The forward dissolution rate and elemental release rates for ceramic are consistently lower than those for glass. There will always be uncertainty as to whether there is a separation between plutonium and the neutron absorbers as the immobilization form degrades, because the process of modeling geochemical behavior over very long times is one of the large uncertainties in a performance assessment. Thus it could be argued that the safest approach is to minimize the release of the plutonium and the neutron absorbers in the first place. To this end, the added ${ }^{238} \mathrm{U}$ in the ceramic formulation provides an isotopic diluant for the decay-product ${ }^{235} \mathrm{U}$, which may reduce the potential for far-field criticality at long times. However, the degree to which this will offer a significant margin in criticality safety has not been assessed.

\subsection{Environment, Safety, and Health Compliance}

Environment, safety, and health issues must be satisfied for all operations for both immobilization forms in order to comply with applicable federal statutes and DOE orders. The DOE plants and laboratories have demonstrated the ability to handle and store a wide variety of highly radioactive materials for many years by the proper application of shielding, automation, and remote handling. These methods, coupled with appropriate procedures and operator training, can achieve very low worker radiation exposure.

The immobilization processes under evaluation by the TEP will process a substantial amount of plutonium with a higher specific radiation level than weapons grade plutonium. This is due to both the larger fraction of heavier plutonium isotopes $\left({ }^{240} \mathrm{Pu}\right.$ and ${ }^{241} \mathrm{Pu}$ ) as well as ${ }^{241} \mathrm{Am}$, a daughter product of ${ }^{241} \mathrm{Pu}$. In addition, the mixing with frit and the dissolution of finely ground plutonium oxide into LaBS glass will generate neutrons through the (alpha,n) reaction. This is due to the presence of boron in the LaBS glass, an effect that can be reduced by roughly a factor of two by using boron isotopically enriched in ${ }^{10} \mathrm{~B}$ in place of natural boron.

The TEP concurs that for both the glass and ceramic processes, the application of automation, shielding, and procedural controls can keep worker radiation exposure below mandated levels. There is an expected difference in cost to meet the design-basis operator radiation exposure for glass due to the higher (alpha,n) neutron flux from the glass form. However, we note that the DOE ALARA (as low as reasonably achievable) guidelines and safeguards and security requirements will likely drive the ceramic process to at least partial if not full automation.

\subsubsection{Public and Worker Health and Safety}

Industrial Hazards. Industrial hazards exclusive of radiation exposure were assessed for both immobilization forms. These hazards include those involved in most operations and are characterized by fire hazards, spills, operator injuries, etc. From an industrial point of view, there 
is no difference in the hazards for the two immobilization forms of the operations extending up through milling and blending. Similarly, there are no real differences for those operations involving the canned immobilization form or canister loading.

The only differences involve the press and sinter operations (for ceramic) compared to the melter operations (for glass). These operations are all carried out in a protected glovebox environment with no or minimal operator access to thermally hot components or physically dangerous operations. Due to the safety requirements usually imposed in a plutonium facility, it is very unlikely that operators will be exposed to any significant industrial hazards from these operations. At this point in time, there appears to be no difference between the immobilization forms in terms of industrial hazards.

Contamination Potential. Since both waste forms use the same feed preparation and particle sizing operations, they are judged to be essentially identical in contamination potential.

Radiation Exposure. Exposure of the general public to ionizing radiation will be controlled by overall plant design and operating conditions and potential accident scenarios. Of the potential accident scenarios, those that deal with fine powders are most problematic due to the chance for aerosol formation and dispersion outside of the plant boundaries. The design bases of both immobilization forms presumes milling to a $20-\mu \mathrm{m}$ particle size. Since most of the dispersion potential exists in operations that are common to both immobilization forms (plutonium conversion, milling, and blending), public exposure is not a discriminator between the two forms.

The two forms do differ in their potential radiation exposure to the worker population. This difference results from the substantially higher neutron radiation from glass due primarily to the (alpha,n) reaction with the ${ }^{11} \mathrm{~B}$ isotope and the alpha particle emissions from ${ }^{238} \mathrm{Pu},{ }^{239} \mathrm{Pu}$, and ${ }^{241} \mathrm{Am}$. Applicable DOE regulations limit maximum worker exposures to $5 \mathrm{rem} / \mathrm{y}$ for whole-body dose and $50 \mathrm{rem} / \mathrm{y}$ for extremity dose. Furthermore, DOE orders require design exposure levels of $1 \mathrm{rem} / \mathrm{y}$ for whole-body dose and $10 \mathrm{rem} / \mathrm{y}$ for extremity dose [CFR, 1997]. For a given set of source terms, the facility design will presumably incorporate shielding, isolation, and automation coupled with administrative controls and operator training combined to meet these requirements.

Once these basic requirements are met, there is an additional requirement generally referred to as "as low as reasonably achievable" or ALARA. Although operation is allowed up to regulatory limits, additional steps within reasonable limits must be taken to further reduce operator exposure (e.g., additional shielding, design modifications) so long as these exposure reductions can be reasonably achieved. Various levels of resource expenditure have been used as guidelines beyond which further reduction is not required, and these generally have the units of cost per man-rem saved. Values ranging from $\$ 10,000$ to $\$ 50,000$ per man-rem have been informally cited throughout the DOE complex in the past, but to the TEP's knowledge none has been officially adopted. (There are no expenditure limits to achieve the formal radiation exposure limits for workers, since they must be met in order to start or continue operations of the plant or facility.)

Worker Radiation Exposure Calculations. The estimation of expected worker exposure in the immobilization facility requires information on the processing equipment design, source terms, backgrounds, and worker tasks and time-motion data. Because the immobilization facility design is currently in a preconceptual state, the above information is not available to accurately quantify worker exposure in order to compare the glass and ceramic forms. However, estimates of exposure rates based on expected sources terms indicate that hands-on operation of the 
process equipment almost certainly produces unacceptable worker radiation exposure. Radiation exposure for worker's hands is dominated by gamma radiation, which is approximately equal for the glass and ceramic forms. Whole-body radiation exposure, on the other hand, is higher for the glass form due to its higher neutron radiation. The TEP assumes, in the absence of detailed designs or worker exposure projections, that the plant design team will minimize manual handling and close-in operations in order to reduce operator exposure through the use of automation where appropriate.

Given the above state of information, it is still useful to understand potential radiation exposure impacts that would result for the different immobilization forms for different hypothetical combinations of shielding and possible operating scenarios. Calculations of the radiation fields have been performed for the two forms under consideration for various combinations of source and glovebox shielding and plutonium mass values by Rainisch at SRS [1997] and Lee at LLNL [1997a]. The calculation performed by Rainisch considered masses of about $3 \mathrm{~kg}$ of plutonium as $\mathrm{PuO}_{2}$ in ceramic and $2.5 \mathrm{~kg}$ of plutonium in glass, whereas Lee calculated dose rates assuming $1 \mathrm{~kg}$ of plutonium in both glass and ceramic. Lee also calculated dose rates for a single ceramic pellet [1997b]. Rainisch did not report the dose rates for ceramic in the first reference; however, subsequent clarification [Bickford, 1997] and comparisons with Lee's calculations justified the assumption that the neutron dose rate for ceramic was comparable to the $\mathrm{PuO}_{2}$ calculations. Similarly, both Lee and Bickford verified that the gamma dose rate for : ceramic was almost identical to that for glass. Using these relationships, it was possible to construct a dose rate table for ceramic comparable to that already existing for glass to permit a side-by-side comparison of the radiation fields for both forms.

Since the masses of plutonium and americium were different between the calculations by Lee and Rainisch, it was desirable to convert these to a common mass basis. In the absence of multiplication (which is a valid assumption in the current case due to the high content of neutron absorbers and diffuse geometry), neutron dose rate corrections were first made that are proportional to the plutonium mass for a given americium concentration. In the case of the gamma corrections, the cube root of plutonium mass for a given americium concentration was used as the correction factor. This assumes that gamma emissions will be surface-area dominated, particularly for the soft gamma rays and $\mathrm{x}$ rays that dominate the gamma source term. Next, the relative impacts on both neutron and gamma ray dose rates were calculated for the americium contribution and the results were interpolated to an americium concentration of $1 \%$. These corrections to Rainisch's calculations were verified by comparison with Lee's calculations, which had assumed $1 \mathrm{~kg}$ plutonium with $1 \%$ americium.

Based on the calculations prepared by Rainisch [1997], corrected by Bickford [1997], and compared with Lee's calculation [1997a], Table 6.5.1 and Figure 6.5.1 summarize the dose rates for both glass and ceramic for the various defined conditions of shielding and spacing assumed by Rainisch. Note that entries are shown for glass using both natural boron and glass with isotopically enriched boron.

As Table 6.5.1 shows, there is little difference between the glass and ceramic for a bare source, due to the high flux of soft gamma and $x$ rays. However, even with the minimal shielding afforded by a 3/16-in. stainless steel can, these $x$ rays are dramatically attenuated such that the difference in estimated neutron dose rates now dominates. This is evident in the remaining cases, which have varying degrees of additional shielding and separation. 
Table 6.5.1. Dose rates (in $\mathrm{mrem} / \mathrm{h}$ ) for glass and ceramic for various conditions of shielding and spacing (source: $1 \mathrm{~kg}$ plutonium with $1 \%$ americium dispersed in the immobilization form).

\begin{tabular}{lccc}
\hline & Glass & Glass with ${ }^{10} \mathbf{B}$ & Ceramic \\
\hline Bare contact & 4283 & 3926 & 3732 \\
Stainless steel can & 564 & 253 & 84 \\
Stainless steel can + & 558 & 247 & 78 \\
lead-lined gloves & & & \\
Stainless steel can + & 25 & 11 & 3 \\
34.5-cm spacing & & & \\
7-in. SRS shield & 5 & 2.3 & 0.6 \\
7-in. SRS shield + & 1.4 & 0.7 & 0.2 \\
30-cm spacing & & & \\
\hline
\end{tabular}

Figure 6.5.1. Total dose for glass and ceramic immobilization forms for various shielding and separation combinations.

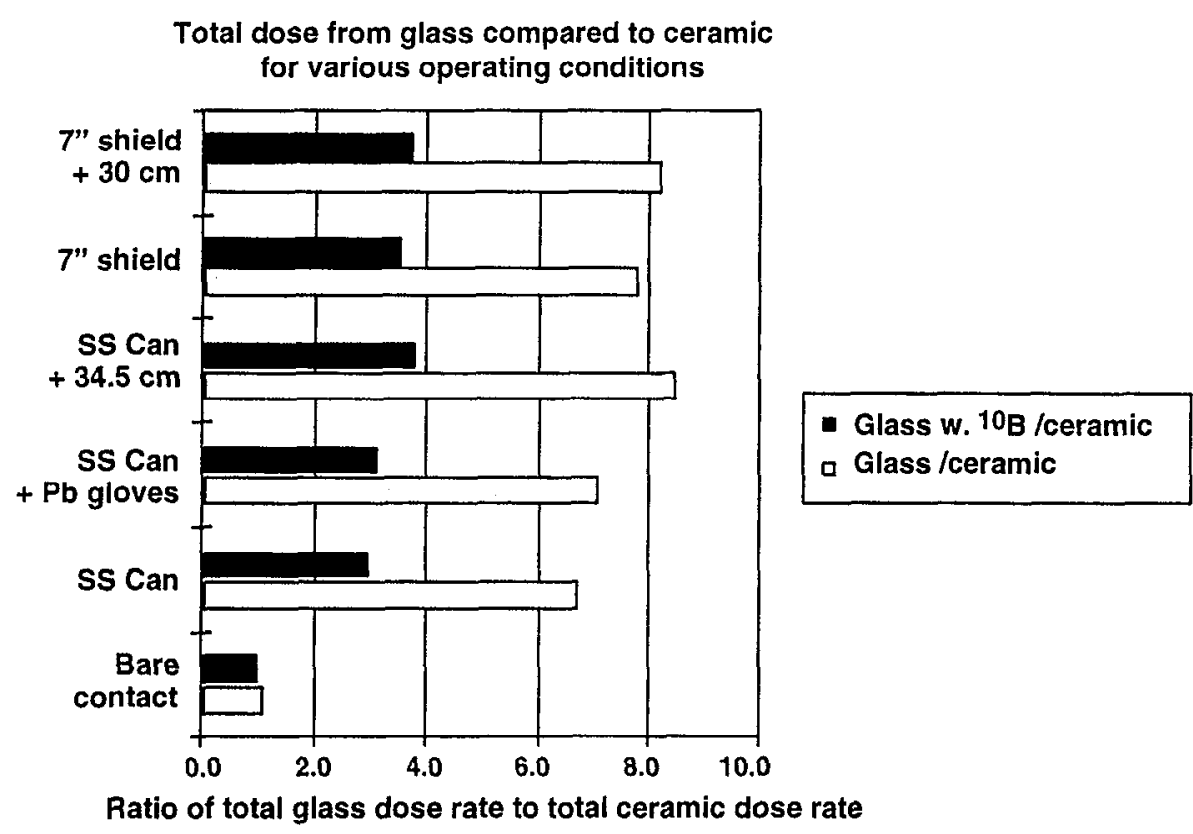

Figure 6.5.1 plots the ratio of neutron to gamma dose rate estimates for the two immobilization forms for the various shielding and separation combinations. The baseline glass formulation generates between seven and nine times higher radiation field than the ceramic form and this is dominated by the neutron contribution. If isotopically enriched boron is used, the difference in radiation field falls to a factor of three to four times higher for glass than ceramic.

The neutron dose rates shown in Figure 6.5.1 were estimated with an effective neutron quality factor of 10 . Considerations have been under way for some time to increase the neutron quality factor to 20 [DOE, 1986; NCRP, 1980; ICR Report, 19??; ICRP, 1985]. Although 
current regulations do not require this, such an increase would have a doubling impact on the differences between the glass and ceramic dose rate estimates.

These calculations make the assumption that the glass will only be present as a full batch poured into a mold for most handling operations and that the ceramic will be formed into pellets ( $\sim 2.5$ in. long) containing about 40 grams of elemental plutonium. Since the pellets could be handled singly through gloves for certain operating scenarios, an estimate was made for the dose rate associated with a single pellet through leaded gloves with an equivalent lead thickness of $0.25 \mathrm{~mm}$ (Figure 6.5.2).

Several of the shielding and source term conditions defined for the estimated dose rate values in Table 6.5.1 provide bases for estimating hand and whole-body dose rates for the canned forms under possible manual handling scenarios. Figure 6.5.3 shows the estimated dose rates for hand contact with the canned product (both ceramic and glass) and estimated dose rates to the hands located $35 \mathrm{~cm}$ from the can (for glovebox operations). Table 6.5.1 can be also used to estimate the whole-body dose rates for manual handling of both glass and ceramic canned forms for the 7-in. shielding case, which corresponds to the glovebox shielding commonly used at SRS. Note: the case with 7-in. shielding plus $35-\mathrm{cm}$ separation in Table 6.5 .1 corresponds to operators in the vicinity of the glovebox but not in the gloves.

These data do not imply that operators will receive high dose rates in the processing facility for either immobilization form. Rather, the data are presented to document the quantitative dose rates under "typical conditions" with baseline source terms and to illustrate the need for automated processing equipment. Additional calculations (not included in this report) show that estimated operator exposure would preclude 40-h/wk manual operations for most of the processing steps. The only exception appears to be the manual handling of single ceramic pellets, which would likely be avoided due to ALARA considerations. With reasonable automatic handling and using the current SRS shielding for the new gloveboxes, all of the currently envisioned glovebox operations for both forms can be conducted at acceptable to low operator exposure levels. The lower neutron dose rates associated with the ceramic form will potentially make this goal easier to achieve and will give lower operator dose rates than the glass immobilization form.

Figure 6.5.2. Dose rate for a single ceramic pellet containing 40 grams of plutonium through a 10-mil $(0.25-\mathrm{mm})$ leaded glove.

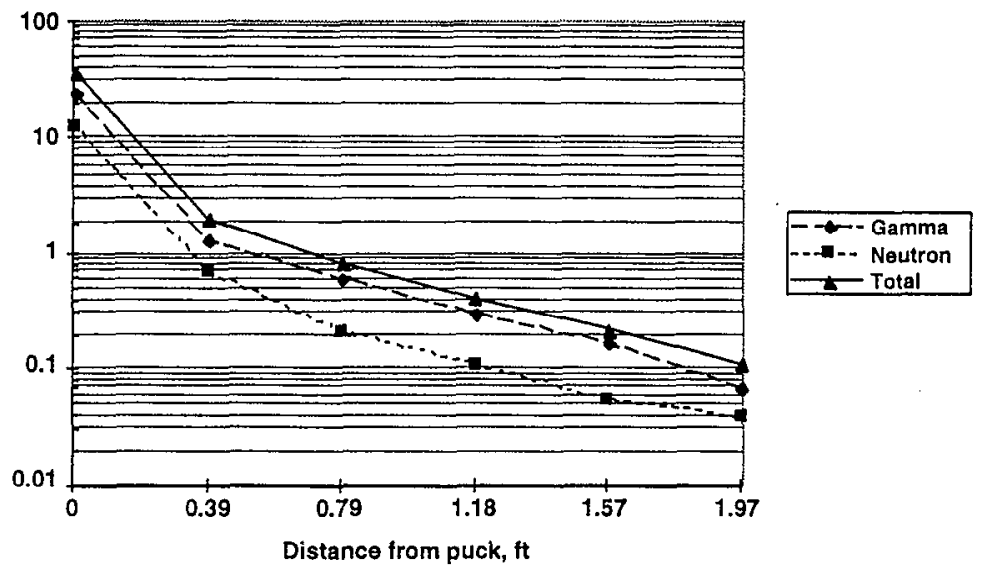


Figure 6.5.3. Hand dose rate for can contact and general glovebox operations (ceramic and glass immobilization forms).

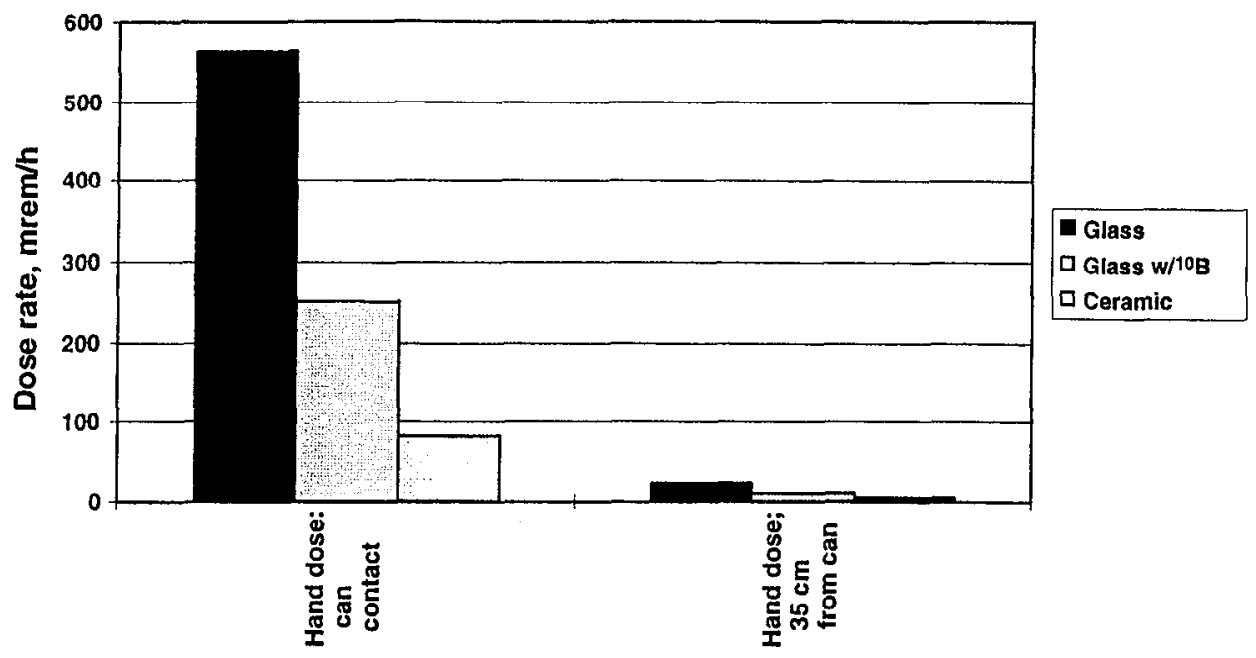

Dose Calculations for Canister Loading. The final operation involves assembling the cans and loading them into a canister. Current plans are to conduct this and all subsequent operations behind heavily shielded walls. This is based on the presumption that it would be more cost effective to do so remotely in the F-Canyon entrance tunnel than it would be to build new facilities to do it elsewhere. The remote loading and welding are not viewed as significant technical hurdles.

Calculations of the radiation field of the canister as a function of the plutonium loading and radial distance from the canister are shown in Figures 6.5.6 and 6.5.7 for glass and ceramic, respectively. These approximate dose rates were generated by the simple addition of the radiation field contributions of the individual cans within the canister.

Based on these estimated dose rates, canister loading must be automated for both glass and ceramic. Maintenance and repair operations in the SRS canyons have historically been carried out by remotely removing failed equipment from the high radiation area and decontaminating it. The equipment is then either repaired outside of the shielding walls or replace

Dose Calculations for Process Upset Scenarios. Process upsets can occur, and the exposure associated with recovering from such upsets or equipment failures is strongly dependent on the glovebox background and the inventory of radioactive material present in the equipment and the glovebox at the time. Most background is traditionally associated with loose $\mathrm{PuO}_{2}$, and a major contributor is dust from the milling and blending operations. Little difference in background between the forms is expected due to the similarity of the feed preparation operations.

The main process differences lie in the immobilization operation step. In the case of ceramic, press failure involves small inventories and thus the related exposure impact is comparatively small. The ceramic sintering furnaces however have relatively large inventories. Cleanup of upsets in such systems could involve dose rates similar to those given in Table 6.5.1 for the stainlesssteel-shielded case (furnace body) since the ceramic radiation field is largely dominated by the gamma rays. In the case of the glass melter, somewhat smaller inventories of plutonium are involved, but the estimated neutron dose rate is substantially higher. For both forms, the actual 
exposure received by operators is defined by the facility design, equipment reliability, ease of repair, and operating procedures.

At this time, insufticient information exists to assess the overall exposure impact for process upset and equipment failure. However it is clear that this issue must be carefully considered in the design of the equipment and facility.

Figure 6.5.6. Radiation field around the unshielded canister as a function of plutonium loading and distance for the glass immobilization form.

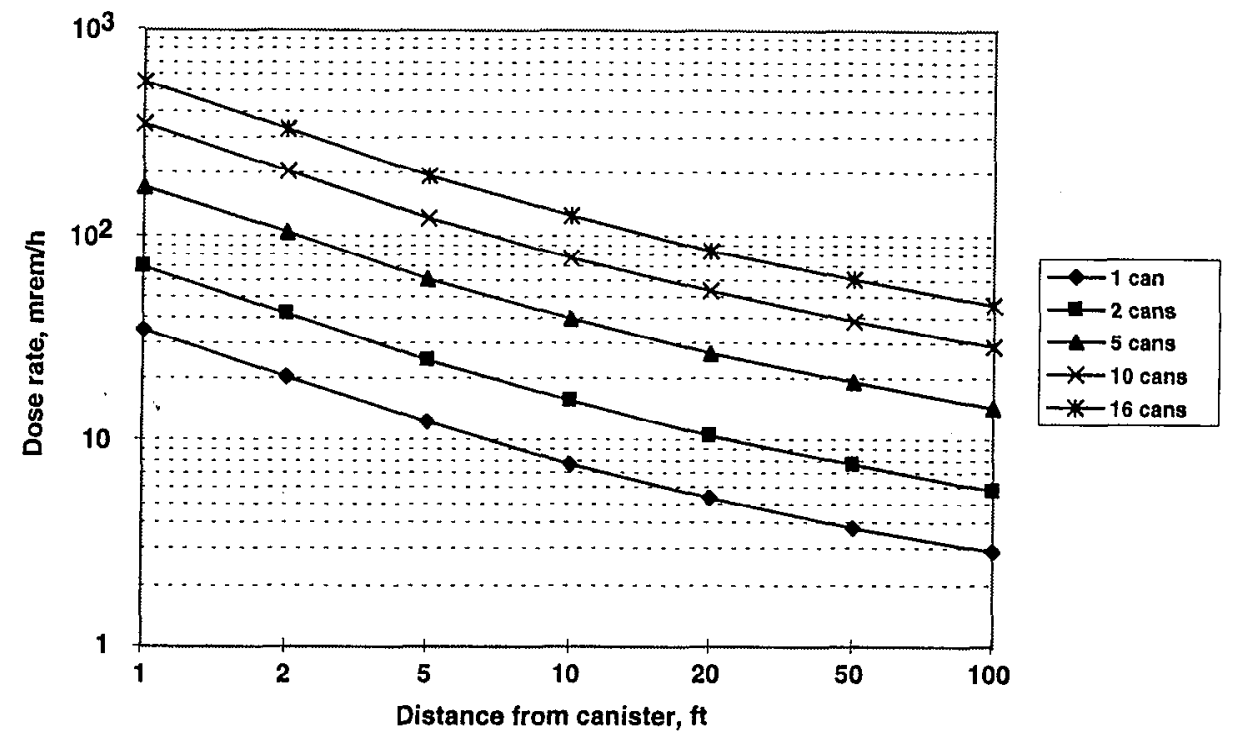

Figure 6.5.7. Radiation field around the unshielded canister as a function of plutonium loading and distance for the ceramic immobilization form.

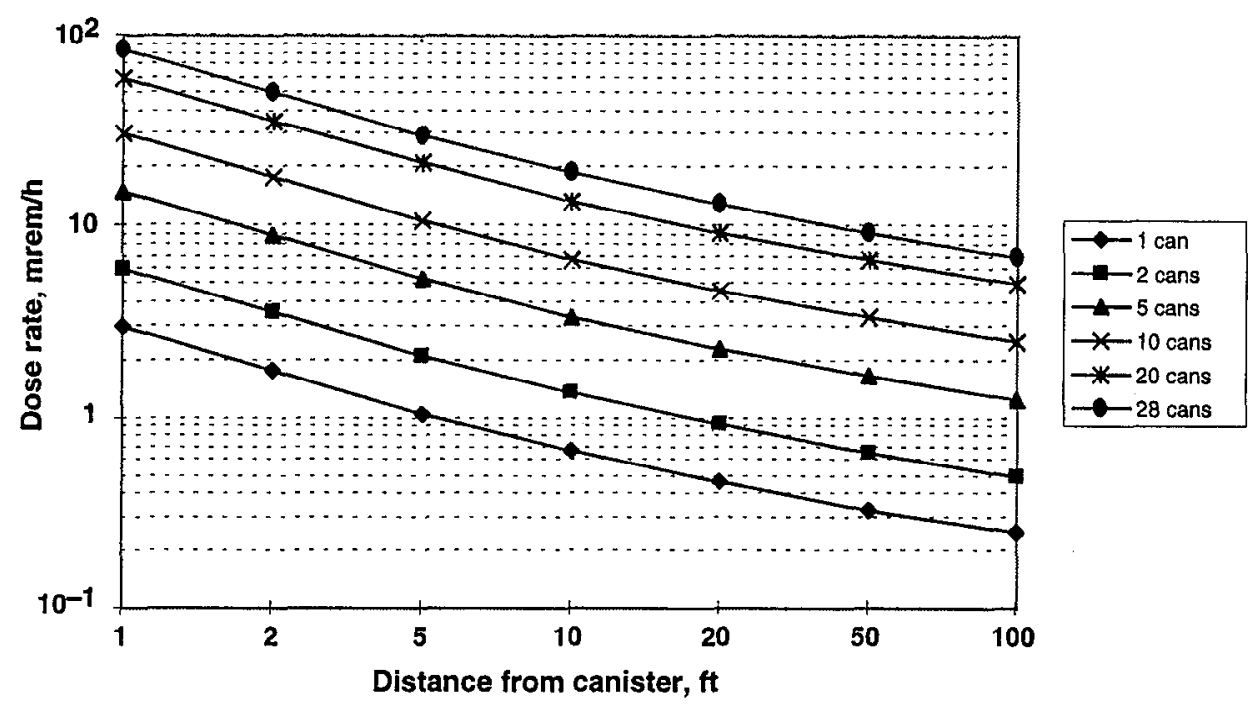




\subsubsection{Waste Forms and Minimization}

As currently planned, any failed immobilization form is recycled back into the feed stream for subsequent immobilization. As such, no residues or form-dependent waste forms are generated. The remaining waste streams involve glovebox-line waste and facility waste. Equipment maintenance differences and potential waste streams are considered minimal. There are no other discriminating operations involving waste for the two immobilization forms.

\subsection{Cost}

Cost has been established as one of the criteria used to judge the selection of the immobilization form, although it is of less importance than the nonproliferation criteria provided that the cost differentials are not excessive. Both Bechtel and WSRC have evaluated the baseline flowsheet implementations for glass and ceramic since the processes would be implemented either in 221-F or in a new facility [Marais, 1997; Maddux, 1997]. Within the general range of assumptions that were used in the EIS process discussed in these briefings, there are insufficient data or design detail to discern differences in the cost of implementing either waste form. In general, facility size requirements are about the same and insufficient data exist to establish a differential based on équipment requirements or operating personnel.

In the absence of differences discernible at the conceptual design level, there are potential differences in a number of specific cost categories that can be estimated and used as a basis for understanding possible cost advantages that would result from selection of a given immobilization form. These potential cost differential areas are discussed in more detail in the following sections. The possible cost impacts include both the possibilities of cost savings as well as the possibility of minimizing certain types of costs risks. The overall net effect of the range of potential cost differences will require further consideration of interacting effects and conditions.

To keep potential cost impacts in perspective in a number of areas, the summary table of total program costs for the immobilization can-in-canister option is given in Table 6.6.1 [FMDP, 1996].

Table 6.6.1. Summary of total program costs (in millions of dollars) for the immobilization can-in-canister option.

\begin{tabular}{lccc}
\hline Facility & Investment & Operating & Total \\
\hline First-stage immobilization & 340 & 980 & 1320 \\
Second-stage immobilization & 220 & 170 & 390 \\
Repository differential & 0 & 100 & 100 \\
Total & 560 & 1250 & 1810 \\
\hline
\end{tabular}

\subsubsection{Potential Cost Differential Areas}

Near-Term R\&D Program. The potential differences between the glass and ceramic forms in the near-term $R \& D$ program focus on identified differences in the technical maturity of the two forms. The first difference is associated with the need to determine the relationships between 
ceramic form process control parameters and the repository acceptance of ceramic immobilization forms, which is felt to be at a lower state of maturity compared to equivalent data requirements for glass. The second difference is the relative state of maturity of the glass melter system, which is felt to be at a lower state of maturity than the MOX-based ceramic processing system and thus will require development and testing. No cost differentials have been identified in the current R\&D plan between these two areas [Immobilization Program R\&D Plan, 1997] and no estimate is available to evaluate a possible differential at this time.

Plutonium Immobilization Loading Differentials. The combination of differentials in immobilization form density and projected plutonium loading percentages of these forms in the baseline and variant scenarios results in substantial differences in plutonium loading in mass per unit volume of the cans between the ceramic and glass immobilization forms. This differential directly impacts the displacement of DWPF glass, independent of the canister loading strategy or total number of canisters involved, and is simply a measure of the additional DWPF canisters that must be poured as a result of the direct displacement of the DWPF HLW glass.

Based on the baseline designs in terms of immobilization form size, plutonium loading, form density, and can dimensions used to contain the form, estimates have been made of the additional canisters that will be required for the baseline and enhanced plutonium loading scenarios for both glass and ceramic using the glass displacement curves presented by Kan [1997]. For $10.5 \mathrm{wt} \%$ plutonium $\left(11.9 \mathrm{wt} \% \mathrm{PuO}_{2}\right)$ for ceramic and $8.8 \mathrm{wt} \%$ plutonium $\left(10 \mathrm{wt} \% \mathrm{PuO}_{2}\right)$ for glass, the differential is about 140 canisters. For $15 \mathrm{wt} \%$ plutonium $\left(17 \mathrm{wt} \% \mathrm{PuO}_{2}\right)$ ceramic and $10.6 \mathrm{wt} \%$ plutonium $\left(12 \mathrm{wt} \% \mathrm{PuO}_{2}\right.$ ) glass, the differential is also about 140 canisters, even though fewer canisters are now involved. At the assumed program repository fee of $\$ 500,000$ per extra canister [FMDP, 1996], this corresponds to a $\$ 70$ million extra cost for canisters containing the glass immobilization form. Note that no other DWPF operating costs differentials (if any exist) are included in this number.

It should also be noted that the above cost differential is a rough estimate based on the current baselines and variants. Further optimization of form loading, can design, and canister loading and hardening concepts will likely change this cost differential. In addition, the cost per canister is currently under review by DOE/RW and is likely to increase [Farmer, 1997].

Radiation Dose Impacts. The potential cost differentials will be driven by the considerably higher neutron dose rate associated with the glass form after the blending operation. As indicated in Section 6.5, the total radiation dose field is on the order of seven to nine times higher for the glass form and is dominated by neutron dose. This higher dose rate, which impacts operations and is more difficult to shield than soft gamma rays, has impacts in several cost areas.

As discussed in Section 6.5, one approach for reducing the radiation dose from glass is the use of ${ }^{10} \mathrm{~B}$-enriched feed in the glass frit to reduce the (alpha,n) radiation. This enriched isotope is estimated to cost about $\$ 3.50$ per gram, which would result in a total cost increase for glass of $\$ 50$ million over the mission life for the 50-MT immobilization baseline case [Bickford, 1997]. This cost may decrease somewhat if the plutonium loading in glass is increased (as in the glass variant case) since less frit would be used; however, this cost decrease may be offset by increased product control development costs. The actual need for ${ }^{10} \mathrm{~B}$ will not be defined until the process design is finalized and time and motion studies are completed. 
Design requirements for dose control will drive the design to meet the dose limits as mandatory requirements for operation. Substantial automation is planned for the facility, and this will substantially aid dose reduction. Often, the bulk of the benefits gained will occur for relatively simple automated operations that are cost effective If the high neutron dose rates from the immobilized glass form require additional automation, then additional costs will be incurred. The total incremental cost for this additional automation will include both the added development and testing as well as the installation and operation of the enhanced system. There are currently no estimates available for evaluating this potential impact.

Maintenance is a separate area where higher glass neutron dose rates can have an effect. Normally, SRS designs their glovebox lines with both an operating side and a maintenance side. The operating side is often well shielded. In the current plant concept, multiple processing stations (e.g., melters) are placed in adjacent locations within a glovebox line. Routine maintenance procedures, not yet developed, may involve additional costs to ensure acceptable radiation exposure to maintenance personnel. The possible additional alternatives of increased station and glovebox spacing and additional shielding walls may also be considered and would further add to the cost.

Considerations of cost differentials in the baseline did not consider the potential impact of the higher neutron dose from glass in the potential utility of 221-F for the immobilization mission, given the dispersed facilities and limited space. No estimate of this potential impact could be made at this time by the TEP, pending additional evaluation and further development of designs and implementation strategies.

\subsection{Timeliness}

The criterion for timeliness states that the goal is to act in an urgent manner for disposition. Urgent action reduces the risks of theft or diversion of weapons-usable material and sends a positive signal to Russia and to the international community regarding disarmament.

\subsubsection{Time to Start Disposition}

The time required to start disposition is one measure of timeliness. Preferred options show progress sooner. The measurement used here to assess this factor is the date of or time to significant initiation of "full scale demonstration." The current immobilization schedule calls for a "hot" demonstration in 2000 and actual production in the year 2005 (Figure 6.7.1.). Both forms and processes are currently on a development track consistent with this startup date.

Independent of which form is selected for further development and deployment, the immobilization startup is currently funded and planned for that date. Since one of the underlying assumptions in the TEP assessment is that funding will be provided as needed to achieve this schedule, there is by definition no difference between the two forms for this metric.

\subsubsection{Time to Complete Disposition}

The time to complete disposition is the time to process and immobilize the full inventory of surplus plutonium. For immobilization forms that are ultimately slated for a high-level waste repository, the time to complete disposition is the time to achieve the proliferation-resistant waste form, which would be stored pending repository disposal. Options that complete 
disposition sooner are preferred. Consideration should be given to the expected difficulty in obtaining a license, although the criteria definitions state that this is probably a low discriminator and only applies to Greenfield sites. Consideration should also be given to the expected difficulty in obtaining Defense Nuclear Facility Safety Board (DNFSB) approval. According to the criteria definitions, this too is probably a low discriminator.

Both forms and processes are currently under development consistent with the a plant throughput of $5 \mathrm{MT}$ per year. Independent of which is selected for further development and deployment, each process is aimed at a 5-M'T per year design throughput. Since one of the underlying assumptions in this assessment is that funding will be provided to achieve this, there is by definition no difference between the two forms using this metric.

Regarding licensing, both processes are assumed (for this evaluation) to be located at the Savannah River Site. This criterion was defined to be applied at a Greenfield site only and hence is not applicable here. Obtaining DNFSB approval would likely be similar for the two forms and processes under the assumption that either would have to fully comply with all DOE orders and other applicable regulations and would therefore have equal likelihood of approval.

\subsubsection{Impacts to Existing or Future Missions}

This factor attempts to assess the impacts on site and facility selection due to ongoing or already-planned missions that would affect the attractiveness of a site or facility. Should there be a potential conflict, the effect on relocating the plutonium immobilization mission or the conflicting mission must be taken into consideration. In addition, the effect on site staff availability, infrastructure support, and contractor and field office support must be gauged. This is to be measured by the time delays incurred if relocation is necessary.

Since this evaluation assumes that the DWPF facility will be used to process the glass-filled or ceramic-filled cans, there will be a possible impact on DWPF operations. The immobilization of plutonium with either the glass or ceramic can-in-canister packaging in the DWPF facility will displace a volume of glass in each canister. This, in turn, will reduce the quantity of high level waste in each canister and will therefore increase the total number of canisters required to dispose of the SRS inventory of high level waste.

The nominal period for the immobilization of $50 \mathrm{MT}$ of plutonium is 10 years (5 MT per year design throughput). The amount of plutonium in a plutonium-bearing canister (which is determined in part by the concentration of plutonium in the immobilized form) can affect the timeliness for completion of the immobilization mission. If the number of canisters with HLW glass generated per year to complete the immobilization mission in 10 years exceeds the rate at which DWPF can pour HLW glass, then the immobilization mission will be stretched out in time. The nominal DWPF glass pour rate planned for FY 1998 is feed-limited by the amount of funding available to the program at about 220 canisters per year. This number of canisters per year is presently an upper bound on the number of canisters per year that the ProCast code indicates can be successfully filled with HLW glass.

The immobilization form with the higher plutonium volumetric density potentially has a lower impact on this timeliness issue. As can be seen from Table 6.7.1, the volumetric plutonium density is considerably higher for ceramic than for glass. It is important to note that there is an impact (and a discriminator between the glass and ceramic forms) only when the number of plutonium-bearing canisters exceeds the HLW disposal rate. At the current rate of $220 \mathrm{HLW}$ 
canisters per year, this is not the case. However, if either the (DOE/EM-funded) HLW canister rate falls or the plutonium disposition rate is raised, this could become an issue. In the case of glass immobilization, the option of higher plutonium loading in the glass exists.

Table 6.7.1. Baseline plutonium volumetric loading.

\begin{tabular}{lcc}
\hline & Ceramic & Glass \\
\hline Baseline 1 (50 MT plutonium) & $0.578 \mathrm{~g} / \mathrm{cm}^{3}$ & $0.334 \mathrm{~g} / \mathrm{cm}^{3}$ \\
Baseline 2 (17 MT plutonium) & $0.578 \mathrm{~g} / \mathrm{cm}^{3}$ & $0.270 \mathrm{~g} / \mathrm{cm}^{3}$ \\
\hline
\end{tabular}

Figure 6.7.1. Immobilization project top-level schedule defined as the baseline schedule for the TEP evaluation.

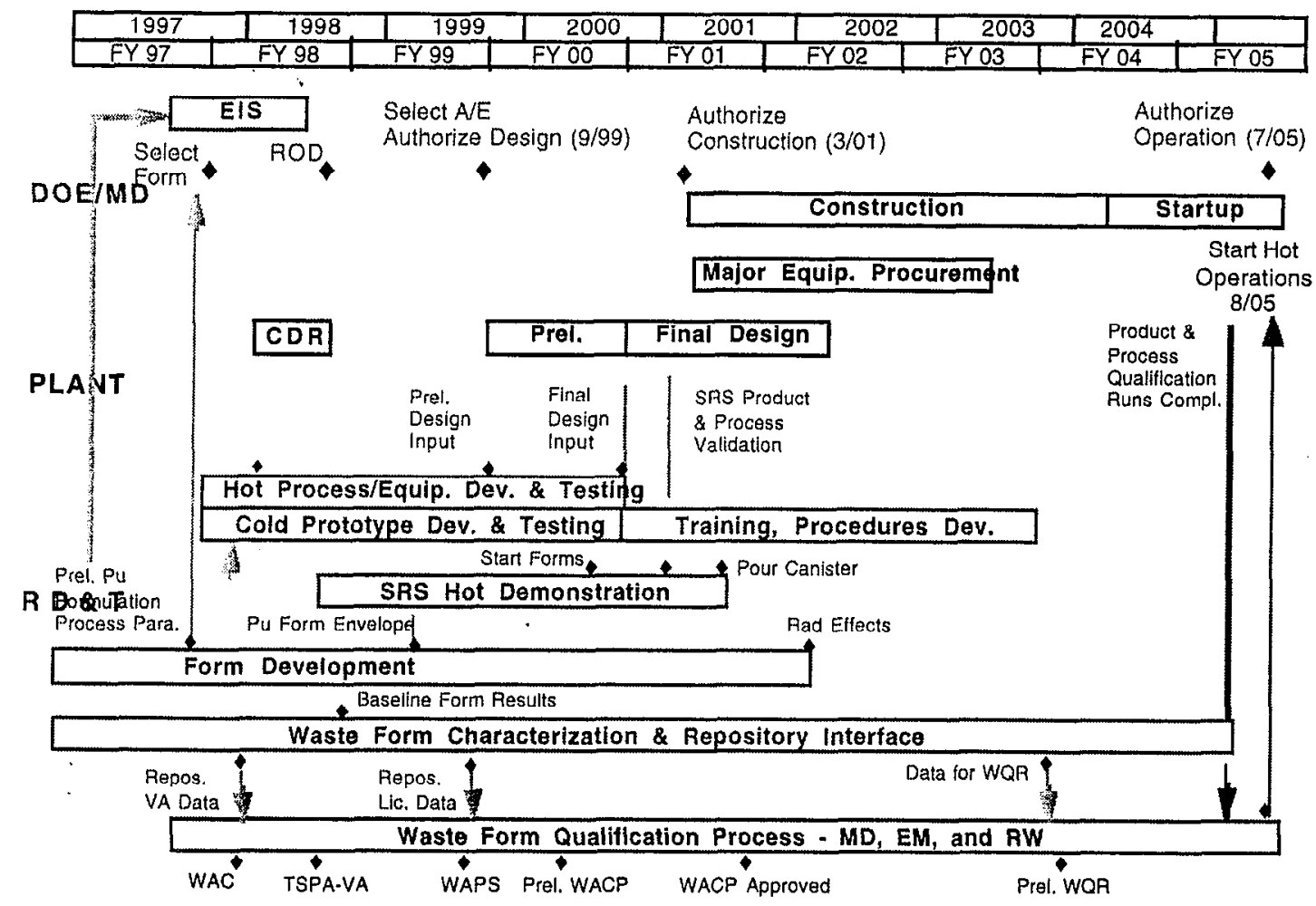




\section{ALTERNATIVES TO THE BASELINES}

In this section, the alternative ceramic and glass forms are described. The ceramic and glass form attributes are given in Table 5.2.1 in a side-by-side comparison with the baseline cases. Only major negative or positive impacts of the alternative immobilization forms and/or processes on the evaluation criteria are noted below.

\subsection{Alternative Ceramic and Glass Forms}

The alternative ceramic and glass baseline forms that have been tested for both the 50-MT and 17-MT plutonium feed streams are capable of immobilizing higher concentrations of plutonium (Table 5.2.1).

For the ceramic, the plutonium loading increases from 10.5 to $>15.7 \mathrm{wt} \%$ for the $50-\mathrm{MT}$ case and from 10.5 to $>16.2 \mathrm{wt} \%$ for the $17-\mathrm{MT}$ case. Depending on the amount of uranium associated with these plutonium loadings, less $\mathrm{UO}_{2}$ needs to be purchased as an additive. Indeed, for the 17-MT case at the higher plutonium loading, no additional $\mathrm{UO}_{2}$ needs to be added (Table 5.2.1). Note that loadings of up to $30 \mathrm{wt} \%$ plutonium $\left(34 \mathrm{wt} \% \mathrm{PuO}_{2}\right)$ in the absence of $\mathrm{UO}_{2}$ are possible in the ceramic form, but the $\mathrm{UO}_{2}$ loading would need to be decreased by a corresponding amount so that the total $\mathrm{PuO}_{2}+\mathrm{UO}_{2}$ loading would be $34 \mathrm{wt} \%$.

For the glass form, the plutonium loading increases from 8.8 to $>10.6 \mathrm{wt} \%$ (Table 5.2 .1 ) or a combined $\mathrm{PuO}_{2}+\mathrm{UO}_{2}$ loading of $24 \mathrm{wt} \%$ (12:12:6 ratio of $\mathrm{PuO}_{2}: \mathrm{UO}_{2}$ :impurity oxides). The glass is now a glass-ceramic containing or micro-encapsulating precipitated $\mathrm{PuO}_{2}$ as planned for encapsulation of Rocky Flats $\mathrm{PuO}_{2}$ residues in glass [Vienna, 1997; Rudisill, 1997]. Since the concentration of $\mathrm{UO}_{3}$ that the LaBS glass can accommodate in the absence of $\mathrm{PuO}_{2}$ is in the range of 25-30 wt\% [Meaker, 1995] and $\mathrm{PuO}_{2}$ is the only precipitated phase observed to form when $\mathrm{PuO}_{2}$ is added, a combined $\mathrm{PuO}_{2}+\mathrm{UO}_{2}$ loading of $>42 \mathrm{wt} \%$ is achievable. Therefore, the $>10.6-\mathrm{wt} \%$ plutonium-loaded glass cited in Table 5.2.1 which precipitated $2-3 \mathrm{wt} \% \mathrm{PuO}_{2}$ represents a conservative lower boundary for the alternative glass baseline. Due to the rapid change of viscosity of the LaBS glass with temperature [Vienna, 1996], any precipitated $\mathrm{PuO}_{2}$ would not be able to gravity-settle to the bottom of the can upon pouring.

Soda-lime-silica (SLS) glass could be used for the alternate baseline glass-ceramic rather than borosilicate glass. SLS glass has a lower solubility for $\mathrm{PuO}_{2}$ but does not experience the neutron irradiation that results from the boron in the borosilicate glass. It should be noted that SLS glassceramic is the baseline being used at Rocky Flats for encapsulation of plutonium residues [Vienna, 1997; Rudisill, 1997].

The higher concentrations of plutonium in the ceramic and glass forms allow more plutonium to be immobilized per DWPF canister (Table 5.2.1). However, this higher loading may make the forms more attractive for host nation reuse or to terrorists. No changes in the process lines or designs are required for the higher plutonium loading. The precipitation of $\mathrm{PuO}_{2}$ has been shown to decrease the release of plutonium from the glass during durability testing [Bibler and Meaker, 1997; Meaker and Bibler, 1997b; Bibler et al., 1995; Chamberlin, 1996]. In addition, significantly lower plutonium recovery rates have been observed for glass containing precipitated $\mathrm{PuO}_{2}$ [Chamberlin, 1997]. 


\section{SUMMARY}

In this document we have described the background (Section 1) of the Fissile Materials Disposition Program starting with the fundamental problem-namely, the large amount of U.S. and Russian plutonium that has become surplus to national defense needs. For excess plutonium disposition, the currently accepted measure of proliferation resistance is the Spent Fuel Standard. This standard, developed as a part of a study on plutonium disposition by the National Academy of Science (NAS), uses expended commercial reactor fuel as a ruler to measure the relative difficulty of theft or retrieval and recovery. The Fissile Materials Disposition Program was formed by DOE shortly after release of the NAS study.

Following an evaluation and screening of options, DOE released a Record of Decision (ROD) that selected two options: immobilization of plutonium in glass or ceramic, and burning in commercial reactors. A surplus quantity of $50 \mathrm{MT}$ of plutonium was defined in the ROD, with roughly $33 \mathrm{MT}$ of relatively pure plutonium and $17 \mathrm{MT}$ of impure plutonium from a variety of sources. The presumption is that the pure plutonium will be burned in the reactors and the relatively impure plutonium will be disposed of through immobilization, which is more tolerant of impurities. If necessary, the immobilization pathway could process the entire $50 \mathrm{MT}$.

The DOE Plutonium Immobilization Program is now approximately two years into a research and development effort and plans to make a decision by October 1997 on the preferred technology (ceramic or glass) for plutonium immobilization. The decision process included a technical review by a Technical Evaluation Panel (TEP), which formally reviewed scientific and engineering data and analysis, process demonstrations, equipment tests, and design and cost studies. The TEP evaluated the ceramic and glass technologies against the set of criteria that DOE used in the screening and down-selection that led to the choice of the reactor and immobilization pathways. These criteria are derived from the NAS Spent Fuel Standard (SFS) and from other requirements, such as cost effectiveness and environmental and other factors (Section 4).

The assumptions and constraints under which this evaluation was conducted are described in Sections 3-5. Principal among these are the plutonium chemical specifications, the postulated site (SRS) and facilities (DWPF and 221-F facilities at SRS), the schedule for startup (2005) and completion (2015) of the 50-MT mission, and the criteria used for the comparative evaluation. The disposition baseline was the can-in-canister configuration, which consists of cans of plutonium-bearing glass or ceramic embedded in DWPF canisters filled with vitrified high-level waste (HLW) (Section 5.3). The cans will be secured by a frame assembly within the canister. The assessment assumes that the canisters will ultimately go to the proposed Yucca Mountain HLW repository.

In order to carry out a side-by-side comparison of the glass and ceramic options, baseline cases were established for both the forms and the processes used to manufacture the forms. These are defined in Section 5, along with details of the glass and ceramic compositions and their manufacturing processes. The known or expected physical properties of the forms (e.g., density, plutonium loading, impurity tolerance) are documented. The planned manufacturing processes are also documented, including all major unit operations, processing parameters and limits, and equipment specifications. Baseline cases are defined for the 50-MT and 17-MT cases (Table 5.2.1). 
The baseline ceramic uses a titanate precursor made up of oxides of titanium ( $56 \mathrm{wt} \%)$, hafnium (17 wt\%), calcium (15 wt\%), and gadolinium (12 wt\%). Plutonium and uranium oxides are added to this precursor to form a powdered mixture that contains $\sim 10 \mathrm{wt} \%$ plutonium and $\sim 21 \mathrm{wt} \%$ uranium. The hafnium and gadolinium are neutron absorbers added for criticality control. Following milling and blending, the powders are loaded into a hydraulic press and compressed into pellets, which are then sintcred at $1350^{\circ} \mathrm{C}$ into a dense hard ceramic. After inspection, the pellets are loaded into cylindrical cans, which are welded closed, loaded into frames, and placed into empty DWPF canisters. The canisters are then filled with HLW glass in the DWPF.

The glass baseline is a homogeneous single-phase lanthanide borosilicate (LaBS) glass made from a frit containing oxides of aluminum, boron, gadolinium, hafnium, lanthanum, neodymium, silicon, and strontium (Table 5.0.2). Following milling and blending, the oxidized uranium and plutonium is co-milled. The powder mixture is then loaded into a stirred melter, where it is heated to approximately $1500^{\circ} \mathrm{C}$. Once the plutonium and uranium oxides have dissolved in the glass, a valve on the bottom of the melter is opened and the glass is poured into a stainless steel can below the melter. After cooling, the cans are trimmed and placed into clean bagless transfer cans. These cans are then welded closed and loaded into frames, which are placed into empty DWPF canisters. The canisters are then filled with HLW glass in the DWPF.

The TEP evaluated the two glass and ceramic forms against the following criteria:

- Resistance to theft and diversion by unauthorized parties.

- Resistance to retrieval, extraction, and reuse by host nation.

- Technical viability.

- Environment, safety, and health compliance.

- Cost effectiveness.

- Timeliness.

Three criteria were not used in the review because of their inherently nontechnical nature:

- Fostering progress and cooperation with Russia and other countries.

- Public and institutional acceptance.

- Additional benefits.

In the following pages, we summarize the key points of each assessment.

Criterion 1. Resistance to theft or diversion by unauthorized parties:

- Low inherent attractiveness.

- Minimization of transportation, facilities, and sites.

- Minimization of processing.

- Safeguards and security assurance.

- Difficulty of retrieval, extraction, and use by a clandestine group or rogue nation. 
The first applicable factor under this criterion is low inherent attractiveness. According to DOE's attractiveness scale, the key metric is the processing time required to reach Category and Attractiveness Level II-D or lower, as defined by DOE Order 5633.3B. Because both processing lines are roughly equal in number and type of unit operations, the processing times are expected to be very similar. However, it was felt by the TEP that the higher plutonium loading in the ceramic is slightly more attractive than the plutonium content of the glass. Overall, this factor is a small discriminator in favor of glass.

The next factor that applies here is the minimization of processing. The first metric is the number of processing steps, including the number of times that plutonium changes physical or chemical form, and the second is the complexity of processing. Both metrics are essentially the same for both glass and ceramic processes.

The safeguards and security factor has the metric of measurement uncertainty or confidence level associated with the ability to measure the amount of plutonium existing in a form. A small discriminator exists here in favor of ceramic because the neutron radiation from the (alpha,n) reactions on the boron in the glass complicates the use of standard nondestructive analysis and measurement techniques. This is not a fundamental problem, however, and gamma spectroscopy may well fill the requirement. The other metric under safeguards and security assurance is accessibility. This is defined as a combination of packaging, access, and special equipment required to handle the nuclear material. In all three, the two forms are indistinguishable. A qualification to this assessment is that many process details have not yet been defined. Collection of dust, compacted, or molten material as well as component corrosion and equipment failure where material resident on removed parts will all make a difference in the accuracy of accountability in the process line, as will equipment complexity or failure rates that cause accountability can become less reliable or accurate. No preference for glass or ceramic is implied by this statement.

The last factor considered under this criterion is the difficulty of retrieval, extraction, and use by a clandestine group or rogue nation. The first metric that applies here is the time and cost to reprocess, defined as the time required to process one significant quantity of plutonium. This metric was regarded by the TEP as roughly the same for glass and ceramic, with ceramic taking somewhat longer because of the more complex recovery process. The White Team draft report discusses process flowsheets and equipment concepts and provides time estimates for recovery. Preparation and recovery times are somewhat greater for the ceramic form than for glass, but not by large margins. A qualification of the above evaluation is that the less capable the chemist attempting the plutonium recovery, the greater the difference in difficulty between the glass and ceramic processes. Evidence of this can be found in examples of nations that have failed at "conventional" recovery operations. Additional metrics here are detectability of reprocessing activities and separability from radiation barrier. The TEP noted no distinguishable differences between the glass and ceramic baselines cases for these metrics.

\section{Criterion 2. Resistance to retrieval, extraction, and reuse by the host nation:}

- Difficulty of retrieval, extraction, and reuse.

- Assurance of detection of diversion and extraction. 
This report assume that the host nation is the United States. However, the plutonium disposition efforts may be driven by concerns in Russia and elsewhere. Another qualification is that this assessment is very context-dependent, in that a particular immobilization technology may achieve the spent fuel standard in one country but not in another. Among the factors that determine this context are the general level of technical and industrial capability, the openness of the socicty, and prior or current reprocessing capability. These factors would affect both the relative difficulty of retrieval and the detectability of such activities.

The first factor for this criterion is difficulty of retrieval, extraction, and reuse, which has the metrics of time and cost required to retrieve and process immobilized plutonium, producing purified plutonium at a rate of at least $1 \mathrm{MT}$ per year. The case studied for this assessment was the postulated use of the 221-F facility at SRS. The White Team estimates that preparing for the ceramic form would take about six months to a year longer than for glass because of additional process steps and materials of construction. The estimate of the metric cost is that the design, procurement, and construction costs would be at least $\$ 100$ million for the glass case and that the ceramic option would cost about $\$ 75$ million more than the glass option. Thus, for the first factor for this criterion, a discriminator exists that slightly favors ceramic.

The second factor under this criterion is the assurance of detection of diversion and extraction. As noted above, this factor is very dependent on the nation of interest. In summary, a difference exists for the detectability of extraction that favors the ceramic option because of its more complex process requirements. However, this difference exists only under a limited set of assumptions and cannot be generalized. Therefore no resolvable discriminator has been identified here.

Criterion 3. Technical viability:

- Technical maturity.

- Viability risks.

- Repository acceptability of disposal form.

The first factor in the technical viability criterion is technical maturity. For this evaluation, the assessment of technical maturity was applied to individual process steps. Ceramic and glass technologies are of similar overall technical maturity. A comparison of process steps for each form reveals finer detail and enables direct comparison of the two forms. Most process steps were rated high in maturity by the TEP members. Section 6.4 .1 contains a more detailed discussion of each of the process steps.

There are two process areas in which technical maturity discriminators were identified: product control, in which glass was ranked medium and ceramic low, and melting/sintering, where ceramic ranked high and glass medium. Although the glass process uses a melter that is only in conceptual design at present, there was no disagreement over the feasibility of the melter, provided adequate development is planned and supported. Outside of these issues, there were no other significant differences identified for the two forms and processes.

The second factor is viability risk. All TEP members expressed the opinion that all process steps for both the glass and ceramic options could be brought to reliable operation, if adequate 
development and testing is scheduled and funded. Based on test data and modeling, there was some uncertainty over void formation in the can-in-canister DWPF glass pour. However, the TEP felt that adequate canister filling could be ensured so long as adequate time and resources are provided. No serious risk issues were identified.

The third factor is repository acceptability of disposal form. The TEP assumed that the geologic repository for the U.S. will be located at Yucca Mountain (Section 3.3). Therefore, at a minimum, the immobilization form must be compatible with the groundwater chemistry and the geologic strata to be acceptable to the Civilian Radioactive Waste Management System (CRWMS). At present, there is no directly applicable guidance for the plutonium immobilization form, but the requirements for the HLW glass were assumed to form the basis for the minimum requirements for this assessment. The immobilized form presents new issues related to criticality safety that were not of concern for the disposal of HLW, and it is possible that additional requirements and/or specifications will be imposed on the immobilized form.

Within the uncertainties of the data and existing analysis, both the glass and ceramic form appear to be adequate with respect to behavior in a geologic repository. In the current baseline for both materials, ample amounts of hafnium are present so that it is likely that more than 100 $\mathrm{kg}$ of plutonium could be safely placed in each waste package. The current baseline processes call for $27 \mathrm{~kg}$ plutonium per DWPF canister for the ceramic form in both the 50-MT and 17-MT options and $23 \mathrm{~kg}$ and $16 \mathrm{~kg}$ plutonium for the $50-\mathrm{MT}$ and 17-MT options, respectively, for the glass form (Table 5.1).

Although both forms appear adequate, there are resolvable differences between them. The degree to which these differences may have value was not assessed by the TEP. The resolvable difference is in the rate at which the materials degrade in water as measured with the four types of dissolution tests employed in the R\&D program. The forward dissolution rate of and elemental release rates from the ceramic are consistently lower than those for glass. Because the process of modeling geochemical behavior over very long times is inherently uncertain, there will always be uncertainty as to whether the plutonium, uranium, and neutron absorbers remain together as the immobilization form degrades. It could therefore be argued that the safest approach is to minimize or delay their release in the first place. The lower degradation rate of the ceramic may be of value in this context. In addition, the added ${ }^{238} \mathrm{U}$ in the ceramic formulation provides an isotopic diluant for the decay-product ${ }^{235} \mathrm{U}$, which may reduce the potential for farfield criticality at long times. The degree to which this will offer a significant margin of criticality safety has not been assessed.

Criterion 4. Environment, safety, and health compliance:

- Public and worker health and safety.

- Waste minimization.

- Known and manageable waste forms.

This criterion must be satisfied for all operations for both immobilization forms in order to comply with applicable federal statutes and DOE orders. 
The first factor is public and worker health and safety, which has the metrics of industrial hazards, radiation exposure, and contamination potential. The TEP concluded there is no differentiation in industrial hazards for the glass and ceramic forms or their processes.

The risk of radiation exposure to the general public is effectively identical for both glass and ceramic process lines and thus is not a discriminator. There is, however, a difference between the glass and ceramic forms when considering worker radiation exposure. There is a substantially higher neutron dose rate from glass, due primarily to the (alpha,n) reaction on the boron in the borosilicate glass. Shielding, isolation, and automation coupled with administrative controls and operator training will be used to meet DOE requirements for worker exposure limits. Once these requirements are met, there is an added requirement to make worker dose as low as reasonably achievable, commonly referred to as ALARA. In the case of glass, further measures (e.g., additional shielding, automated operation) must be taken to control operator dose. The baseline glass formulation generates a radiation dose field seven to nine times higher than the ceramic form which is dominated by the neutron dose contribution. If isotopically enriched ${ }^{10} \mathrm{~B}$ is used, then the glass radiation dose field drops to a factor of three to four times higher than ceramic. The TEP was not able to address worker exposure during process upsets or equipment repairs, where the advantages of remote operation may be lost. Overall, this metric is a small to medium discriminator that favors the ceramic form.

The third metric is contamination potential. Because both waste forms use the same feed preparation operations and particle sizing in the discriminating operations, they are judged to be identical in contamination potential.

The last two factors are waste minimization and known and manageable waste forms. As currently planned, any failed immobilization form will be recycled back into the feed stream for subsequent immobilization. As such, no residues or form-dependent waste forms will be generated. The remaining waste streams involve glovebox waste and facility waste. The TEP was not able to identify any discriminating features between the glass and ceramic forms involving waste.

Criterion 5. Cost effectiveness:

- Life cycle cost.

- Investment and start-up cost.

- Establish product acceptability requirements.

- Potential for cost sharing.

- Utilization of existing infrastructure.

- Cost estimate certainty.

Bechtel and WSRC have evaluated the baseline flowsheets (Section 5) for both glass and ceramic as the processes would be implemented either in 221-F or in a new facility. Within the general range of assumptions that were used in the EIS process, there are insufficient data and design details to discern differences in the cost of implementing either form. In addition, cost data available to the TEP were inadequate to resolve costs along the five factors under the criterion and thus this section does not address these individually. There are, however, identifiable differences that can be estimated for each form. 
There is a differential due to the cost of the additional DWPF canisters that must be poured as a result of the direct displacement of the DWPF HLW glass by cans containing immobilized plutonium. For the 50-MT baseline designs, 140 additional canisters will be required for glass over ceramic. This is based on a $10.5 \mathrm{wt} \%$ plutonium $\left(11.9 \mathrm{wt} \% \mathrm{PuO}_{2}\right.$ ) baseline ceramic loading and a $8.8 \mathrm{wt} \%$ plutonium $\left(10 \mathrm{wt} \% \mathrm{PuO}_{2}\right)$ baseline glass loading. At the assumed program cost of $\$ 500,000$ per extra canister [DOE ATSR, 1997; DOE ROD, 1997] this corresponds to a $\$ 70$ million extra cost for canisters containing the glass form. The cost per canister is currently under review by $\mathrm{DOE} / \mathrm{RW}$ and is likely to increase.

There are also cost differentials due to the higher neutron flux associated with the glass form. As indicated in Section 6.6, the total radiation dose field (external to a glovebox) is approximately seven to nine times higher for the glass form and is dominated by the neutron dose. This higher dose rate, which affects operations and is more difficult to shield than soft gamma rays, impacts cost in several areas. Dose reduction through the use of glass with enriched boron would add $\$ 50$ million in the 50-MT case and $\$ 17$ million in the 17-MT case. This estimate is based on a projected cost of $\$ 3.50$ per gram of boron enriched in ${ }^{10} \mathrm{~B}$. Automation of the processing hardware and additional shielding for maintenance areas would add costs for glass, although no cost data are available for these at present. If, in the glass case, worker dose limits preclude the use of the $221 \mathrm{~F}$ facility, an additional $\$ 140$ million will be required [Maddux, 1997]. Finally, the need to implement ALARA guidelines will be more costly for glass than ceramic, although these costs will not be known until the processing equipment design is more complete. An increase in the neutron quality factor from 10 to 20 (under discussion within the DOE) would effectively double the radiation source terms for neutrons and amplify these issues.

In summary, the overall cost of the baseline glass and ceramic processes, if either were built and installed in the 221-F facility, is effectively the same. There is a cost differential that favors ceramic due to the need to produce more DWPF canisters in the glass case and the added costs for radiation dose control and reduction associated with glass.

\section{Criterion 6. Timeliness:}

- Time to start disposition or time to open facility.

- Time to complete.

- Impacts to existing or future missions.

The first factor to be considered when applying this criterion is the time to start disposition or time to open facility. Because an underlying assumption in the TEP assessment is that funding will be provided as needed to achieve the schedule, there is by definition no difference between the two forms for this metric. The same is true for the second factor, time to complete.

The third factor is the possibility of impacts to existing or future missions. This factor attempts to assess the impact on site and facility selection due to ongoing or already planned missions that would affect the attractiveness of a site or facility. The immobilization of plutonium with can-in-canister packaging in the DWPF facility will reduce the quantity of HLW in each canister and therefore will increase the total number required to dispose of the SRS inventory of high-level waste. The nominal DWPF glass pour rate planned for FY 1998 is feed- 
limited by the amount of funding available to the program at about 220 canisters per year. The immobilization form with the higher plutonium volumetric density potentially has a lower impact on this timeliness issue, which would favor ceramic over glass. This is a discriminator only if the number of plutonium-bearing canisters exceeds the HLW disposal rate. It is not the case at the current rate of canister production. However, if either the (DOE/EM-funded) HLW canister rate falls or the plutonium disposition rate is raised, this could become an issue. In both the glass and ceramic cases, there is an option to use a higher plutonium loading.

\section{Conclusion}

This report documents the results of a technical evaluation of the merits of ceramic and glass immobilization forms for the disposition of surplus weapons-useable plutonium. The evaluation was conducted by a Technical Evaluation Panel (TEP) whose members were selected to cover a relevant range of scientific and technical expertise and represent each of the technical organizations involved in the Plutonium Immobilization Program. The TEP held a formal review at LLNL on July 28-31, 1997. The TEP documented the review and its evaluation in this report to provide a technical basis for a recommendation by LLNL to the DOE as to the preferred immobilization form.

The two forms and their processes are similar in many ways, and the comparison of the glass and ceramic forms and their manufacturing processes was a tremendous challenge to the TEP. The TEP went to great effort to accurately assess fine details of the processes, unit operations, and the glass and ceramic forms themselves. The set of criteria used by the Fissile Materials Disposition Program in past screenings and down-selections was used here to measure the two options, with the exception that the TEP did not consider the nontechnical criteria (namely international impact, public acceptance, and effect on other programs or missions). Care was taken to ensure that data used were well documented and traceable to the source.

It was not within the TEP's charter to draw a conclusion as to which form is "better" and no such conclusion was reached. Nonetheless, the TEP notes that there were more discriminators in favor of ceramic. Without a relative weight applied to the individual discriminators, no overall conclusion is possible. The decision to select one form over another will, of course, require the consideration of many additional factors, constraints, and policy issues, all of which are well outside the scope of this review. 


\section{GLOSSARY}

\author{
Absorbed Dose \\ Accident Sequence
}

Actinides

Acute

Acute Exposure

Additivity

Alloy

Alpha Activity

Alpha Particle

Alpha Wastes

Alternative Option

Ambient Air

Annealing

As Low as Reasonably Achievable

Section 9 - Glossary
The energy imparted to matter by ionizing radiation per unit mass of irradiated material at the place of interest in that material. Expressed in units of radiation (rad) or grays, where 1 rad equals 0.01 gray. See "radiation absorbed dose."

An initiating event followed by system failures or operator errors which can result in significant core damage, confinement system failure, and/or radionuclide release.

Radioactive elements with atomic numbers greater than 88 (i.e., 89 or higher). Minor actinides: radioactive elements with atomic numbers greater than 95 (i.e., 96 or higher).

Extremely severe or intense for a limited amount of time.

The exposure incurred during and shortly after a radiological release. Generally, the period of acute exposure ends when long-term interdiction is established, as necessary. For convenience, the period of acute exposure is normally assumed to end one week after the inception of a radiological accident.

Properties of individual oxides in glass are thermodynamically defined partial : molar quantities which are additive; in additive calculation of glass properties from composition it is, therefore, possible and advantageous to conceive of the additive factors as thermodynamic quantities and to determine the property as a specific contribution of each oxide in the glass [M. B. Volf, "Mathematical Approach to Glass," Glass Science and Technology, Vol. 9, Elsevier Science Publishing Co., New York, 1988].

A homogeneous mixture of two or more metals.

The emission of alpha particles by fissionable materials (uranium or plutonium).

A positively charged particle, consisting of two protons and two neutrons, that is emitted during radioactive decay from the nucleus of certain nuclides. It is the least penetrating of the three common types of radiation (alpha, beta, and gamma).

Wastes containing radioactive isotopes which decay by producing alpha particles.

A group of alternative pathways through a different specific set of facilities than that of the baseline option.

The surrounding atmosphere as it exists around people, plants, and structures.

A controlled cooling process for glass designed to reduce residual stress to a commercially acceptable level and modify structure [Ceramic Glossary, W. W. Perkins, Ed., The American Ceramic Society, Westerville, Ohio, 1984].

A concept applied to the quantity of radioactivity released in routine operation of a nuclear system or facility, including "anticipated operational occurrences." It takes into account the state of technology, economics of improvements in 
Atomic Energy Act of 1954

Background Radiation

Baseline

Beta Activity

Beta Particle

Brannerite

Calcination

Calcine

CANDU

Cesium

Conceptual Design

Container

Conversion

Section 9-Glossary relation to benefits to public health and safety, and other societal and economic considerations in relation to the use of nuclear energy in the public interest.

Legislation originally enacted in 1946 and amended in 1954 calling for "...a program for Government control of the possession, use, and production of atomic energy and special nuclear material whether owned by the Government or others, so directed as to make the maximum contribution to the common defense and security and the national welfare, and to provide continued assurance of the Government's ability to enter into and enforce agreements with nations or groups of nations for the control of special nuclear materials and atomic weapons..." [Section 3(c)].

Ionizing radiation present in the environment from cosmic rays and natural sources in the earth; background radiation varies considerably with location. See "natural radiation."

A quantitative expression of conditions, costs, schedule, or technical progress to serve as a base or standard for measurement during the performance of an effort; the established plan against which the status of resources and the progress of a project can be measured.

The emission of beta particles by radioisotopes.

An elementary particle emitted from a nucleus during radioactive decay; it is negatively or positively charged, identical in mass to an electron, and in most: cases easily stopped, as by a thin sheet of metal.

In nature, essentially (UO,TiO, $\mathrm{UO}_{2}$ ) TiO 3 [E. S. Dana, $A$ Textbook of Mineralogy, 4th Ed., Wiley \& Sons, New York, 1932].

The process of converting high-level waste to unconsolidated granules or powder. Calcined solid wastes are primarily salts and oxides of metals (heavy metals) and components of high-level waste (also called calcining).

Drying of liquids or other material at high temperature (approximately $800^{\circ} \mathrm{C}$ ) to drive off water and other volatile substances.

A nuclear reactor in which circulating heavy water is used to cool the reactor core and to moderate (reduce the energy of) the neutrons crated in the core by the fission reactions.

A silver-white alkali metal. A radioactive isotope of cesium, ${ }^{137} \mathrm{Cs}$, is a common fission product.

Efforts to develop a project scope that will satisfy program needs, ensure project feasibility and attainable performance levels of the project for congressional consideration, develop project criteria and design parameters for all engineering disciplines, and identify applicable codes and standards, quality assurance requirements, environmental studies, construction materials, space allowances, energy conservation features, health and safety safeguards, security requirements, and any other features or requirements necessary to describe the project.

The metal envelope in the waste package that provides the primary containment function of the waste package and is designed to meet the containment requirements of 10 CFR 60 .

An operation for changing material from one form, use, or purpose to another. 


\section{Counterproliferation}

Criticality

Crystalline Rock

Decay (Radioactive)

Decay Heat (Radioactivity)

Decontamination

Density

Depleted Uranium

Design Basis
Activities across the full range of U.S. efforts to combat proliferation, including diplomacy, arms control, export controls, and intelligence collection and analysis, with particular responsibility for ensuring that U.S. forces and interests can be protected should they confront an adversary armed with weapons of mass destruction.

A state in which a self-sustaining nuclear chain reaction is achieved.

Rock consisting of minerals in a crystalline state.

The decrease in the amount of any radioactive material with the passage of time, due to the spontaneous transformation of an unstable nuclide into a different nuclide or into a different energy state of the same nuclide; the emission of nuclear radiation (alpha, beta, or gamma radiation) is part of the process.

The heat produced by the decay of certain radionuclides.

The removal of radioactive or chemical contamination from facilities, equipment, or soils by washing, heating, chemical or electrochemical action, mechanical cleaning, or other techniques.

Without modifier, the weight of an object or material divided by the volume it occupies (its external volume), hence its weight per unit volume; ordinarily expressed in either grams per cubic centimeter $\left(\mathrm{g} / \mathrm{cm}^{3}\right)$ [or in pounds per cubic foot $\left.\left(\mathrm{lb} / \mathrm{ft}^{3}\right)\right]$. The weight of an object or material is readily determined. However, in materials handling and usage, several characteristic "volumes" and their corresponding void fractions must be recognized; each "volume" gives rise to a different characteristic density. These are named and described below, in order from the highest density (smallest "volume") to the lowest density (largest "volume"): True or theoretical density, computed from the true volume or theoretical volume of the solid as measured, for example, by $\mathrm{x}$-ray diffraction. The true volume contains no pores or voids. Apparent density, computed from the apparent volume as measured, for example, by determining the nominal or envelope volume and subtracting from it the water absorption or mercury porosity (approximating the connected or open pore volume). The apparent volume is the true volume plus the volume of closed pores only. For nodules, pellets, and extrudates used as desiccants and catalysts, the apparent density is also called the skeletal density. Particle density, computed from the nominal or envelope volume. This characteristic volume includes the true volume plus that of all internal pores, both closed and connected or open. Bulk density, computed from the bulk volume of an unconsolidated solid. This is the overall volume (viz. volume of container) occupied, including the interparticle packing space. The manner of filling (e.g. loose, packed, tapped, tamped, or vibrated) must be specified as well. For a consolidated solid, the bulk volume and nominal volume are the same, and the bulk density computed therefrom accounts for the total porosity. Consolidated materials may require further descriptors prefixed to density as well (e.g., green, dried, cured, fired) [Ceramic Glossary, W. W. Perkins, Ed., The American Ceramic Society, Westerville, Ohio, 1984].

Uranium whose content of the isotope ${ }^{235} \mathrm{U}$ is less than $0.7 \%$, which is the ${ }^{235} \mathrm{U}$ content of naturally occurring uranium.

For nuclear facilities, information that identifies the specific functions to be performed by a structure, system, or component and the specific values (or ranges of values) chosen for controlling parameters for reference bounds for design. These values may be (1) restraints derived from generally accepted stateof-the-art practices for achieving functional goals, (2) requirements derived from 


\section{Devitrification}

\section{Disposal}

Disposition

\author{
Dissolution
}

Dose

Dose Equivalent

Effective Dose Equivalent

Empirical

Engineered Safety Features

Environmental Assessment

Environmental Impact Statement analysis (based on calculation and/or experiments) of the effects of a postulated accident for which a structure, system, or component must meet its functional goals, or (3) requirements derived from federal safety objectives, principles, goals, or requirements.

Controlled or uncontrolled crystallization of glass (ASTM C162). A surface defect manifested by loss of gloss as a result of crystallization [Ceramic Glossary, W. W. Perkins, Ed., The American Ceramic Society, Westerville, Ohio, 19841.

The process of placing waste in an interim or final repository.

The ultimate condition of surplus fissile material following transformation into a highly radioactive form similar to spent nuclear fuel and/or emplacement into a deep borehole.

The chemical dispersal of a solid throughout a liquid medium.

The energy imparted to matter by ionizing radiation. The unit of absorbed dose is the rad.

The product of absorbed dose in rad (or gray) and the effect of this type of radiation in tissue and a quality factor. Dose equivalent is expressed in units of rem or sievert, where 1 rem equals 0.01 sievert. The dose equivalent to an organ, tissue, or whole body will be that received from the direct exposure plus the 50-year committed dose equivalent received from the radionuclides taken into the body during the year.

The summation of the products of the dose equivalent received by specified tissues of the body and a tissue-specific weighting factor. This sum is a riskequivalent value and can be used to estimate the health effects risk of the exposed individual. The tissue-specific weighting factor represents the fraction of the total health risk resulting from uniform whole-body irradiation that would be contributed by that particular tissue. The effective dose equivalent includes the committed effective dose equivalent from internal deposition of radionuclides and the effective dose equivalent due to penetrating radiation from sources external to the body. Effective dose equivalent is expressed in units of rem (or sievert).

Something that is based on actual measurement, observation, or experience rather than on theory.

For a nuclear facility, features that prevent, limit, or mitigate the release of radioactive material from its primary containment.

A written environmental analysis that is prepared pursuant to the National Environmental Protection Act to determine whether a federal action would significantly affect the environment and thus require preparation of a more detailed Environmental Impact Statement. If the action does not significantly affect the environment, then a finding of "no significant impact" is prepared.

A document required of federal agencies by the National Environmental Protection Act to determine whether a federal action would significantly for major proposals or legislation significantly affecting the environment. A tool for decision-making, it describes the positive and negative effects of the undertaking and alternative actions. 


\section{Exposure Limit}

Fissile

Fissile Material

Fission

Fission Products

Fissionable Material

Frit

\section{Gamma Radiation}

Gamma Rays

Geologic Repository (Mined Geologic Repository)

Glass
The level of exposure to a hazardous chemical (set by law or a standard) at which or below which adverse human health effects are not expected to occur. Reference dose is the chronic exposure dose $(\mathrm{mg} / \mathrm{kg} / \mathrm{d})$ for a given hazardous chemical at which or below which adverse human noncancer health effects are not expected to occur. Reference concentration is the chronic exposure concentration $\left(\mathrm{mg} / \mathrm{m}^{3}\right)$ for a given hazardous chemical at which or below which adverse human noncancer health effects are not expected to occur.

Nuclear materials that are fissionable by slow (thermal) neutrons. Fissile materials include ${ }^{235} \mathrm{U},{ }^{233} \mathrm{U},{ }^{239} \mathrm{Pu}$, and ${ }^{241} \mathrm{Pu}$. Materials such as ${ }^{238} \mathrm{U}$ and ${ }^{232} \mathrm{Th}$, which can be converted into fissile materials, are called fertile materials. It should be noted that ${ }^{232} \mathrm{Th},{ }^{238} \mathrm{U}$, and all plutonium isotopes are fissionable by fast neutrons but not by thermal (slow) neutrons. They are not fissile materials but may be called fissionable materials.

The isotopes ${ }^{239} \mathrm{Pu},{ }^{241} \mathrm{Pu},{ }^{233} \mathrm{U},{ }^{235} \mathrm{U}$, or any material containing any of the foregoing.

The splitting of a heavy atomic nucleus into at least two nuclei of lighter elements, accompanied by the release of energy and generally one or more neutrons. Fission can occur spontaneously or can be induced by neutron bombardment.

Nuclei formed by the fission of heavy elements (primary fission products); also, the nuclei formed by the decay of the primary fission products, many of which : are radioactive.

Material whose nuclei fission when bombarded by neutrons.

Finely ground glass used as feedstock input for vitrification. (MD Glossary). Glass in particulate form, generally of controlled size distribution (ASTM C162). A glass produced by fritting, which contains fluxing material and is employed as a constituent in a glaze, body, or other ceramic composition [Ceramic Glossary, W. W. Perkins, Ed., The American Ceramic Society, Westerville, Ohio, 1984].

Short-wavelength electromagnetic radiation of nuclear origin, similar to but with higher energy than $x$ rays.

High-energy, short-wavelength electromagnetic radiation accompanying fission and emitted from the nucleus of an atom. Gamma rays are very penetrating and can be stopped only by dense materials (e.g., lead) or a thick layer of shielding materials.

A facility for the disposal of nuclear waste; the waste is isolated by placement in a continuous, stable geologic formation at depths greater than $300 \mathrm{~m}$.

An inorganic cooled product of fusion that has cooled to a rigid condition without crystallizing. (a) Glass is typically hard and brittle and has a conchoidal fracture. (b) A glass may be colorless or colored. (c) When a specific kind of glass is indicated, such descriptive terms as flint glass, barium glass, and window glass should be used following the basic definition, but the qualifying term is to be used as understood by trade custom. (d) Objects made of glass are loosely and popularly referred to as glass, such as glass for a tumbler, a barometer, a window, a magnifier, or a mirror [Ceramic Glossary, W. W. Perkins, Ed., The American Ceramic Society, Westerville, Ohio, 1984]. 
Glovebox

\section{Granulator}

Half-Life (Radiological)

Hazardous/Toxic Waste

Heavy Metals

High Efficiency Particulate Air (HEPA) Filter

High-Level Waste

Highly Enriched Uranium

Interim Storage

Isotope

Joule

Liquid Phase Sintering

Long-Lived Radionuclides
An airtight box used to work with hazardous material, vented to a closed filtering system, having gloves attached inside of the box to protect the worker.

A machine that produces body raw material in the form of grains with a minimum of fines [Ceramic Glossary, W. W. Perkins, Ed., The American Ceramic Society, Westerville, Ohio, 1984].

The time in which half of the atoms of a radioactive substance decay to another nuclear form; this varies for specific radioisotopes from millionths of a second to billions of years.

Any solid waste (can also be semisolid or liquid, or contain gaseous material) having the characteristics of ignitability, corrosivity, toxicity, or reactivity, defined by the Resource Conservation and Recovery Act and identified or listed in 40 CFR 261 or by the Toxic Substances Control Act.

Metallic or semimetallic elements of high molecular weight, such as mercury, chromium, cadmium, lead, and arsenic, that are toxic to plants and animals at known concentrations.

A filter used to remove particulates from dry gaseous effluent streams.

Highly radioactive waste material that results from the reprocessing of spent nuclear fuel, including liquid waste produced directly in reprocessing and any : solid waste derived from the liquid. High-level waste contains a combination of transuranic waste and fission products in concentrations requiring permanent isolation.

Uranium enriched in isotope ${ }^{235} \mathrm{U}$ to $20 \%$ or above, which becomes suitable for weapons use.

Providing safe and secure capacity in the near term to support continuing operations in the interim period ( 20 years).

An atom of an element with a specific atomic number and atomic mass. Isotopes of the same element have the same number of protons (atomic number) but different numbers of neutrons and different atomic masses.

A metric unit of energy, work, or heat, equivalent to 1 watt- second, 0.737 footpound, or 0.239 calories.

A means of manufacturing dense ceramic components from powder compacts in the presence of a liquid phase (usually 1-20 vol\%). Sometimes considered a form of vitrification due to the presence of the liquid phase at the sintering temperature. Liquid phase sintering is highly dependent on the viscosity of the liquid phase at the sintering temperature since the viscosity of the liquid phase can change 10,000 poise over a $100^{\circ} \mathrm{C}$ change in temperature. In general, more parameters to be controlled than during solid phase sintering. During liquid phase sintering, the redox, particle size, mixedness, and liquid phase composition must be carefully controlled. The liquid phase sometimes crystallizes during cooling of the ceramic and sometimes remains amorphous [W. D. Kingery, Introduction to Ceramics, John Wiley \& Sons, New York, 1960; O. H. Kwon, "Liquid Phase Sintering," in Ceramics and Glasses, Vol. 4, ASM International].

Radioactive isotopes with half-lives greater than about 30 years. 
Low Enriched Uranium

Low-Level Waste

Macrobatch

Metal

Metamict

Mixed Oxide

Mixed Waste

Mixedness

Natural Uranium

Neutron Poison

Nonproliferation

Nonproliferation Treaty
Naturally occurring uranium contains only about $0.7 \%{ }^{235} \mathrm{U}$ and almost all of the rest is ${ }^{238} \mathrm{U}$. Low enriched uranium is enriched in the isotopic content of ${ }^{235} \mathrm{U}$ to greater than $0.7 \%$ but less than $20 \%$ of the total mass for use as light water reactor fuel.

Waste that contains radioactivity but is not classified as high-level waste, transuranic waste, spent nuclear fuel, or " $11 \mathrm{e}(2)$ by-product material" as defined by DOE Order 435.1, Radioactive Waste Management. Test specimens of fissionable material irradiated for research and development only and not for the production of power or plutonium may be classified as low-level waste, provided the concentration of transuranic waste is less than 100 nanocuries per gram. Some low-level waste is considered classified because of the nature of the generating process and/or constituents, because the characteristics of the waste would reveal too much about the process by which it was produced.

Any time a chemical change is made to the incoming feed batch [Waste Acceptance Product Specifications for the DWPF, 1996].

Essentially pure plutonium metal that meets weapons specifications. The plutonium can be weapons grade, fuels grade, or reactor grade. The metal may have oxidation or casting residues on the surface.

Crystalline substances that have become amorphous from the passage of alpha particles emitted from their own radioactive content [W. Primak, "The Metamict State," Phys. Rev. 95 (3), 1954]. One of three classes of amorphous : substances defined by Broegger [1893] as follows: "For this third class of amorphous substances there is herewith proposed the name 'metamict' (from $\mu \varepsilon \tau \alpha \mu \imath \gamma \cup \mu$, mix otherwise, that is by a molecular rearrangement to another molecular structure than the original crystalline) amorphous substances. The reason for the amorphous rearrangement of the molecules might perhaps be sought in the lesser stability which so complicated a crystal molecule as that of these minerals must have in the presence of outside influences." In nature, the most common metamict minerals are niobates, tantalates, titanates, zircon, gadolinite, thorite, etc. [A. Pabst, "The Metamict State," Amer. Mineralogist 37 (3-4), 137-157, 1952].

A physical blend of uranium oxide and plutonium oxide.

Waste that contains both hazardous waste and radioactive waste as defined in this glossary.

The state of the mixture that can be described after chemical or physical analysis [J. S. Reed, Introduction to the Principle of Ceramic Processing, John Wiley \& Sons, p. 280, 1988].

Uranium with $\mathrm{a}^{235} \mathrm{U}$ concentration of approximately $0.7 \%$, the average concentration of ${ }^{235} \mathrm{U}$ in uranium in the natural pre-enriched state.

A chemical solution (e.g., boron or rare earth solution) injected into a nuclear reactor to absorb neutrons and end criticality.

Preventing the spread of nuclear weapons, nuclear weapons materials, and nuclear weapon technology.

A treaty with the aim of controlling the spread of nuclear weapons technologies, limiting the number of nuclear weapons states and pursuing, in good faith, effective measures relating to the cessation of the nuclear arms race. The treaty 
Nuclear Facility

Nuclear Grade

Nuclear Material

Nuclear Weapon

Nuclide

Option

Oxidation

Oxide

Perovskite

Person-rem

pH

Plutonium

Precipitate

Precursor

Section 9 - Glossary does not invoke stockpile reductions by nuclear states, and it does not address actions of nuclear states in maintaining their stockpiles.

A facility whose operations involve radioactive materials in such form and quantity that a nuclear hazard potentially exists to the employees or the general public. Included are facilities that produce, process, or store radioactive liquid or solid waste, fissionable materials, or tritium; conduct separations operations; conduct irradiated materials inspection, fuel fabrication, decontamination, or recovery operations; or conduct fuel enrichment operations. Incidental use of radioactive materials in a facility operation (e.g., check sources, radioactive sources, and $\mathrm{x}$-ray machines) does not necessarily require a facility to be included in this definition.

Material of a quality adequate for use in a nuclear application.

Composite term applied to (1) special nuclear material; (2) source material such as uranium or thorium or ores containing uranium or thorium; and (3) byproduct material, which is any radioactive material that is made radioactive by exposure to the radiation incident to the process of producing or using special nuclear material.

The general name given to any weapon in which the explosion results from the energy released by reactions involving atomic nuclei, either fission, fusion, or both.

A species of atom characterized by the constitution of its nucleus and hence by the number of protons, the number of neutrons, and the energy content.

A group of related alternative pathways through a specific set of facilities that takes surplus fissile material to complete disposition. See "alternative options."

The combination of an atom with another atom (normally oxygen). During this reaction, the atom combines with oxygen and loses electrons.

A compound in which an element (such as plutonium) is bonded to oxygen.

In nature, essentially $\mathrm{CaTiO}_{3}$ [E. S. Dana, $A$ Textbook of Mineralogy, 4th Ed., John Wiley \& Sons, New York, 1932].

The unit of collective radiation dose commitment to a given population; the sum of the individual doses received by a population segment.

A numeric value that indicates the relative acidity or alkalinity of a substance on a scale of 0 to 14, with the neutral point at 7.0. Acid solutions have $\mathrm{pH}$ values less than 7.0 and basic (alkaline) solutions have $\mathrm{pH}$ values greater than 7.0.

A heavy, radioactive, metallic element with the atomic number 94 . It is produced artificially in a reactor by bombardment of uranium with neutrons and is used in the production of nuclear weapons.

To cause a solid substance to become separate from a solution; the solid substance that has separated from solution.

Mechanical mixture of oxides, oxide gels, alkoxides, nitrates, hydroxides, carbonates, etc., mixed together before a ceramic is either sintered, fired, or hotpressed into a crystalline oxide ceramic [Jantzen, personal communication]. 
Probabilistic Risk Assessment

Process

Programmatic Environmental Impact Statement

Project

Project-Specific Environmental Impact Statement

Proliferation

Protected Area

Pyrochlore

Rad.

Radiation

Radiation Absorbed Dose

Radioactive Waste

Radioactivity

Radioisotopes

Radiolysis

Radionuclide
A comprehensive, logical, and structured methodology to identify and quantitatively evaluate significant accident sequences and their consequences.

To extract, separate, or purify a substance by physical or chemical means (e.g., to remove actinides).

A legal document prepared in accordance with the requirements of $102(2)(\mathrm{C})$ of the National Environmental Protection Act that evaluates the environmental impacts of proposed federal actions that involve multiple decisions potentially affecting one or more sites.

Any undertaking with a defined starting point and defined objectives by which completion is identified.

A legal document prepared in accordance with the requirements of 102(2)(C) of the National Environmental Protection Act that evaluates the environmental impacts of a single action at a single site.

The spread of nuclear, biological, and chemical weapon capabilities and the systems to deliver them.

An area encompassed by physical barriers, subject to access controls, surrounding material access areas, and meeting the standards of DOE Order 473.1, Protection and Control of Safeguards and Security Interests.

In nature, essentially niobates and tantalates of $\mathrm{RNb}_{2} \mathrm{O}_{6}$ and $\mathrm{RTa}_{2} \mathrm{O}_{6}$ and in part pyroniobates, $\mathrm{R}_{2} \mathrm{Nb}_{2} \mathrm{O}_{7}$. Titanium is prominent in a number of the species, which are hence intermediate between the niobates and titanates where $\mathrm{R}=\mathrm{Ca}^{+2}$ or $2 \mathrm{Na}^{+}$. Chiefly a niobate of the cerium metals, calcium and other bases, with also titanium, thorium, fluorine $\mathrm{RNb}_{2} \mathrm{O}_{6} \cdot \mathrm{R}(\mathrm{Ti}, \mathrm{Th}) \mathrm{O}_{3}$ [E. S. Dana, $A$ Textbook of Mineralogy, 4th Ed., John Wiley \& Sons, New York, 1932].

See "radiation absorbed dose."

The emitted particles or photons from the nuclei of radioactive atoms. Some elements are naturally radioactive; others are induced to become radioactive by bombardment in a reactor. Naturally occurring radiation is indistinguishable from induced radiation.

The basic unit of absorbed dose equal to the absorption of 0.01 joule per kilogram of absorbing material.

Materials from nuclear operations that are radioactive or are contaminated with radioactive materials and for which use, reuse, or recovery are impractical.

The spontaneous decay or disintegration of unstable atomic nuclei, accompanied by the emission of radiation.

Radioactive nuclides of the same element (same number of protons in their nuclei) that differ in their number of neutrons.

Chemical decomposition induced by radiation.

A radioactive element characterized according to its atomic mass and atomic number which can be manmade or naturally occurring. Radionuclides can have a 


\section{Record of Decision}

Reduction

Rem

Residue

Resource Conservation and Recovery Act, as amended

Risk

Roentgen

Roentgen Equivalent Man

Rutile

Scrap

Shielding

Short-Lived Nuclides

Silica

Sinter

Sintering long life as soil or water pollutants and are believed to have potentially mutagenic or carcinogenic effects on the human body.

A document prepared in accordance with the requirements of 40 CFR 1505.2 that provides a concise public record of the DOE's decision on a proposed action for which an Environmental Impact Statement was prepared. A Record of Decision identifies the alternatives considered in reaching the decision, the environmentally preferable alternative(s), factors balanced by the DOE in making the decision, whether all practicable means to avoid or minimize environmental harm have been adopted, and if not, why not.

The conversion of a compound such as plutonium dioxide or plutonium tetrafluoride into metal or the conversion of $\mathrm{UO}_{3}$ to $\mathrm{UO}_{2}$.

See "roentgen equivalent man."

Plutonium materials in process or left over from processes of making weapons.

Legislation that provides "cradle to grave" regulatory program for hazardous waste and which established, among other things, a system for managing hazardous waste from its generation until its ultimate disposal.

A quantitative or qualitative expression of possible loss that considers both the probability that a hazard will cause harm and the consequences of that event.

A unit of exposure to ionizing $\mathrm{x}$ or gamma radiation equal to or producing one electrostatic unit of charge per cubic centimeter of air. It is approximately equal to $1 \mathrm{rad}$.

The unit of radiation dose for biological absorption; equal to the product of the absorbed dose (in rads) and a quality factor that accounts for the variation in biological effectiveness of different types of radiation. Also known as "rem."

In nature, essentially $\mathrm{TiO}_{2}$ [E. S. Dana, $A$ Textbook of Mineralogy, 4th Ed., John Wiley \& Sons, New York, 1932].

Plutonium materials in process or left over from process of making weapons.

Any material of obstruction (bulkheads, walls, or other construction) that absorbs radiation in order to protect personnel or equipment.

Radioactive isotopes with half-lives no greater than about 30 years (e.g., ${ }^{137} \mathrm{Cs},{ }^{90} \mathrm{Sr}$ ).

Silicon dioxide, a common mineral that occurs naturally as quartz.

To densify, crystallize, bond together, and/or stabilize a particulate material, agglomerate, or product by heating or firing close to but below the melting point. A ceramic material or mixture fired to less than complete fusion, resulting in a coherent mass, or the process involved [Ceramic Glossary, W. W. Perkins, Ed., The American Ceramic Society, Westerville, Ohio, 1984].

The bonding of adjacent surfaces of particles in a mass of powder or a compact by heating [Ceramic Glossary, W. W. Perkins, Ed., The American Ceramic Society, Westerville, Ohio, 1984]. 
Solubility

Special Nuclear Material

Spent Nuclear Fuel

Spent Fuel Standard

Stabilize

Storage

Technology

Thermal Stability

Theoretical Density

Transuranic

Transuranic Waste

Treatment

Uranium

Vitrification

Waste
The solubility of a given solute is that quantity of the solute that will dissolve in a specified quantity of solvent to produce a saturated solution [W. H. Nebergall et al., College Chemistry with Qualitative Analysis, pp. 303-304, D.C. Heath \& Co, 1980].

As defined in Section 11 of the Atomic Energy Act of 1954, special nuclear material means plutonium, uranium enriched in the isotope 233 or in the isotope 235 , and any other material which the Nuclear Regulatory Commission determines to be special nuclear material, or any material artificially enriched by any of the foregoing materials.

Irradiated reactor fuel that is no longer useful as fuel.

A disposal standard whereby weapons-usable plutonium is made as inaccessible and unattractive for weapons use as is the plutonium in spent fuel from commercial reactors.

To convert a compound, mixture, or solution to a nonreactive form.

Any method of keeping items while awaiting use, transportation, consumption, or other disposition.

A specific technical component that is subset of a facility; e.g., glass melter and feed preparation technology might fall under vitrification of plutonium in borosilicate glass.

Range of temperatures in which a glass remains a glass and does not crystallize or devitrify [Jantzen, personal communication].

The density of a material calculated from the number of atoms per unit cell and measurement of the lattice parameters [Ceramic Glossary, W. W. Perkins, Ed., The American Ceramic Society, Westerville, Ohio, 1984]. See also "density."

Any element whose atomic number is higher than that of uranium (atomic number 92). All transuranic elements are produced artificially and are radioactive.

Waste contaminated with alpha-emitting radionuclides with half-lives greater than 20 years and concentrations greater than 100 nanocuries per gram at time of assay. Transuranic waste is not a mixed waste.

An operation necessary to prepare material for disposal.

A heavy, silvery-white metallic element (atomic number 92) with many radioactive isotopes. Isotope ${ }^{235} \mathrm{U}$ is most commonly used as a fuel for nuclear fission. Isotope ${ }^{238} \mathrm{U}$ is transformed into fissionable ${ }^{239} \mathrm{Pu}$ following its capture of a neutron in a nuclear reactor.

A waste treatment process that uses glass (e.g., borosilicate glass) to encapsulate or immobilize radioactive wastes to prevent them from reacting in disposal sites. The characteristic of a clay product resulting when the kiln temperature is sufficient to fuse grains and close surface pores, forming an impervious mass. The progressive reduction in porosity of a ceramic composition as a result of heat treatment, or the.process involved [Ceramic Glossary, W. W. Perkins, Ed., The American Ceramic Society, Westerville, Ohio, 1984].

A discardable residue from a manufacturing or purification process. 


\section{Waste Package}

Weapons-Grade Material

Weapons-Usable Material

Zirconolite

Zirconia Grain Stabilized
The waste, waste container, and any absorbent that are intended for disposal as a unit. In the case of surface-contaminated, damaged, leaking, or breached waste packages, any overpack shall be considered the waste container and the original container shall be considered part of the waste.

Plutonium or highly enriched uranium (HEU), in metallic form, that has been removed from nuclear weapons as a result of stockpile downsizing, and plutonium and HEU parts that were manufactured for weapons application and are no longer required.

Plutonium and highly enriched uranium, in various forms (e.g., metals and oxides), that could be used in weapons (with varying degrees of processing difficulty)

In nature, essentially $\mathrm{CaZrTi}_{2} \mathrm{O}_{7}[\mathrm{~V}$. Bouska, "A Systematic Review of Metamict Minerals," Acta Universitatis Carolinae-Geologica (3), 143-169 (1970)].

A variety of oxide grain stabilized (OGS) which is solid solution strengthening of an alloy by inclusion of oxide particles in the metal matrix and subsequent alignment of the particles on the grain boundaries. The oxide particles strengthen the alloy by pinning the grain boundaries and inhibit grain growth during thermal cycling. The oxides commonly used are $\mathrm{ZrO}_{2}$ for zirconia grain stabilization (ZGS) or $\mathrm{Y}_{2} \mathrm{O}_{3}$ for yttria grain stabilization (YGS) in a platinum/ruthenium alloy. 


\section{SECTION TO COME? OR RENUMBER?}




\section{REFERENCES}

1. ASTM, "Standard Test Method for Static Leaching of Monolithic Waste Forms for Disposal of Radioactive Waste," ASTM-C-1220-92, 1992.

2. ASTM, "Standard Test Methods for Determining Chemical Durability of Nuclear Waste Glasses: The Product Consistency Test (PCT)," ASTM-C-1285-94, 1994.

3. Bakel, A. J. and E. C. Buck. "Corrosion Testing of the MD Ceramic." Presentation to the Technical Evaluation Panel, 1997.

4. Bibler, N.E., et al., "Durabilities and Microstructures of Radioactive Glasses for Immobilization of Excess Actinides at the Savannah River Site," Scientific Basis for Nuclear Waste Management, XIX, Materials Research Society, Pittsburgh, PA, p.65-72 (1996).

5. Bickford, W. E., "Summary and Status of WSRC Radiation Calculations in Support of Plutonium Immobilization," Letter Report Dated July 26, 1997 and submitted by Mal McKibben to TEP.

6. Bickford. D.F. and Pellarin, D.J., "Large Scale Leach Testing of DWPF Canister Sections, Scientific Basis for Nuclear Waste Management, X," J.K. Bates and W.B. Seefeldt (Eds.), Materials Research Society, Pittsburgh, PA, 509-518 (1986).

7. Bourcier, W., "Durability Studies of LaBS Glass and Pyrochlore Ceramic." Presentation to the Technical Evaluation Panel, 1997.

8. Bowan, B.W. and Brandys, M.M., "Development of a Vitrification Process to Solidify Savannah River M-Area Waste," Ceramic Transactions, V. 61, American Ceramic Society, Westerville, $\mathrm{OH}, 213-220$ (1995).

9. Brown, C. et al., 1997, "Development and manufacture of thermal reactor MOX fuel in U.K.," Nuclear Europe Worldscan, vol. 3-4, pp 34-35 (1997).

10. Brumley, W.J. "The Defense Waste Processing Facility: The Vitrification of High-Level Nuclear Waste," Advances in Ceramics, V.20, The American Ceramic Society, Westerville, $\mathrm{OH} 37-44$ (1985).

11. Brummond, W.A., "Process Development - Ceramic Baseline" Lawrence Livermore National Laboratory, July 1997. 
12. Brummond, W.S., "Plutonium Immobilization Ceramic Process Development and Demonstration," Presentation to the Technical Evaluation Panel, LLNL (1997)

13. Chamberlain, D. B., et al.,"Corrosion Testing of the MD LaBS Glass." Presentation to the Technical Evaluation Panel, 1997.

14. Chamberlain, D.B. et al., "Development and Testing of a Glass Waste Form for the Immobilization of Plutonium," Scientific Basis for Nuclear Waste Management (1996).

15. Civilian Radioactive Waste Management System, Report on Evaluation of Plutonium Waste Forms for Repository Disposal, Rev 01, DI: A000000000-01717-5705-00009 REV 01, March 29, 1996.

16. Civilian Radioactive Waste Management System, Total System Performance Assessment 1995: An Evaluation of the Potential Yucca Mountain Repository, DI:B00000000-17172200-000136 REV 01, 1995.

17. Congdon, J.W., "Impurity Tolerance and Thermal Effects Tests: Plutonium Immobilization Program," Inter-Office Memorandum, Westinghouse Savannah River Company, SRT-MTS97-3015, July 18, 1997.

18. Couglin, J.T. et al., "Plutonium Pilot Scale Melter System Design," US DOE Report SRTPUM-97-97011 (1997).

19. Couglin, J.T., et al., "Plutonium Pilot Glass Melter System Design," SRT-PUM-97-97011, Westinghouse Savannah River Company, Aiken, SC, and Clemson Environmental technology Laboratory, July 24, 1997.

20. Diaz, J.C., Letter on Impurity Concentrations January 1997.

21. Diaz, J. C., "Projected Plutonium Feed Materials for the Disposition Program and their Characteristics" (U), CD-97-0004. April, 1997.

22. Ebbinghaus, B., "Summary of Microprobe Data," Presentation to the Technical Evaluation Panel, LLNL (1997d).

23. Ebbinghaus, B., et al., "Thermal and Mechanical Stability in the Heating and Cooling Cycle in the DWPF Panel," Presentation to the Technical Evaluation Panel, LLNL (1997e).

24. Ebbinghaus, B., et al., Actinide Oxide Dissolution Kinetics and Redox Effects." Presentation to the Technical Evaluation Panel, LLNL (1997b). 
25. Ebbinghaus, B., et al.,"Ceramic Formulation for the Immobilization of Plutonium." Presentation to the Technical Evaluation Panel, (1997a).

26. Ebbinghaus, B., et al., "Impurity Tolerances in the Ceramic Form,". Presentation to the Technical Evaluation Panel, LLNL (1997c).

27. Ebinghaus, B.B. and Van Konynenburg, R., "Form Development - Ceramic Baseline,"। Lawrence Livermore National Laboratory, July 1997.

28. Edwards, J. , et al, "MOX Fuel and BNFL," The Nuclear Engineer, vol. 37 (6), pp 178-181 (1996).

29. Edwards, T.B., "A Statistically Designed Plan For The Exploration of A Vitreous Plutonium Product Compositional Space As It Relates to Solubility and Thermal Stability," U.S. DOE Report SRT-SCS-97-001 (January, 1997).

30. Etherington, H. (Ed.), Nuclear Engineering Handbook, McGraw-Hill Book Co., New York (1958).

31. Ewing, R.C., et al, "Radiation Effects in Nuclear Waste Forms for High-Level Radioactive Waste," Prog. In Nuclear Energy, 29, No 2, pp 63-127 (1995).

32. Fanderlik, M. in "Science and Research in the Glass Industry" (in Czech), MSP, Prague, J. Dvorak (Ed.) Series IV, p.81 (1958) as cited in Volf, 1984 (M.B. Volf, "Chemical Approch to Glass," Glass Science and Technology, V.7, Elsevier Science Publishing Co., Inc., New York, 594 pp., 1984).

33. Farmer, J., Private communication to TEP, LLNL, Aug 1997.

34. Gould, T. H., "Plutonium Immobilization Decision Process," Lawrence Livermore National Laboratory, Livermore, CA, FM97001, January 14, 1997.

35. Gray, L W. and Gould, T. H., "Immobilization Technology Down-Selection Radiation Barrier Approach," Lawrence Livermore National Laboratory, Livermore, CA, UCRL-ID-127320, 1997, [http://lasers.llnl.gov/lasers/smap/Intro.html].

36. Gray, L., "Non-Proliferation - Ceramic Baseline" Lawrence Livermore National Laboratory, July 1997.

37. Gray, L.W. and Gould, T.H., "Immobilization Technology Down-Selection Radiation Barrier Approach." Lawrence Livermore National Laboratory UCRL-ID-127320, May 23, 1997.

38. Gray, L.W., et al, (White Team Report), August, 1997 
39. Hardy, B.J., "Trip to Corning and Ameritherm 2/19/97 - 2/20/97," SRT-AMC-97-0025, Westinghouse Savannah River Company, Savannah River Technology Center, Aiken, SC, February 25, 1997.

40. International Congress of Radiology (ICR), "Radiation Quality," 1985, Hawaii.

41. J. Deibler, et al., "Predictions of Structural Integrity for the Glass Plutonium Immobilization Melter," PNNL, Richland, WA (January, 1997).

42. Jantzen, C.M. and Brown, K.G., "Statistical Process Control of Glass Manufactured for Nuclear Waste Disposal," Am. Ceram. Soc. Bull., 72 [5], 55-59 (1993).

43. Jantzen, C.M. and Brown, K.G., "Statistical Process Control of Glass Manufactured for Nuclear Waste Disposal," Westinghouse Savannah River Company, Savannah River Technology Center, Aiken, SC 1993.

44. Jantzen, C.M., et al., "Reactive Additive Stabilization Process (RASP) for Hazardous and Mixed Waste Vitrification," Proceedings of the Second International Mixed Waste Symposium, Baltimore, MD, A.A. Moghissi, R.K. Blauvelt, G.A. Benda, and N.E. Rothermich (Eds.), University of Maryland, 14.2.1-14.2.13 (1993).

45. Jantzen, C.M., et al., "Reactive Additive Stabilization Process (RASP) for Vitrification of Hazardous and Mixed Waste," Environmental and Waste Managment Issues in the Ceramic Industry, Ceramic Transactions, 39, American Ceramic Society, Westerville, OH, 91-100 (1994).

46. Jostsons, A., "Status of Synroc Development," Proc. 9th Pacific Basin Nuclear Conference, Sydney, Australia, May 1-6, pp 865-871 (1994).

47. Jostsons, A., et al., "Surplus Plutonium Disposition via Immobilization in Synroc" Proc. Of Spectrum '96, Seattle, WA, August 18-23, vol- III, pp 2032-2039 (1996).

48. Jostsons, A., et al., "The Role of Synroc in Partitioning and Conditioning Strategies in Radioactive Waste Management", accepted for publication in Proc.of Global '97, 5-10 October, 1997, Yokohama, Japan (1997).

49. Jouan, A.,et al., "Present Status of the French Continuous FIssion Product Vitrification Process," Advances in Ceramics, V. 20, American Ceramic Society, Westerville, OH, 105-116 (1985).

50. Kaiser, R., et al., "Bechtel's Independent Review of the MOX industry," Presentation to the Technical Evaluation Panel,LLNL. (1997). 
51. Kan, T., "Cost and Timeliness - Ceramic Baseline" Lawrence Livermore National Laboratory, July 1997.

52. Kan, T., "Number of MD Canisters," TEP Review held at LLNL July 28-31, 1997.

53. Kesson, S.E. and Ringwood, A.E., "Safe Disposal of Spent Nuclear Fuel," Radioactive Waste Management and the Nuclear Fuel Cycle, 4(2), 159-174. (1983).

54. Knabenschuh, J.L., et al., "West Valley: Implementing Modern Waste Technology," Advances in Ceramics, V. 20, American Ceramic Society, Westerville, OH, 375-382 (1985).

55. Lee, J. D., "Neutron Source \& Neutron Dose Estimates for Glass \& Ceramic Pu Immobilization Forms," Presentation at the TEP review in the LLNL presentation book, $7 / 28 / 97$.

56. Lee, J. D., Private Communication to TEP, August 1997.

57. Li, H.,et al., "Component Solubility in Lanthanum Borosilicate Glasses for the Vitrification" of Plutonium Oxide and Plutonium-Bearing Materials," Pacific Northwest National Laboratory, Richland, WA (1997).

58. Loffler, J., Glastechnic Bericht, 10, 204- (1932).

59. Lủmpkin, G.R. and Ewing, R.C., "Geochemical alteration of pyrochlore group minerals: Pyrochlore sub-group," Am. Mineralogist, vol. 80, pp 732-743 (1995).

60. Lumpkin, G.R. and Ewing, R.C., "Geochemical alteration of pyrochlore group minerals: Betafite sub-group," Am. Mineralogist, vol. 81, pp 1237-1248 (1996).

61. Lumpkin, G.R., et al., "Application of analytical electron microscopy to the study of radiation damage in the complex oxide mineral zirconolite," Micron, vol. 28, accepted for publication. (1997).

62. Lumpkin, G.R., et al., "Retention of Actinides in Natural Pyrochlores and Zirconcolites," Radiochemical Acta, vol.66/67, pp 469-474 (1994).

63. Maddux, E. P., "Immobilization Project Cost / Timeliness Considerations," Presentation at the TEP review, July 28-31, 1997.

64. Marais, B., "Costs," Presentation at the TEP review, July 28-31, 1997. 
65. Marra, J. and Elliott, M., "Process Development - Glass Baseline" Lawrence Livermore National Laboratory, July 1997.

66. Marra, J.C., et al., "Glass Composition Development for a Thermal Spray Vitrification Process," Advances in Ceramics, V. 72, Am. Ceram. Soc., Westerville, OH, 419-426 (1996).

67. Marra, J.C., et al., "Plutonium Immobilization: Glass Process Technical Maturity and Viability Risks," Presentation to the Technical Evaluation Panel (1997).

68. Marra, S.L. and Plodinec, M.J., "DWPF Glass Product Control Program (U)," WSRC-IM91-116-6, Rev. 1, Attachment 1, Westinghouse Savannah River Company, Savannah River Technology Center, Aiken, SC, January 1995.

69. Marra, S.L., "Plan for Qualification of Plutonium Waste Form Using The Can-In-Canister Disposition Option," US DOE Report WSRC-RP-97-297, Westinghouse Savannah River Company, Aiken, SC (June, 1997).

70. Marshall, K.M., "Plutonium Surrogate Vitrification Demonstration in Induction Melter System (U)," SRT-PUM-97-0015, Westinghouse Savannah River Company, Savannah River Technology Center, Aiken, SC, July 1997.

71. McGrail, B. P. "Downselect Technical Review Fissile Materials Disposition Program Waste Form Characterization Task." Presentation to the Technical Evaluation Panel, 1997.

72. McIntyre, D.M., et al., "Dissolution of Hafnium Dioxide in Lanthanide Borosilicate Glass," U.S. DOE Report SRT-PUM-97-0024 (July, 1997a).

73. McIntyre, D.M., et al., "Effect of Hafnium Dioxide on Thorium Dioxide Solubility in Lanthanide Borosilicate Glass," U.S. DOE Report SRT-PUM-97-0012 (July, 1997b).

74. McKibben, M. Personal communication, 1997.

75. Meaker, T.F. and Peeler, D.K., "Solubility of Independent Plutonium Bearing Feed Streams in a Hf-Based LaBS Frit," U.S. DOE Report SRT-PUM-0016, Westinghouse Savannah River Company (1997).

76. Meaker, T.F. and Peeler, D.K., "Result of An Intra-Laboratory Study of Glass Formulation for the Immobilization of Excess Plutonium," SRT-PUM-97-0017, Westinghouse Savannah River Company, Savannah River Technology Center, Aiken, SC, July 18, 1997.

77. Meaker, T.F. and Peeler, D.K., "Solubility of Independent Plutonium Bearing Feed Streams in A Hf-Based LaBS Frit(U)," SRT-PUM-97-0016, Westinghouse Savannah River Company, Savannah River Technology Center, Aiken, SC, July 12, 1997. 
78. Meaker, T.F., "A Partial Time-Temperatue-Transformation Diagram for a Plutonium Loaded Lanthanide Borosilicate (LaBS) Glass," U.S. DOE Report SRT-PUM-0018, Westinghouse Savannah River Company (1997).

79. Meaker, T.F., "Homogeneous Glass rocessing Region Defined for a Lanthanide Borosilicate Glass Composition for the Immobilization of Plutonium Using Thorium as a Surrogate," Westinghouse Savannah River Company (1996).

80. Meaker, T.F., and Bibler, N.E., "Characterization and Product Consistency Leach Tests of Lanthanide Borosilicate Glasses Containing Plutonium and Uranium or Impurities," U.S. DOE Report SRT-PUM-0022, Westinghouse Savannah River Company (1997b).

81. Meaker, T.F., and Bibler, N.E., "Comparison of the Durabilities and Microstructures of an Amorphous and Devitrified Plutonium Bearing Lanthanide Borosilicate Glass," U.S. DOE Report SRT-PUM-0023, Westinghouse Savannah River Company (1997a).

82. Meaker, T.F., et al., "The Developement of a Plutonium Glass Compositional Region Design Matrix," (DRAFT-\#9 in 3 volume set).

83. Meaker, T.F., WSRC-NB-95-143, Laboratory Notebook, Westinghouse Savannah River Company (1995).

84. Morey, G.W., Optical Glass, U.S. Patent 2150694 (1939).

85. Moricca, S., et al., "Demonstration of Pu Immobilization in Synroc at the $50 \mathrm{~g}$ of $\mathrm{PuO}_{2} \mathrm{Scale,"}$ ANSTO Report/C 511 (1997).

86. NAS Committee on Arms Control and International Security, 1994.

87. National Academy of Sciences, Committee on International Security and Arms Control, "Management and Disposition of Excess Weapons Plutonium," National Academy Press, Washington, D.C., 1994.

88. National Council on Radiation Protection and Measurements (NCRP "Statement on Dose Limits for Neutrons." Bethesda, Maryland. (1980)

89. Pabst, A., 1954, "Brannerite from California" American Mineralogist, 39, 109-117 (1954).

90. Palmer, R.A., "WVDP Vitrification Process Control Program," Attachment 2, Proceedings of Spectrum 1994, West Valley Nuclear Services Company, West Valley, NY 14171-091. 
91. Peeler, D.K., et al., "Am/Cm Glass Formulation: $\Lambda$ Study of Liquidus Tempcrature and Viscosity, U.S. DOE Report WSRC-TR-97-0081, Westinghouse Savannah River Company, Aiken, SC (1997a).

92. Peeler, D.K., et al., "Results of an Inter-Laboratory Study of Glass Formulation for the Immobilization of Excess Plutonium," U.S. DOE Report SRT-PUM-97-0017, Westinghouse Savannah River Company, Aiken, SC (1997b).

93. Rainisch, R., "Handling of Plutonium Glass and Plutonium Ceramic Batches," SRS Calculation N-CLC-G00053, May 23, 1997.

94. Ramsey, W.G., et al., "Compositions and Durabilities of Glasses for Immobilization of Plutonium and Uranium," Waste Management '95, Record 23828-23907, WM Symposia, Inc., Tucson, AX (1995.)

95. Rathmann, C. "Induction Heating," Letter and Information, Rathmann Associates, Corning, NY, July 16, 1997.

96. Riley, D., “Tilt-Pour Furnace Experimental Work,” LLNL Internal Report (1997).

97. Riley, D., "Tilt-Pour Furnace Experimental Work," Lawrence Livermore National Laboratory, July 29, 1997.

98. Ringwood, A.E., et al., "Synroc" in Radioactive Waste Forms for the Future, eds. W. Lutze and R.C. Ewing, Elsevier Science Publishers B.V., pp 233-334 (1988).

99. Rudisill, T., Letter to Erickson re the use of Soda-Lime-Silica glass for Rocky Flats residues.

100.Schumacher, R.F., "Justification for Induction Melter System - Pu Vitrification," SRTPUM-97-0014, Westinghouse Savannah River Company, Savannah River Technology Center, Aiken, SC, March 10, 1997.

101.Schumacher, R.F., et al., "Induction Melter System for Actinide Vitrification Program," US DOE Report SRT-PUM-97-003 (April, 1997a).

102.Schumacher, R.F., et al., "Status of Vitrification for DOE Low-Level Mixed Waste Form," Ceramic Transactions, V. 39, American Ceramic Society, Westerville, OH, 63-70 (1994).

103.Sinclair, W. K. "Fifty Years of Neutrons in Biology and Medicine: The Comparative Effects of Neutrons on Biological Systems," page 1, Proceedings of the 8th Symposium on Microdosimetry, Brussels, Belgium. 1984. 
104.Smith, F.G. and Hardy, B.J., "Preliminary Results from Pu Melter Modeling," US DOE Report SRT-PUM-970013, Westighouse Savannah River Co., Aiken, SC (April, 1997)

105.Solomah, A.G., et al., "Phase Identification, Microstructural Characterization, Phase Microanalysis and Leaching Performance Evaluation of Synroc-FA Crystalline Ceramic Waste Form," J. Nuclear Material, 148, 157-165. (1987)

106.Staples, B.A., et al., "Technology for the Long-Term Management of Defense HLW at the Idaho Chemical Processing Plant," Advances in Ceramics, V. 20, American Ceramic Society, Westerville, $\mathrm{OH}, 45-52$ (1985).

107."Statement for the 1985 Paris Meeting of the International Commission on Radiological Protection," Journal of the Society for Radiological Protection, Vol. 5, No. 2, PP 87-88, 1985.

108.Sundaram, "Corrosion Evaluation and Material for Pu Immobilization," PNNL, July 1997.

109.TRW, "Degraded Mode Criticality Analysis of Immobilized Plutonium Waste Forms in a Geologic Repository," A00000000-01717-5705-00014 REV 01, February 7, 1997.

110.U.S. Department of Energy, "Fissile Materials Disposition Program Integrated Immobilization Plan for Research Development and Testing (Draft)," April 1997.

111.U.S. Department of Energy, "Record of Decision for the Storage and Disposition of Weapons-Usable Fissile Materials Final Programmatic Environmental Impact Statement," January 14, 1997.

112.U.S. Department of Energy, "Storage and Disposition of Weapons-Usable Fissile Materials Final Programmatic Environmental Impact Statement," Washington, DC, December, 1996.

113.U.S. Department of Energy, "DOE AD HOC Committee Report - Neutron Quality Factor," Letter report to Mary Walker, Asst. Secretary of DOE/ES\&H on March 11, 1986.

114.U.S. Department of Energy, "Record of Decision for the Storage and Disposition of Weapons-Useable Fissile Materials: Final Programmatic Environmental Impact Statement," January, 1997.

115.U.S. Department of Energy, "Storage and Disposition of Weapons-Usable Fissile Materials, Draft Programmatic Environmental Impact Statement," DOE/EIS-0229-D, February 1996.

116.U.S. Department of Energy, "Summary Report of The Screening Process," DOE/MD-0002, March 29,1995. [http://web.fie.com/htdoc/fed/doe/fs1/pub/text/any/rep21.htm] 
117.U.S. Department of Energy, "Technical Summary Report for Surplus Weapons-Usable Plutonium Disposition," DOE/MD-0003, Office of Fissile Materials Disposition, July 17, 1996.

118.United States Code of Federal Regulations (CFR) - 10CFR835 (1997)

119.Van Konynenburg, R., "Radiation Effects on Ceramics and Repository Criticality Prevention." Presentation to the Technical Evaluation Panel, 1997.

120.Vance, E. R. "Review of Synroc, Zirconolite and Pyrochlore-Rich Ceramics." Presentation to the Technical Evaluation Panel, 1997.

121.Vance, E.R., et al., "Pyrochlore-rich Titanate Ceramic for Incorporation of Plutonium, Uranium, and Process Chemicals," Australian Nuclear Science and Technology Organisation interim report, July 1997.

122.Vance, E.R., et al., "Pyrochlore-rich Titanate Ceramics for Incorporation of Plutonium, Uranium and Process Chemicals," ANSTO Interim Report. 18 July,. (Presented to the Technical Evaluation Panel, LLNL.) (1997).

123.Vance, E.R., et al., "Zirconolite-rich Ceramics for Actinide Wastes" Mat. Res. Soc. Symp. Proc. Vol. 353, p 767-774 (1995).

124.Vienna, J.D., Fissile Materials Disposition Program, Immobilization Program Monthly Report, excerpt on glass viscosity (date unspecified).

125.Vienna, J.D., et al., "Plutonium Dioxide Dissolution in Glass," U.S. DOE Report PNNL11346, Pacific Northwest Laboratory, Richland, WA (1996).

126.Vienna, J.D., et al., "Frit Screening for Rocky Flats Ash and Sand, Slag, and Crucible Vitrification," U.S. DOE Report PNNL-1 1591, Pacific Northwest National Laboratory, Richland, WA (June, 1997).

127.Volf, M.B., "Mathematical Approach to Glass," Glass Science and Technology, 1988.

128.Weber, E.T., et al., "Vitrification Technology for Hanford SIte Tank Waste," V. 61, American Ceramic Society, Westerville, OH, 233-246 (1995).

129.Weber, W.J., et al., "Effects of Alpha-Radiolysis on Leaching of a Nuclear Waste Glass." $J$. Amer. Ceram. Soc., 68(9) C-253, 1985.

130.Weber, W.J., et al., "Effects of Self-Radiation Damage in Cm-Doped $\mathrm{Gd}_{2} \mathrm{TiO}_{7}$ and $\mathrm{CaZrTi}_{2} \mathrm{O}_{7} . " J$. Nucl. Mater. 138, 196-209, 1986. 
131. Whitehouse, J.C., et al., "Design and Fabrication of a Transportable Vitrification System for Mixed Waste Processing," Proceedings of the Third International Mixed Waste Symposium, Baltimore, MD, A.A. Moghissi, R.K. Blauvelt, G.A. Benda, and N.E. Rothermich (Eds.), Univ. of Maryland (1995).

132.Wilson, C.N., et al., "Melter Technology Evaluation for Vitrification of Hanford Site LowLevel Waste," V. 61, American Ceramic Society, Westerville, OH, 247-260 (1995). 


\section{APPENDICES}

\subsection{Criteria Definitions}

In developing and applying the factors and metrics in previous screenings and selections, different metrics were sometimes needed when considering sites for disposition as opposed to forms or processes. In some cases, two sets of metrics were developed. Where this is the case in the descriptions below, they are called out appropriately. Although the glass and ceramic evaluation only considers the form and process, the site-related metrics have been left in for completeness.

\section{Criterion 1. Resistance to Theft or Diversion by Unauthorized Parties}

This first criterion addresses the risk of theft of weapons-usable nuclear material by terrorists, subnational groups, or aspiring nuclear states in addition to potential theft by disgruntled employees. This threat exists throughout all phases of disposition: transportation, storage, processing, as well as after immobilization has been completed.

In general, risk can be reduced by rapidly achieving a low material attractiveness (material characteristics), minimizing the handling, processing, and transportation of the material (environment), and applying effective safeguards and security (S\&S) measures. ["International Atomic Energy Agency (IAEA) safeguards should be applied to excess fissile material as early as possible. As disposition is intended to reduce the risk of proliferation rather than increasing it, it is critical to maintain stringent standards of safeguards and security throughout the process. Physical security approaches to be applied to all phases of the disposition processes should be developed jointly with Russia, the IAEA, and, where relevant, with other nations involved in the process." Secretary of Energy Advisory Board Task Force, September 26, 1996.]

The transportation, storage, and processing must, where meaningful, meet the stored weapons Standard and the condition after disposition must be roughly equal to the proliferation resistance of commercial spent fuel (i.e., the spent fuel standard ).

Note: While repository acceptability is considered under Criterion 3, the final disposition site (repository) is not considered as a discriminator in this evaluation. All immobilized forms are assumed to go to the same final disposition location.

Note: Timeliness of start-up and mission completion are covered under Criterion 6.

Factors to be considered when applying this criterion are:

A. Low inherent attractiveness. This factor favors immobilization options that rapidly lower the attractiveness of the physical, chemical, or isotopic makeup of the nuclear material.

Metrics:

1. DOE attractiveness (applies to process and form). Processing time to reach Category and Attractiveness Level II-D or lower, as defined by DOE Order 5633.3B. 
2. Other fissile material (applies to site and process). Minimization of processing, separation, and handling of fissile material other than plutonium. The presence of other separated fissile material in a process or facility represents a possible diversion path.

B. Minimization of transportation, facilities, and sites. The more complex the logistics, the more opportunities there are for theft. Immobilization scenarios that involve complex logistics with many transfers and storage locations, with attendant transportation requirements, are considered to be more vulnerable to theft.

Metrics:

1. Number of safe, secure transport (SST) miles (applies to site). Total number of miles traveled, requiring an SST, to take plutonium through the alternative (end-to-end).

2. Number of trips (applies to site). Total number of trips traveled, requiring an SST, to take plutonium through the alternative (end-to-end).

3. Number of facilities (applies to site). Total number of facilities that the plutonium resides within (end-to-end).

C. Minimization of processing. The more complex the processing, the more opportunities there are for theft. Immobilization scenarios that involve many complex processing steps and bulk (not item) materials are considered to be more vulnerable to theft.

Metrics:

1. Number of processing steps (applies to site and process). The number of times that plutonium changes physical or chemical form (does not include shipping, receiving, etc.).

2. Complexity of processing (applies to process and form). Measure of the processing complexity.

D. Safeguards and security assurance. The effectiveness of the S\&S protection depends on the form of the fissile material and the characteristics of the processes and facilities involved in the immobilization activities.

Metrics:

1. Measurement uncertainty (applies to process and form). Confidence level associated with the ability to measure the amount of plutonium existing in a form. Task is made more difficult by other radioactivity, attenuators, etc. This factor is expressed as a percentage and is based on future technology capabilities (best guess assuming technology is researched and developed).

2. Accessibility (applies to site, process, and form). Accessibility is a combination of three separate factors, each of which has two possible conditions. First is the accessibility of the plutonium itself: is the plutonium material able to be touched or is it in a sealed container? Second is the accessibility of the container or material: is it hands-on or does it require remote handling? Third is the size and form of the target: is it in a large or bulky form that requires special handling equipment to be moved or not? 
E. Difficulty of retrieval, extraction, and use by a clandestine group or rogue nation. This factor considers the difficulty of retrieval of surplus weapons-usable material and its possible use in clandestine weapons.

Metrics:

1. Location (applies to site, process, and form). The time the plutonium spends under inherently less-secure conditions (i.e., processing vs storage) and the S\&S barriers in effect.

2. Time and cost to reprocess (applies to form). Measure of time and cost to process one significant quantity (SQ) of plutonium. (based on easily developed experimental data).

3. Detectability of reprocessing activities (applies to form). Measure of detectable "signatures" produced to reprocess one significant quantity (SQ) of plutonium.

4. Separability from radiation barrier (applies to form). Measure of relative ease to remove plutonium-bearing matrix from high-level radiation barrier matrix.

\section{Criterion 2. Resistance to Retrieval, Extraction, and Reuse by the Host Nation}

The goal of this criterion is to make it unlikely that surplus weapons-usable materials will ever be used in weapons. ["Ensuring irreversibility, and in particular ensuring that the plutonium in the forms and locations resulting from disposition would be roughly as inaccessible and unattractive for use in weapons by the host state as plutonium in commercial spent fuel, is also critical to achieving the objectives of disposition. Achieving this Spent Fuel Standard will contribute to encouraging Russia to take comparable steps in parallel, to reducing the risk of reversal of ongoing arms reductions and laying the basis for further reductions, and to politically strengthening the nonproliferation regime by demonstrating the U.S. commitment that its reductions will not be reversed." Secretary of Energy Advisory Board Task Force, September 26, 1996.] High resistance to retrieval would provide confidence to other nations that a relatively large resource expenditure (cost and time) would be required to reconstruct the stockpile from disposed material. Barriers to reuse include the form of the material, physical location of the material, and institutional controls (such as IAEA safeguards). A goal of disposition is to reduce reliance on institutional controls.

Modification of weapons-usable material to make it "roughly" as difficult to use for weapons production as plutonium contained in spent commercial reactor fuel would make the rearmament threat associated with surplus weapons-usable materials no greater than the threat resulting from plutonium in spent fuel, and materials would no longer require a unique level of domestic and international safeguards.

For specific issues to be addressed in current immobilization evaluations, the "host nation" is the United States. However, the motivation for taking material disposition actions are additionally driven by concerns in Russia as well as other nations. How U.S. actions would foster progress and cooperation with Russia to provide effective disposition of their materials is addressed under Criterion 7.

Note: The final disposition site (repository) is not considered as a discriminator in this evaluation. All immobilized forms are assumed to go to the same disposition location.

Note: Timeliness of start-up and mission completion and covered under Criterion 6. 
Factors to be considered when applying this criterion are:

A. Difficulty of retrieval, extraction, and reuse. This factor considers the difficulty of retrieval of surplus weapons-usable material and its reuse in weapons. For this criterion, breakout is assumed to be the recovery of $1 \mathrm{MT}$ of plutonium by the host nation. Since both the U.S. and Russia have plutonium processing and purification plants that use the PUREX process, breakout is assumed to be carried out by the appropriate modifications to these plutonium processing plants. These plants include both 221-F and 221-H Separations Canyons at Savannah River in the U.S., the Siberian Chemical Combine at Tomsk-7 (Seversk), Russia, and the Mayak Production Association at Chelyabinsk, Russia.

Metrics:

1. Time and cost to retrieve and reprocess (applies to form). Measure of time and cost for the host nation to reprocess $1 \mathrm{MT}$ of plutonium.

2. Health risk to retrieve and reprocess (applies to form). Measure of health risk for the host nation to reprocess $1 \mathrm{MT}$ of plutonium.

3. Separability from radiation barrier (applies to form). Measure of relative ease for the host nation to remove plutonium-bearing matrix from the high-level radiation barrier matrix.

$B$. Assurance of detection of diversion and extraction. This factor primarily deals with how difficult the material would be to retrieve and extract in a clandestine manner, which depends on the resultant material location and form.

Metrics:

1. Measurement uncertainty (applies to process and form). Confidence level associated with the ability to measure the amount of plutonium existing in a form. Task is made more difficult by other radioactivity, attenuators, etc. This factor is expressed as a percentage and is based on future technology capabilities (best guess assuming technology is researched and developed).

2. Accessibility (applies to site, process, and form). Accessibility is a combination of three separate factors, each of which has two possible conditions. First is the accessibility of the plutonium itself: is the plutonium material able to be touched or is it in a sealed container? Second is the accessibility of the container or material: is it hands-on or does it require remote handling? Third is the size and form of the target: is it in a large or bulky form that requires special handling equipment to be moved or not?

3. Delectability of reprocessing activities (applies to form). Measure of detectable "signatures" produced for the host nation to reprocess $1 \mathrm{MT}$ of plutonium.

\section{Criterion 3. Technical Viability}

There should be a high degree of confidence that an disposition alternative will be technically successful. It is therefore of interest to rely on technologies that have been proven for similar applications and thus have a high likelihood of success. New technologies (or new applications of old technologies) may also require an extended period for licensing or regulatory approval due to the immaturity of the process or regulatory framework. This includes the state, readiness, and projected lifetime of facilities and infrastructure and the processing, storage, and disposal 
capacity of the facilities. Technical viability can be applied to complete global processes or to unit operations within the overall process.

Factors to be considered when applying this criterion are:

A. Technical maturity. Near-term actions require mature and proven processes. Technologies that are less mature may require a number of years to prove themselves and increase the risk that they will not meet technical goals, may not be adequately mature for deployment, or may be more costly and take more time than projected.

Metric:

1. Readiness of the process for deployment (applies to process and form). Readiness for deployment is based on the stage of development, as measured using the seven stages listed in Table 11.1.1. (This is an adaptation of the gate process used by both the Department of Defense and the DOE/EM Office of Science and Technology.) The current stage of development is based on whether all of the criteria for completion of the previous stage have been met.

B. Viability risks. There is a risk to the program associated with getting the process from where the experts think we are today in a given option (unit operation by unit operation) to Stage 7 . The viability risk will be based upon expert judgment utilizing comparisons with like-unit operations, where available, in use in various industries today. The seven stages in Table 11.1.1. will be utilized to determine these risks.

C. Repository acceptability of disposal form. The immobilization form must be acceptable for disposal in the federal repository. Acceptability of the form for disposal in a geologic repository is a fitness-for-purpose criterion that has regulatory and licensing implications as well as longterm post-emplacement performance implications from both nonproliferation and ES\&H perspectives. A number of regulatory requirements must be satisfied by the disposal form. With the exception of Requirement 1.4, which is covered more extensively below, these pass-fail requirements are the same for all variants and hence are not discriminators. The issue of postdisposal proliferation resistance is dealt with separately in Criteria 1 and 2, and predisposal ES\&H issues are dealt with separately in Criterion 4 . Therefore, only the regulatory and licensing requirements and post-emplacement ES\&H performance issues affecting acceptability for repository disposal are considered here.

The two main long-term post-emplacement performance considerations affecting repository acceptability are criticality safety and the potential for contamination of the biosphere by the release and transport of radioactive materials to the accessible environment. There may be substantial differences between long-term post-emplacement ES\&H performance of different disposal forms. These differences could provide a basis for differentiating between disposal forms.

- Post-Emplacement Criticality Safety. The disposal form emplaced in the geologic repository must remain criticality-safe over the performance period. In the U.S., the current regulatory performance period for high-level waste and spent fuel in a geologic repository has been specified as 10,000 years. (The pertinent regulations are currently under review and this may change.) 
Table 11.1.1. Scale for assessing technical maturity.

\begin{tabular}{|c|c|c|}
\hline & Stage of development & Criteria for completion \\
\hline 1 & Basic research & Benchtop cold experiments are successful. \\
\hline 2 & Applied research & $\begin{array}{l}\text { Benchtop experiments with radioactive material are successful. All of } \\
\text { the process steps have been successfully demonstrated with expected } \\
\text { average feedstock (success means that the desired product has been } \\
\text { produced, in terms of product quality, with the required loading of } \\
\text { plutonium, or that the output of the process step, for example, } \\
\text { pretreatment, has achieved its desired goals). }\end{array}$ \\
\hline 3 & $\begin{array}{l}\text { Exploratory } \\
\text { development }\end{array}$ & $\begin{array}{l}\text { Performance and costs of process and product are reasonably } \\
\text { established. Product requirements are clearly defined. Integrated } \\
\text { demonstrations on a laboratory scale with the full range of } \\
\text { radioactive feedstocks (of the appropriate chemical and physical } \\
\text { forms) expected to be processed have been successfully completed. }\end{array}$ \\
\hline 4 & Advanced development & $\begin{array}{l}\text { All show-stoppers have been eliminated. Costs are favorable. The } \\
\text { program is ready to proceed to develop functional design } \\
\text { requirements for the process or form. At the completion of this stage, } \\
\text { there should be confidence that the process can be operated reliably } \\
\text { in a glovebox or remote environment. }\end{array}$ \\
\hline 5 & $\begin{array}{l}\text { Engineering } \\
\text { development }\end{array}$ & $\begin{array}{l}\text { Functional design requirements have been developed. Site readiness } \\
\text { issues are identified, and addressed. (One cannot exit this stage until } \\
\text { a site is selected). This includes provision for disposition of off- } \\
\text { specification products and for treatment of secondary wastes. }\end{array}$ \\
\hline 6 & Demonstration & $\begin{array}{l}\text { The process and form are successfully demonstrated on a large } \\
\text { enough scale so that implementation is straightforward (i.e., there are } \\
\text { no scale-up issues). This can be achieved either radioactively or } \\
\text { nonradioactively, with the radioactive option normally being } \\
\text { preferred. The quality control/quality verification program for the } \\
\text { product is validated. No technical issues remain that will impart risk } \\
\text { to implementation (e.g., testing has been sufficiently rigorous so that } \\
\text { there is confidence that the process or form will tolerate credible } \\
\text { upset conditions). }\end{array}$ \\
\hline 7 & Implementation & Process and form have been implemented at full scale \\
\hline
\end{tabular}

However, the emplaced plutonium and its ${ }^{235} \mathrm{U}$ decay product remain fissile over much longer periods (plutonium for hundreds of thousands of years, ${ }^{235} \mathrm{U}$ for billions of years) over which criticality safety may need to be assured. Scenarios for criticality events can be divided into three categories: criticality safety of the "essentially undisturbed" waste package, criticality safety of degraded configurations of disrupted waste packages, and criticality safety of fissile materials that have been transported out of a failed waste package. Criticality safety of the essentially undisturbed waste package can be assured with very high confidence, but assuring the safety of the disrupted or failed waste packages is more difficult and depends on many factors. 
Notwithstanding the complexity of the problem, key properties of disposal forms that affect criticality safety can be identified for the purpose of selecting a preferred disposal form. The key properties are the concentration of neutron absorbers, the neutron absorption properties of the immobilization matrix, the resistance to release and transport by groundwater of disposal form constituents, and the rates and relative timing of releases of different components. The release characteristics may be very different for different disposal forms and are affected by the compositions of the groundwater and disposal form, the solubility of the constituents, the active surface areas available for reaction with water, the compositional and thermal stability of disposal forms, the physical and chemical homogeneity of disposal forms, and radiation effects.

- Post-Emplacement Isolation of Contaminants from Biosphere. The disposal form emplaced in the geologic repository must remain isolated from the biosphere over the performance period. The performance period for isolation of the radionuclides present in high-level waste and spent fuel for a geologic repository in the U.S. has been specified as 10,000 years. (The pertinent regulations are currently under review, and this may change.)

Key disposal form properties that affect contaminant migration can be identified for the purpose of selecting a preferred disposal form without detailed consideration of the complex problem of possible contamination of the biosphere. These factors are essentially the same as those considered for criticality safety.

Metrics:

1. Criticality safety and contaminant isolation from biosphere for site (applies to ???). Not a processing site discriminator.

2. Criticality safety and contaminant isolation from biosphere for process and form (applies to ???). Computed as a weighted average of the metrics for neutron absorption, leach resistance, colloid generation resistance, and mechanical stability.

3. Neutron absorption (applies to ???). Fabricated effective thermal neutron absorption cross-section (for all constituents in disposal form).

4. Leach resistance (applies to ???). Computed as a weighted average of the metrics for reciprocal dissolution rate, reciprocal active specific surface area, reciprocal radiation damage, reciprocal radiolysis effects, and colloid generation resistance.

5. Dissolution rate (applies to ???) Matrix dissolution rate from standard flow through test under specified standard conditions.

6. Active specific surface area (applies to ???). Estimated accessible surface area per unit volume at the time of emplacement in the repository.

7. Radiation damage (applies to ???). Increase in the release rate of matrix components due to radiation damage under agreed-upon standard conditions

8. Variability of dissolution rate under varying chemical conditions, including radiolysis effects (applies to ???). Equal to: $\left[\log \left(\mathrm{NR}_{\mathrm{pH}}-2\right)-\log \left(\mathrm{NR}_{\min }\right)+\log \left(\mathrm{NR}_{\mathrm{pH}}+2\right)-\right.$ $\left.\log \left(\mathrm{NR}_{\min }\right)\right] / 4$, where $\mathrm{NR}_{\min }$ is the normalized release rate of a matrix element at the $\mathrm{pH}$ of the minimum rate and NR -2 and $N R+2$ are the normalized release rates of that element measured at two $\mathrm{pH}$ units below and above the $\mathrm{pH}$ of the minimum rate, respectively. All rates are measured using saturated flow through tests under agreed-upon test conditions. 
9. Colloid generation resistance (applies to form). The maximum fissile material mass concentration in a stable suspended colloid for a realistic, agreed-upon fluid chemistry.

\section{Criterion 4. Environment, Safety, and Health Compliance}

The goal is to select immobilization options that would provide safe and healthy conditions for workers and the public and provide as little environmental impact as possible.

Factors to be considered when applying this criterion are:

A. Public and worker health and safety. This factor considers the risk of public and worker exposure to radiation and hazardous materials during transportation, storage, processing, and final disposition of the immobilized forms. As published in the PEIS, high standards of public and worker health and safety and environmental protection must be met, and significant additional ES\&H burdens should not be created. Exposure to workers and the public under normal operating conditions and in the event of an accident are considered.

Metrics:

1. Transportation miles (applies to site).

2. Industrial hazards (applies to process and form).

3. Radiation exposure (applies to process and form).

4. Contamination potential (applies to site, process, and form).

$B$. Waste minimization. This factor considers the potential impact of waste created by disposition options including transportation, storage, processing, and final disposition. It assessed the longterm irreversible consequences of the disposition that are not captured by cost.

Metric:

1. Waste disposition pathway identified (go/no go) (applies to process).

C. Known and manageable waste forms: This factor considers the ability to deal with waste created by the disposition option. It would screen out options that create waste for which there is no known or likely practical treatment or disposal capability because the technical viability or costs of dealing with these wastes cannot be readily estimated.

Metrics:

1. ???? (applies to ???).

\section{Criterion 5. Cost Effectiveness}

The goal is to minimize the incremental cost impact on the government and taxpayers. Timing, allocation, and uncertainties of costs were assessed. The following cost-related performance factors must be evaluated to determine the extent to which a particular option is cost effective.

Factors to be considered when applying this criterion are:

A. Life-cycle cost. Life-cycle costs are defined as including: (1) development costs required to bring a technology to a state suitable for deployment, (2) deployment costs required to design, construct, and install the technology, including facility upgrades and refurbishment, (3) operating 
costs, including operators, supervisors, consumable materials, replacement melters or furnaces, and waste handling and disposal, and (4) decommissioning and decontamination costs to remove the systems and dispose of solid wastes, including gloveboxes, secondary containment, and ventilation systems.

Metric:

1. Dollars (applies to site, process, and form). There is also a subset of the life-cycle cost metric that must be considered. Although these are captured in total life-cycle cost, metrics listed in this subset affect the timing of the dollars spent. These are listed below.

B. Investment and start-up cost. Investment and start-up cost refers to research and development, including cost of establishing product acceptability, construction, retrofit, and program infrastructure costs that are incurred early in the program.

Metric:

1. Dollars (applies to site, process, and form).

C. Establishment of product acceptability requirements. This factor will assess the ability of each waste form to be accepted by the geologic repository. An estimation is required of cost and schedule to provide data and documentation to meet repository requirements. Differences between currently approved waste forms and the plutonium waste form options will be determined, and an estimation of impacts to cost, schedule, and technical aspects is needed. Ease of verification of product conformance to disposal specifications must also be considered (e.g., can representative samples be extracted from the process or must the final product be characterized to meet the characterization acceptance requirement?).

Metrics:

1. Dollars and time (applies to form).

D. Potential for cost sharing. Potential cost sharing refers to other government agency or private industry partial funding of the immobilization effort. Some immobilization options may provide benefits to these organizations such as demonstration of a new technology or production of a useful product.

Metric:

1. Dollars (applies to process and form). However, the only program identified was the 94-1 plutonium stabilization program. Both glass and ceramic were judged to have about the same potential. Therefore, this feature is a low-level or nondiscriminator.

E. Utilization of existing infrastructure. Utilization of existing infrastructure refers to the use of existing facilities with associated infrastructure (e.g., safeguards and security and analytical support for plutonium disposition). This use might affect the cost, environmental, or socioeconomic impacts of plutonium disposition.

Metric:

1. Dollars (applies to site).

F. Cost estimate certainty. Cost estimate certainty refers to the level of confidence regarding forecast costs of an option and actual cost that would be incurred if the option is selected. Cost 
estimates must be based upon assumptions and approximations and may be in error. Cost estimate certainty was lower for those technology options that are in the research and development stage and higher for mature technologies or existing facilities. Expert judgment will be utilized as a part of this determination.

Metric:

1. Dollars (applies to site and process).

\section{Criterion 6. Timeliness}

The goal is to act in an urgent manner for disposition. ["...By far the most important statement the U.S. can make about its determination to permanently dispose of plutonium from its dismantled nuclear weapons is to do so at the earliest possible date. An early start on disposition is very important to the credibility of the process and to gaining international confidence in the program." Secretary of Energy Advisory Board, September 26, 1996.] Urgent action reduces risks of theft or diversion of weapons-usable material and sends a positive signal to Russia and to the international community regarding disarmament.

Factors to be considered when applying this criterion are:

A. Time to start disposition and time to open facility. The time required to start disposition is one measure of timeliness. Preferred options show progress sooner.

Metric:

1. Date of or time to significant initiation (not token, e.g., "full scale demonstration") (applies to site).

$B$. Time to complete. The time required to complete disposition is a measure of timeliness. Options that would complete disposition or storage transition sooner were preferred. For options that achieve a proliferation-resistant waste form (e.g., spent fuel, immobilization with radionuclides) that is ultimately slated for a high-level waste repository, the "time to complete" is the time to achieve the proliferation-resistant waste form, which would be stored pending repository disposal.

Metrics:

1. Date of or time to completion (applies to site).

2. Difficulty in obtaining a license (applies to site, form, and process). Probably a low discriminator for form and process; probably a low discriminator for sites and then only to Greenfield sites.

3. Difficulty in obtaining Defense Nuclear Facility Safety Board (DNFSB) approval (applies to site, form, and process). Probably a low discriminator.

C. Impacts to existing or future missions. This factor assesses the impacts on site and facility selection due to ongoing or already planned missions that would affect the attractiveness of a site or facility. Should there be a potential conflict, the effect on relocating the plutonium immobilization mission or the conflicting mission must be taken into consideration. The effect on staff availability, infrastructure support, contractor, and field office support must also be gauged.

Metric: 
1. Time, schedule, and costs if relocation is necessary (applies to site, process, and form).

\section{Criterion 7. Fostering of Progress and Cooperation with Russia and Other Countries}

In view of current political and economic instability in Russia, it is essential that plutonium disposition activities in the U.S. set appropriate standards and promote timely implementation of secure monitoring regimes and ultimate disposition of nuclear materials in Russia and other countries. ["Prompt agreement with the Russians on disposition schedules is key to national security and arms reduction objectives and will contribute significantly to an early start." Secretary of Energy Advisory Board Task Force, September 26, 1996.] An important element of the U.S. disposition program is to work jointly with Russia to study issues and develop solutions that are appropriate for each country. Agreements for the secure, safeguarded management and disposition of fissile materials from dismantled nuclear weapons could also help make clear that the nuclear powers are fulfilling their disarmament obligations under Article VI of the Non-Proliferation Treaty.

The factors listed below identify the features of disposition options that would lead to a more secure status of weapons-usable nuclear material in other countries:

A. Appropriateness às international standard. The goal is to implement immobilization standards that are jointly developed to achieve similar results in Russia or other countries. Analysis of options must consider their adequacy if applied by other countries. This requires the assessment of threat scenarios in other countries and evaluation of how various immobilization options would perform under these scenarios. For a process or form to be appropriate as an international standard, a commensurably low risk of the material being used in weapons by either the host nation or any other group must be achieved.

Metric:

1. This feature is not a discriminator for process, form, or site.

B. Leverage provided for international negotiations. The goal is to provide the technical basis for negotiation of bilateral or multilateral reductions in inventories of weapons-usable fissile materials. This requires consideration of the technical, economic, and policy contexts associated with implementation of disposition form options in Russia and other countries.

Metric:

1. This feature is not a discriminator for process, form, or site.

C. Transparency. It is desirable that disposition activities in the U.S., Russia, and other declared nuclear states be observable by others and provide assurances that weapons stockpiles are being reduced. Such transparency requires processes, forms, and sites amenable to observation of fissile material processing activities and material accounting systems. Consideration of the difficulties to reverse the disposition process in a clandestine fashion are captured in Criterion 1 and by the host nation in Criterion 2.

Metric:

1. This feature is not a discriminator for process, form, or site.

Criterion 8. Public and Institutional Acceptance 
The goal is to select immobilization alternatives that are acceptable to the public and cognizant government agencies. It is anticipated that each option will incur some amount of opposition from various governmental agencies, public interest groups, or individuals. An option that is generally acceptable is preferred.

Factors to be considered when applying this criterion are:

A. Ability to create a sustainable consensus. This factor considers the ability to generate and maintain a broad constituency for a particular immobilization option (site, process, and form). Changes in governmental bodies will occur throughout the implementation period. Public dissemination of pertinent information explaining the reasoning behind decisions will contribute to creating a sustainable consensus.

Metrics:

1. Time estimated as a function of the number of groups with which the option would have to deal (applies to site).

B. Socio-economic impacts. Positive socio-economic impacts include an increase in the tax base for local governments or the employment base for citizens where facilities are being constructed or staffed. Negative socio-economic impacts include disruption of a local community due to increased traffic, denial of land use for other purposes, and the boom-bust economic cycle associated with construction or site abandonment.

Metric:

1. This feature is believed to be either low level or not a site discriminator.

C. Policy-statute compatibility. One measure of the potential for gaining public approval is the degree to which selection of an option is compatible with existing policies and statutes. The need for significant legislative or regulatory changes may imply an incompatibility with current public and institutional interests.

Metrics:

1. Time delay due to public opposition (applies to site, form, and process). There is a potential risk that the selection of a waste form, facility site, or a combination could face public opposition. This possibility may occur, for instance, when one waste form is selected to be produced at a site where another form has been selected for all other waste, and the decision to do so is part of a consent agreement with the affected public and regulators. Based on past experience, time delays could result from prolonged negotiations and/or lawsuits that could, in the worst case, lead to rejection of the waste form or site. Although this possibility exists, the evaluation of this programmatic risk is outside the scope of this ranking activity for waste form and site selection. However, it needs to be considered as the selection process proceeds.

\section{Criterion 9. Additional Benefits}

A number of options proposed for plutonium immobilization may have potential benefits to the government, the commercial sector, and the public in general. These potential additional benefits will be considered when evaluating options as a positive factor. However, a lack of additional benefits will not be a negative factor. 
Factors to be considered when applying this criterion are:

A. Contribution to national initiatives. Some proccss or form options could benefit other government missions through the sharing of costs and other burdens with other Department of Energy or Department of Defense missions or with other government agencies.

Metric:

1. This feature is not a discriminator for process, form, or site. 


\subsection{Committee Members}

\section{Guy A. Armantrout}

Education

Ph.D. $\quad$ EE/Physics, Purdue University, 1969

MS EE, Oregon State University, 1964

BS EE, Oregon State University, 1962

\section{Professional Experience}

1996-Present Project Leader for Immobilization Systems Development and Demonstration, Fissile Materials Disposition Program: Development and demonstration of processing systems for the production immobilization of plutonium in glass and ceramic in preparation for disposal in a geologic repository.

1992-1996 Section Leader, Systems Modeling and Analysis, Weapons Complex Reconfiguration Program and Surplus Fissile Materials Disposition Program: Identified key issues, developed computer models to simulate plutonium and uranium processing and manufacturing plant performance, acquired detailed database, and jointly managed the LLNL/LANL/DOE collaborative simulation effort. Computer model studies of key plutonium disposition issues and planning for implementation of weapons manufacturing capability at LLNL.

1989-1992 Section Leader, Robotics Implementation for DOE/ER\&M: LLNL representative on the DOE Plutonium Processing Automation Review Team. Conceptualized, planned, and initiated startup of the LLNL robotics program for nuclear weapons complex reconfiguration and ER\&WM applications.

1987-1989 Deputy Assistant Manager for Engineering, SIS Plant Design Team: Plant design, which involved extensive interaction with the architect engineer (Bechtel) and the operating contractor (WINCO), was completed at the $30 \%$ level before termination of the SIS project by the end of the Cold War.

1983-1987 Section Leader, Special Isotopes Separation Program: Developed corrosion-resistant materials for molten plutonium containment which were key to the technical success of the SIS program. Managed the design, construction, and activation of the Pu metal processing line (MPL) in Building. 332.

1980-1983 Senior Staff, Nuclear Systems Safety Program: Detailed computer simulations for calculating the health physics dose equivalent index. Researched and authored the NRC NUREG on the response of health physics instruments. LLNL representative to the NEST access working group. Developed DOE/OMA safeguard and security upgrade 5-year plan, including needs analysis, security objectives, and budgeting priorities. Safeguards planning for the NRC Office of Research. Management of nuclear waste repository study for NRC.

1979-1980 DOE Office of Safeguards and Security (OSS), Germantown, MD: Technical advisor to the office director, developed goals and objectives and annual program plan for OSS.

1965-1979 Group Leader for Materials and Effects Research: Radiation detector development, crystal growth, radiation detector applications, and thin film device development; photovoltaic thin film device research; geothermal studies; and nuclear medicine semiconductor camera development.

\section{Professional Society Activities}

Member, Institute of Electrical and Electrical Engineers (IEEE).

General Chairman, IEEE Nuclear Science Symposium for 1995.

Various program, planning, and review committees, Nuclear and Plasma Sciences Society, IEEE. 


\section{Carol M. Jantzen}

\section{Educational Background}

B.S. Geology, 1967, Queens College of the City University of New York

M.S. Geochemistry, 1970, Queens College of the City University of New York

1969-1970 Department of Geochemistry, Pennsylvania State University

Ph.D. Materials Science and Engineering (glass chemistry), 1978, State University of New York at Stony Brook

\section{Professional Background}

1989-present Clemson University, Department of Ceramic Engineering. Adjunct Professor.

1982-present Savannah River Technology Center (Westinghouse Savannah River Co. and E.I. duPont deNemours \& Co.), Senior Fellow Scientist. Responsible for glass chemistry and formulation for stabilization of high level, hazardous and mixed wastes at various DOE/DOD sites and in the commercial sector. Research in glass physical property measurements, glass decomposition mechanisms, glass leaching and dissolution mechanisms. Development of statistical process/product control by which the DWPF and the Transportable Vitrification System (TVS) currently operate.

1981-1982 Bechtel Group, Senior Engineer. Responsible for materials selection decisions for the Defense Waste Processing Facility (DWPF) and design review of high level waste processes for the Japanese.

1979-1981 Rockwell International Science Center, Member of the Technical Staff. Responsible for development of ceramic waste forms for high level nuclear wastes. Included supercalcine ceramics, high aluminum-containing ceramics, and SYNROC C and D ceramics.

1977-1979 University of Aberdeen, Department of Chemistry, Postdoctoral Research Fellow. Responsible for development of cementitious waste forms for stabilization of US and UK high level nuclear wastes.

\section{Professional Society Activities}

1970-present Member of American Ceramic Society (ACerS; Nuclear, Glass, and Basic Science Divisions; Contributing Editor Phase Diagrams for Ceramists from 1982-1994; Associate Editor, Journal of the American Ceramic Society from 1982-present).

1996-1997 President (ACerS).

1991-1997 Executive Committee/Board of Trustees, ACerS.

1982-present National Institute of Ceramic Engineers.

1979-present Materials Research Society (1989-91 Executive Committee; 1991-93 Council).

1967-present Mineralogic Society of America.

1988-present South Carolina State Registered Geologist.

\section{National/International Committees}

1987-present ASTM committee C14 on Glass and Glass Standards.

1987-present ASTM committee C26 on Nuclear Fuel Cycle (wrote standards).

1992-1996 ASTM committee D34 on Waste Management (1992-1994 chaired subcommittee on mixed waste standards). 
Carol M. Jantzen (cont.)

\section{Honors/Awards}

1992, 1993, George Westinghouse Corporate "Gold" Signature Awards of Excellence (highest and 1996 corporate award achievable at national level).

1990 Fellow, ACerS.

1981 Winner of American Ceramic Society Nuclear Division Best Paper Award.

1975 NATO Grant to examine phase transformations of high temperature oxides and glasses by small angle neutron scattering at Kernforschunanlanger (KFA), Julich, W. Germany.

\section{Publications/Patents}

More than 120 external publications and external publications; 27 internal publications; 11 in-preparation publications; 8 patents. 


\section{Adam Jostsons}

\section{Educational Background}

B.Sc (Hons 1), University Medal, Metallurgy, 1963, The University of New South Wales, Australia Ph.D. Metallurgy, 1996, The University of New South Wales, Australia

\section{Professional Experience}

1984-present Director, Materials Division ANSTO. Responsible for the scientific leadership and effective management of an R\&D program on materials to reinforce Australia's national and international interests in nuclear technology. Responsibilities also include the maintenance of strong interactions with local industry, research organisations and academia. Managed programs on the SYNROC process development; advanced ceramics, development of remaining life estimation techniques and data on Australia's research reactor HIFAR, plasma and surface technologies for improving wear resistance of tools.

$1981-1984$

Counsellor (Atomic Energy) Australian High Commission, London, U.K.

$1972-1980$

Leader, Materials Science Section, Australian Atomic Energy Commission. Radiation effects in zirconium alloys, corrosion of zirconium alloys, neutron scattering.

$1970-1972$

Visiting Scientist, Metals and Ceramics Division, ORNL, Oak Ridge, TN, U.S.A. Participated in research on radiation damage in aluminum, fast reactor cladding and $\mathrm{B}_{4} \mathrm{C}$ control rods. P.I.E. of mixed oxide fuels.

$1966-1970$

Leader, Physical Metallurgy Group, Materials Division, Australian Atomic Energy Commission. Led studies on radiation effects in reactor materials, characterization of Australian uranium minerals and production of ADU powders.

\section{Professional Society Activities}

Fellow, Australian Academy of Technological Sciences and Engineering. Member, Australasian Institute of Metals and Materials.

Member, Australian Nuclear Association Inc.

Member, Australian Electron Microscopy Society.

Member, American Ceramic Society.

\section{International Committees}

Chair, Waste Technology Advisory Group (WATAC) to the Director General, IAEA, Vienna.

1989-1995

$1981-1985$

IAEA -Member of International Waste Advisory Committee (INWAC) to the Director General, IAEA, Vienna.

Member, Australian Delegation to the 7th Consultative Meeting of the Contracting Parties to the Convention on the Prevention of Marine Pollution by Dumping of Wastes and Other Matter, London.

Member of International Committees of OECD - Nuclear Energy Agency, Paris - Steering Committee For Nuclear Energy, Radioactive Waste Management, Radiation Protection and Public Health, Safety of Nuclear Installations, Steering Group on Uranium Resources, Coordination Group on Geological Disposal, Expert Group on Nuclear Waste Forms, Expert Group on Economics of the Nuclear Fuel Cycle. Vice-Chairman, Fuel Cycle Committee. 
Adam Jostsons (cont.)

National Committees

1997

1986-1992

1986-present

$1974-1981$

199?-present

199?-present
Member, National Repository Advisory Committee.

Member and chair, National Materials Research Committee.

Management Committee, Australian Institute of Nuclear Science and Engineering.

Member, AAEC Reactors Safety Committee.

Member, various ad hoc federal and state government committees on nuclear and materials, science and engineering.

Member, Australian bilateral nuclear science delegations and committees on nuclear waste management R\&D with China, France, Japan, Korea, Russia, and the U.K. 


\section{J. Malvyn (Mal) McKibben}

\section{Education}

BA Chemistry, 1955, Emory University, Atlanta, GA

\section{Professional Experience}

34 years with E. I. duPont and 8 years with Westinghouse Savannah River Company, all at SRP/SRS.

\section{Technical (Professional) Experience}

- Reactor technology at SRP production reactors and Heavy Water Components Test Reactor.

- Development of radiochemical analytical methods, and solving process problems via laboratory development.

- Development of radiation and process control instruments.

- Reprocessing of spent nuclear fuel.

- Chemical separation and purification of special isotopes.

\section{Managerial Experience}

- Technical oversight of reprocessing plants (221-F \& H).

- Project liaison for DWPF project.

- Senior Project Manager for design and construction of DWPF.

\section{Current Position}

Senior Advisory Scientist and Team Leader for Surplus Materials Immobilization Programs, Strategic Planning and Integration Department, SRS.

\section{Professional Society Activities}

- American Chemical Society: Division of Nuclear Chemistry and Technology, Past Chair of Savannah River Section.

- American Nuclear Society: Program Chair for Fuel Cycle and Waste Management Division, General Chairman Topical Meeting, "DOE Spent Nuclear Fuel and Fissile Management."

- ASTM Committee C-26, Nuclear Fuel Cycle, Sub-Committees C-26.07 (Waste Materials) and C-26.09 (Nuclear Processing).

\section{Committees}

- University of Chicago Review Committee for Argonne National Laboratory Technology Development.

- Department of Energy Committee investigating explosion at the reprocessing plant in Tomsk, Russia.

- Department of Energy Office of Environmental Safety and Health Committee investigating explosion in Plutonium Recovery Facility tank containing hydroxylamine nitrate. 


\title{
Booth Richard Myers (TEP Chairman)
}

\author{
Education \\ Doctor of Philosophy \\ University of California at Berkeley, January 1976, Department of Electrical Engineering \\ and Computer Science. \\ Bachelor of Arts \\ University of California at Berkeley, March 1968, Department of Physics; includes \\ undergraduate work at Harvey Mudd College, Claremont, CA.
}

\section{Professional Experience}

1996- present

Program Leader for the Strategic Materials Applications Program, reporting to the Associate Director for Laser Programs. This program, formed in 1996, consolidates a number of defense-related material processing and production technology efforts within Laser Programs.

$1992-1996$

Senior Scientist for Long Range Planning for both the Isotope Separation and Advanced Manufacturing (ISAM) and ER/WM Applied Research Programs. Responsible for developing Program strategy, with particular emphasis on Technology Transfer activities. Also supported efforts in the LLNL Reconfiguration and Material Disposition Programs, and support a number of collaborative efforts with several Russian Institutes.

1990-1992 "Acting Deputy Associate Director and Program Leader for the Advanced Processing Technology (APT) Program at LLNL. This Program, with a staff of approximately 150, developed a number of advanced process technologies for both DOE Defense Programs (DP) and Environmental Restoration and Waste Management (ER/WM) Programs.

1988-1990 Lawrence Livermore National Laboratory, Associate Program Leader for Solid State Laser System Development in the Advanced Laser Applications Program. Also Program manager for the Active Optical Countermeasures (AOCM) Program at LLNL.

1979-1988 Lawrence Livermore National Laboratory, Associate Program Leader for Plutonium Processing in the Laser Isotope Separation Program. Responsible for the design, development and testing of isotope separator systems for the isotopic purification of plutonium isotopes using the Atomic Vapor Laser Isotope Separation (AVLIS) process.

1975-1979 Lawrence Berkeley Laboratory, Physicist supporting the TORMAC magnetic fusion research program. Oversaw the design, construction and operation of test systems aimed at validating the TORMAC magnetic fusion concept.

1971-1975 Graduate Student research assistant with the University of California Department of Electrical Engineering and Computer Sciences. Responsibilities included the design and construction of an intense electron beam experiment, development of diagnostics for the experiment, data-taking and analysis and publication of the final results as a Ph.D. thesis.

Awards 


\section{Henry F. Shaw}

\section{Educational Background}

B.A. Geology, 1977, Amherst College, Amherst, MA

M.S. Geology, 1978, California Institute of Technology, Pasadena, CA

Ph.D. Geology/Chemistry, 1984, California Institute of Technology, Pasadena, CA

\section{Research Interests}

- Nuclear waste management, actinide chemistry, waste form performancc, reactive transport processes.

- Isotope geochemistry and cosmochemistry, igneous and metamorphic petrology and phase equilibria, trace element geochemistry.

\section{Professional Experience}

11/95-present Leader, Immobilization Form R\&D for the Fissile Materials Disposition Program, LLNL. Responsible for the scientific direction and management of a multilaboratory effort to develop, test, select, and qualify a glass or ceramic wasteform for the immobilization of surplus weapons plutonium.

7/91-present Deputy Division Leader, Geosciences and Environmental Technologies Division (formerly Earth Sciences Division), LLNL. Responsible for direction of the Division's basic research programs, hiring decisions, establishing directions for future growth of the Division.

10/90-7/91 Energy Program/Earth Sciences staff, LLNL. Assisted Program Leader and Division Leader in areas of guiding program direction, strategic planning, new program development, and other management functions.

12/89-9/90 Leader, NEAR Program, LLNL. Responsible for directing the earth-sciences component of a multidisciplinary research project to study contaminant transport in the subsurface, with emphasis on problems at the Nevada Test Site.

9/85-10/89 Task Leader for Spent Fuel/Technical Area Leader for Waste Form Modeling and Testing, Yucca Mountain Project, LLNL. Responsible for the scientific direction and management of all project work to determine the long-term behavior of spent fuel and vitrified high-level nuclear waste under repository conditions.

10/83-9/85 Postdoctoral staff member, Nuclear Chemistry Division, Lawrence Livermore National Laboratory (LLNL). Established a new clean laboratory and solid-source mass spectrometer facility for isotopic and trace-element analysis of geological materials.

\section{Professional Affiliations}

- American Geophysical Union.

- Geochemical Society.

- International Association of Geochemistry and Cosmochemistry.

- Mineralogical Society of America.

- American Association of Physics Teachers.

- Sigma Xi. 


\section{Denis M. Strachan}

\section{Educational Background}

B.S. Chemistry, 1966, Gonzaga University, Spokane, WA

Ph.D. Chemistry, 1971, Iowa State University, Ames, IA

\section{Professional Experience}

1995-present Argonne National Laboratory. Acting Manager of the Waste Management Department.

1979-1995 Pacific Northwest National Laboratory. Responsible for the development of standard tests for nuclear waste forms, characterization the behavior of glass in contact with water, development of dimensionally stable anodes for aluminum smelting, development of the model for the understanding of gas generation in Hanford waste, and Chief Scientific Advisor to the Manager of the Tank Waste Remediation System.

1974- 1979 Atlantic Richfield Hanford Company/Rockwell Hanford Company. Scientist in charge of developing glass and ceramic waste forms for Hanford wastes.

1971-1974 Gonzaga University: Taught chemistry.

\section{Professional Society Activities}

- Member, American Ceramic Society.

- Member, American Chemical Society (ACS).

- Member of the Organizing Committee for the Industrial and Engineering Chemistry Division, ACS.

- Member, Materials Research Society.

\section{National/International Committees}

- Technical Advisory Committee to the Japan, Swiss, Swedish Project (1985-1987).

- Organizing Committee for the ASME International Conference on Nuclear Waste Management.

- Technical Co-chairman for the technical program of Spectrum '96 (American Nuclear Society). 


\section{John Vienna}

Mr. Vienna received his masters degree in Ceramic Engineering and Science from Alfred University in 1993 and expects to earn his Ph.D. in Materials Science from Washington State University in 1999.

Mr. Vienna manages the Fissile Materials Disposition Projects at PNNL. He has been involved with the screening of waste forms for treatment of excess weapons usable plutonium. He chaired a committee to select between glass technologies for the immobilization of plutonium residue materials.

He joined Pacific Northwest National Laboratory (PNNL) in January of 1993 and is currently a research scientist in the Environmental Technology Division. While at PNNL, Mr. Vienna has lead studies on the effect of glass composition on nuclear waste glass properties. Specific investigations include the modeling of viscosity, durability, liquidus temperature, glass transition, and electrical conductivity of nuclear waste glasses as a function of composition and temperature history. His most recent work focuses on the development of glass waste forms for plutonium-bearing materials and the formulation of high-level waste glasses.

In addition to glass property-composition relationships, Mr. Vienna has focused on the conversion of raw materials to glass and transformation kinetics. Specifically, a fundamental understanding of glass redox, batch reactions, volatilization, and crystallization kinetics were pursued and related to nuclear applications.

Mr. Vienna has published 37 research articles and publicly released reports. Six articles are currently in preparation. $\mathrm{He}$ is a member of the Nuclear Division and Vice-Chair of the Eastern Washington Section of the American Ceramic Society and a member of the Materials Research Society, the American Nuclear Society, and the American Chemical Society. 


\subsection{Review Questions Considered by the Technical Evaluation Panel}

This set of questions was sent by the TEP to the glass and ceramic proponent teams on July 21,1997 , one week prior to the formal review.

\section{Background}

Criteria have been developed by FMDP during the past several years in order to assist in evaluating approaches and options for the disposition of surplus plutonium. These criteria have been considered for application to the current form selection action and pertinent metrics have been identified.

To guide the presenters of input to the selection process, specific questions or specified data have been proposed for each of these metrics relating to the form under consideration. The advocates for a given form are asked to prepare specific responses to the questions and to provide the requested data for the baseline process and any variants to this baseline as outlined below. Note that a complete response across each question or data item is required for any variant which is defined. This uniformity of data input and format will make comparison between the forms possible and will expedite the process with a minimum of confusion and chance for error.

These questions and data requests were submitted by numerous individuals, and some duplication may have occurred. In many cases, the requests are rephrased or may ask for additional information. Rather than "wordsmithing" the document further, timely issuance was preferred: please do your best to address the points made without nit-picking the probable duplication.

Note that it is likely that all items of information of importance to this down-selection have not been covered in the guidance below. We request the advocates of each form to submit additional information to the TEP which they feel is pertinent to this selection as they see fit. Such input should be limited to technical issues since this is the limited scope of the TEP process.

Finally, there will not be data or answers for all the questions posed here. When that occurs, please indicate the status of the known information (unknown may be OK) and any work currently under way to address these issues.

\section{Required Process Definition}

1. The introductory presentation will serve to describe the rationale for the selection of a given waste form, summarize the technical justification for the selection, identify the process operations to produce the form, establish the process baseline operations and implementation parameters, and identify any variants to the baseline which will be considered.

2. Define whether the immobilization matrix feed is modified for different source materials, or is it constant?

3. Identify preconditioning needs of $\mathrm{PuO}_{2}$ before glass or ceramic dissolution process step, e.g., redox control, co-grinding / mixing needs, maximum acceptable particle size.

4. Discussion of all process cycle times. 
5. What is the projected behavior of this material, and what data do you have to support that?

6. What are the weak points or attributes of this product?

7. What is the preferred process flowsheet? What are the strengths of the preferred flowsheet? What are the weaknesses of the preferred flowsheet? What is the most likely variant and why are you presenting this? (What benefits does it offer?)

8. For the baseline and variant cases of this form, what is the plutonium content of each canister (kilograms of plutonium per canister)? What is the volume of HLW glass displaced from each canister, expressed as a percentage of the nominal $1680 \mathrm{~kg}$ of glass in a DWPF canister? What is the plutonium content of each "can" of immobilized plutonium?

\section{Specific Criteria Questions}

\section{Criterion 1: Resistance to theft and diversion by unauthorized parties}

Metric: Diversion detection.

Questions and requested data:

1. Number of locations and likelihood of SNM diversion in each process line?

2. What information is available (including any studies or assessments that have been done) on how well the production processes for the glass and ceramic forms could be safeguarded, and what specific procedures and technologies would be used? Does either production process pose greater or lesser difficulties for measurement of the plutonium content of the material stream? Does either production process involve more, or more complicated, steps in processing the plutonium? What is the NDA method for your process? What is the uncertainty?

3. If the argument in the ceramic case is that the production process will be similar to production of MOX fuel pellets (except without the final grinding-to-shape step), how much of the difficulties with holdup and measurement uncertainties encountered in the MOX production process are associated with that final step? How will the different chemical composition of the pellets affect manufacture and safeguarding? Is there any experience in accurately assaying plutonium in glass, and safeguarding vitrification processes involving significant amounts of plutonium, that would be relevant?

4. What are the most vulnerable stages of your process?

Metric: Time and cost to reprocess.

Questions and requested data:

1. What is needed to dissolve/leach to recover a significant quantity of plutonium? What is the time and cost to an unauthorized party to process one significant quantity of plutonium?

2. Plutonium loading on a percentage and volumetric basis.

Metric: Detectability of reprocessing activities. 
Questions and requested data:

No questions are posed or data of a technical nature are requested in this category.

Metric: Separability from radiation barrier.

Questions and requested data:

1. Potential options to respond to the issues raised in the "Red Team Report." What is the current thinking on how to ensure that "can in canister" is "irreversible" enough to meet the spent fuel standard? Specifically, what options exist for increasing the proliferation "robustness" of the can-in-canister design when using this immobilized form? How do you know that thesc designs are feasible? What would be the side effects (i.e., increased volume of displaced HLW glass, increased design complexity, changes in process, etc.)?

2. How easy is it to separate your form from the can (assuming it is in the canister)?

\section{Criterion 2: Resistance to diversion, extraction, and reuse by the host nation}

Metric: Time and cost to retrieve and reprocess immobilized plutonium.

Questions and requested data:

1. Time and cost to the host nation to recover $1 \mathrm{MT}$ of plutonium utilizing facilities likely to be available for the next 20 years? What existing U.S. facility would you use to extract plutonium from a canister if it became a national priority? What are the kinetics/retrieval rate of plutonium from the form?

2. In the case of the host state wanting to recover a substantial fraction of the $50 \mathrm{MT}$ of excess plutonium, for example, if one assumes that the inner material is glass but that the cans are arranged in such a way that the plutonium-only material cannot practically be removed from the HLW glass, so that the entire canister with all its HLW would have to be dissolved, could existing reprocessing facilities be modified to do this (and if so, how expensive and timeconsuming would the modifications be), or would it be necessary to build new remotely operated facilities? In the ceramic case, with the same assumptions, could existing reprocessing facilities be used to get rid of the HLW glass, leaving only the plutonium-bearing ceramic? How much would it then cost to provide facilities capable of recovering plutonium from the ceramic on a substantial scale?

Metric: Separability from radiation barrier.

Questions and requested data:

1. Potential options to significantly increase the difficulty of recovery by the host nation.

2. If the United States or Russia could recover cans of glass or ceramic from the larger canisters, would this greatly reduce the cost and time required for them to recover the plutonium, since remote handling facilities would no longer be needed? If so, why specifically (what facilities could they use to recover the material vs what facilities would otherwise be needed, etc.)? If not, why not?

Metric: Detectability of reprocessing activities. 
Questions and requested data:

No questions are posed or data of a technical nature requested in this category.

\section{Criterion 3: Technical viability}

Factor: Technical maturity.

Metric: Readiness of the form for deployment.

Questions and requested data:

1. Discuss the characteristics and technology of the waste form, including dissolution parameters (rate and saturation values), phases formed, location of actinides (uranium and plutonium), location of neutron poisons, and impact on these parameters of identified impurities at various loading concentrations.

2. What is the projected behavior of this material and what data do you have to support that?

3. What are the absolute (i.e., solubility) limits on plutonium, uranium, and neutron absorber concentrations in this form for the baseline formulation and process conditions? Are these are different for the variant(s)? How do they vary?

4. What are the impurity tolerances of each waste form?

5. Quantitative estimate of the amount of crystalline material in the glass form, both following glass formation and after the DWPF thermal cycle.

6. Quantitative estimate of the amount of glassy phase in the ceramic form, both following ceramic formation and after the DWPF thermal cycle.

7. Discussion of thermal and mechanical stability of glass and ceramic during fabrication of the form and during the can-in-canister filling operation.

8. Discussion of the impact of the DWPF thermal cycle on the immobilized waste form characteristics.

Metric: Readiness of the process for deployment.

Questions and requested data:

1. Define the process operating parameters and the sensitivity of the process to these parameters on the product quality. Discuss how difficult it would be to control these parameters.

2. Develop a table that defines the detailed processing operations, starting with the feed $\mathrm{PuO}_{2}$ from plutonium conversion after blending and batch preparation through loading into the canister which (1) describes the operation, (2) identifies commercial equipment or developmental equipment required, (3) identifies related plutonium operations with the identified equipment, (4) specifies required adaptations of process and/or equipment for the intended plutonium immobilization application, (5) identifies potential process or operational risks, and (6) identifies alternative process operations and/or equipment should problems be encountered. 
3. Provide an overall assessment of where you are on the technical maturity scale (gate chart). What data and experience do you have to support this contention and how good are those data? How do you plan to get from were you are to implementation?

4. What is the maximum particle size you can handle and achieve in the baseline design?

5. How do you plan to manage dusting/powder handling?

6. What sort of redox control must be imposed during the sintering/melting process? What are the effects of poor control on the fabricated form? What are the effects on processing equipment?

7. How different is the production process planned for the new glasses with plutonium compared to borosilicate glasses with HLW? To what extent can the extensive worldwide experience with HLW glass be "counted" toward the technical maturity of the glass option? How confident can we be that unexpected problems will not arise?

8. Even if the ceramic is produced in a way similar to production of MOX pellets, how much will the different chemical composition affect the details of the production process? To what extent can the extensive worldwide experience with production of MOX fuel be "counted" toward the technical maturity of the ceramic option?

9. How much plutonium-bearing ceramic and plutonium-bearing glass have others produced? How confident can we be that unexpected problems will not arise?

Factor: Viability risks.

Metric: Process risks.

Questions and requested data:

1. What are the most likely process equipment failure modes or problem areas? What are the consequences (cost, downtime, ES\&H, etc.)? What is the strategy to deal with such failures?

2. How do you justify that there is low risk in obtaining implementation successfully?

Factor: Repository acceptability of disposal form.

Metric: Criticality safety.

Questions and requested data:

What is being done to address waste package and external criticality issues?

1. Dissolution rate comparisons between neutron absorbers and plutonium for the various dissolution tests which have been performed. Particularly, note partitioning of neutron absorbers and plutonium between the immobilized form and the surrounding near field.

2. List the neutron absorbers being used to control criticality during processing, form handling, and long-term criticality control.

3. Provide thermal neutron absorption cross-sections for the immobilization matrix.

4. Indicate the uranium/plutonium ratio in the immobilized form. 
5. What is the current thinking on the best way to prevent criticality over the long term? Can neutron absorbers in the glass or ceramic reliably be expected not to chemically separate from the plutonium over very long times? Would it be desirable or essential to add substantial quantities of ${ }^{238} \mathrm{U}$ to the waste forms themselves? Does glass or ceramic have any significant advantage in preventing long-term criticality?

Metric: Biosphere isolation.

Questions and requested data:

1. How much impact is the choice of glass or ceramic for the inner cans likely to have on acceptance of the overall waste form for geologic disposal or performance of the overall waste form in a repository environment? Which approach is likely to prove more difficult or more time consuming to gain waste-form approval?

2. How much do we know about how performance in laboratory leach tests relates to long-term performance in a repository environment?

3. How do you intend to predict/assess/bound the long-term dissolution/leaching behavior of this form under repository conditions? What are the plans for achieving repository acceptance? What are the risks?

4. Provide all data on static dissolution tests performed for each form.

5. Provide all flow-through data tests performed for each form.

6. Provide form modification information and analysis for each form. What secondary phases have been observed to form in alteration tests? What are their compositions and their relative abundance? How are fissile elements and neutron absorbers partitioned among these phases?

7. How long are the glasses designed for plutonium immobilization likely to survive? Is it likely to be several half-lives of plutonium before the plutonium is released from the glass into the surrounding medium, and how much longer is it likely to be for the ceramic, based on our current understandings?

8. Address the expected impacts of radiation damage on the leach rate of plutonium from each form. Heavy reliance on published literature is anticipated.

9. Assess the potential for colloid formation for each form. How quickly is plutonium likely to be transported through the surrounding medium? Is this solubility-limited or do colloids transport the material at rates far beyond the solubility limits? Would the use of glass lead to greater transport by colloids (since colloids that can transport plutonium form from the glass), or would it not matter much (since plutonium can apparently form colloids by itself, and colloids might form from the surrounding rock material)? Are colloids bearing plutonium likely to pass through the tuff, or are they likely also to be absorbed?

10. Provide an estimate of the active surface area of the form at emplacement per kilogram of immobilized plutonium.

\section{Criterion 4: Environment, safety, and health compliance}

Metric: Public and worker health and safety. 
Questions and requested data:

1. List potential industrial safety concerns. What is the worst credible accident? What are the consequences?

2. How are you assuring criticality safety during processing?

3. Provide radiation dose rates for gamma rays and neutrons as a function of distance from the surface of immobilized forms containing about $1 \mathrm{~kg}$ plutonium. Assume two cases:

4. (a) shielding of lead-loaded gloves only (10 mil lead equivalent) and (b) 0.5 in. of stainless steel.

5. Consider the applicability of dose control measures up through can loading for the formation of the immobilization form. Include both automation possibilities and shielding opportunities.

6. Indicate process particle size requirements for dissolution into immobilization matrix and how these are obtained. Describe dust control measures that can be employed and indicate industrial experience with these measures, especially with $\mathrm{PuO}_{2}$.

7. Consider potential exposure during maintenance operations. As part of this, consider possible failure modes that may require operator action and the likely inventories during these operations.

\section{Criterion 5: Cost effectiveness}

Metric: Life-cycle costs.

\section{Questions and requested data:}

1. Provide life-cycle cost estimates for waste forms on a consistent estimating basis to indicate differences in construction and operating costs between glass and ceramic operations.

Metric: Investment and start-up cost.

Questions and requested data:

1. Indicate extent of $R \& D$ to adapt equipment to plutonium operations and to bring process operations to an operational state for the immobilization operations planned.

2. What are the largest cost uncertainties from your process?

3. What shielding/remoting is required to process your form? How much will the shielding cost?

4. What costs differences are there between your form and the other?

Metric: Establishment of product acceptability requirements.

Questions and requested data:

1. Identify known verification and testing steps needed to develop repository qualification requirements for each immobilization form.

2. Identify process control parameters that are anticipated to be required to ensure product compliance with waste form qualification requirements to be developed.

3. Provide cost and time estimates to achieve 1 and 2 above. 
Metric: Cost risks.

Questions and requested data:

1. Provide estimates of the cost and time that may be required to resolve the process risk factors and unknowns identified under technical maturity.

2. What process equipment has the lowest (and next lowest) expected repair cycle or useful life? What is the cost of repair or replacement of that equipment?

\section{Criterion 6: Timeliness}

Metric: Time to start immobilization facility.

Questions and requested data:

1. How soon could you build a plant? What do you need before you can? What is your planning basis?

Metric: Schedule certainty

Questions and requested data:

1. Identify any known process uncertainties that could extend the schedule for plant startup beyond FY 2005 as contained in the current draft of the R\&D plan.

Metric: Regulatory and licensing requirements.

Questions and requested data:

1. Identify any known factors or regulatory concerns that could extend the plant start-up time beyond the above referenced plant schedule.

\section{Criterion 7: Fostering of progress and cooperation with Russia and other countries}

No questions are posed or data of a technical nature requested in this category.

\section{Criterion 8: Public and institutional acceptance}

No questions are posed or data of a technical nature requested in this category.

\section{Criterion 9: Additional benefits}

No questions are posed or data of a technical nature requested in this category. 